
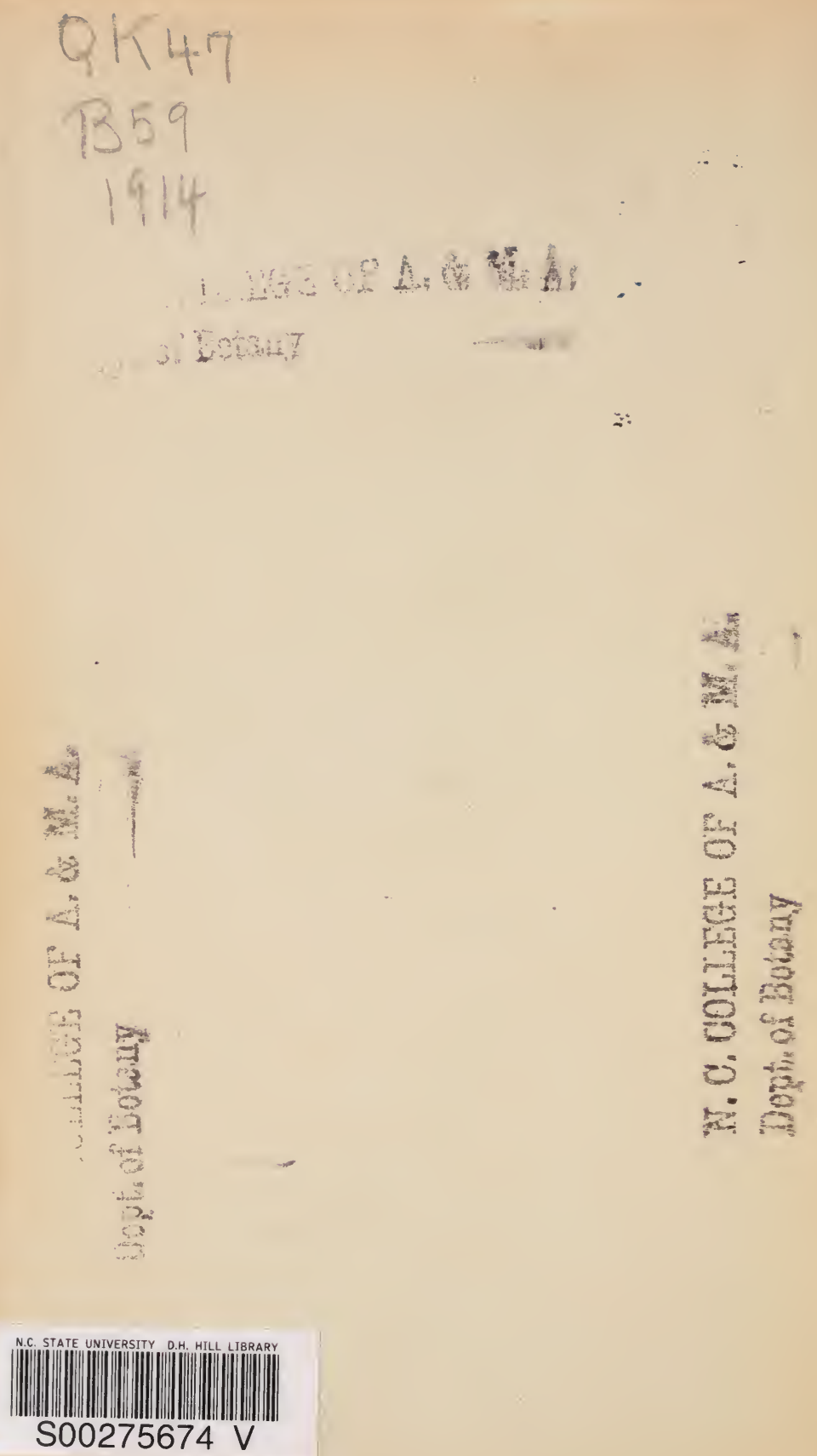
This book is due on the date indicated below and is subject to an overdue fine as posted at the Circulation Desk.

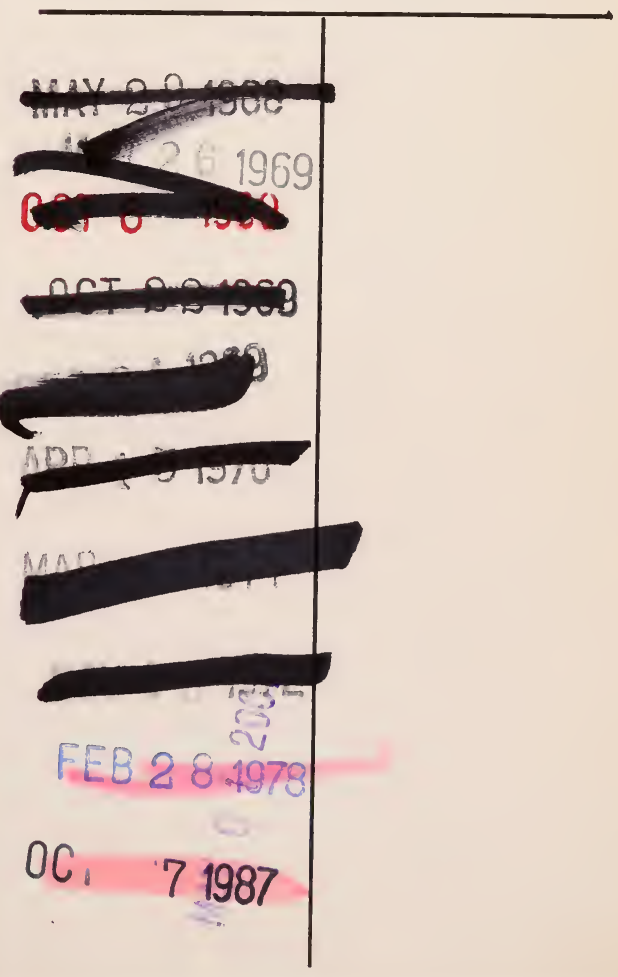






\section{ESSENTIALS OF}

\section{COLLEGE BOTANY}

BY

CHARLES E. BESSEY, Ph. D., LL. D.

HEAD PROFESSOR OF BOTANY IN THE UNIVERSITY OF NEBRASKA

AND

ERNST A. BESSEY, Pн. D.

PROFESSOR OF BOTANY IN THE MICHIGAN AGRICULTURAL COLLEGE

EIGHTH EDITION OF "THE ESSENTIALS OF BOTANY" ENTIRELY REWRITTEN

With 206 Diagrammatic Illustrations

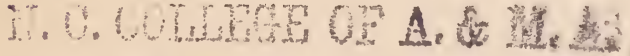

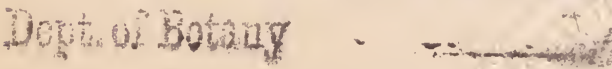

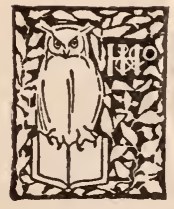

NEW YORK

HENRY HOLT AND COMPANY 
COPYRIGHT, 1914

BY

HENRY HOLT AND COMPANY

THE. A A PLE. PRESS Y TOK P P 


\section{PREFACE}

In offering this book to college teachers it may not be amiss to refer to the great change that has taken place in the teaching of Botany in America since the preparation of its predecessor thirty-five years ago. Then botanical laboratories were just coming into existence, and for the first time students of Botany were able to study protoplasm and cells and tissues and other minute structures of plants. It is a matter of history that half a dozen years later the publisher's objection to the caption "Laboratory Studies" for a new edition, was able to bring about the substitution of "Practical Studies," as less likely to prejudice teachers against such presentation of the subject. Looking back to that time we realize what progress has been made in the teaching of the science, for to-day every college has its laboratory for the study of plant structure, and this change in teaching has gone so far that it has invaded the secondary schools, in which there are now many well-equipped botanical laboratories.

Looking at the science from another standpoint it is of interest to note that thirty-five years ago the number of species of known plants was between 125,000 and 150,000 , while to-day it has risen to more than 233,000 . Then the number of flowering plants was placed at a little more than 100,000, while now it is about 133,000 : then the lower plants ("cryptogams") were thought to number from 25,000 to 40,000 , while now there are more than 100,000 enumerated.

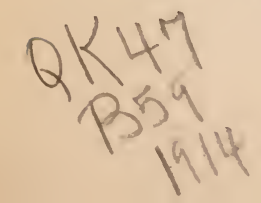


Another indication of the change that has taken place in the science is suggested by the fact that then the Plant Kingdom was divided into the "Phaenogams" and "Cryptogams," and that the usual sequence of the study was first proper "Botany" as a course in the structure, reproduction and classification of the "Phaenogams," with a possible Anhang of "Cryptogamic Botany" for such students as wished to invade this mysterious realm. How completely this has given way to a more scientific conception of the Plant Kingdom is shown by the practical disappearance of these terms from botanical literature and their relegation to more or less popular usage.

Again, it was formerly the very general practice of teachers to present the subject of plant study beginning with the higher plants, and indeed devoting the far greater time to them, so that the sequence was from the higher to the lower forms. However, with the more complete acceptance of the doctrine of evolution the opposite sequence from the lower forms to the higher has become the general rule, since it permits greater emphasis to be placed upon the progressive structural changes by which higher organisms have been evolved from lower.

In the earlier period there was not yet a general agreement as to the nature of the fungi, and their relationship to the algae. They were treated for the most part as a group of quite isolated plants with only obscure if any relationship with other groups. They were contrasted with other groups, little attempt being made to emphasize similarities in structure, or to suggest possible genetic relationships. Today, on the contrary, we constantly suggest to the students the probabilities as to the origin of each group of fungi. 
In like manner the older botanists of today remember the incoming of the belief in the heteroecism of rusts, and how timorously the fact was accepted by teachers of good standing among botanists. And this hesitancy as to the acceptance of a new view was still more marked in regard to the nature of "lichens," which by tradition formerly constituted a third group in the triumvirate of the lower plants, Algae, Fungi and Lichens-the "thallogens" of that day. Happily we have outlived this provincial timidity in regard to the startling conclusions of the German botanists, and in recent years have calmly accepted the substitution of a radically different system of the flowering plants for that which had generally prevailed for seventy-five years or more. Many of us still remember that the Gymnosperms used to be regarded as a division of the Dicotyledons, being sandwiched between the Monocotyledons and the Angiospermous Dicotyledons. Now the Gymnosperms are regarded as belonging to a genetic line different from the Angiosperms, although still associated with them as "seed plants."

It will be noticed that this book follows the usual German sequence of Morphology first, followed later by Physiology. The experience of the authors leads them to think that it is better to give the student a good foundation in plant structure and then to have him study the plant in action. However, this does not require the teacher to defer all physiological topics until the completion of Chapters I, II and III; indeed it has been our practice to introduce such topics as soon as the student is prepared to master them.

In the systematic chapters (VII to XX) and especially in Chapter XXII the Plant Kingdom is divided into fourteen groups of primary rank, here called "phyla." To 
some teachers this may seem to be an unnecessarily large number of primary groups, especially to those who have been in the habit of clividing plants into Thallophytes, Bryophytes, Pteridophytes and Spermatophytes, but we may remind all such that Engler in the seventh edition of his "Syllabus der Pflanzenfamilien" divides the thallophytic plants into eight primary groups, instead of seven, as is done in this book. On the other hand the Bryophytes, Pteridophytes, Calamites, and Lycopods are brought into one primary division by Engler, and the Cycads, Conifers and Flowering Plants into another. We are assured that the phyla here recognized are natural groups, and while they are by no means equally separated from one another, they are easily distinguishable. This is no less true for the phyla below the Bryophytes than it is for those including and above this group. We feel that the Calamites and Lycopods are entitled to first rank independently of the Pteridophytes, and that the latter and the Bryophytes are very certainly to be treated as genetically separate phyla. In like manner it seems to us that genetically the Cycads and Conifers are so remote from the Flowering Plants that they can no longer be placed in the same phylum, and that they differ so much from one another that they must be separated.

Thirty-five years ago the treatment here given the "lichens" would have called for explanation and defense; now we are so familiar with their structure that the suggestion that they were the first of the higher fungi will cause little surprise. So, too, there is less need now than formerly to defend the treatment of the Rust Fungi, as to whose general relationship there is less and less disagreement. With the growing acceptance of the structural homology of ascus and basidium in the higher 
fungi, it now signifies less than formerly whether the Rusts are regarded as related to the Ascus Fungi or the Basidium Fungi. As will be seen in Chapter XIII we still hold to the theory that their relationship is somewhat closer to the former than the latter.

For many years it has been evident to us that the apocarpous Flowering Plants must be regarded as primitive and that from these the syncarpous forms arose. Moreover the apopetalous preceded the apetalous flowers, the latter being derived from the former by a simplification of the flower structure. The flowers of willows, oaks, elms, nettles, etc., are quite simple, but they are not primitively so: they have been simplified from more complex structures, and are to be associated with the latter, rather than given place near the beginning of the phylum.

The diagrammatic illustrations used in this book are similar to those used on our lecture room blackboards. We have felt that in a textbook involving laboratory work elaborate drawings were unnecessary and often subject to grave abuse.

It is scarcely necessary to-day to insist that this book requires a botanical laboratory; nor is it necessary to give "forms" to be followed by the student in his laboratory work; for it may be assumed that no one will attempt to use this book who has not himself received training in a good laboratory. We have purposely suggested many more laboratory exercises than can be performed by the ordinary student, affording the teacher a large list from which he may make his own selection. A few suggestions here as to this laboratory work may not be out of place, as follows: (1) Have each pupil prepare his own specimens, as far as possible; only in a few special cases should he make use of specimens prepared by some one else. 
(2) Require simple, accurate drawings of the essential features of each specimen. (3) Label the different parts of the drawings, upon the sheet. (4) Do not require long descriptions of the specimens studied, for the student needs more to see and study plants than to attempt to write about them. (5) Do not ask for "conclusions," for the student has not yet enough knowledge of plants to make generalizations. (6) The exact name of the plant, or part of plant studied should be written upon the sheet of drawings.

It remains only for us to say that while the junior author originally prepared Chapters I to V, and the senior author the remainder, all have been gone over again and again by both of us so that we are both responsible for what is here set forth. We hope that this presentation that has approved itself to us in our classrooms and laboratories may be equally helpful in those of other teachers of Botany in the Colleges and other high schools of the country.

May, 1914

The Authors. 


\title{
CONTENTS
}

\author{
CHAPTER I \\ Protoplasm and Plant Cello (Cytology)
}

Protoplasm. The Plant Cell. Coenocytes. Plastids. Cell Inclusions. Cell Sap. Formation of New Cells. Mitosis (Karyokinesis) . . . . . . . . . 1

\section{CHAPTER II}

The Tissues of Plants (Histology)

Aggregations of Cells. Differentiation of Cells. Meristern. Parenchyma. Sclerenchyma. Collenchyma. Fibrous Tissue. Conductive Tissues. Tracheary Tissue. Sieve Tissue. Laticiferous Tissue . . . . . . . . . . . . 27

\section{CHAPTER III}

Groups of Tissues, or Tissue Systems (Histology)

In Lower Plants. In Higher Plants. Apical Cells. Dermatogen. Periblem. Plerome. Three Tissue Systems. Epidermal System; Epidermis; Hairs; Stomata. Conducting System; Vascular Bundles; Radial Bundles; Concentric Bundles; Collateral Bundles; Closed Bundles; Open Bundles. Secondary Thickening. Supporting System; Collenchyma Strands; Fibrous Strands. Palisade Parenchyma. "Sponge" Parenchyma. Storage Parenchyma. Cork. Lenticels . . . . . . . . . 43

\section{CHAPTER IV}

\section{Plant Physiology}

Nutrition; Water; Imbibition; Osmosis; Turgor; Path of the Water; Evaporation of Water; Root Pressure; Solutions; 
Mineral Nutrients; Photosynthesis; Carbohydrates; ProPAGE teins; Root Nodules; Hysterophytic Plants; Respiration; Anaerobic and Aerobie Respiration; Fermentation; Tem. perature Relations; Effect of Poisons. Growth; Relaticn to Nutrition, Temperature,Light. Reproduction; Asexual, and Sexual; Behavior of Chromosomes, Diploid and Hap. loid Number; Inheritance; Mendelism; Natural Selection; Survival of the Fittest; Variations; Mutations; Evolution; Phylogeny; Plant Breeding. Movements; Hygroscopic Movements; Protoplasmic Movements; Turgor Movements; Growth Movements, Nutation, Tropisms, Phototropism, Geotropism, Thigmotropism, Chemotropism, Hydrotropism. Pathology; "Physiological Diseases;" Diseases due to Parasites . . . . .

\section{CHAPTEIR V}

\section{The Chenistry of the Plant}

Inorganic Acids and Salts. Organic Acids. Alcohols. Fats and Fatty Oils. Aromatic Oils and Camphors. Carbohydrates; Monosaccharids; Disaecharids; Trisaceharids; Tetrasaccharids; Polysaceharids. Glucosides. Alkaloids. Protein Group. Enzymes. Miscellaneous Substances . 139

\section{CHAPTER VI}

\section{The Classification of Plants}

Number of Species. Relationship. Species and Genera. Higher Groups; Families; Orders; Classes; Phyla. Evolution. Origin of Phyla. The Place of Plants in Time. Table of Geologic Time Divisions . . . . . . . . . . 157

\section{CHAPTER VII}

Phylum I. Mrxophyceae: Sline Algae

General Charaeters. Two Classes. Blue Greens; Unicellular; Filamentous. Bacteria. Higher Blue Greens 


\section{CHAPTER VIII}

\section{Phylum II. Chlorophyceae: Simple Algae}

General Characters. Two Classes. Green Slimes; Palmellales; Coenohiales. Confervas; Ulothrix; Oerlogonium; Disk Algae . . . . . . . . . . . . . . . . . 170

\section{CHAPTER IX}

\section{Phylum III. Zygophyceae: Conjugate Algae}

General Characters. Two Classes. Pond Scums; Desmids.

Diatoms. Origin of Zygophyceae . . . . . . . . 177

\section{CHAPTER $\mathrm{X}$}

Phylum IV. Siphonophyceae: Tube Algae

Cieneral Characters. Lower Tube Algae; Water Flannel; Green Felts. Tube Fungi; Water Molds; Downy Mildews; Black Molds; Insect Fungi. Higher Tube Algae; Bladder Algae; Sea Ferns; Sea Umbrellas; Stoneworts. Summary . . . . . . . . . . . . . . . 184

\section{CHAPTER XI}

Phylum V. Phaeophyceae: Brown Algae

General Characters. Origin. Ectocarpus. Kelps. Rockweeds. Gulfweeds . . . . . . . . . . . . . 199

\section{CHAPTER NII}

Phylum Vi. Rhodophyceae: Red Algae

General Characters. Cell-walls. Color. Reproduction. "Laver." Nemalion. Corallina. Polysiphonia. "Irish Moss" . . . . . . . . . . . . . . . 205 


\section{CHAPTER XIII}

Phylum Vil. Carpomyceteae: Higher Fungi

General Characters. Reproduction. Three Classes. Ascus Fungi; Disk Lichens; Cup Fungi; Morels; Slit-Fungi; Closed Fungi; Mildews; Yeast-plants; Truffles. Basidium Fungi; False Tubers; Puff-balls; Bird-nest Fungi; Stink-horns; Toadstools. Brand Fungi; Rusts, Heteroecism, Wheat Rust, Sexual Reproduction; Smuts, Corn Smut, Wheat Smut, Bunt. Imperfect Fungi; SpotFungi; Black-dot Fungi; Molds

\section{CHAPTER XIV}

\section{Phylum VIII. Bryophyta: Mossworts}

General Characters. Life Cycle. Two Classes. Liverworts; Riccia; Hornworts; Great Liverwort; Scale-Mosses. Mosses; Reproduction; Protonema; Black Mosses; Peat Mosses; True Mosses . . . . . . . . . . . . . . . 212

\section{CHAPTER XV}

\section{Phylum IX. Pteridophyta: Ferns}

General Characters. Life Cycle. Two classes. Old-fashioned Ferns; Adder Tongues; Marattias; Quillworts. Modern Ferns; Land Ferns; Water Ferns . . . . . . . 254

\section{CHAPTER XVI}

\section{Phylum $\mathrm{X}$. Calamophyta: Calamites}

General Characters. Wedge-leaved Calamites. Horsetails.

Old Calamites. . . . . . . . . . . . . . 261

\section{CHAPTER XVII}

Phylum Xi. Lepidophyta: Lycopods

General Characters. Two Classes. Lower Lycopods; Ground Pines. Club Mosses; Selaginellas; Lepidodendrids . . . 266 


\section{CHAPTER XVIII}

Phylum Xit. Crcadophyta: Crcads

General Characters. "Seed-ferns." Common Cycads. "Flowering Plant Ancestors." Conifer Ancestors. Maidenhair Trees. Joint-firs . . . . . . . . . . 271

\section{CHAPTER XIX}

Phylum XiII. Strobilophyta: Conifers

General Characters. Taxodiums. Old Pines. Modern Pines, Genera of Modern Pines. Cypresses. Junipers. Yews. 277

\section{CHAPTER XX}

\section{Phylum XIV. Anthophyta: Flowering Plants}

General Characters. Typical Flower; Buttercup; Water Plantain; Strawberry. Two Classes. Monocotyledons; Lilies; Calla Lilies; Palms; Grasses; Amaryllises; Orchids. Dicotyledons; Axis Flowers, Magnolia, Mallow, Geranium, Violet, Mustard, Pink, Primrose, Phlox, Petunia, Snapdragon, Sage; Cup Flowers, Spiraea, Rose, Apple, Plum, Pea, Currant, Evening Primrose, Prickly Pear, Walnut, Oak, Parsnip, Honeysuckle, Sunflower, Dandelion. Summary of Anthophyta; Evolution; Progressive Development through the Phyla. . . . . . . . . 284

\section{CHAPTER XXI}

\section{Sone Special Adaptations}

Plant Body; Thorns; Storage Organs; Mesophytes; Xerophytes; Hydrophytes; Parasites. The Flower; Anemophilous; Entomophilous; Colors and Odors; Nectar; Actinomorphic; Zygomorphic; Proterogynous; Proterandrous; Dimorphic; Parthenogenesis. Seed Distribution. 319 
xiv

\section{CONTENTS}

\section{CHAPTER XXII}

The Plant Phyla

Number of Classes, Orders, Families, and Species. Key to the Phyla. Systematic Arrangement of the Fourteen Plant Phyla . . . . . . . . . . . . 327 $I_{N D E X} \ldots \ldots \ldots \ldots 1$ 


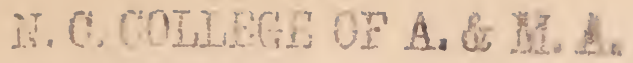 Dopt of Butang
}

\section{ESSENTIALS OF COLLEGE BOTANY}

\author{
CHAPTER I

\section{PROTOPLASM AND PLANT CELLS}

\section{CYTOLOGY}

1. Protoplasm. Plants, like animals, possess as their living portion a soft, viscid, more or less granular substance called protoplasm. This living matter makes up, ordinarily, only a rather small proportion of the total substance of the larger plants, being present in larger proportion in the smaller, simpler organisms. In the rapidly growing parts of plants it is far more abundant than in the fully developed organs.

2. Protoplasm, when studied under high magnifications with the use of certain stains, is found not to be a homogeneous substance but to occur in various forms as follows: (1) Cytoplasm. This is the bulk of the protoplasm and that which probably performs most of its ordinary functions. It is less dense than the other forms, being often of about the consistency of the white of an egg. It appears to consist of a clear, more or less liquid portion in which are imbedded innumerable granules of all sizes, from those easily visible under moderately high magnification to those barely visible at the highest possible magnification. (2) Nucleus. This is a somewhat denser portion of the protoplasm, usually of definite 
shape (mostly rounded) and separated from the cytoplasm by a delicate membrane. Like the cytoplasm, the bulk of the nucleus seems to be a colorless fluid in which is found a network of fine threads (the linin network) on which occur more or less numerous coarser or finer granules of chromatin. A rounded, usually nearly homogeneous body, the nucleolus, is mostly visible as a small, highly refractive drop within the nucleus. (3) Centro-

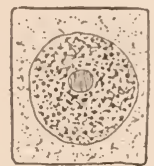

FIG. 1.-Protoplasm enclosed by a eell wall.

some. Although of general occurrence throughout the animal kingdom centrosomes are definitely known only in certain of the lower plants. In a cell not in division the centrosome appears as a minute body in close proximity to the nucleus. It takes an active part in nuclear division in animals, and possibly may do so in those plants in which it is present. (4) Plastids. These consist of denser masses of protoplasm lying in the cytoplasm and are colorless (leucoplasts) or colored (chloroplasts and chromoplasts). They are lacking in the cells of many plants.

3. All these forms of protoplasm possess many characteristics in common, both as to physical and chemical structure. They are very complex compounds with most of the characteristics belonging to the proteins but differing from them in some important points. Protoplasms consist mainly of carbon, hydrogen, oxygen, nitrogen and sulphur and of phosphorus also in the case of the nucleus. In all probability certain metallic elements also enter into the combination.

4. The most remarkable property of protoplasm and that which distinguishes it from all other chemical substances is its power of manufacturing new protoplasm out of simpler substances, in other words, the power of 
growth and reproduction. In addition, protoplasm possesses in great degree the power of movement as well as of perception. Motion is not always evident but in certain stages at least it can almost always be found. The protoplasm may move as a whole or certain portions of the cytoplasm may stream to and fro in a most complicated manner. Such streaming may affect only the small granules, or the larger bodies such as nucleus and plastids may be transported from one place to another.

5. Protoplasm possesses the power of imbibition of water. It may imbibe so much water that it becomes very thin and watery and yet still retain its powers of motion and of reproduction. There is a limit, however, to the amount of water protoplasm will imbibe, for some of the naked masses of protoplasm set free by some plants for reproductive purposes retain their shape and size in spite of being immersed in water.

6. The complex chemical and physical structure of protoplasm renders it very susceptible to injury. This injury may be simply physical, or certain of the groups of atoms making up the complex protoplasmic molecule may be changed chemically in such a way that the proper functions can not be carried on. When the changes reach such a point that on removal of these external unfavorable conditions the protoplasm does not resume its functions, we say that death has occurred. Heat, cold, electricity, even light, also mechanical injury such as crushing, as well as innumerable chemicals will cause death. Many of these agents when applied in smaller amounts or to a lesser degree check the functions of protoplasm only temporarily. Thus a jar or sudden cooling will check for a time the streaming within the protoplasm.

7. All of the modifications of protoplasm are, at least when active, in a more or less liquid state. The two 
theories as to its physical structure that receive the strongest support are the emulsion and the fibrillar theories respectively. By the first theory protoplasm is a very complex emulsion of various substances more or less closely related chemically. The bodies appearing as granules would be then, in part at least, small drops suspended in the emulsion. These drops are perhaps themselves also emulsions. The fine lines visible under certain conditions would be not fine strands but rather the edges of surfaces separating adjacent units of the emulsion. It is readily seen that this theory would accord well with the observed fact of the great power of imbibition of water by the protoplasm, for this would but separate the droplets of the emulsion somewhat more without necessarily disturbing their relative positions. The viscidity or relative firmness of some protoplasm (e.g. plastids and nucleus) is in agreement with what we know about emulsions. Thus two thin liquids may sometimes be brought to such a state of emulsion that the whole mass is firm and will stand upright. The fibrillar theory supposes that the delicate lines mentioned above are fine threads, connected at innumerable points and traversing the clear liquid making up the bulk of the protoplasm. The granules are looked upon as being situated on these fibrillae or sometimes in the spaces between them.

8. The Plant Cell. In all plants we find that the protoplasm occurs in definite units which are independent or more or less connected with neighboring units; in the latter case the whole mass of these units constitutes the plant. These units are called cells and consist always of at least two parts, a mass of cytoplasm and a nucleus. In most plant cells the protoplasm deposits a firmer substance as a box-like covering called the cell wall, 
which gives firmness to the cell and acts as a protection to it. Plastids are very frequent constituents of cells although large groups of the lower plants, the so-called fungi, lack them entirely. Most cells contain spaces within the cytoplasm filled with watery solutions. These are called vacuoles, and the contained solutions are known as cell sap. At its outer surface as well as at the surfaces in contact with the larger vacuoles and the nucleus the cytoplasm forms a denser layer, free from granules, which holds the cytoplasm in shape, prevents passage of certain substances into or out of the cytoplasm, etc. This is the plasma membrane. The plasma membrane about the nucleus is usually, however, called the nuclear membrane. The layer next to the vacuoles is frequently spoken of as the tonoplast.

9. The cell wall consists usually of cellulose or related substances, i.e. of some of the more complex carbohydrates. These are composed of carbon, hydrogen and oxygen in the proportion, usually, of six parts of carbon, ten of hydrogen and five of oxygen. In many of the fungi and some other plants the cell wall is composed of a form of chitin, containing nitrogen in addition to the substances mentioned. This has been called fungus cellulose, although not related to cellulose chemically. In the walls of older cells there are frequently deposited various other substances such as silica in the diatoms and in the epidermal cells of joint rushes and grasses, suberin and eutin in the walls of cork and epidermal cells, respectively, hadromal, or perhaps vanillin and coniferin in wood cells, etc., these being in part the so-called "lignin" of earlier botanical works. Aside from cellulose the chief constituent of cell walls is pectose, chemically very similar to it and frequently mixed with it. Under the influence of certain not well understood 
conditions the cellulose or pectose may become changed into gums, e.g. gum arabic, cherry gum, slime of flaxseed, etc.

10. The cell wall when first formed is very thin. Growth occurs either by apposition (deposition of cell wall substance on the inner surface of the wall) in which case the wall becomes thicker and may or may not appear layered, or by intussusception (the deposition of new material among the particles of the old), in which case the wall becomes larger as well as often thicker. The first layer formed is the thin middle lamella. Upon this is deposited, on either side, a thicker layer of somewhat different composition, the secondary lamella. A tertiary lamella is sometimes formed also. These different layers are usually of somewhat different chemical composition. Thus the middle lamella is often composed of calcium pectate or some other pectose compound while the secondary lamellae are cellulose or a mixture of cellulose with other substances. When present, the tertiary lamella is usually nearly pure cellulose.

11. The walls between adjacent living cells are quite generally perforated by very minute pores through which delicate fibrils of cytoplasm extend from one cell to the

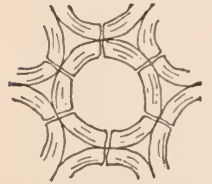

FIG. 2.-Thickened cell walls. other, apparently thus binding all the living cells of the plant together into one more or less coordinated unit.

12. The thickening of the cell wall is not always uniform. Indeed, except in comparatively thin-walled cells thinner areas or spots are almost always left be tween the more thickened parts. These thickenings may be ridges which are in the shape of rings, spirals or reticulations or may occupy so much of the surface that the unthickened parts appear as pits. Usually these thick- 
enings are on the inner surface of the cell wall, but in many spores (e.g. pollen grains or spores of ferns or fungi) they are external. This is also the case in some of the lower, one-celled plants such as desmids. The thickenings have various functions, such as strengthening the wall, providing means for transportation (in the case of spores and pollen grains which sometimes depend upon animals for their dispersal, the rough projections enabling them to cling to the animal), etc.

13. After attaining their full differentiation most of the cells of the higher plants (at least of the woody plants) die, their cell walls remaining to make up the bulk of the plant body. We usually continue to speak of such dead, empty cell walls as cells, although the essential parts, the cytoplasm and nucleus, may have disappeared long ago.

14. Cells vary greatly in size, those of some of the bacteria being less than half a micron (i.e. less than onefifty-thousandth of an inch) in diameter, while the egg cell of Zamia may have a thickness of over a millimeter and a length of $3 \mathrm{~mm}$. (i.e. a volume over twenty billion times as great), the egg cell of Dioon being even larger. Some fiber cells have a length of many centimeters, e.g. bast fibers of ramie (Boehmeria nivea).

15. In some of the lower aquatic plants occur reproductive cells with no cell walls (e.g. zoospores, tetraspores, etc.). These cells are frequently motile by means of protoplasmic processes called cilia or flagella. Such cells in many cases settle down and, becoming attached to something, form a cell wall before proceeding further in their development. Even in the higher plants the egg and sperm cells are naked.

16. Typical cells have but a single nucleus. In certain stages of the life history of some groups of plants the 
cells are binucleate while they are uninucleate in the remaining stages. In some groups of plants, however, we find that, enclosed in an outer cell wall, there is a mass of cytoplasm containing many nuclei. Such a structure is called a coenocyte. It is frequently regarded as consisting of as many cells as nuclei are present, not separated, however, by partition walls. Perhaps it may better be considered as a sort of compound cell as the nuclei do not seem to control definite masses of cytoplasm. In some coenocytes of the seaweed Griffithsia over 4,000 nuclei are present, while in the enormous coenocyte of Caulerpa, likewise a seaweed, which often attains a length of several decimeters, the number of nuclei is vastly greater. Coenocytes are mostly restricted to certain groups of lower plants, but cells of coenocytic nature may occur even in the higher plants.

17. In shape cells are very variable. Usually we find that free-living cells approach the spherical shape although they are often elongated somewhat. Cells united to other cells are usually flattened on the sides where they are in contact. When surrounded by cells at all sides cells are usually more or less regular, several to many-sided polyhedra. Some cells are cylindrical while often we have fiber or spindle shaped cells. Some cells are lobed or branched.

Laboratory Studies. It is assumed that the attempt will not be made to use this book without endeavoring to carry out in the laboratory all or at least a selection of the laboratory exercises suggested here and there in connection with the various topics. So far as possible the suggested exercises have been made simple enough for the student to undertake himself, depending as little as possible upon specimens prepared or experiments set up by the teacher. It is absolutely essential that each student have the use of a good compound microscope, and that he possess the proper tools for making sections, 
etc., as well as a few simple reagents such as alcohol, iodinepotassium-iodide solution, potash solution, ete. The measurements used throughout this book are metric; $1 \mathrm{~cm} .=0.394 \mathrm{in}$. $1 \mathrm{~mm}$.=about $1 / 25$ inch, 1 micron (written $\mu$ ) $=0.001 \mathrm{~mm}$. (i.e. about one-twenty-five-thousandth of an ineh).

(a) Make a thin longitudinal section of the tip of a large root of Indian corn or hyacinth or any other plant with stout roots, or of the growing point of a herbaceous stem, and mount in water and examine under the microseope. The small cells near the tip will be found to be full of protoplasm. The following tests should be made on different sections: Add strong iodine solution; this turns the protoplasm brown or yellowish brown. (2) Test with a drop or two of Millon's reagent (dissolve a small amount of mercury in an equal weight of strong nitric acid, and dilute with an equal amount of distilled water. Use fresh): the protoplasm is turned bright yellow. (3) Mount a section in strong sugar solution and after a few moments add a drop of fairly strong sulphurie acid: the protoplasm is stained red or pink. (4) Treat a section with nitric acid and then with strong potash: the yellow color of the protoplasm shows the so-called xanthoprotein reaction.

(b) Repeat these tests with raw white of egg, which consists of proteins. Note that the results are the same. For the sulphuric-acid-sugar test it is more satisfactory to mix the egg white with a strong sugar solution in a test tube, rolling the latter so that the sides are moistened with the mixture. Now very carefully run a small drop of concentrated sulphuric acid down the side of the tube. This browns the solution where it comes in contact in most concentrated form but at the edge of its path and at its point of entrance into the mixture the red coloration is shown beautifully.

(c) To study the motion of cytoplasm make a cross or longitudinal section of a stem (the upper, younger portion) of Petunia or tomato without injuring the hairs. Mount in water and examine a cell of a hair. The cytoplasm will usually be found to be streaming. Note that the streams seem frequently to center upon the nucleus. Note the effect upon the motion of placing the slide on a piece of ice. Warm it up again to a temperature of about $30^{\circ}$ to $35^{\circ} \mathrm{C}$. and note the 
results. Heat to $55^{\circ}$ to $60^{\circ} \mathrm{C}$. Now cool to about $30^{\circ}$. Examine again.

(d) On similar specimens test the effect upon motion of iodine solution, alcohol, glycerine, etc.

(e) Various types of protoplasmic motion may be found in the long cells of the young silk of Indian corn, in the cells of the leaves of water weed (Philotria), the cells, especially those near the ends of the shoots, of Chara or Nitella, etc.

$(f)$ To observe the different parts of a cell study again the stem hairs of Petunia. Note nucleus, nucleolus cytoplasm, vacuoles, cell wall. Cells from the leaf of a moss may also be used for this purpose.

(g) Bring into the laboratory some growing Ulothrix, Cladophora, Stigeoclonium or other zoospore-producing algae, and place in fresh water near the window. In a few hours one can often find myriads of zoospores. Examine these for cells lacking walls and provided with motile organs (flagella).

(h) Make a thin cross-section of a herbaceous stem. Treat with iodine solution and then with somewhat diluted sulphuric acid. Cellulose walls are turned blue, cutinized and lignified (wood) walls, yellowish brown. Stain another section with anilin-water safranin. This stains cutin walls yellowish and lignin walls bluish.

(i) Examine a thread of green felt (Vaucheria) or a vegetative thread of bread mold (Mucor) for a plant of coenocytic structure. Note the lack of cross walls. The numerous minute nuclei are not visible without staining.

(j) The stone cells making up the shells of various nuts are good objects to show the deposition of the cell wall in layers, i.e. by apposition. With a pocket knife cut as thin a section as possible, and place it in water containing a little potash. At the edges may be found areas thin enough for examination. Here and there in the plainly layered cell wall will be found pits, i.e. thin places left when the rest of the wall thickened.

18. Plastids. Three kinds of plastids occur in plants. They all agree in general structure in that they are denser bodies of protoplasm imbedded in the cytoplasm. They may have many shapes but are more frequently round or elliptical in outline. So far as is certainly known new 
plastids are formed only from the division of old plastids in to two parts. They are difficultly visible in some plant cells, e.g. in the small rapidly dividing meristem cells at the growing points of a plant, and are entirely lacking in some great groups of plants, viz. the bacteria and fungi.

19. Chloroplasts are plastids containing chlorophyll. Ordinarily they are green, from the color of the chlorophyll itself, but in some groups of plants the green color is masked by the presence of other pigments in the chloroplasts in addition to the chlorophyll. Thus in the Red Seaweeds (Rhodophyceae) the chloroplasts are usually red, in the Brown Algae (Phaeophyceae) they are brown, in some Myxophyceae the chloroplasts are bluish green, etc. Chlorophyll proper is a bluish green, apparently somewhat oily substance, probably contained in inter- (chloroplasts) in a stices of the chloroplast. It is soluble in alcohol, by means of which it can be removed, leaving the chloroplast colorless. In addition to chlorophyll most chloroplasts contain an orange yellow pigment, to which the name xanthophyll is often applied. It appears to be a form of carotin. The mixture of these two gives the grass-green color to the chloroplast. With rare exceptions chlorophyll is not produced in the absence of light. It usually disappears in prolonged darkness, leaving the chloroplast stained yellow with xanthophyll or colorless. In many of the lower plants the chloroplasts are of various shapes, often being star-, band-, plate-, or even net-shaped. In the higher plants they are mostly more or less disk shaped. In some of the liverworts and many of the algae they contain one or more highly refractive bodies, called pyrenoids, which are probably crystals of some albuminous substance. 
20. Leucoplasts are colorless plastids occurring in the parts of the plant not exposed to light. When exposed to light they usually produce chlorophyll and become green, showing that they are essentially the same as the chloroplasts. They are abundant in parts of the plant where starch is being stored up.

21. Chromoplasts are found in the cells of many flowers and fruits and other colored parts of plants. They are small, round or angular or needle shaped plastids, mostly red or yellow in color. They contain carotin or other coloring matters but no chlorophyll. In many cases they are directly developed from chloroplasts by the loss of chlorophyll and the development of some other pigment.

Laboratory Studies. - (a) Mount a leaf of moss and examine for chloroplasts.

(b) Soak a few moss leaves in strong alcohol for twenty-four hours and note the decoloration of the chloroplasts.

(c) Examine Spirogyra for spiral, ribbon-shaped, or Zygnema for star-shaped chloroplasts.

(d) Soak a handful of leaves in alcohol for several hours. If the flask containing the alcohol and leaves be placed in hot water the extraction of the chlorophyll will progress more rapidly. Note the green color of the extract. Add a little gasoline or benzine (not benzene, i.e. benzol) to the alcoholic solution and shake thoroughly and then let it stand until the alcohol and gasoline separate. The chlorophyll will be found now in the gasoline, the earotin remaining in the alcohol.

(e) Examine the cells of various fungi, e.g. toadstools, puffballs, molds, etc., or of a parasitic flowering plant, e.g. dodder (Cuscuta), and note the absence of chloroplasts.

$(f)$ Sprout a potato in darkness. Nake a section of its stem and compare with a similar section of the stem of a potato grown in light. Note the leucoplasts in the former and the chloroplasts in the latter. Similarly compare the stomatal guard cells of the epidermis of green and blanched celery.

(g) Examine the cells of a carrot root for chromoplasts 
stained with earotin. Examine also the red eells of a ripe tomato or the yellow cells of a petal of nasturtium (Tropacolum) or the cells of rose hips.

22. Cell Inclusions. Within many cells are often found bodies not living and not an essential part of the cell but which have been produced by the cell itself. They may be temporary or permanent. They may lie in the cytoplasm, in the vacuoles or in the plastids. Such bodies are called cell inclusions. The most frequent cell inclusions are stareh, aleuron, erystals and sometimes drops of fat or oil.

23. Starch. In the green cells of many plants there are produced in the chloroplasts on exposure to light small pearly white grains of starch. These are usually transformed into sugar during the night and used by the plant for food or transported to some other part such as root, tuber or seed, where the sugar may be again converted to starch, in the leucoplasts, to remain until needed by the plant for

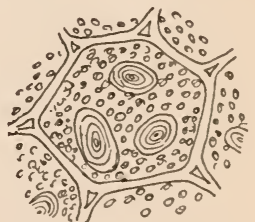

FIg. 4.-Starch grains ( 1 a rge ) and aleuron (small). food. Whereas in the green cells of a leaf the starch does not ordinarily accumulate in great quantities, the storage cells of a plant become so packed with it sometimes that little else can be seen.

Starch is a carbohydrate and is elosely related chemically to cellulose and to the sugars. It is composed of carbon, hydrogen and oxygen in the proportions indicated by the formula $\left(\mathrm{C}_{6} \mathrm{H}_{10} \mathrm{O}_{5}\right) \mathrm{n}$, in which " $\mathrm{n}$ " is a fairly high but not exactly ascertained amount. By the action of certain organic substances produced by the cell and called enzymes, or of some of the acids and heat, it can be converted into some forms of sugar.

Starch grains frequently show a concentric structure, 
due apparently to the successive deposition of denser and less dense layers. At first the grains are entirely enclosed by the plastid but as they increase in size they become excentrically located and seem eventually to burst out of the plastid at one sicle. In the chloroplasts containing pyrenoids the starch grains are mostly produced in intimate connection with the latter.

24. Aleuron. In the dry seeds of many plants there may be found, sometimes in a definite layer of cells, sometimes scattered throughout the cells of the seed, small rounded or frequently angular granules of a protein substance called aleuron. This is stored up in the cells as food for the young seedling. These aleuron grains are formed in small vacuoles in the cytoplasm, the aleuron being in solution at first but appearing as granules or even crystalloids as the seed loses its moisture in the process of ripening. As the seed absorbs water preparatory to germinating the aleuron goes into solution again and is used up for food. Aleuron is frequently found in cells containing other stored up food matter such as starch or oil. It was formerly supposed to be a dry stage of protoplasm but is now recognized as one of the highly complex food substances out of which protoplasm can be formed by the cell.

25. Oils or Fats. Many plants provide for the use of the young seedling a supply of fat instead of starch. This is usually present in the cell as very minute drops, in fact almost as an emulsion throughout the cytoplasm. Sometimes the oil droplets are of considerable size, in very oily seeds often filling all the interstices of the cytoplasm. Usually these fats are liquid but in some plants they are semisolids of the consistency of butter. They are mostly true fats, similar to those found in animals, 
but in some plants cells are found which contain so-called "ethereal oils," which are not true fats.

26. Crystals. In many plants may be found cells containing crystals. These may be cubical, prismatic, regular or irregular polyhedrons, needles, compound crystals, etc. Sometimes the cells containing them are unchanged but often they are enlarged or of special shape. This is especially the case with the needleshaped crystals which are called raphids and occur in large bundles in the central vacuole of rather large, thin-walled cells. The crystals seem to be formed by the cytoplasm, in which they occasionally lie, or more frequently in special small vacuoles in the latter. Eventually they are found in most cases in the

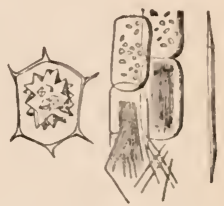

Fi g. 5. - Com pound, and needleshaped crystals. central vacuole in which some of them may have had their origin.

27. Crystals in most plants are composed of calcium oxalate. In some plants calcium carbonate crystals occur, while crystals of still different composition are occasionally found. The purpose of crystals is not clear in all cases but in many cases they are probably the product of the combination of waste substances set free in the course of some of the important chemical processes of which the cell is constantly the seat.

Laboratory Studies. (a) Make a thin section of a potato tuber. Mount in water. Note the large, thin-walled cells packed with numerous ovoid, concentrically marked starch grains. Treat with iodine solution. The starch grains become blue or purple. In very young tubers, where the starch grains are not so large nor so numerous, they may be scen to be enclosed in leucoplasts.

(b) Study the different types of starch grains in corn, wheat, rice, oats, etc. 
(c) Place a dish of water containing Spirogyra in the light for some hours and then examine a few filaments. In the spirally wound chloroplasts, around the pyrenoids will be found masses of starch which become more evident on staining with iodine.

(d) Make thin sections through various leaves that have been exposed to the light for some time, staining with iocline. In some of these minute grains of starch will be found in the chloroplasts.

(e) Make longitudinal sections of ripened apple twigs, in the fall or winter especially, and note the starch stored in the rather thick-walled cells of the pith.

(f) Mount in strong alcohol or glycerine a thin section of a pea or bean. In addition to starch grains the cells will be found to contain very numerous fine granules. Stain with iodine. These small aleuron granules will be stained brown and the starch blue. To another section apply one of the tests for proteins given on p. 9. Mount another section in water and note the effect on the aleuron. Examine cotyledons of germinated peas and beans for presence or absence of aleuron.

(g) Examine a cross-section of a wheat grain. The aleuron will be found in a layer of cells outside of the starch-containing cells. This layer is largely removed with the bran in the process of making flour.

(h) Make a thin section of a seed of the castor oil plant (Ricinus). Mount without adding water or any other reagent. Large aleuron grains will be seen, each containing an angular protein crystal and a spherical, so-called "globoid," of inorganic nature. Add a little water and some of the oil will escape and appear at the edges of the section as large drops.

(i) Examine various oily seeds such as cotton, flax, peanut, or an oily fruit such as the avocado (Persea gratissima) or olive. In the cells will be found varying amounts of oil. By treating the sections with 1 per cent. solution of osmic acid or with alkannin solution the oil will be stained respectively black or red.

(j) Make a thin longitudinal section of the stem of spiderwort (Tradescantia) and mount in water. Certain thinwalled cells will be found containing bundles of needle-shaped crystals (raphids). Many of these will be torn out of position 
and scattered throughout the specimen. These erystals are composed of calcium oxalate. Add a little hydrochloric acid and they will dissolve without effervescence.

(k) Similar crystals may be found in many other plants, e.g. Indian turnip (Arisaema), evening primrose (Oenothera), fuchsia, garden balsam (Impatiens), garden rhubarb, etc.

(l) For erystals of other types examine sections of prickly pear (Opuntia), young basswood twigs, scales of onion, stem of lamb's quarters (Chenopodium), petiole of beet, etc. These are also composed of calcium oxalate.

( $m$ ) Examine a thin eross-section of the leaf of the rubber plant (Ficus elastica). In some of the modified epidermal cells will be found peculiar stalked erystalline bodies of calcium carbonate deposited upon a cellulose core which hangs down into the cell eavity from the outer portion of the cell wall. Treat the section with hydrochloric acid. The eystolith, as it is called, dissolves with the evolution of $\mathrm{CO}_{2}$, leaving the cellulose core, thus distinguishing it from calcium oxalate, which dissolves without effervescence.

28. Cell Sap. The cytoplasm of a cell usually contains a large amount of water imbibed by it but not really a part of it. Water is also found frequently in drops (vacuoles) within the cell. This is the cell sap. It holds in solution the various soluble substances absorbed by the plant as well as those manufactured by the cell itself. It makes up by far the greater part of the bulk of the contents

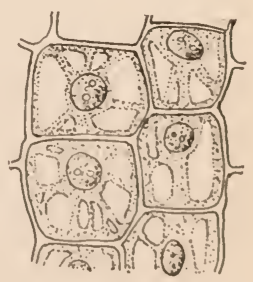
of the average cell. Among the sub- Fig. 6.-Large vacuoles. stances dissolved in the cell sap, in addition to the mineral matters absorbed by the plant from the soil water, are many sorts of organic compounds produced by the cytoplasm. The most important of these are the various sugars and organic acids. The commonest of the sugars are saccharose or cane sugar 


\section{$\left(\mathrm{C}_{12} \mathrm{H}_{22} \mathrm{O}_{11}\right)$, glucose or grape sugar $\left(\mathrm{C}_{6} \mathrm{H}_{12} \mathrm{O}_{6}\right)$, fructose $\left(\mathrm{C}_{6} \mathrm{H}_{12} \mathrm{O}_{6}\right)$, etc.}

29. Cane sugar is found in great quantities in the cell sap of the sugar cane, sugar beet, sugar maple, sorghum, Indian corn and many other plants. The first two plants produce the bulk of the sugar of commerce. In many fruits, such as grapes, cherries, gooseberries, figs, etc., glucose is present, while in still others, e.g. pineapple, peach, plum, strawberries, etc., the two are mixed. Fructose, as the name implies, is found in many fruits, e.g. the grape. In many, if not in most plants glucose seems to be the form in which green cells manufacture their food, storing up the excess over immediate consumption usually as starch, from which it is again obtained as glucose. Inulin is found mostly in plants of the sunflower family, e.g. sunflower (Helianthus), Dahlia, elecampane (Inula), etc.

30. The organic acids found in the cell sap may occur in acid form, but frequently are found as acid salts of calcium or potassium or some other base. The most common of these acids are malic, citric, tartaric and oxalic. They seem to be present in some cases as food for the plant while in others they doubtless help to keep the cell turgid by raising the osmotic pressure within the cell to the proper degree.

31. Among the substances found in the cell sap in solution are certain compounds known as alkaloids. These are perhaps in some cases products of the breaking down of more complex substances and to be looked on as a sort of excretion product comparable to urea in animals. However, in certain plants they may serve as reserve food as they are used up by the plant if no other food is available. They are nitrogenous compounds of compli- 
cated composition, usually bitter to the taste and very frequently poisonous to animals.

Laboratory Studies. (a) To show the large amount of water in living cells place a few threads of pond-seum (Spirogyra) in a little water and examine under the microscope. Add a little strong glycerine which has a great avidity for water. Note how the cells collapse as the water is withdrawn. Repeat the experiment with thin sections of some herbaceous stem or simply allow the latter to dry out in the air.

(b) Taste the stem of sugar cane or growing Indian corn or a piece of a sugar beet. The presence of sugar is readily recognizable. Put small pieces of these plants into considerable quantities of 95 per cent. alcohol to remove the water, or into pure glycerine. The water is withdrawn rapidly by the reagents and the cane sugar, which is practically insoluble in them, crystallizes out in fine stellate crystals Sections for examination must be mounted in the alcohol or glycerine as water will redissolve the sugar.

(c) Make thin sections of the root of Dahlia or sunflower (Helianthus) that has been preserved in strong alcohol and note the large sphacrocrystals of inulin.

(d) To study glucose or fructose test the juices of various fruits with Fehling's solution, which gives a precipitate of copper oxide with both these sugars but not with cane sugar or inulin.

(e) The presence of acids or acid salts is readily discernible by the taste in many plants, e.g. stem of rhubarb, leaves of Oxalis, fruit of lemon, cranberry, etc. In smaller quantities it can be demonstrated by placing the cut surface of the tissue to be tested in contact with a piece of blue litmus paper which will be turned red by the action of acids.

\section{Formation of New Cells. No cell can originate} except from some pre-existing cell or cells. Most cells are capable of producing new cells at some stage of their development, but frequently the power is soon lost. New cells arise either through the division of a cell or through the union of two (or rarely more) cells. In the cell formation by division we distinguish two types, each 
with modifications, viz., fission, in which the cell divides jnto two adjacent parts which may or may not remain attached, and internal cell formation, in which the protoplasm within the cell divides into several cells which eventually escape from the old cell wall as naked cells (zoospores and motile gametes) or form new walls for themselves within the old wall and become free on the rupture or decay of the old wall. The latter type includes cases in which all the protoplasm is used up in forming the new cells, as in zoospore formation, as well as those in which only a part is so used, the remainder

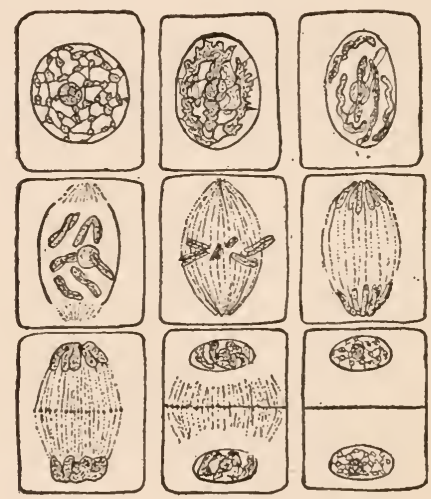

Fig. 7.-Karyokinesis (mitosis).

lying between the new cells and the old wall, as in the formation of ascospores within the ascus. Several forms of fission may be distinguished. The commonest type is that in which the protoplasm of the cell separates into two parts that secrete a new wall between them, the new cells thus remaining attached to each other. The new separating wall may be formed as a ring-like thickening on the old wall which gradually increases in 
width until it has completed the separation of the two protoplasmic masses, this being the commoner way in the lower plants, or the wall may be produced simultaneously at all points at the plane of separation between the two protoplasts, as is the case in most higher plants. In some of the lower plants the whole wall begins to constrict at the middle, giving the appearance of pinching the cell into two separate cells which are then free from one another. A peculiar type of fission is that termed budding, in which a small outgrowth appears at a point on the cell, gradually enlarging until it is as large as the old cell and then becoming separated from it by constriction of the wall at the point of emergence. This is especially characteristic of, but not confined to, some of the yeasts.

33. Cell division is in most cases initiated by, or more or less immediately preceded by, the division of the nucleus. In coenocytes, on the contrary, this connection between nuclear division and that of the coenocyte seems to be lacking. Two types of nuclear division may be distinguished, direct or amitotic and indirect or mitotic. The latter process is generally known as mitosis or karyokinesis. The direct division is comparatively rare and appears to consist of a simple pinching in two of the nucleus. By far the commonest method is that of mitosis. This is a very complicated process and is essentially as follows, being subject, however, to many more or less pronounced variations in different plants. If a centrosome is present, which is apparently the case only in some of the lower plants, it clivides into two centrosomes which move around outside the nucleus until they lie at opposite sides in a line at right angles to the plane of division. The nuclear reticulum now begins to resolve itself into a fine tangled thread without cross connections, the chro- 
matin granules spreading themselves out along the thread until it is of even thickness. The thread rapidly shortens and thickens, eventually becoming a thick, more or less distinetly spirally arranged thread (spirem stage). At the same time the nucleolus has been growing smaller or less distinct and soon disappears entirely. In the spirem thread there often becomes visible at this stage a split for its whole length. However, it does not separate along this split as yet. In the mean time outside the nucleus there begin to appear in the cytoplasm immediately surrounding the centrosomes fine lines, or fibrillae (of kinoplasm), which appear to center at the centrosome and extend from it in all directions but especially toward the nucleus. In the plants which have no centrosomes there appear near the poles of the nucleus tangled masses of fine fibrillae which in some cases form a sort of cap at each pole or even may entirely surround the nucleus. From this tangled mass the fibrillae gradually untangle themselves somewhat and finally lie in the form of a cone at each pole, with the apex away from the nucleus. In the forms with centrosomes one of the latter lies at each apex, often surrounded by radiating fibrillae which may reach out even to the cell wall. Where the mass of fibrillae comes in contact with the nucleus the nuclear membrane disappears and soon after vanishes at all other points also. The fibrillae push into the nuclear cavity. In the meanwhile the spirem thread breaks transversely into a number of segments called chromosomes, the number being constant for all vegetative nuclei of a given species of plant. Two sets of kinoplasmic fibrillae can now be recognized. Some push through the nuclear cavity until they meet and unite with similar ones from the other pole, forming a spindle-shaped structure commonly spoken of as the nuclear spindle. Other sets of fibrillae push toward 
the chromosomes and become attached to them, one or more sets from each pole being fastened to each chromosome. In some way, perhaps by the contraction of these fibrillae, the chromosomes are brought to lie at the equator of the spindle, forming the so-called equatorial plate. The ehromosomes are of various shapes, like rods, or resembling the letters $\mathrm{J}, \mathrm{V}$ or $\mathrm{U}$, more frequently the last two. Usually the faint longitudinal split which first became visible during the spirem stage is quite distinct. As the fibrillae attached to the chromosomes continue to contract the latter are torn in two along the line of this longitudinal split, one half being dragged toward each pole. When these daughter chromosomes, as they are called, reach the two poles they soon join to each other end to end and form spirem threads similar to those formed before the cleavage into chromosomes (the dispirem stage). These elongate and finally form a long tangled thread along which the ehromatin begins to assemble in lumps and which soon forms short lateral connections to make the typical nuclear reticulum. In the meantime the nuclear membrane has appeared around each daughter nucleus and the nucleolus has made its appearance. The kinoplasmic fibrillae around the centrosome gradually disappear in the plants with centrosomes, while in plants without centrosomes they disappear in about the same way that they appeared, or in the higher plants take part in the formation of the separating membrane. In this latter case the spindle fibrillae seem to increase in number until they occupy the whole width of the cell. At the equatorial plane a little knot appears on each fibrilla. The fibrillae contract and as they shorten the knots increase in size until by the contact of the knots with each other a thin membrane (of kinoplasm) is formed which separates the protoplasm of 
the cell into two parts. This membrane splits and between these two plasma membranes is secreted the first layer of the cell wall (middle lamella). It is of interest to note that mitotic nuclear division is essentially the same in animals and plants. In the former, however, centrosomes are usually present while they are lacking in plants except in some of the lower groups.

34. In internal cell formation the nucleus usually divides several times before the cytoplasm separates. Usually the new cells are formed almost simultaneously

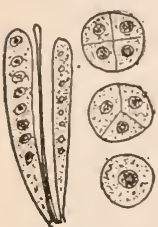

FIG.8.Internal cell formation. in this case. In many cases the cleavage of the cytoplasm is such that all of it is used up in forming the new cells, the spindle fibrillae taking no part in the process. In other cases, as in the formation of ascospores in the ascus, the kinoplasmic fibrillae radiating from the centrosome outline the new cell in the midst of the mass of cytoplasm, leaving much of the latter outside of the new cells, the so-called epiplasm.

35. Cell formation by union is in the main the opposite process to that by division. The union of the cytoplasm of the uniting cells is usually followed by the union of the nuclei to form one nucleus. If the cells are naked the process is comparatively simple, but when enclosed in walls the cells must either escape before uniting, or openings must be made in the walls so that one cell ean pass into the other. By the union of the two nuclei the number of chromosomes is doubled and remains at this socalled diploid number until by a peculiar modification of the mitotic process (the reduction division or meiosis) the number is reduced to the original (or haploid) number.

Laboratory Studies. (a) Scrape off, after moistening with alcohol, a little of the young white moldy growth on a lilac leaf (powdery mildew) or of similar mildews on cherry shoots

\section{moperty LIRRART
N. C. State College}


grass leaves or other plants. Mount in dilute potash. Threads will be found showing the formation of new cells (spores) by fission.

(b) Add a little sugar (preferably glucose) to a little potato water (made by grating up a raw potato and heating with water to extract the soluble matter and filtering) and break up in it part of a yeast eake ("compressed yeast") setting the solution in a warm place. Examine a small drop of the seum or sediment after a few hours for cells showing the type of fission called budding.

(c) By growing yeast for a few days on a moist slab of plaster-of-Paris under a bell jar or, less successfully in many cases, on the cut surface of a raw potato or carrot some of the cells may be found to have produeed four cells by internal eell division.

(d) Make a very thin cross-section through a young flower bud, or moss eapsule. In the stamens of the former or in the interior of the latter, if they are at the right stage, will be found cells which have divided internally into four parts whick subsequently beeome spores, each with a thick wall of its own.

(e) Take a flower bud of Tradescantia just before opening and remove a stamen and mount in water of about the room temperature. By examining with proper manipulation of the light, some cells near the tips of the stamen hairs may be found in division and the main features of the mitotic division of the nucleus may be dimly seen.

(f) Examine specially prepared, stained seetions of rapidly growing root tips, stamens, etc., where cell divisions are taking place frequently. Find and study as many stages as possible of the mitotic division of the nucleus and cells. These preparations require especial technique and cannot be made suceessfully by the beginning student. It is desirable that he study good preparations. Such can be obtained of various supply houses if the teacher has not the time or desire to make them.

(g) Cell formation by union can be observed in the conjugation of pond scums (Spirogyra or Zygnema) or of black molds (Mucoraceae, especially Sporodinia, which is frequent on decaying toadstools and can be transferred to bread where it grows luxuriantly). 


\section{PROTOPLASM AND PLANT CELLS}

REFERENCE BOOKS

B. M. Davis, Studies on the Plant Cell (American Naturalist, (1904-1905, Boston).

Strasburger, Jost, Schenck and Karsten, Lehrbuch der Botanik, 11 Ed., Jena, 1911 (or English Edition), and the 12 German Ed. 1913. 


\section{CHAPTER II}

\section{THE TISSUES OF PLANTS}

\section{HISTOLOGY}

36. In many groups of plants a single cell makes up the whole plant. In such groups the eells may vary considerably in different species but there is not possible a differentiation into cells of different structure for different functions. All of the normal activities of the plant are carried on by the same cell and, therefore, the modifications of the cell are limited to those that do not interfere with any of these functions. Aside from these limitations the cell may vary much in size, shape, structure of wall, location and size of nucleus and vacuoles, ete.

37. In other forms of plants there are several to many cells forming one plant in which all of the cells are essentially alike and each capable of continued existence by itself even if the others should be destroyed. Such a plant is scarcely more than a group of nearly independent individuals. As we study the more and more complex forms of plants, however, we find that the cells are no longer all alike or nearly so, but that some are different from the others in shape, strueture and function. The cells are not all equivalent, the plant is not now a collection of nearly independent individual parts (cells) but the whole must be considered as an individual made up of numerous differentiated parts. It is true that in the history of every plant there oecurs a one-celled stage and 
by the division of this cell the plant originates, but nonethe-less the whole plant is to be considered as a unit and not as an association of distinct cells.

38. In such higher plants we can distinguish several types of differentiated cells and can with correctness speak of tissues. A tissue may be defined as an association of similar cells for a common function. In the less differentiated plants the same tissue will have many different functions; in the more highly specialized forms there will be more kinds of tissues each with fewer functions. In the study of tissues we must distinguish between the so-called "false" and "true" tissues. The former are those that are formed by the subsequent close association of cells that originated independently of one another. Thus many separate motile cells (zoospores) may join themselves to one another in such a way as to form a definite structure (e.g. Hydrodictyon) or a sort of tissue may be formed by the growing together of numerous originally separate filaments of cells. On the other hand a true tissue is formed by successive divisions from one or a few cells, so that every cell may be said to have been formed in place. In the false tissues the walls between adjacent filaments or cells of different origin are double, without a true middle lamella while in true tissues the walls are single and the middle lamella is present (at least at first). It is sometimes impossible to make a very sharp distinction between these two kinds of tissues as one method of origin may be combined with the other. False tissues are found almost exclusively in the higher fungi and some of the algae while the tissues of the higher plants are true tissues.

In the following discussion only the more highly differentiated types of tissues, such as occur in the higher plants, will be described in their main features while the 
less differentiated or more generalized tissues of the lower plants will not be considered.

39. Meristem. This is the form of tissue from which ultimately all the other kinds arise. It is often spoken of as rudimentary tissue from this fact. It consists of small, usually rapidly dividing cells (at least during the growing season), some of which usually continue as meristem, while others by enlarging and ceasing their active division and by other modifications become other kinds of tissues. Meristem is present in those parts of the plant where new cells are being formed, i.e. in young buds, at the apex of growing stems and roots, in the developing seeds, etc. Meristem cells are usually small and very thin-walled, and filled with cytoplasm, and with a nucleus which is large in proportion to the size of the cell and mostly central in location. The vacuoles are small or entirely wanting. At the growing points of stems and roots the cells are usually nearly cubical, in other locations (e.g. cambium) they may be elongated. If the plant be one with plastids they are present in meri-

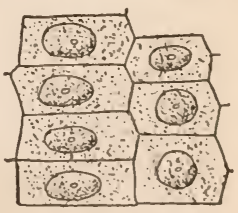

FIG. 9.-Meristem tissue. stem cells often as a single, very small, harlly distinguishable body. Some botanists, however, are of the opinion that plastids are newly formed in the tissues developed from the meristem.

40. Parenchyma. This is the chief vegetative tissue of the higher plants and makes up much the larger part of the living portions of the plant. It is the main nutritive, storage and reproductive tissue. Its cells are much larger than those of meristem, from which it is directly derived, but they preserve in general much the same shape, i.e. they are rounded or poly hedral and usually not much elongated. The cell walls are thicker than 
in meristem but are still usually thin, although in certain modifications, e.g. the parenchyma occurring in wood and sometimes that in the pith of woody twigs, the walls may be considerably thickened. In composition the wall is usually a form of cellulose except where thickening has begun in which case the walls are often lignified. A large vacuole occupies the center of the cell and leaves the cytoplasm as a thin parietal layer (i.e. lining the wall) although there are often cytoplasmic strands running across the cell from one sicle to the other through the vacuole. The nucleus is generally imbedded in the parietal cytoplasm and appears relatively small owing to the great increase in size of the cell in its development from meristem, unaccompanied by a corresponding increase in the size of the nucleus. The chloroplasts are well developed in those parenchyma cells exposed to the light (except of course in plants devoid of chlorophyll). Very generally at the angles of contact of three or more parenchyma cells the middle lamella is ruptured or dis-

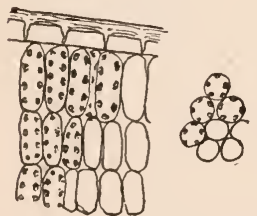
solved and the corner of each cell becomes rounded off leaving a space which becomes filled with air, a socalled intercellular space, these forming a continuous aerating system throughout the living parts of the Fig. 10.- Parenchyma plant. In some parts of a plant, as in the pith, the parenchyma cells die early and the cell contents disappear, being replaced by air. Probably this occurs by the absorption of the protoplasm by the adjacent cells.

Laboratory Studies. (a) For undifferentiated cells examine the one-celled green slime plants (Protococcus)found as a green coating on the north sicle of trees or walls and the many-eelled pond scums (such as Spirogyra or Zygnema) or one of the simple filamentous blue-green algae (as Oscillatoria) which often 
forms a purplish or brown slimy layer on flower pots in greenhouses.

(b) For false tissues examine a longitudinal section of the stalk of a toadstool. Here the longitudinal rows of cells are distinct filaments grown together into one mass. Similarly the basal portion of the apothecium of cup-fungi is made up of false tissue, although here the separate filaments are often indistinguishable. Some of the algae are also good examples, e.g. Udotea, Lemanea, Nemalion, etc.

(c) For meristem examine a thin longitudinal section of a root tip. For this purpose the first strong root from a germinating grain of Indian corn or the young, so-called "brace roots" from near the base of the stem of that plant are good, as are young roots from onion or hyacinth bulbs. By staining lightly with cosin or safranin the nuclei and cytoplasm become more distinet.

(d) Make similar longitudinal sections of a very young floweror leaf-bud, e.g. lilac or elder, or of the growing tip of asparagus or of a pumpkin or squash vine and examine the meristem tissue. Compare the cells with those in corresponding locations in sections made in the older parts of the stem.

(e) For parenchyma cells make thin longitudinal and crosssections of a young green stem of Indian corn or of a green shoot of elder. Excluding the woody and epidermal parts the bulk of the stem at this stage consists of parenchyma. Treat the section with iodine solution and then with sulphuric acid. A blue coloration indicates cellulose.

(f) Make a cross-section of a typical leaf such as apple, lily, nasturtium, etc. The green cells are parenchyma tissue.

(g) Make a thin seetion of the tuber of potato to show storage parenchyma. Similar parenchyma may be found in the fruit of an apple or pear, etc.

(h) In thin cross or tangential sections of a living woody twig will be found the medullary rays. These consist of rather thickwalled living parenchyma, the walls being more or less lignified and provided with thin spots (pits) here and there through which water and food substances can pass from cell to cell. Stain different sections with iodine and sulphuric acid as a test for cellulose, and with a five percent aqueous solution of phloroglucin and hydrochloric acid as a test for lignified cell walls, the latter taking a red coloration. Examine in similar manner 
the pith cells of one or two year old twigs of apple. These are also somewhat thick-walled.

41. Sclerenchyma is the name given to a tissue consisting of more or less rounded or polyhedral, usually not much elongated, thick-walled cells whose function is to give support or protection to other tissues. These cells originate from meristem by the thickening and lignification of the walls, passing through an intermediate parenchymatous stage. During the process numerous spots on the walls remain thin so that

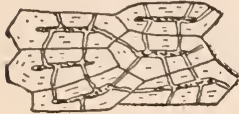

Fig. 11.-Sclerenchyma correspond in adjacent cells. Upon (hickory nut). eventually they show as canals from the small central lumen of the cell to the original outer wall. These canals or pits reaching their final development the cell contents die. Sclerenchyma cells are often called stone cells. They are found in seed coats, nut shells, bark, etc., where protection or support is required.

42. Of a much different type from the foregoing are those tissues consisting of elongated cells with more or less thickened walls whose function is the mechanical strengthening and support of the plant body. To permit bending while at the same time retaining their supporting function they are more or less elastic, a characteristic less marked in the short-celled sclerenchyma whose function is protection or only local support. We can distinguish two types of these sup-

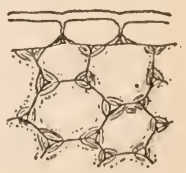
porting or mechanical tissues, collenchyma and fibrous tissue.

43. Collenchyma. Directly beneath the epidermis of many plants are found smaller or larger strands of elongated cells whose longitudinal cell walls are thickened at the angles where three or more cells come in contact. 
Except in old cells the thickening rarely extends out upon the wall lying between the angles. The cells remain alive, for a long while, and usually contain chloroplasts. They remain capable of growth longitudinally. Aceordingly collenchyma is found to be the chief mechanical tissue in growing parts of plants, such as stems, leaf-stalks, ete. The thickened parts of the walls are composed of cellulose and transmit the light with a peculiar pearly luster when viewed in cross-section, the lumen of the cell under these conditions appearing darker than the cell walls.

44. Fibrous tissue consists of elongated cells, thickened on all sides, usually overlapping at their more or less tapering, often pointed, ends. The walls show minute, usually obliquely placed, slitlike pits. After they reach full development, the cell contents die, so that the cells are incapable of further growth or development. The thickened walls are usually strongly lignified. In cross-section the cells are round or by mutual Frg. 13.-Wood and pressure, angled. Fibrous tissue is

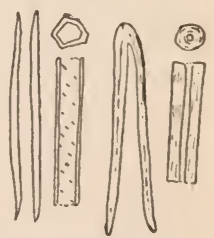
found as the chief mechanical tissue in parts of plants which have completed their longitudinal growth. Two types ean be distinguished, viz., bast and wood fibers. The former are located in the outer part of the stem (in the cortex in the Dicotyledoneac), the latter in the true wood. Bast fibers are usually longer than wood fibers, and more slender, with often thicker but less completely lignified and hence more elastict walls. Their usual length is from 1 to $2 \mathrm{~mm}$. but in Bochmeria nivea, the ramie plant (according to Haberlandt) they reach a length of $220 \mathrm{~mm}$., the longest plant cells known. Wood fibers are usually shorter (mostly 0.3 to $3.1 \mathrm{~mm}$.) often 
somewhat thicker, with less tapering ends and frequently with less thickened walls which are more strongly lignified than those of bast fibers.

Laboratory Studies. (a) Break the shell of a hickory nut, almond, coconut, walnut, peach-stone, etc., and after sinoothing the broken surface, cut off a thin shaving, using a pocket knife or scalpel held at rather an oblique angle. Mount in water and a little potassium hydrate. The very small cell cavities show connecting pits or canals radiating from them to the original eell wall where they meet similar canals from the centers of adjoining cells, being separated only by the thickness of the original wall. Concentric markings are visible in the cell walls in some cases.

(b) Determine whether the walls in sclerenchyma are made of cellulose or are lignified, by testing one section with a 5 per cent. aqueous phloroglucin solution followed by hydrochloric acid which gives a red color for lignified walls, and another section with iodine solution followed by somewhat diluted sulphuric acid which gives a blue color for cellulose walls.

(c) Sclerenchyma may be found and studied (1) as the little "grit" bodies in the flesh of the pear or sapodilla (Achras sapota), (2) in the underground stem of the brake (Pteridium aquilinum), (3) next to the epidermis in the prickly pear (Opuntia), as well as (4) in coats of many seeds, e.g. apple, squash, wild cucumber, and (5) forming the body of the sceds of many palms, e.g. date.

(d) Examine a young leaf-stalk of the squash or pumpkin and note the whitish bands, 1 or $2 \mathrm{~mm}$. wide, which extend from end to end just beneath the epidermis. These are bands of collenchyma. They may be readily torn out, when the stalk will be found to have lost much of its strength.

(e) Make a very thin cross-section of the leaf-stalk of one of the foregoing plants, exactly at right angles to the axis of the collenchyma strands, and examine under low and high magnifications. Test with iodine and sulphuric acid to determine the composition of the walls.

(f) Make longitudinal sections through these collenchyma bands. If good sections are obtained the thickened angles (becoming thin toward the point where the thin cross walls occur), chloroplasts and nuclei will be found. However, only 
those cells that happen to be so placed that a thickened angle appears in the section will show this feature. On the other hand, if the section passes between the corners of the cell the walls will appear thin.

(g) Collenchyma may be found also in the young green shoots of elder (Sambucus) and some other shrubs, in the stems of lamb's quarters (Chenopodium), pigweed (Amaranthus), petioles of beets and very many other plants.

(h) Make thin longitudinal sections of the wood and bark of the basswood ('Tilia) or maple (Acer) and macerate, to separate the cells, in Schulze's reagent (i.e. heat in a test tube in nitric acid to which has been added a little potassium chlorate). Mount a bit of the macerated wood section on a slide and tap the cover glass, or tease the section apart with needles. Study the wood fibers. Do the same for the bast fiber's in the bark.

(i) Now make thin longitudinal and cross-sections of the same kind of twig without macerating and study the fibers in place to note the relation of the overlapping cells. In the crosssection, note the appearance of the fibers and their position in the twig.

45. Besides the foregoing, there is a group of tissues which have as their chief function the conduction of water and food, the so-called conductive tissues. These are of three kinds: tracheary tissue, whose primary function is the transportation of water, and sieve and laticiferous tissues, which are chiefly concerned with the conduction of food substances manufactured by the leaves.

46. Tracheary tissue is of many kinds. The term is here used to include those elongated cells, whose chief function is the transport or storage of water. The lumen is usually rather large with the wall thickened in a more or less regular manner to give strength. At the same time, a considerable portion of the wall remains thin, permitting the entrance or exit of water. The cells are not living, i.e. their protoplasm dies as soon as they have attained their final 
development, so that the conduction of the water is not dependent upon the activity of these eells but oceurs in the cavities left empty by the disappearance of the protoplasm. Since the cells lack protoplasmic contents which would furnish the turgor to keep them from collapsing, the thickening of the walls is necessary. It of ten happens that adjoining living cells swell out through the thinner places into these cells, these bladder-like projections being called tyloses. A distinction is made between tracheids which are formed of single cells, and tracheae (singular, trachea) or vessels, which are more or less elongated tubes formed by the absorption of the cross walls of adjoining cells so that the lumens of many successive cells are all connected. The latter usually attain the greater diameter. Tracheids are mostly not over 1 $\mathrm{mm}$. long although in some cases they reach a length of 1 centimeter or even much more. Tracheae, aceording to Strasburger, average about 10 centimeters long, but in some eases reach a length of 2 to even 5 meters. In some vines, the diameter reaches $0.3-0.7 \mathrm{~mm}$. Tracheary tissue is found only in the higher plants, i.e., Seed Plants and Ferns and Fern Allies.

47. In accordance with the character of the thickening,

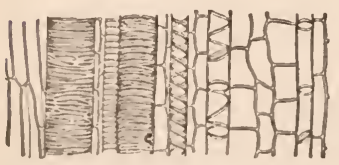

Fig. 14.-T Tacheary tissue (ringed, spiral, reticulated). there may be distinguished several types of tracheary tissue, these same types of thickening being found both in tracheids and tracheae. These are ringed (or annular), spiral, reticulated (netted), scalariform (ladderlike) and pitted tracheae or tracheids. All but the last are named after the manner of the internal thickenings of the walls. The pitted cells, however, are those in which the thickening is more extensive than in the others, the 
thin places remaining only as small pits. The cells of all these structures are usually more or less pointed and overlapping at the ends, except in some of the tracheae in which the square end walls were dissolved out. They are mostly round or by mutual pressure somewhat angled in cross-section.

48. The spiral and annular thickenings are the only types found in the tracheary tissue that is formed in stems or roots that are still elongating, as it is possible for such cells to elongate by the stretching or growth of the unthickened portion, whereby the rings become farther apart or the spirals stretehed out at a greater angle. Very of ten adjacent rings may be conneeted here and there by a spiral or the same vessel may have annular thickenings in one part and spiral in another. There may be from one to three or four spirals. The reticulate type of thickening is perhaps to be considered as a many-spiraled type with numerous cross connections from one spiral to the next so as to form a network. Scalariform vessels are usually angular in cross-section and have their thickenings on the flat faces of the prisms as horizontal bars connected to the somewhat thickened angles, and leaving horizontally elongated thin areas between them like the openings between the rungs of a ladder. All transitions may be found from the reticulated or scalariform structure to the pitted type. The pitted tissues are of two types: (a) with simple pits, and (b) with bordered pits. In the first the pits are of the same diameter through their whole depth or even wider toward the center of the cell. In the second, they are narrow, adjacent to the cell lumen and are much wider as they approach the middle of the cell wall, the cavity of each pit having the shape of a planoconvex lens. The wall or diaphragm separating the adjacent pits of ad- 
joining cells is very thin and permeable to water except a button-like thickening, in the center. When seen in surface view, a bordered pit shows a double circle, the smaller inner one being the opening into the pit and the outer circle, the outer edge of the diaphragm.

49. Special mention must be made of the tracheids of

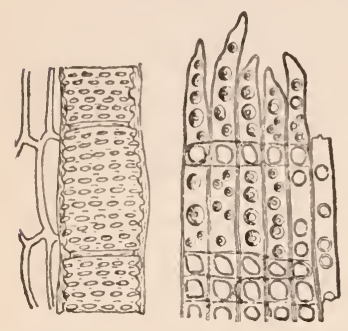

Fig. 15.-Tracheary tissue (pitted and tracheids).

Conifers (Spruces, Pines, etc.). These are shaped and thickened like wood fibers but differ in possessing on their radial faces one or more longitudinal rows of bordered pits. They combine the functions of tracheids and fibrous tissue, serving both for conduction of water and for mechanical support.

50. Sieve Tissue. In almost all of the higher plants and in many of the more massive lower plants, there are found rows of elongated rather wicle cells whose transverse separating walls are pierced by numerous larger or smaller perforations. Where two such cells lie side by side parts of the lateral separating wall will often show similar perforated areas. These are the socalled sieve plates which give the name to this tissue. The walls of the sieve tubes, as the elongated cells are called, are usually rather thin. The sieve plates, on the contrary, are rather thick. In surface view

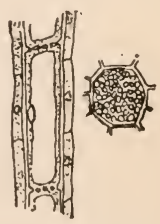

Fig. 16.-Sieve tissue. they look like a sort of network. In some cases, the meshes of the net are perforations, in others, they are thin walled areas perforated by several to many fine holes. The mature sieve tubes have the walls lined with a thick layer of cytoplasm in which the nucleus is imbedded. 
The central vacuole is filled with a liquid very rich in protein matter, the masses of this protein substance often being continuous through the pores of the sieve plates with those of the adjoining sieve tubes.

51. The sieve tubes of the Flowering Plants are accompanied by usually slender parenchyma cells full of protoplasm, the so-called companion cells. The walls between these and the sieve tubes are perforated by numerous very minute passages invisible except by special manipulation. Other forms of parenchyma cells are usually found adjacent to the sieve tissue. The function of the sieve tissue is probably the transportation of protein substances from the leaves to parts of the plant where they are needed in the construction of new cells. Possibly, also, sugars are transported, at least in part, in the same tissues as well as in the ordinary parenchyma cells near them. The function of the companion cells is not certain.

52. Laticiferous Tissue. This consists of a system of tubes extending throughout the plant and filled with a substance called latex. This is usually white (hence the name "milk tissue" of ten applied to this kind of tissue), but may be colored red, yellow or even be almost clear and colorless. The latex consists of water containing usually much pro- Fra. 17--Taticiftein matter as well as some sugar and

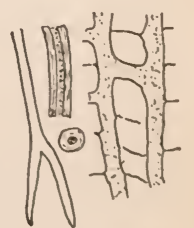
erous tissue. salts dissolved in it, and holding in suspension numerous minute globules of resin or in many cases, caoutchouc. On exposure to the air, the latex often coagulates. It is from the latex of many plants that rubber and gutta percha are obtained, while other substances of great value are often found in it also, e.g. opium in the latex of the poppy. In some plants, starch grains are found in 
the laticiferous tubes. The walls are lined with cytoplasm containing nuclei. They are mostly thin but in Euphorbia the walls are thick and elastic.

53. Two distinct types of laticiferous tissue may be distinguished: (1) Non-anastomosing and (2) Anastomosing. The former consists of branching tubes which originated from single cells in the embryo. These cells elongate and branch, keeping pace with the growth of the plant, forcing their way between the meristem cells exactly as if they were part of a fungus instead of a tissue of the plant in which they occur. They appear never to anastomose. They are found in the Euphorbiaceae, Moraceae, Apocynaceae, etc., i.e. in the chief rubberproducing families.

54. The anastomosing milk vessels are formed by the fusion (that is through the resorption of the separating walls) of adjacent meristem cells in such a way as to form a network of latex-bearing tubes. Short lateral outgrowths may also be sent out from one tube to another, thus increasing the number of anastomoses. Laticiferous tissue of this type is found especially in the Lactucaceae, Papaveraceae, etc., as well as in a few of the Euphorbiaceae, e.g. Manihot and Hevea, both rubber-producing trees of great economic value.

Laboratory Studies. (a) Make a thin longitudinal section of the stem of garden balsam (Impatiens) or any other herbaceous plant that has not begun to become thickened and woody. The section should pass through one of the vascular bundles. There will be found various types of tracheary tissue, those facing the interior of the stem being usually of the annular or spiral type, with reticulated and pitted types toward the outside.

(b) Good plants for study are Tradescantia, especially for ringed and spiral types of tracheary tissue; Sida, for good spiral and reticulated types; Indian corn, pumpkin or squash, etc., for large pitted ressels. 
(c) Study the foregoing types of tracheary tissue in crosssection in comparison with the longitudinal sections.

(d) The larger pores in the wood of oak, hickory, etc., as well as in the grape, are pitted vessels.

(e) Excellent sealariform vessels are to be found in the leaf-stalks or better still, in the underground stems of the brake (Pteridium aquilinum).

(f) The tracheids of pine, spruce, ete., resembling wood fibers in shape, but with bordered pits, should be studied by making tangential and radial longitudinal sections as well as crosssections of the wood. The bordered pits oceur only on the radial surfaces of the tracheids.

(g) Spirally marked tracheids, similar in shape to the foregoing, may be found in the wood of the hackberry (Celtis), and ash.

(h) By treating various kinds of wood with Schulze's reagent (nitric acid and potassium chlorate, warmed) the various cells will be separated and the tracheary elements of different kinds can be studied separately.

(i) Sieve tissue is easily found by making longitudinal sections of the stems of squashes or pumpkins (Cucurbita) or other vines such as grape, elematis, hop, etc. They will be found in the part of the vascular bundle lying toward the outside of the stem and in the case of Cucurbita also on the inner side. By staining with eosin or earmine, the protoplasm and protein contents will be stained. If alcoholic material be used, the contents will be found shrunken away from the sieve plates. If portions of living stems are killed before sectioning by dipping into very hot water, the protein and protoplasmic contents will be coagulated without much contraction.

(j) Make numerous very thin cross-sections of the same stems and examine until sieve plates are found and studied in surface view.

(k) Examine a drop of latex from milkweed, spurge or poppy, under high magnification. The suspended granules will be visible as fine dark brown bodies by transmitted light. Test with iodine to determine whether starch grains are present.

(l) Collect a quantity of latex of spurge (Euphorbia) and let it evaporate in a watch glass. The residue is a sticky, rubbery mass, which on being burned, has the characteristic odor of burning rubber. 
(m) For the study of laticiferous tissue thin tangential sections are best. The tissues will show as tubes filled with a brown granular mass, the latex. The non-anastomosing type can be found in the milkweed (Asclepias), dogbane (Apocynum), and spurge (Euphorbia), especially the more fleshy forms of the latter. The anastomosing type can be studied in the petioles of dandelion or lettuee, or in the stem of the poppy.

(n) The long, branching, non-anastomosing laticiferous tubes of Euphorbia can be isolated from the more fleshy leaved sorts by boiling the leaves in dilute potash solution and then teasing out a piece of the softened tissues.

(o) To examine the tissues in situ, the leaves should be placed in strong alcohol $(90-95 \%)$ for some hours. If the leaves are thick, thin sections should be made parallel to the surface. These sections, or the whole leaves if they are thin, should then be placed for an hour or so in a clearing fluid made of equal parts of turpentine and carbolic acid (phenol). Mount the section or leaf in this fluid. The tissues are made transparent, and the laticiferous tubes filled with granules of latex can be studied with great ease. The same method can be used for studying both types of laticiferous tissue.

\section{REFERENCE BOOKS}

The books enumerated for Chapter I and the following.

A. DeBary, Comparative Anatomy of the Vegetative Organs of Phanerogams and Ferns (Engl. Ed. 18S4. Oxford).

G. Haberlandt, Physiologische Pfanzenanatomie, Leipzig, 1904. (Engl. Ed. 1914. London.) 


\section{CHAPTER III}

\section{GROUPS OF TISSUES, OR TISSUE SYSTEMS}

\section{HISTOLOGY}

55. In the lower plants, where all cells are essentially alike and no distinction of tissues can be made, we often find that growth takes place in all parts of the plant, almost every cell being capable of growth and division at any age. In many plants, however, in which the differentiation into various kinds of tissues is still almost lacking, we find that growth is more or less limited to certain regions of the plant. In those plants where the tissue differentiation is strongly marked, we find that the formation of new parts, as well as growth, is localized in groups of meristem cells at the apices of stems and roots (and also in many plants at the nodes), the older cells of these groups gradually changing into the more permanent tissues of the plant.

56. In many seaweeds and fungi, where the plant body consists of separate or adjacent rows of cells, the terminal cell of each row elongates and divides by a cross partition and perhaps division occurs in one or two cells behind it. Except for the formation of branches, longitudinal divisions may be lacking and the result is only the formation of rows of cells.

57. In the plants which are not so markedly filamentous in structure the new tissue at the apex may arise by the division of a single apical cell. This division may be by horizontal partitions, the segments thus 
formed dividing subsequently by both horizontal and longitudinal partitions (as in Sphacelaria and many other algæ). More often, we find that the apical cell is a three sided pyramid, the convex base of the pyramid being the apex of the shoot. Successive cells are cut off from

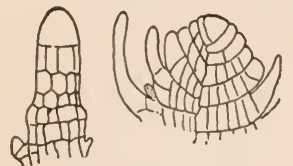

Frg. 18.-Apical cells of a seaweed (Sphacelaria), and a moss. the three sides and the segments thus produced divide by various partitions so as to produce the mass of meristem cells from which the tissues become differentiated. Sometimes, instead of the apical cell cutting off three rows of segments, it produces only two or in other cases, four.

58. In most of the Flowering Plants, a group of cells is found at the apex of the stem or root instead of one cell, these giving rise, by their division, to the mass of meristem. This group of apical cells, or the single apical cell with the cells derived from it, is called the growing point.

59. We can usually distinguish three different tissue regions at or a short distance back from the growing point of higher plants. At the outside we find a single layer, the epidermis, which consists of cells that divide only by walls perpendicular to the surface. When this layer has an initial cell or cells distinct from the inner layers the portion near the apex is often spoken of as the dermatogen. The next region is spoken of as periblem, and may consist of one or several layers of cells surrounding the centrally located plerome. These two regions may have separate sets of apical cells or the distinction may occur only some distance from the apex. In most roots, the apex is covered by the root cap, a mass of cells produced by the periclinal division (i.e. by walls parallel to the surface) of a layer of cells outside 
of the dermatogen, or in some cases, of the dermatogen itself, or, in still other cases, by the division of some of the cells of a common mass of initial cells from which the root cap as well as epidermis, periblem and plerome arise. On the growing points of stems, the new branches arise by the formation of secondary growing points at the side of the main one, these having the same general plan. Those that produce the leaves often grow faster than the mai growing point and surround and protect it, thus forming a bud.

60. As the growing point progresses, the cells formed in it come to lie further and further from the apex. They increase in size and, after a while, cease to divide. Certain of the cells remain meristematic a long while; others become elongated, i.e. cease early to divide transversely, and eventually become transformed into fibrous, tracheary, sieve tis-

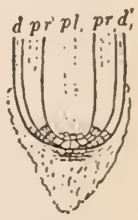

FIg. 19. Dermatogen, periblem and plerome in root of Flowering Plant. sue or collenchyma. Some cells merely enlarge and become parenchyma. Thus, near the tip the cells will be found to be all meristematic, but further back, various kinds of tissues may be found.

Laboratory Studies. (a) Make a longitudinal section of the end of a branch of the marine alga, Codium tomentosum. Here the growing region is not a few cells as in a true growing point, but each filament elongates at the apex without the production of eross walls. Many of the Red Seaweeds (Rhodophyceae) show the same type of apical growth except that transverse walls are formed near the apex of each filament (e.g. Melobesia, Nemalion, etc.).

(b) Examine the end of a shoot of Sphacelaria, one of the Brown Seaweeds. Here there is a single apical cell which divides by a transverse partition, the segments thus formed dividing longitudinally and transversely.

(c) Make a thin longitudinal section through the growing point of a moss or of a stem or root of a fern or horsetail 
(Equisetum). This is a difficult section to make, but if successful the growing point, with its single apical cell, can be studied. Sometimes this can be seen better by making successive, very thin cross-scetions at the tip of a fern root. In this case, the apical eell will be seen in transverse view.

(d) Make a longitudinal median section through the growing points of a stem and a root of a Flowering Plant. (Stained microtome sections are preferable to hand sections since they are thinner and more likely to show the desired features.) Note that all of the tissue near the tip is meristem. Observe the three regions, dermatogen (epidermis), periblem and plerome. Trace them to their origin. On the root section, note also the root eap and its origin.

61. The tissues produced from the primary meristem in the manner described above have definite functions to perform, and occupy definite positions in the plant body. The outer layer or epidermis is set off as a boundary tissue; other cells are developed into the skeletal or supporting tissues, still others are for transportation of water and food, while the remainder of the cells are at first not so clearly differentiated for special functions. This less differentiated group of tissues may eventually fulfill various functions depending upon the part of the plant they occupy, the nature of the plant, etc. Thus they may be food making, as in leaves; for storage purposes, as in tubers, many roots, some pith, etc.; protective, as in the shell of nuts where the tissue is changed to sclerenchyma.

62. According to the kinds of tissues and functions, it is customary to differentiate several so-called "tissue systems." These may be defined as aggregations of elementary tissues, forming definite portions of the plant and with a definite function. It is at once evident that tissue systems cannot be distinguished where tissues are not yet differentiated. In fact, we usually speak of them only in connection with the higher plants. 
63. Three tissue systems are easily recognizable in the higher plants apart from the less differentiated mass of cells in which they lie. These are: (1) the epidermal system, composed mainly of the boundary cells and their appendages (hairs, seales, stomata, etc.); (2) the conducting system, comprising those tissues which are water or food conducting and the tissues immediately associated with these; and (3) the mechanical or skeletal system, consisting of the fibrous tissue, collenchyma and sclerenchyma which furnish the rigidity and strength necessary for the plant. The latter two are sometimes considered together as the fibrovascular system, while the remaining tissues are often grouped under the name fundamental system. The latter is, however, no definite aggregation of tissues but rather the residue of less strongly specialized tissues from which we have rather arbitrarily set off the other tissue systems, for we must remember that these are all coherent parts of one plant body and not separate parts without close interrelation.

64. The Epidermal System of Tissues. This is perhaps the earliest tissue system to have been differentiated from the remainder of the plant. In many lower plants, the exterior and interior cells show no visible differences, but even here among some we find that the outer cells are more closely crowded together and smaller while the inner cells are loosely arranged. In the fruits of some fungi, the outer layers of cells are firm and resistant. Some of the Liverworts and Mosses possess an outer layer of cells distinct from the inner cells and evidently of protective nature. It is only in the higher, more massive land plants, however, that we find a really distinet epidermal system of tissues. Thus in the Ferns and onward through the various Fern Allies and throughout the Seed Plants, the epidermis and its 
appendages are well developed. It is worthy of note, however, that those plants of these groups that have reassumed the aquatic habit have their epidermis scarcely distinguishable from the rest of the tissues. The roots of most plants, being usually in moist soil, have their epidermis not very strongly differentiated.

65. The Epidermis. In most cases the epidermis consists of a single outside layer of cells which surrounds the whole plant in an almost uninterrupted sheet. It frequently originates from an apical cell or group of cells

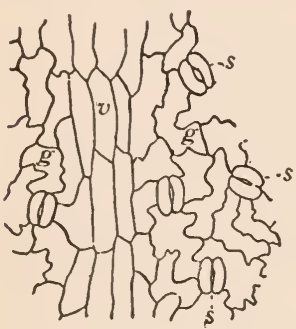

FIG. 20.-Epidermis, with distinct from those producing the rest of the tissues, or is differentiated from the latter near to the growing point. Mostly the epidermal cells may be considered as a special kind of parenchyma tissue with a protective function. In many plants, however, especially those of hot, dry climates, the cells soon become thickened and more or less sclerenchymatous. Usually they remain alive, but in the forms where they have been changed to sclerenchyma the contents commonly die. In most cases, epidermal cells show no well developed chloroplasts although the cell sap may be brightly colored.

66. In shape, the epidermal cells are usually more or less flattened parallel to the surface of the plant. If the growth of the organ is nearly equal in length and width, the epidermal cells seen from the outside will be nearly isodiametric, but if the longitudinal growth has been markedly greater than the transverse growth, the epidermal cells will usually be elongated. Frequently the cells are very irregular in outline. Except for the 
stomata, to be described later, no openings oceur between the cells, even at their angles.

67. The most characteristic feature of well developed epidermis cells is the thickening of the external wall and the deposition in the outer layers of this wall of a waxy or fatty substance called eutin. This water-proofs the walls to a large extent and prevents loss of water through them by evaporation. The cutin is not deposited equally throughout the outer wall, but is least toward the cell eavity and greatest at the outside. The outer, strongly cutinized portion of the wall is often very distinct in appearance from the remainder of the wall and can sometimes be stripped off as a continuous sheet, the cuticle. Often this is coated externally with a waxy or resinous coating, the "bloom" of some leaves or fruits.

68. The cutinized layer extends, in many cases, not merely over the outer surface of the cell wall but even down between the adjacent cells for some distance. In roots, on the other hand, the younger parts are not at all cutinized and further from the tip the eutinization is only comparatively slight. The root hairs are cutinized, if at all, only in their basal portion.

69. While the epidermis always consists at first of but one layer of cells it becomes two to four layered in some plants, e.g. oleander (Nerium oleander), rubber plant (Ficus elastica), various cactuses (Opuntia), etc., by subsequent periclinal division (i.e. division by the formation of a cell wall parallel to the outer surface) of the original layer. The outer walls of these new layers may become cutinized successively, from the outer toward the inner layers.

70. The hairs originate mostly as outgrowths of single epidermal cells. In the case of young roots the epidermal 
cells at a distance of a few millimeters from the tip grow out into long, normally unbranched, thin-walled hairs, whose lumen is continuous with that of the main body of the cell. These root hairs are not cutinized, or only so at the base. They may attain a length of two or three centimeters but are mostly not over one centimeter in length and often much less. The thin wall is lined by a delicate layer of cytoplasm and the central vacuole is very large. These hairs push in between the particles of soil and lie in the film of water with which these are covered, absorbing some of this water by osmotic action.

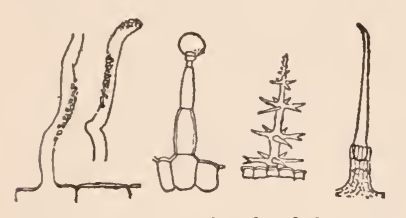

Fig. 21.-Root hair, glandular hair, branched hair, hair of nettle.
Such mineral salts as are in solution in this soil water in greater concentration than that of the same salts in the cell sap diffuse into the cell and upward through the plant except so far as the plasma membrane is impermeable to them.

71. The hairs on those parts of the plant exposed to the air may be continuous with the epidermal cells from which they have arisen, but mostly are separated from them by cross partitions. They may remain one-celled or may become many celled by cross septa. Sometimes they are much branched or merely bifid or stellately divided. In some cases the end cell of a short hair divides by vertical partitions in several planes to form a shield-shaped structure. Some hairs have the terminal cell enlarged and functioning as a gland which secretes sticky or oily substances. Certain hairs (as those of nettles) contain strong irritant poisons. The tip of the hair penetrates the skin of animals coming in contact with the plant and then breaks, permitting the poison to be forcel out into the skin. 
72. Not to be confused with hairs are those outgrowths called emergences. These are not epidermal in nature but are projections produced by the development of cells beneath the epidermis. Often such emergences are found bearing, and as it were, forming the support for a stout hair, as in the sunflower or nettle.

73. The presence of hairs seems to be advantageous to plants in many ways. They make it difficult for small insects to ascend the plant, especially if the hairs are pointed downward or are sticky-glandular. Stinging hairs like those of the nettle, and also merely sharppointed stiff hairs, such as abound on many plants, are deterrents for animals that would otherwise feed on the plant. The same is probably true of various evil-smelling substances secreted by some glandular hairs. Finally, it has been shown that the presence of hairs and scales reduces the loss of water from the plant by forming an entanglement for a layer of air, thus preventing the air currents from coming into direct contact with the epidermis.

74. Stomata (singular, stoma), or breathing pores, are definite openings through the epidermis to air cavities beneath, through which an exchange of gases takes place. These cavities ("substomatal chambers") are connected with the intercellular air spaces throughout the plant.

75. Except in the Liverworts (Hepaticae), where the stomata are of different structure, the typical stoma consists of an opening, slit-shaped or narrowly ellip-

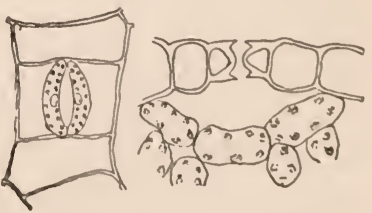
tical, bordered by two, usually chlorophyll-bearing, epidermal cells, somewhat kidney-shaped, and in contact with 
each other at both ends. When these guard cells become more turgid they curve outward, thus opening the stoma, while a loss of turgidity results in its closure. Usually the stomata open while the plant is in the light and close partly, sometimes completely, in darkness. An excessive loss of water by the plant reduces the turgor of the guard cells, overcoming the effect light has in opening the stomata, and causes them to close, thus conserving the moisture in the plant.

76. Stomata occur on aerial leaves and stems and more rarely on flowers and fruits. On underground stems and leaves they are less abundant (and often not functional), while they are wanting on roots. On submerged parts of aquatic higher plants they are lacking or only rudimentary. On leaves they are usually more abundant on the lower than on the upper surface. The numbers as well as size of the stomata vary greatly for different species. The following table will give an idea of their relative abundance in some plants. (Page 53.)

Laboratory Studies. (a) Strip off the epidermis from the upper and lower surfaces of the leaves of various plants, and mount with the outer surface upward. If air bubbles interfere, add alcohol, and follow this by a weak potash solution, to swell the tissues again. Leaves of various grasses or of carnation will show epidermal cells much elongated, while more isodiametric cells may be found on the leaves of such plants as the live-for-ever (Sedum or Sempervivum), dock (Rumex), cabbage, ete.

(b) In the same specimens that were used for the foregoing, study the stomata and their relations to the adjacent cells. Compare the numbers of stomata on the two sides of the leaf, and their relative size and number on different species of plants.

(c) Cut cross-sections of various leaves. Those of eabbage and carnation, as well as of many other plants that grow in dry regions, will show a considerable development of cuticle. Note the structure of the stomata as shown in cross-section, and their 


\begin{tabular}{|c|c|c|}
\hline & \multicolumn{2}{|c|}{$\begin{array}{l}\text { In one square } \\
\text { millimeter }\end{array}$} \\
\hline & $\begin{array}{l}\text { Upper } \\
\text { side }\end{array}$ & $\begin{array}{l}\text { Lower } \\
\text { side }\end{array}$ \\
\hline Olive, Olea europaea................ & 0 & 625 \\
\hline Black Walnut, Juglans nigra........... & 0 & 461 \\
\hline Red Clover, Trifolium pratense.......... & 207 & 335 \\
\hline Lilac, Syringa vulgaris............... & 0 & 330 \\
\hline Sunflower, Helianthus annuus. ......... & 175 & 325 \\
\hline Cabbage, Brassica oleracea.......... & 138 & 302 \\
\hline Sycamore, Platanus oceidentalis......... & 0 & 278 \\
\hline Lombardy Poplar, Populus nigra italica... & 55 & 270 \\
\hline Hop, Humulus lupulus. . . . . . . . . . . . . . & 0 & 256 \\
\hline Plum, Prunus domestica............. & 0 & 253 \\
\hline Apple, Malus malus................. & 0 & 246 \\
\hline Barberry, Berberis vulgaris. . . . . . . . . . & 0 & 229 \\
\hline Pea, Pisum sativum.............. & 101 & 216 \\
\hline Box, Buxus sempervirens........... & 0 & 208 \\
\hline Cherry, Prunus mahaleb........... & 0 & 204 \\
\hline Thorn Apple, Datura stramonium.... & 114 & $1 S 9$ \\
\hline Indian Corn, Zea mays.............. & 94 & 158 \\
\hline Cottonwood, Populus deltoides.......... & S9 & 131 \\
\hline Wind Flower, Anemone nemorosa........ & 0 & 67 \\
\hline Lily, Lilium bulbiferum............ & 0 & 62 \\
\hline Iris, Iris germanica............. & 65 & 58 \\
\hline 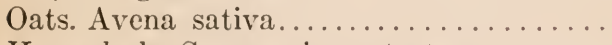 & 48 & 27 \\
\hline House leek, Sempervivum tectorum...... & 11 & 14 \\
\hline Water Lily, Castalia lotos............. & $62 \tilde{j}$ & 0 \\
\hline
\end{tabular}

relation to the substomatal chambers and the inter-cellular spaces of the leaves.

(d) Make a cross-section of the leaf of oleander (Nerium oleander) or rubber plant (Ficus elastica). In the former the epidermis is in two layers, and in the latter sometimes as much as four. This point ean only be determined by making comparative sections of very young leaves and old leaves. Note the depressed, eistern-like pits in the oleander leaf, into which the stomata open. 
(e) Root hairs may be studied in cross- or longitudinal-sections of the young roots of seedlings that have been germinated between damp cloth or paper, or in moist air. By adding a rather strong sugar, or potassium nitrate solution the cytoplasm may be drawn away from the walls sufficiently (plasmolyzed) to become visible.

(f) The leaves of various grasses (e.g. Panicum capillare) will show simple one-celled hairs. The petunia stem possesses unbranched hairs, consisting of rows of cells. Many will be found to terminate in glandular cells. Hairs of these same types may be found on tobacco, various species of Silene and very many other plants.

(g) The stems and leaves of various crucifers (e.g. Erysimum, Arabis, Bursa), show bifid hairs. Stellate and peltate hairs are shown best on the leaves of species of Elaeagnus and Shepherdia.

(h) The hairs of the common mullein (Verbascum thapsus) may be studied as examples of greatly branched hairs.

(i) Cross-sections of the leaf or stem of nettle (Urtica and related genera) will show the peculiar stinging hairs. Under high power note the terminal knob which breaks off as the hair penetrates the skin, thus permitting the distended base of the turgid hair to contract and discharge the poisonous contents into the skin.

77. The Conducting System. In most of the lower algae and in the fungi, the plant body consists of separate branching filaments, which are in some cases woven together into a more or less firm body. These filaments are about alike, and are mostly not differentiated into conducting and other filaments. In some of the more massive algae, however, as in the larger kelps (Laminaria, etc.), or rock weeds (Fucus, etc.), the internal cells are much more elongated, and seem to conduct the elaborated food stuffs from one part of the plant to the other, true sieve tissue sometimes being present. A system of water-conducting tissue is not evolved until the Mosses are reached. Here the center of the stem is occupied by elongated cells, that serve probably in part 
as water-conducting cells, in part probably for support. Around these are somewhat elongated thin-walled cells that are possibly food-conducting in function.

78. It is in the higher plants, however, the Ferns and Fern Allies and Seed Plants, that a true conducting system is developed. This consists usually of strands of tracheary and sieve tissue, each associated with some living parenchyma cells, passing longitudinally through the stems and roots and out into the leaves. These strands are called vascular bundles.

79. A vascular bundle consists of two parts which are distinguished both structurally and functionally. Xylem is the name given to that part of a vascular bundle consisting of the tracheary tissue and the parenchyma associated with it. Its function is primarily waterconducting. The phloem, on the other hand, consists of the food-conducting sieve tissue, with the accompanying parenchyma in the form of companion cells, sieve parenchyma, etc. Frequently fibrous tissue is found intimately connected with the xylem and phloem, usually in the form of wood fibers with the former and bast fibers with the latter. In such a case, we find the supporting system to be partially united with the conducting system.

80. The vascular bundles originate in the growing points by the conversion of certain of the rows of meristem cells into strands of elongated, rather narrow cells. These, beyond elongating considerably and dividing longitudinally so as to become narrow, retain their meristematic character long after the surrounding tissues have acquired the more permanent forms. They are then known as procambium or as procambial strands. Eventually, the cells composing them begin to change into the permanent tissues, these changes 
taking place first in a few cells and finally including all the procambium in the so-called closed bundles or leaving a sheet of unchanged meristem between the xylem and phloem in the so-called open bundles.

81. Classifying them by the relative positions of the xylem and phloem parts of the bundle, we may distinguish three main types of vascular bundles, radial, concentric, and collateral. In the radial type, the xylem is present in two to many radially situated, more or less flattened strands, which may or may not reach the center. Alternating with these are the masses of phloem. In the concentric type, the xylem is central
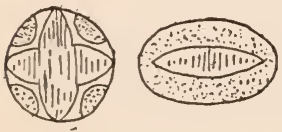

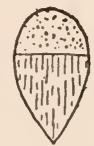
and is surrounded by an almost continuous layer of phloem, or much more rarely phloem and xylem have re-

Fig. 23.-Plans of radial, concentric, verse positions. In the coland collateral vascular bundles.

lateral type, the xylem occupies one side of the bundle (usually that toward the center of the stem), and the phloem the other side (usually the centrifugal side).

82. The radial vascular bundle is typical of roots. It occupies that part that was marked off as plerome at the growing point. Bounding it is a layer of rather thickwalled cells, often with suberized or cutinized walls, the endodermis (or bundle sheath). This is actually the inner layer of the cortex, and is not really a part of the bundle itself. Within this is a delicate layer of thin-walled cells, the pericycle (or pericambium). Bordering on this, or in some families of plants interrupting it, and therefore touching the endodermis, are the xylem strands. These are made up of tracheary tissue. The elements vary in size, the smallest (those first differentiated from the procambium) being those next to the pericycle, those lying 
nearer the center being gradually larger. The various xylem strands may meet in the center in one large vessel or in a mass of tracheary elements, or the center may consist of parenchyma, or of sclerenchyma, or even of fibrous tissue. Midway between the xylem strands, and like them bordering upon the pericycle are smaller or larger phloem masses, consisting mainly of large sieve tubes, and small companion cells, and other parenchyma cells. The tissue between the phloem and xylem strands may be parenchyma or in part fibrous or sclerenchyma.

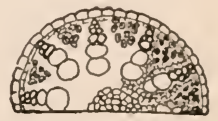

FIG. 24.- Half of a radial vascular bundle.

83. Lateral roots arise by the conversion of portions of the pericycle into active meristem cells which soon become arranged in definite layers, as in the growing root tip. This rootlet forces its way out through the cortex until it reaches the outside. The plerome part becomes the vascular bundle whose tracheary and sieve elements are connected respectively with the xylem and phloem strands of the main bundle.

84. The concentric type of bundles is found mainly

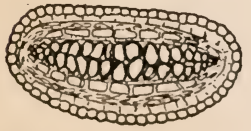

Fig. 25.-C o n centric vascular bundle. in the stems and leaves of Ferns and Fern Allies. In these plants the stem usually possesses several vascular bundles, which may be variously located and of different shapes and crosssections. They branch more or less frequently and in some cases anastomose very freely. Some of the bundles pass out from the stem into the leaves, there to branch again to form the veins. In general, the bundle consists of a plate of xylem, surrounded on all sides or on all except the edges of the plate, by large sieve tubes and small parenchyma cells. Around these are often one or more layers of starch-bear- 
ing cells, with usually a thick-walled bundle sheath about the whole. In some species of Lycopodium there are several plates of xylem alternating with phloem, with one bundle sheath around all. Transitional forms are found between this type and the radial type of bundle on the one hand and the collateral on the other.

85. The collateral type of bundle is present in stems and leaves of Seed Plants, and of many of the Fern Allies. Three types may be distinguished, open collateral, closed collateral, and bicollateral. The first two differ in the presence or absence, respectively, of a layer of meristem cells (cambium) between the xylem and phloem, while the third type is characterized by the presence of a layer of phloem on the inner, as well as on the peripheral side of the xylem.

86. The closed collateral type of bundles is especially characteristic of the class Monocotyle-

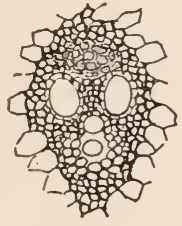

F I G. 26 . Closed collateral vascular bundle. doneae. It is usually associated, also, with a scattered arrangement of the bundles in the stem. There is usually less anastomosing of such bundles with each other than is the case in the open collateral type. This type is present in some of the Dicotyledoneae as well, but not so frequently as the open collateral type. As an example that may be easily obtained to study, the vascular bundle of Indian corn may be taken. In this the xylem portion shows, in cross-section, four (rarely three or five) large vessels, of which two (annular or spiral) are placed in the radial plane, and the other two (large pitted vessels) lie a little externally to and to the right and left of these two. Between these large pitted vessels, and bordering the outermost of the other two vessels, is a mass of smaller cells, sometimes fibrous, sometimes tracheary in nature. 
The innermost vessel borders a large intercellular air space. Partly enclosed between the large pitted vessels, but in the main placed peripherally to the xylem, is the phloem. In cross-section this is elliptical and consists of large sieve tubes and small companion cells. The whole bundle is surrounded by a mass of eells, mainly fibrous. No meristem tissue is present at all in the completed bundle.

87. Open collateral vascular bundles can be found most typically in the class Dicotyledoneæ, though they are also present in the Strobilophyta and related groups. In the stem they are usually placed almost equidistant from the center, surrounding a central mass of parenchyma, the pith, and separated from each other laterally by the masses of parenchyma (primary medullary rays), which connect the pith to the cortex. The tendency to anastomose is very great in open collateral bundles, so that these medullary rays are interrupted above and below at frequent intervals, and are not continuous

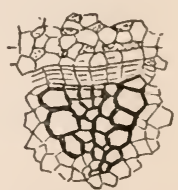

Fig. 27.-Open collateral vas. cular bundle. for a long distance in the stem. Bicollateral bundles of the open collateral type are similarly placed in the stem.

88. When first completed, the xylem portion consists of two or three to several rows of tracheary tissue, usually not crowded but loosely placed with reference to each other, and with the spaces filled in with parenchyma. The outer boundary of the xylem is parallel to the surface of the stem, and is succeeded by a layer, one to several cells thick, of meristem, the so-called cambium. Bounding this externally is the phloem region, consisting at first of sieve and companion cells and other parenchyma tissue, and sometimes even of masses of bast fibers. In young woody stems there may be considerable 
fibrous tissue among the tracheary tissue. In bicollateral vascular bundles, the inner mass of phloem is not separated from the xylem by a cambium layer.

89. Wherever a leaf is attached, one or more vascular bundles in the stem pass out into it. These usually run downward in the stem for some distance before they unite with the other bundles there. In the leaf the phloem portion is downward (i.e. toward the back of the leaf), and the xylem mass uppermost. Here the bundles are the so-called "veins." At first

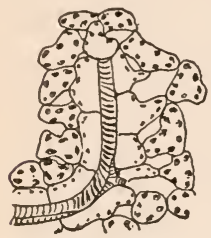

FIG. 28.-Ending of a vascular bundle. they are much like the stem bundles, although usually the cambium is lacking, but the more they are divided, the smaller and simpler they become until finally they may consist of only one or two rows of tracheids, a single row of sieve cells, and a row of companion cells, with a few thin-walled parenchyma cells surrounding the whole. In some cases these bundles end blindly in the parenchyma of the leaf. In other cases they meet other similar bundles and so form a network with no free ends.

90. Secondary Thickening. The fact that in the formation of the open collateral bundles from the procambial strands of meristem tissue, a portion of the meristem remains unchanged as the cambium layer, separating the xylem and phloem, makes it possible for the bunclle to continue to grow in thickness. This it does by the growth and periclinal division of the cambium cells, and the transformation of the inner cells thus formed into xylem and of the outer ones into phloem, continually leaving, however, an intermediate portion of cambium which can grow and divide further.

91. The xylem formed during the process of secondary 
thickening differs usually quite materially from the primary xylem. It contains much more fibrous tissue, is more compact, and forms a true wood. The phloem also is interspersed with more bundles of bast, and may by its formation soon crush out of recognizable shape the primary phloem. In addition, the tissues forming the primary medullary rays become active. The layer of parenchyma cells that connects the edge of the cambium of one bundle with that of the next bundle becomes itself converted into cambium by the accumulation of large amounts of cytoplasm in the cells, and the formation of periclinal walls. Part of this interfascicular cambium thus formed gives rise only to cortical and medullary parenchyma, but at intervals new bundles arise by the formation of xylem and phloem, respectively, on the inner and outer faces of the cambium layer. Thus, secondary bundles are formed, which divide the medullary rays longitudinally, and as the bundles become more and more numerous, these primary rays may eventually be reduced to thin plates of parenchyma, only one or two cells thick, and perhaps only a few cells wide (measured in vertical direction), but still extending from the pith to the cortex. Additional ("secondary") medullary rays are formed within the bundles when certain cambium cells cease to form xylem elements and from that time

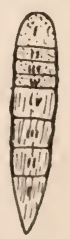

Fi G. $29 .-$
Four growth of a vascular bundles. forward produce parenchyma cells. These secondary medullary rays usually arise at varying distances from the center, a certain number of new ones being laid down each year.

92. Where the growth is continuous and equal, the wood is usually of fine grain and uniform. Most woody plants of the temperate zones, however, and of those 
portions of the tropics where there are marked wet and dry seasons have annual growth periods, separated by seasons, where growth ceases entirely or nearly so. In such cases the first part of the xylem laid down each year consists of a greater proportion of tracheary elements and fewer wood fibers, the proportion of the latter increasing as the season progresses. The wall of each successive fiber is thicker and the lumen smaller.

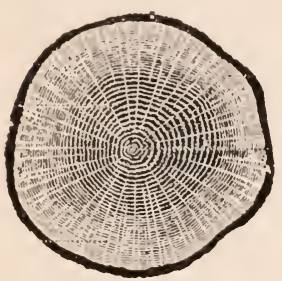

FIG. 30.-Growth rings Such tracheae as are produced later in the season are smaller than those first formed. The contrast of these small thick-walled numerous wood fibers, produced at the close of one season's growth, and the large lumened tracheary and wood cells formed at the beginning of the next, makes a very distinct line and marks off the growth rings, which, as they are usually annual, are of great value in determining the age of a tree.

93. Usually the wood nearest the center of a tree undergoes changes after it has reached a certain age. Among these changes are the deposition in the lumina of the cells of various organic substances, which seem to make the tracheary elements no longer able to carry water, and the death of all living cells (e.g. cells of medullary rays, wood parenchyma, etc.), and often a change in color. Such wood is called heart wood, to distinguish it from the water-conducting sap wood, in which the medullary rays and wood parenchyma cells are still alive.

Laboratory Studies. (a) By studying successive thin crosssections of the stem, beginning at the growing point, there will be found the procambial strands, which give rise to the vascular bundles. They appear, in cross-section, as masses of eells of 
small diameter. Further down, part of these strands will be found to consist of tracheary tissue.

(b) Study a vascular bundle of the radial type, by making cross-sections of the larger roots of corn, iris, hyacinth, or of the main roots of seedlings of bean, pea, sunflower, etc. Note the number of xylem plates, location and extent of phloem, the endodermis, pericyele, etc.

(c) Make longitudinal sections of the same kinds of roots, and identify the tissues shown in cross-section.

(d) Using a bean seedling, in which lateral rootlets have begun to show, make numerous eross-sections, so as to find such rootlets in various stages of development, and study their origin and mode of emergence.

(e) The concentric type of bundle may be studied best in cross-sections of the rhizomes of the brake (Pteridium aquilinum). Make a longitudinal section also, so as to identify the tissues present.

(f) Vascular bundles that may perhaps be assigned to the concentric type may be studied in cross and longitudinal sections of the stems of Selaginella and Lycopodium.

(g) Make cross and longitudinal sections of the stem of Indian corn, sugar cane, Smilax herbacea, or other monocotyledons, for vascular bundles of the closed collateral type. Note their distribution in the stem.

(h) Open collateral bundles may be studied to advantage in the younger internodes of elover and alfalfa, or the upper ones of sunflower. Note the arrangement of the various xylem elements. Note how the bundles are distributed in the stem.

(i) Study the lower internodes of the same plants, for secondary thickening. Note the differences between the secondary xylem and that formed in the bundle before the secondary thickening had begun. Note the secondary vaseular bundles, interfascicular cambium, etc.

(j) Make and study a cross-section of a two-year-old twig of basswood, elm, or other tree. Note the growth rings, and in cross and longitudinal sections determine their strueture. Study the primary and secondary medullary rays.

(k) For bicollateral vaseular bundles, the best objects are the stems of Cucurbitaceae, e.g. squash, cucumber, etc., although they are found also in the Solanaceac, e.g. younger parts of the stems of petunia, potato, ete. 
(l) Reduced bundles and bundle endings can be studied in leaves and petals by placing them in some clearing fluid, e.g. a mixture of phenol (carbolic acid), and turpentine after 15 to 20 minutes' treatment with 95 per cent alcohol. Mount in the same fluid and examine under low and high powers. If these objects are previously placed with their cut ends in an aqueous safranin or eosin solution until the colored liquid has filled the bundles these are more conspicuous.

(m) Examine the eut ends of logs and stumps of various kinds, to distinguish the heart wood and sap wood. That they are different in some of their chemieal characteristics will be shown by their different proneness to decay.

94. The Supporting System. In many plants the supporting and conducting systems are intimately connected, the vascular bundles containing not only the conducting cells but also an abundance of wood and bast fibers. However, at first the stems are often supported by other means. Thus, a strong development of collenchyma strands under the epidermis is a very common occurrence. By the natural turgor and growth of the stem, these collenchyma strands are stretched, and thus stiffen the stem until the fibrous tissues are developed later in connection with the vascular bundles. In the cortex, bast bundles are fre-

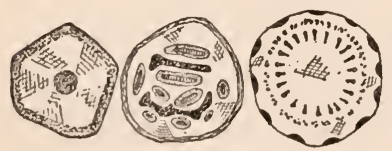

FIG. 31.- Supporting system in stems of '(1) moss, (2) fern, (3) flowering plant. quently encountered, independent of any vascular bundles. In the stems of Ferns and Fern Allies, large bundles of fibrous tissues are scattered here and there. Closely allied to the supporting system of tissues, in function, are those tissues that serve for protection, as for example, the sclerenchyma, deposited in various parts of the plant, such as the bark, roots, fruits, and seeds. 
95. In addition to the conducting and supporting systems, the remainder of the plant serves various functions. Thus, a large portion of green plants consists of nutritive tissues. These are usually found in leaves, but are also present in the younger parts of stems. In leaves we can usually distinguish, underneath the upper epidermis, one or more rows of closely packed cells, with their long axes perpendicular to the surface of the leaf, forming the so-ealled palisade parenchyma. In leaves equally lighted on both sides, this palisade parenchyma is often formed on both surfaces. Below the palisade layers the assimilative eells are looser, forming the "sponge" parenchyma, with larger intercellular spaces between them,

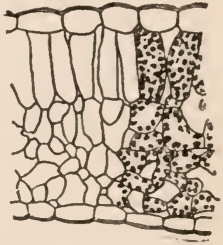

Fia. 32.-Section of a leaf. which connect with the exterior through the stomata.

96. The system of intercellular spaces is quite marked in all higher plants. These passages are usually con-

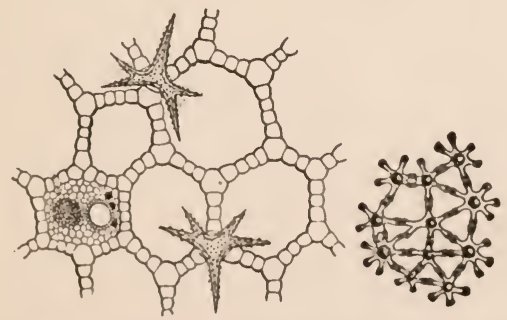

Fı, 33.-Large intercellular spaces in water-lily petiole, and rush stem.

tinuous through the petioles of the leaves into the stems and down into the roots. In plants growing in swampy places or in water these intercellular spaces are very much enlarged and apparently serve the double function of providing an ample air supply to the submerged por- 
tions of the plant and of giving buoyancy to the part in which they occur.

97. Another important function of tissues is that of storage of food substances. Storage tissues are usually

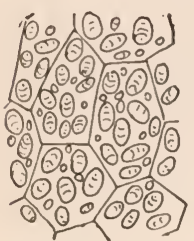

FIG. 34.-Starch storage cells of potato. composed of large parenchyma cells with large central vacuoles and comparatively little protoplasm. In some special cases where the storage product is one of the hemicelluloses this is deposited against the cell wall forming a sort of sclerenchyma tissue.

98. In many plants are found secretory cells. These often line closed cavities (or "reservoirs") or elongated passages. These cavities or passages may be formed simply by the pushing apart of certain cells as the secretion is poured into the space between them (i.e. produced schizogenously) or certain cells may be dissolved, forming "lysigenous" cavities. Good examples of the first type are shown by the gum canals of the ivy (Hedera helix) and the turpentine canals of conifers or the glands of the leaves of St. John's wort (Hypericum).
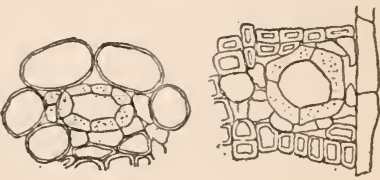

FIG. 35.-Gum and turpentine canals of ivy and pine.

In the leaves and fruits of Rutaceae the cavities more often arise by the dissolving of the secretory cells thus setting free the secretion within a cavity. The secretions are usually gums or ethereal oils, often containing resins, etc. Other cells containing crystals of calcium oxalate and other substances, perhaps including tannin, may possibly be classed as excretory organs in which the excretions are stored up in the absence of any structure that would permit their being thrown out of the plant. 
Externally there may be developed secretory structures such as the nectaries of flowers, etc.

99. Cork. At first the cutinized external wall of the epiclermis of the stem serves to prevent exeessive water loss. When the stem enlarges the increased circumference is met by the enlargement or multiplication of the epidermal cells. There is a limit, however, for most stems to this epidermal growth and furthermore as the stem beeomes enlarged the one layer of cells is no longer sufficient protection against water loss and especially against mechanieal injury. There is accordingly formed beneath the epidermis a layer of meristem cells called phellogen or cork eambium, which gives rise (by periclinal divisions) to radial rows of cells without intercellular spaces, whose walls become strongly suberized by the deposition within them of a fatty substance or substances called suberin, which makes them impermeable to water. The cells die shortly after suberization occurs and remain Fra. 36.-Cork (1), subepidermal, filled with the broken-down

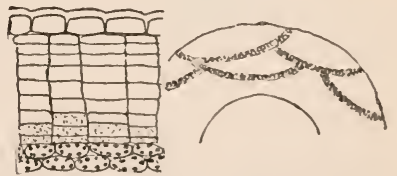
protoplasm or become filled with air. These layers of cork cells, owing to the suberization, cut off the passage of water toward the exterior and the epidermal cells accordingly die. With the growth of the stem in circumference these are soon ruptured here and there and gradually peel off. Since the outer cork cells are also dead they cannot enlarge and so as the stem grows longitudinal fissures occur in the cork extending down nearly to the living phellogen, which however being alive is able to increase in circumference and thus keep pace with the increasing circumference of the stem. Sometimes this phellogen layer is per- 
manent but more often a layer of cells starting at the phellogen and dipping inward into the cortex and finally back to the phellogen also becomes converted into phellogen and begins to produce cork. The more or less lens-shaped mass of tissue cut off by this process promptly dies from lack of water and eventually scales off. Thus is formed the flaky type of bark. This process is repeated time and again so that the bark remains only about the same thickness, no matter what the age of the tree.

100. Lenticels. As cork is about to form, a phellogen of special type arises under many of the stomata on the
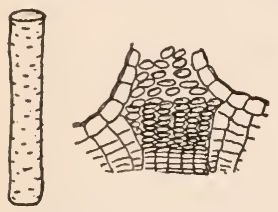

FIG. 37.-Lenticels. young stems and twigs. This forms a loose mass of cork with large intercellular spaces connecting through the intercellular spaces in the phellogen (these being lacking in ordinary phellogen and cork) with those of the cortex. This mass of cork cells ruptures the epidermis and forms a minute lens-shaped fleck. These lenticels function then as openings for the exchange of gases while at the same time the mass of loose cork cells greatly reduces the water loss.

101. In addition to the foregoing cases cork is also formed in many plants as a result of wounds. The injured cells die but those immediately or but a short distance below become converted into phellogen which produces a cork layer that forms an effective barrier against further water loss and probably also prevents in a large measure the entry of foreign organisms. Frequently this cork thus formed serves as an abscission layer, i.e. it splits, and permits the dead tissues to slough off. The layers normally found at the base of the leaf petiole in the autumn are of similar nature, serving to 
permit the fall of the leaves and at the same time covering the exposed surface with a cork layer which prevents the loss of water or entry of harmful organisms.

Laboratory Studies. (a) Examine the cross-section of a very young twig of elder or of a young stem of lamb's quarters (Chenopodium album) and note the supporting system which at this stage consists of longitudinal strands of stretched elastic collenchyma just under the epidermis.

(b) In older parts of the stem of the same plant note how the main supporting function has been assumed by the wood fibers associated with the xylem of the vascular bundles and by strands of bast fibers sometimes closely associated with the phloem of the same bundles and sometimes independent of any bundles.

(c) Make a cross-section of a leaf of beech or lily or other plant and examine. The special nutritive palisade tissue is present next to the upper epidermis. In the lower part of the leaf note the "sponge" parenchyma with its large intercellular spaces. The leaf of cottonwood (Populus sp.), compass plant (Silphium laciniatum), etc., will show palisade tissues on both sides.

(d) Make a cross-section of a stem of a water lily (Castalia, Nelumbo, etc.) or of a rush (Juncus) or of some other semiaquatic or aquatic plant. Note the large intercellular spaces. Note also the rather small development of water-conducting tissues.

(e) For examples of tissues devoted to storage purposes study sections of a tuber of potato, root of sweet potato, pith of twig of apple or sassafras, seed of date, etc.

( $f$ ) Make a cross-section of the stem of ivy (Hedera helix) for gum canals lined with secretory cells. Similar canals in the wood and leaves of Conifers (pines, spruces, etc.) contain turpentine.

(g) Make a cross-section of the leaf of St. John's wort (Hypericum) or leaves or fruit of the orange or lemon (Citrus) for secretory reservoirs ("glands") in the tissue.

(h) Examine various flowers and study the location and structure of the nectaries. Extra-floral nectaries may be found on leaves of various plants, e.g. some of the plums. Other 
types of glands may be found on the "tentacles" of the leaves of the sun-dew (Drosera).

(i) Section a very young twig of basswood (Tilia) or elm or other tree and note the epidermis. Compare this with a one or two year old twig of the same tree and note the cork formation. Study cross-sections of various kinds of tree trunks and note the different types of cork formation in these.

(j) On a young twig of elder (Sambucus), snowball (Viburnum) or birch (Betula) section the lenticels in different stages of development and study them.

(k) In the autumn make longitudinal sections through the base of the petiole of leaves of maple, elm or other deciduousleaved trees. If made at the proper place and time the corklike abscission layer may be found.

\section{REFERENCE BOOKS}

The books enumerated for Chapters I and II. 


\section{CHAPTER IV}

\section{PLANT PHYSIOLOGY}

102. Plant Physiology has for its subject the study of the aetivities of the plant and of its parts. It is not sufficient to learn about the morphology, i.e. the external and internal structure; we must also seek to learn what the different parts are for, how the plant carries on its activities and the relations of the plant to the external surroundings. In the preceding chapters the functions of the parts have been mentioned briefly in connection with the special struetures. In this chapter, it is sought to take up the plant activities as a whole. Much of what is here given ean be used by the skillful teacher at the same time that the foregoing chapters are being studied.

Plant Physiology will be treated under the following heads: (1) Nutrition, (2) Growth and Reproduction, (3) Movements. To these will be added (4) a short consideration of the Pathology of Plants.

103. Nutrition, in its widest sense, includes the taking in and giving out of water and other substances, their transportation from one part to another in the plant, their use in the plant in the formation of food, the use of this food, and the energies required or set free in all these processes.

104. The most important single substance taken in by a plant is, beyond doubt, water. The driest plant parts, such as seeds, possess from 5 to 10 per cent. or more of water while leaves may possess 75 per cent. or 
even greater amounts. Fleshy fruits like the pear and grape contain still larger amounts. Algae are extremely watery, the amount of water in Spirogyra probably exceeding 97 per cent. This water is present not only in the vacuoles but also in the cell wall and protoplasm, both of which have the property of imbibing water to a considerable extent. Thus even lignified cell walls may have one-third of their weight as water and protoplasm is probably not active unless 75 per cent. or more water is contained in it.

105. This water is almost continuous throughout the whole plant, so that we may think of a plant as a mass of water of the shape of a plant with the interstices occupied here by molecules of cell wall substance, there by protoplasm, the water being continuous also with the water surrounding the roots in ordinary plants, or the whole plant if it is aquatic.

106. Although the water is continuous throughout the plant, it is held more abundantly in some parts than others, and may be in motion within

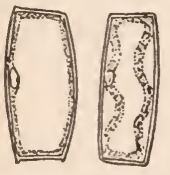
the plant. The entry of water into a cell is through the process called osmosis. The plasma membrane of the cell is a semipermeable membrane which is almost Fic. 38.-A tur- perfectly permeable to water but almost gid, and a plas- impervious to some of the substances in
molyzed cell. solution in the water of the cell. Under such circumstances, if the solutes inside the cell are more concentrated than those outside, the molecules of water pass more rapidly into than out from the cell and it becomes filled with water. The protoplasm is pressed against the cell wall and this stretches until it may be increased in area in some cases by as much as 50 per cent. This stretching continues until the wall can stretch no 
more or until the counter pressure of the stretched walls equals the osmotic pressure (i.e. the power with which, under the given difference in density of the outer and inner solutions, the water from the outside tends to enter the cell). Such a water-distended cell is said to be turgid or in a state of turgor. The pressure within it may equal several atmospheres. Jost gives this pressure for some desert plants as equalling one hundred atmospheres, i.e. about 1500 pounds per square inch.

107. If a cell be in contact with a plentiful water supply, it will become as turgid as the difference in osmotic pressure outside and inside will permit. If a cell adjacent to it is not in contact with the external water, there will be a passage of water from one cell to the other, the direction depending upon which cell has the denser solution in its cell sap. Thus, in a plant with one part exposed to evaporation into the air and with the other part in water there will be a constant passage of water into the plant and up through it from cell to cell, by osmosis, and out into the air by evaporation from the wet surface of the cell walls.

108. In larger land plants, however, this rather slow passage of water from one cell to another by osmosis is too slow to supply the aerial parts with the requisite amount of water. Such plants possess special elongated cells no longer living and often with the separating partitions dissolved out, viz.: the tracheae and tracheids. (See paragraphs 46 to 49.) These serve as tubes through which the water rises, not as a simple diffusion of molecules but with a mass motion, i.e. as a definite current carrying with it whatever may be dissolved.

109. In these plants then we can trace the water through the following steps of progress. It enters the root hairs by osmosis from the surrounding soil where it 
is present in thin or thick films around the soil particles, the entry being molecule by molecule. It passes by osmosis from cell to cell through the cortex of the root until the tracheary tissue of the vascular bundle is reached. It enters these vessels (just by what force is not clear) and ascends through them (also by what force

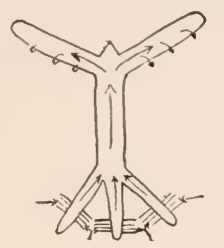

FIG. 39.-Course of w a te $r$ into, an d through a land plant. is uncertain). Some of it is taken out by osmosis, by various parenchyma cells (e.g. medullary rays) bordering the tracheary tissue and passed osmotically to the various tissues at that approximate level, but the bulk passes on out into the leaves where it is taken by osmosis into the parenchyma cells. From the cells bordering the larger air spaces, it evaporates into these and passes as vapor out through the stomata.

110. The evaporation of water from a wet membrane (e.g. cell wall) makes available a large amount of energy for lifting up water to replace that evaporated. It has been shown that the energy thus available in a leaf is many times more than that necessary to lift the water up to the tops of the highest trees (150 meters). However, though the energy is ample, the air pressure at sea level is only sufficient to lift water not quite ten meters into a vacuum. The osmotic pressure developed in roots that are rapidly absorbing water is enough occasionally to lift water to a height of eleven meters in the grape and even twenty-five meters in the Birch (Betu?a lutea). The distance that this root pressure will lift water plus the height air pressure will lift water into a vacuum fall far short of the distance water must be lifted in tall trees. It has been suggested that perhaps the cohesion that exists in water in narrow vessels 
(e.g. in the tracheary tissues) is sufficient to pull the water up from the lowest roots. Other investigators have suggested that some of the living parenchyma cells which accompany all water-conducting tracheids and tracheae are concerned in the lifting of the water (or ascent of sap as it is often called).

111. Path of the Water. This is chiefly in the cavities (lumina) of the tracheary tissue. It is also not to be denied that the water will pass upward slowly from the roots, passing from cell to cell in the parenchyma by osmosis, for the tissues above ground have more concentrated solutions, and so bring about osmosis from the root cells with their less concentrated solutions. This is, however, not sufficient to supply an ordinary plant. Within the tracheary tissue, the lumen contains not only water but some bubbles of air, past which the water flows in a thin film next to the cell wall. In trees the central wood after a number of years suffers deposition of resins or other insoluble substanees within the cell cavities and possibly walls as well, so that water conduction is no longer possible. Such wood is often different in color and is called heart wood and contains no living cells. The unchanged wood around it, the sap wood, contains dead water-conducting tracheary tissue, dead fibrous tissue and living wood parenchyma.

112. The evaporation of water from the leaves and stems is often given the name transpiration. It is an unavoidable loss since the plant must have openings, the stomata, through the epiclermis, for the purpose of gas exchange and when these are open the loss of water cannot be prevented. The thickening of the cuticle in plants of dry regions, the depression of stomata in the pits to provide dead air spaces outside, the formation of thick layers of hairs, etc., all indicate that it is not to the 
advantage of a plant to have transpiration taking place but just the contrary.

113. The amount of water given off by transpiration is very large. The water loss from a Birch tree, standing alone and estimated to have 200,000 leaves was calculated by von Höhnel at about 500 liters on a very hot dry day and about 60 to 70 liters on average days. An acre of hops will evaporate three million to four million liters of water in a season. Dietrich estimates that for every gram of dry substance found in a plant, from 250 to 400 grams of water have been evaporated. In twelve hours, a grape leaf evaporates as much water as would form a film $0.13 \mathrm{~mm}$. deep over the whole leaf, while for cabbage and apple leaves in the same length of time the figures are respectively 0.31 and $0.25 \mathrm{~mm}$. In one season, an oak tree, during the time it holds its foliage, evaporates an amount equivalent to $33 \mathrm{~mm}$. over all its leaves. An open water surface would evaporate, in the same time, 500 to $600 \mathrm{~mm}$., showing that the evaporation (transpiration) is far less from the leaves than from a free surface.

114. It has been shown that an impermeable surface with very numerous openings, as for example, the epidermis with its numerous stomata, evaporates nearly as much water as if it were a free water surface. The stomata, however, are capable of closing and thus almost wholly preventing water loss for such periods of time as they may remain closed. At night they are nearly closed. When the plant begins to wilt, it has been shown that they also close automatically through reduced turgor of the guard cells thus preventing too great a loss of water. All physical phenomena which increase evaporation also increase the water loss from the leaves as long as the stomata remain open, e.g. increased 
temperature and dryness of the surrounding air, sunshine, etc.

115. Many plants exude water from specially modified stomata (the so-called water pores) at the edges of the leaves when the movement of water upward has been strong and then, by increase of the humidity of the air, the evaporation has been checked rather suddenly. This may take place in the form of drops or even as a fine stream. It is called guttation. Its mechanics and use are not clear.

Laboratory Exercises. Note: In a large class, many of these experiments cannot be performed by every student. In that case the instructor should assign some experiments to one student, others to another throughout the class or should set up the experiments himself before the elass. In either case, every student should make complete notes upon the experiment for himself.

(a) Weigh a handful of freshly picked leaves quickly before they have begun to wilt. Place them in an oven at the temperature of about $110^{\circ} \mathrm{C}$. and dry them for twelve to twenty-four hours. Now weigh them and note the loss in weight. This is almost entirely due to the evaporation of the water in the leaf. Calculate the percentage of water in the original weight. Repeat the experiment with various parts of the same plant such as stems, roots, flowers, fruit, seeds, etc., and compare the amount of water in these different parts as well as with the corresponding parts of other plants.

(b) To demonstrate imbibition by cell walls, take a measured block of wood 5 or $6 \mathrm{~cm}$. long and 3 or $4 \mathrm{~cm}$. square. Measure it when perfectly dry, i.e. after having been kept a day or two in an oven at $110^{\circ} \mathrm{C}$. Then soak it in water (preferably warm or hot, to hasten the process). Now measure aceurately. The piece will be found to have become perceptibly larger owing to the imbibition of water by the eell walls. Probably the first entrance of water into dry seeds is also due to imbibition of water by the cell walls and protoplasm. As soon, however, as the latter has imbibed enough to become liquid, osmosis begins to act also in the taking in of water. 
(c) Osmosis may be demonstrated by tying a piece of fresh bladder securely across the mouth of a thistle tube which is inverted and filled with a strong solution of sugar up to a mark on the stem. The larger end with the bladder is now placed in a dish of water so that the water outside stands at the same height as the water inside. The water will enter through the bladder by osmosis and ascend the stem, perhaps reaching a height of a meter or more above the level of the water outside. The more impermeable the membrane is to the substance in solution while still remaining permeable to water, the greater the difference in level and the higher the pressure that can be obtained. The latter can be measured roughly by conneeting the stem of the thistle tube to a mereury manometer.

$(d)$ The relation of osmosis to turgor may be demonstrated by making an "artificial cell." Fill a test tube with a strong sugar solution and tie a piece of

Fig. 40 . Osmosis experi ment $(c)$. bladder firmly over the open end. Place in a dish of water. The water that passes into the tube by osmosis through the bladder causes the latter to be stretched and to bulge out. On removing the tube from the water, and pricking the bladder with a pin, the pressure developed by the stretching of the bladder will foree the water out in a stream.

(e) Mount one or two filaments of Spirogyra in water and examine. Measure the length of a portion including a definite number of cells. Now draw a 2 per cent. potassium nitrate solution or a 5 per cent. sugar solution under the cover glass by adding it at one side and withdrawing the water from the other side with a piece of filter paper. Measure the filament again. Add increasingly strong solutions and when the right strength is reached, the cytoplasm will be found to be drawing away from the corners of the cell wall, i.e. plasmolysis has begun. This indicates that with the withdrawal of water by the solution outside, the much stretched cell walls have lost their tension until they have reached a state in which they are not at all stretched. As the water is still withdrawn from the cell, the cytoplasm is pulled further and further away from the wall. At this stage, again measure the filament and calculate the amount that the turgid filament was stretched.

(f) To demonstrate that evaporation from a membrane filled 
with water has a strong lifting power, cover the end of a thistle tube tightly with a piece of bladder or fill the mouth with a tightly fitting thin layer of plaster of Paris. Invert the tube and fill completely with water that has been boiled to remove the air so that bubbles will not be produced in the tube. Invert again with one end of the tube in a dish of mercury. Wet the bladder or plaster of Paris plug externally. As evaporation progresses, the mercury will be drawn up into the tube until a point is reached where the pressure of air on the outside of the bladder or plaster of Paris is sufficient to force the water back out of it so that it is no longer wet. It then permits air to pass through rapidly and the mercury soon recedes to its original level. Similarly, it is assumed that the evaporation of water from the wet cell walls into the intercellular spaces of the leaves exerts a strong lifting power on the water in the stem of the plant. This will be shown by the following experiment.

(g) Cut a leafy twig and fasten it, without allowing the cut end to dry out, into a glass tube filled with water and with its lower end in mercury. This - Evaporawith water and with its lower end in mercury. This tion experiexperiment, if successful, will also show a rise of mer- ment $(f)$. cury in the glass tube as in the preceding one.

(h) Place the cut end of a stem (preferably a herbaceous one) in a strong aqueous solution of safranin. After an hour or so, make cross-sections at various points. The colored solution will be found in the tracheary tissue (and after longer standing also in some of the immediately surrounding tissues, especially in wood fibers).

(i) Place a branch which has been girdled (i.e. the bark removed to but not including any of the wood) with its lower end in water, the girdled area being protected from drying out by coating with grafting wax or paraffin. Compare with a similar branch not girdled. Take a third branch and through a small slit in the bark cut off the wood entirely with as little injury to the bark as possible. Place it in water like the other two. Note the differences in the rapidity of wilting in the different cases.

(j) Take a potted plant, e.g. a geranium or begonia, and after watering it well, envelop the pot in a sheet of rubber, tying the rubber firmly about the stem of the plant. Instead of using the rubber, the outside of the pot and the top of the 
soil may be made practically water proof by means of melted paraffin whose melting point is sufficiently low so as not to injure the stem when applied to the top of the soil in a melted condition. Weigh the pot and place in a dry room for an hour and weigh again. Calculate the loss of water per square centimeter of leaf surface. Place in a moist room under the same light conditions as before and note the loss of weight in an hour. Such experiments are not accurate as many factors enter in to interfere, but they give an idea of the approximate amount of water evaporated. The experiment may be continued a long time by providing an opening in the rubber or paraffin through which a thistle tube passes and adding every twenty-four hours as much water as was lost in the preceding 24 -hour period. By keeping a record in this way, the amount of water lost in a week ean be determined roughly. (Of course the increase in weight of the plant itself as it grows is a factor not taken into consideration in the foregoing nor the effect upon the roots of the partial exclusion of the air by the rubber or paraffin.)

(k) To show that it is mainly through the stomata that evaporation (transpiration) oceurs, take three lilac leaves of as nearly equal size as possible. Coat the ends of the petioles of each and the under surface of one and the upper surface of another leaf with a varnish made of equal parts of beeswax and lard or ordinary grafting wax if somewhat softened. Both surfaces of the third leaf are to be left uncoated. The stomata are found only on the lower surface and it will be found that the leaf with this surface coated, thus covering the stomata, remains fresh for a long time while the other two wither quickly.

Frg. 42. (l) The leaves of the cottonwood (Populus, varipressure ous species) have stomata on both sides. Repeat the experimen $t$
$(m)$. pare with the results obtained with the lilac.

$(m)$ Root pressure may be demonstrated by cutting off the stem of a rapidly growing sunflower or other rather large plant (e.g. tomato, geranium, castor bean, etc.) and slipping a heavy rubber tube over the cut stump, connecting this with a narrow glass tube. If the soil be kept warm and wet water will soon begin to escape from the cut surface and will rise to a 
considerable height in the tube. If the latter be connected with a mercury manometer the pressure can be measured.

116. Nutrients Other than Water. All other substances can enter the plant only in solution in water. This is true of the gases as well as of mineral salts, for although a gas may enter the air spaces of a leaf in the gaseous state, it cannot penetrate the wet cell walls in this state but must go into solution. It is then subject to the same physical laws of diffusion as the other solutes.

117. The wet cell wall presents no (at least marked) obstacle to the diffusion of any solute. The plasma membrane, however, is impermeable for some, difficultly permeable for others, and easily permeable for still other substances. Accordingly the molecules of the substances in solution outside of a cell will penetrate into the cell with different degrees of rapidity and independent of the direction that the water is passing. The result will be that the solution inside of the cell may have its components in entirely different proportions from the solution outside.

118. The process by which solutes pass into the cell and from cell to cell is diffusion. This is the molecular passage of a solute from that part of a solution where the concentration of that particular solute is greater to where it is less. As long as the plasma membrane is easily permeable for the particular solutes they have no osmotic effect and may diffuse in the same direction with or counter to the osmotic stream. Thus the dissolved salts that enter a plant do so independently of osmosis and diffuse toward those parts of the plant where these particular salts are less abundant. They will not become more concentrated anywhere in the plant than outside of it as long as they retain their same composition and the permeability of the plasma membrane remains 
the same. Frequently, however, they are changed chemically after they enter the plant and then are no longer able to pass through the external plasma membrane. In such a case the plant may be able to take in large amounts of one substance from a dilute solution. Certain seaweeds, for example, accumulate large amounts of iodine compounds from the sea water which contains iodides only in very great dilution.

119. Water consists of hydrogen and oxygen $\left(\mathrm{H}_{2} \mathrm{O}\right)$. Besides these two elements eight others are ordinarily necessary to plant life. They are carbon (C), which chiefly enters the plant in the form of carbon dioxide $\left(\mathrm{CO}_{2}\right)$ (see paragraph on photosynthesis), nitrogen $(\mathrm{N})$ in the form of nitrates or ammonium salts, calcium (Ca), magnesium (Mg) and potassium (K), these mostly oocurring as phosphates, nitrates, sulphates or carbonates, iron $(\mathrm{Fe})$ in very small amounts as salts of various acids, sulphur (S) almost entirely as sulphates (except in those plants that feed on organic food where it may be taken up from the proteins and a few lower plants which use $\mathrm{H}_{2} \mathrm{~S}$ or even free sulphur) and phosphorus (P) as various phosphates. In addition to these, sodium $(\mathrm{Na})$ is required by some plants, while on the other hand calcium (Ca) is not required by certain fungi. Of the ten elements first mentioned the last seven are usually taken in as mineral salts from the water in which they are dissolved. The oxygen is taken in, in the acid radical of the sulphates, nitrates, carbonates and phosphates, in combination with hydrogen in water, and in combination with carbon in carbon dioxide as well as in the elementary form directly from the air or in solution in the water. Carbon in addition to being taken in as carbon dioxide exists in the carbonates and in the case of hysterophytes, also in various organic substances taken in by the plant. 
The use of free nitrogen by certain bacteria will be discussed further on.

120. In addition to the substances mentioned in the preceding paragraph, silicon ( $\mathrm{Si}$ ) is taken up by many plants (as silicates of various kinds) and adds to their hardness but can be dispensed with except by the diatoms whose cell walls are composed largely of silica. Sodium can take the place of potassium for many purposes, e.g. neutralizing acids, but cannot be substituted for it entirely. Similarly an excess of calcium can replace part but not all of the magnesium, while barium (Ba) and strontium (Sr) can replace part of the calcium. Chlorine (Cl) in the form of chlorides is useful to many plants but apparently can be dispensed with by almost all. The various other salts present in the soil solution may be taken up by the plant in greater or less degree, but appear either to have no use whatever or to be used only incidentally without being indispensible. Such are salts of copper $(\mathrm{Cu})$ aluminum (Al) manganese ( $\mathrm{Mn})$ zinc $(\mathrm{Zn})$, etc.

121. The rôle that the various substances mentioned in the foregoing paragraphs play in the plant economy is not certain in all cases. It is probable that calcium and potassium, perhaps also magnesium and iron, are essential parts of the protoplasm molecule. Sulphur is a component of proteins while phosphorus is found in some proteins, especially in the nucleus. Carbon, hydrogen and oxygen are the components of the carbohydrates which are the chief building materials of the plant (e.g. cellulose) and of the proteins out of which protoplasm is built up. In the absence of iron the chlorophyll seems impossible of formation although it does not contain iron itself. Mention must be made of the principle of antagonistic action by various salts. Thus it has been 
shown that solutions of certain salts poisonous to plants become innocuous upon the addition of certain other salts which of themselves may also be poisonous. This discovery has thrown doubt upon many of the conclusions of earlier botanists as to the functions of salts that are supposed to be essential to plant life.

122. So far we have merely considered what substances are required by the plant and something of the form in which the plant takes them in. Before they can be used they must undergo various decompositions and recombinations; in other words after absorption there must be assimilative processes. Perhaps the most fundamental of these processes is that by which the carbon compounds are built up by green plants, a process called photosynthesis.

123. Photosynthesis. The green parts of all chlorophyll-bearing plants absorb carbon dioxide from the surrounding water if aquatic plants, or from the air, which contains about three parts of it to ten thousand. This absorption goes on only when the plant is exposed to the light. At the same time there is an increase in the amount of earbohydrates often manifesting itself to the eye by the formation of starch grains in the chloroplasts, but also demonstrable chemically by the increased amount of sugar's (chiefly glucose $\mathrm{C}_{6} \mathrm{H}_{12} \mathrm{O}_{6}$ ) in the cell sap. At the same time it can be demonstrated that oxygen is given off by the plant. It is this process, the manufacture of carbohydrates by green plants in the presence of light, that has received the name photosynthesis (from the Greek meaning "putting together by light").

124. Careful experiments have shown that this process cannot occur in the absence of any one of the factors mentioned in the preceding paragraph. Thus a 
plant growing in the light in an atmosphere free from carbon dioxide cannot manufacture carbohydrates any more than if it were in the dark. A plant lacking chloroplasts, e.g. the fungi, cannot manufacture carbohydrates from carbon dioxide even if light be present (excepting certain bacteria, the so-called nitrite and nitrate bacteria). The process takes place in the chloroplasts apparently. The light rays most effective in photosynthesis seem to be those in the red part of the spectrum while those at the violet end also have some value. Those lying between seem in the main to be useless. The green color represents the portion of the white light that strikes the chlorophyll and is reflected back or passes through it without being absorbed. The raw materials are carbon dioxide and water, the energy is derived from the absorbed rays of light and the end products are carbahydrates and oxygen.

125. The exact steps in photosynthesis are not certainly known but the following seems to be the probable course of events:

$\mathrm{CO}_{2}+\mathrm{H}_{2} \mathrm{O}=\mathrm{H}_{2} \mathrm{CO}_{3}$ (water, plus carbon dioxide, equals earbonic acid).

$\mathrm{H}_{2} \mathrm{CO}_{3}=\mathrm{H}_{2} \mathrm{CO}+\mathrm{O}_{2}$ (carbonic acid acted on by the energy derived from light by the cholorophyll is changed into formaldehyde and oxygen).

$6 \mathrm{H}_{2} \mathrm{CO}=\mathrm{C}_{6} \mathrm{H}_{12} \mathrm{O}_{6}$ (formaldehyde, probably by the aid of more energy derived from the light is polymerized into glucose).

It will thus be seen that for every molecule of carbon dioxide used up one molecule of oxygen $\left(\mathrm{O}_{2}\right)$ will be set free. Glucose is the carbohydrate first formed in most cases but as this accumulates in the chloroplasts and cell sap it is often transformed rapidly into the insoluble starch $\left(\mathrm{C}_{6} \mathrm{H}_{10} \mathrm{O}_{5}\right)_{n}$ which becomes stored up in large quantities in the chloroplasts. Sometimes instead of 
starch, drops of oil are produced in the cytoplasm and cell sap, or cane sugar $\left(\mathrm{C}_{12} \mathrm{H}_{22} \mathrm{O}_{11}\right)$ or some other carbohydrates.

126. The further fate of the carbohydrates formed in photosynthesis is varied. The excess of glucose or other sugars in the chlorophyll-bearing cells in addition to what is put aside temporarily in insoluble form as starch diffuses through the adjacent cells and finally reaches the vascular bundles where it enters the parenchyma cells bordering the sieve tubes. It probably diffuses through these into the latter in which it diffuses and is probably also carried by streams of protoplasm to those parts of the plant where the tissues contain less glucose. Here it diffuses out into these tissues. Besides passing in the sieve tissues diffusion doubtless occurs from cell to cell throughout the parenchyma of the cortex especially in those cells bordering on the sieve tubes. During the night the starch grains that have accumulated in the chloroplasts in day time are transformed into glucose which diffuses in the manner just described.

127. The carbohydrates transported in this manner may be stored up as reserve food in various forms. Thus they may be transformed into starch in the leucoplasts of the storage organs, e.g. tubers of potato, roots of sweet potato (Ipomoea batatas), pith of various twigs such as apple, sassafras, etc., medullary rays of many trees, endosperm or cotyledons of seeds, etc. Cane sugar may be found in many plants such as beets, maple, sugar cane, etc. Inulin is found in the roots of many plants particularly those belonging to the order Asterales. Transformed into fats they are found in many seeds, e.g. flax, cotton, peanut, castor bean, as well as in the bulb scales of onion, leaves of cabbage, etc. In the seeds of many palms, e.g. date, and the wood of many trees, e.g. elm and 
mulberry, the reserve earbohydrate is in the form of a thick deposit on the inner surface of the eell wall. This is a substance elosely related to cellulose, one of the hemicelluloses. The sugars in fruits perhaps belong in the category of stored foods although they serve rather as a bait for animals which on eating the fruit aid in the distribution of the seeds.

128. The carbohydrates produced, whether first stored up or used immediately, have for their ultimate destination various functions. As building materials they are used up in the formation of cell walls in the growing parts of plants. Whether they are thus used directly or must first become a part of the protoplasm is uncertain. The use of carbohydrates in furnishing energy to the plant will be discussed under the topic Respiration.

129. A considerable portion of the earbohydrates eventually becomes built up into those very complex nitrogenous compounds called proteins. Whether the carbohydrates are taken as such and combined with nitrogen obtained from the nitrates and sulphur and phosphorus from the sulphates and phosphates respectively, the product being proteins, or whether as seems possibly may be the case part of them are broken down and then combined with the nitrogen to form hydrocyanic acid (HCN) this being polymerized and combined with other carbohydrate molecules and with sulphur and phosphorus, is not known. In any case hydrocyanic acid is often formed in plants in which active protein production is taking place.

130. Certain bacteria, chiefly parasitic in the roots of plants of the bean family (Fabaceae), are capable, when supplied with carbohydrates and the necessary mineral salts, of using the atmospherie nitrogen (as dissolved in the soil water) in building up protein com- 
pounds. These bacteria form galls on the roots of the host plants. As they grow old the host plant digests them and is thus able to thrive in a soil free from nitrogenous compounds. Thus if the bacteria are present,

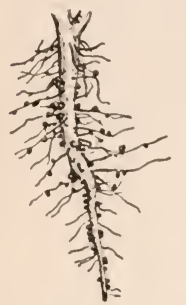

Fig. 43.- $\mathrm{R}$ o o $\mathrm{t}$ nodules (Vicia.) crops of beans, clover, alfalfa, etc. will actually increase the amount of nitrogenous compounds in the soil instead of decreasing it.

131. The proteins formed may be stored up as such for future use by the plant (e.g. aleuron in seeds) or may be transported to those parts of the plant where new cell production and growth are taking place. Here it is built up into protoplasm. How this is accomplished we do not know. The path of transportation seems to be in the sieve and possibly laticiferous tissues. The form in which protein matters are transported may be either as simple proteins or as amids.

132. Hysterophytic plants, i.e. plants that lack chlorophyll, must obtain their organized food (carbohydrates, proteins, fats, etc.) from sources outside of themselves. We find all degrees of ability to make use of various food sources. Some hysterophytes simply require carbohydrates and mineral salts and can produce their own proteins, others must have special, and in the case of parasites, living forms of proteins. Some even are able to use simpler carbon compounds than carbohydrates such as some of the simpler organic acids, glycerine, etc. In general, however, the nutrition of hysterophytes differs but little from that of holophytes (i.e. plants containing chlorophyll) except in their inability to manufacture their own carbohydrates.

133. The means by which hysterophytic plants 
obtain their food supplies are quite varied. One-celled plants like yeasts and bacteria absorb the organic substances directly, or often decompose them to the appropriate form by means of digestive ferments called enzymes, which are organic compounds of complex structure whose exact action is not clearly known. Fungi consist of long filaments of cells which either pass through the substances to be absorbed or send little suckers, called haustoria, into the cell of the host, the latter being often the case with fungi parasitic upon living plants. Among the hysterophytic flowering plants some feed on decayed organic matter in the soil, others, e.g. dodder, send haustoria into living plants, and take organic substances directly from them. Some of the mistletoes which possess chlorophyll take little else than water and mineral salts. Of especial interest are the insectivorous plants which catch and digest insects by means of special structures. The digested insects are the source of their nitrogen for many of these plants that live where nitrogen compounds are lacking in the soil. Some plants have fungous hyphae growing partly within and partly outside of some or all of their roots. Such roots are often of peculiar shape and are known as mycorrhiza. The fungi absorb water and mineral salts from the soil and deliver them to the root from which in turn they take organic foods. Some of these fungi are said to be able to make use of the atmospheric nitrogen as do the bacteria in the root tubercles of the bean family.

134. All the foregoing processes, e.g. transformation of carbohydrates from one form to another, their transportation and storage, their building up into proteins, the transportation and storing away of the latter and their building up into protoplasm, require the expenditure of a considerable amount of energy. This must be 
available in every living cell and not confined to any definite locality in the plant. This is made available by the process known as respiration.

135. Respiration. With the exception of a few bacteria and low fungi to be mentioned later all living cells absorb oxygen and give off carbon dioxide, the process being accompanied by a loss in weight. In green plants in the light the absorption of carbon dioxide and giving out of oxygen are so much greater than this other process that for years it was not known that the latter takes place. It is not dependent upon the presence of light nor are chloroplasts necessary for its occurrence. It takes place more rapidly the higher the temperature until an optimum temperature is reached which is sometimes perilously near to the death point of the cell.

136. The oxygen is taken from the air (which contains nearly 20 per cent. of oxygen) by the aerial parts of the plant. It passes through the stomata and lenticels and also to some extent through the cuticle into the intercellular spaces and from thence is absorbed by the cells. The roots whose outer walls are only slightly cutinized and whose root hairs are practically free from cutin absorb the oxygen which is dissolved in the soil water and which is present in the air spaces between the soil particles. Submerged plants, e.g. algae, absorb the oxygen dissolved in the water. Many trees which grow in swamps where the soil lacks oxygen send up peculiar vertical branches from their roots out to the surface and up into the air, these serving as aerating organs for the roots. Such are the "knees" of the bald cypress (Taxodium distichum) when the latter grows in wet places (and which are lacking when it grows in well aerated soil) and the aerial roots of some of the 
mangroves (e.g. the black mangrove of Florida, Avicennia nitida).

137. Respiration consists primarily in the breaking up of the complex molecules of certain organic compounds (chiefly carbohydrates or even the carbohydrate portions of protoplasm molecules) into simpler compounds. This releases a large amount of energy much of which becomes available for the use of the plant. Since all living parts of the plant require energy, respiration will be found to take place in all parts. The intensity of the respiration varies with many factors, viz. the amount of food available that can be broken down into simpler compounds, the availability of oxygen, the amount of water, the temperature, etc. To what extent the protoplasm itself can regulate the occurrence of this process, if the other conditions are fulfilled, is uncertain.

138. Part of the energy set free in respiration is exhibited in the form of heat. This is especially noticeable where rapid growth and rapid respiration are occurring as in large flower buds, fruiting bodies of large fungi, etc. In ordinary parts of plants the radiating surface is great enough to keep the plant cool so that the heating is not noticeable. In the case of wet leaves, hay, manure, etc., the heat produced by the respiratory processes of the fungi and especially the bacteria present leads in some cases to the kindling of some of the easily inflammable substances produced so that it is a frequent occurrence for hay, especially moist alfalfa hay, and manure to catch fire.

139. It has been shown that there are two distinct stages in respiration which follow one another so closely in most cases that they appear as one. These are the anaerobic and acrobic stages. Certain bacteria and yeasts show only the first stage. In this stage no oxygen 
is required from outside the cell. By the aid of certain enzymes produced by the cell the carbohydrates or other substances used in respiration are started in their disintegration and proceed in it until simpler compounds and some carbon dioxide are produced. Thus glucose is usually decomposed into alcohol and carbon dioxide, the end results being in accordance with the following formula:

$$
\mathrm{C}_{6} \mathrm{H}_{12} \mathrm{O}_{6}=2 \mathrm{C}_{2} \mathrm{H}_{5} \mathrm{OH}+2 \mathrm{CO}_{2} \text {. }
$$

It is probable that the reaction is not as simple as this, but that there are many steps in the process. This process sets free a certain amount of energy. In the production of alcohol and carbon dioxide from sugar by the yeast plant it is this anaerobic stage of respiration that takes place. Corresponding decomposition processes occur in various kinds of bacterial fermentation and decay, the intermediate and end products varying with the composition of the substance fermented and the kind of organism.

140. The aerobic stage consists usually of the oxidation of the rather complex compounds produced in the anaerobic stage to simpler compounds, this also being accompanied by the liberation of energy in large amounts. This process also is probably carried on by the aid of enzymes and it may be that the use of the oxygen is rather to get rid of harmful products instead of being the agent which sets free the energy. Taking the case illustrated in the preceding paragraph the alcohol is broken down and combined with oxygen to form carbon dioxide and water. The final results, but not the intermediate stages, are shown by the following formula

$$
\mathrm{C}_{2} \mathrm{H}_{5} \mathrm{OH}+6 \mathrm{O}=2 \mathrm{CO}_{2}+3 \mathrm{H}_{2} \mathrm{O} .
$$

Alcohol + oxygen $=$ carbon dioxide + water, 
By comparing the final results of the anaerobic and aerobic respiration of glucose with the steps in the photosynthetic production of glucose we realize that the processes are the reverse of one another. It is reasonable to suppose then that the amount of energy set free in the processes of respiration will equal that required to build up the same amount of glucose in photosynthesis. Viewed from this standpoint respiration is the process by which the plant obtains at the places where it is needed the energy taken in from the light by the chloroplasts. The manufacture by photosynthesis of an excess of carbohydrates over that used each day by the plant in respiration enables the plant to store up a large amount of energy for the winter season when photosynthesis cannot occur or for the rapid growth of new organs another season. With all the processes of respiration the protoplasm, the living part of the cell, is intimately connected. It is to it that the energy set free is probably transferred. It is apparently the protoplasm that regulates the amount and location of the respiratory activities. How all this is brought about is still unknown as is the relation of the structure of protoplasm and the energy used to what we call "life."

141. In place of the type of respiration described above a few bacteria obtain their energy in other ways. Thus the nitrite bacteria oxidize the ammonia of ammonium salts to nitrites and the nitrate bacteria oxidize the nitrites to nitrates, each of these processes setting free a small amount of energy which is made use of by the bacteria. In both cases the energy thus obtained is sufficient to enable the cells to build up from carbon dioxide and water the earbohydrates needed in the cell's growth and further to combine these with the neeessary substances to form proteins and protoplasm. 
Still other bacteria inhabiting sulphur springs or places where sewage is abundant obtain the necessary energy by oxidizing $\mathrm{H}_{2} \mathrm{~S}$ to $\mathrm{SO}_{2}$, sulphur frequently being stored up as a reserve food supply. It is held by some investigators that other bacteria obtain their energy by oxidizing certain iron compounds, others by oxidizing methane and still others hydrogen.

142. In the foregoing processes of photosynthesis and respiration (including fermentation) many other substances are produced besides those mentioned. Some of these are perhaps nothing more than waste products, or at least by-products, but others are reserve food of various kinds. Still others perhaps serve for special functions such as protection of plants from attacks of insects, covering of wounds, etc. Among the substances thus produced and whose functions are not certainly known, are the alkaloids of which a great many have been studied, e.g. caffein, nicotine, etc. Besides these may be mentioned resins, rubber, gutta-percha, glucosides, etc. Many of these are of great use to man. Many are very poisonous. The organic acids mostly stand in another category. They are either directly reserve stuffs, replacing carbohydrates, or are stages in the respiration of carbohydrates, or in many cases are the substances which produce the requisite osmotic pressure with in the cell. The commonest organic acids are the following: malic, $\left(\mathrm{C}_{4} \mathrm{H}_{6} \mathrm{O}_{5}\right)$ found in the apple and many other fruits as well as in the leaves of many succulent plants, citric $\left(\mathrm{C}_{6} \mathrm{H}_{8} \mathrm{O}_{7}\right)$ in the fruits of lemon, orange, etc., tartaric $\left(\mathrm{C}_{4} \mathrm{H}_{6} \mathrm{O}_{6}\right)$ in fruit of grapes, oxalic $\left(\mathrm{C}_{2} \mathrm{H}_{2} \mathrm{O}_{4}\right)$ in the leaves of many plants, e.g. Oxalis, Rumex, etc., and tannic acid $\left(\mathrm{C}_{14} \mathrm{H}_{10} \mathrm{O}_{9}\right)$ and its derivatives which appear to play a very important but little understood part in the energy relations of the plant. Many of these 
acids are present in the free form but some of them appear mostly as the acid salts of various metals.

143. Temperature. The relation of the plant to temperature will be discussed here as it is chiefly a question of the effect of temperature upon the nutritive functions. Five cardinal points for temperature can be distinguished for these different processes. They are: death point from cold, death point from heat (points which are the same whatever the process and mentioned here simply because when reached the process cannot be resumed when normal temperatures are again regained), minimum, optimum and maximum. The last three are quite different for different life processes. Thus the optimum and maximum for respiration are usually much higher than for photosynthesis, in fact they often lie close to the death point from heat. Between the death point from cold and the minimum for various processes may be a small range or sometimes a great range of temperature. Usually the minimum point is a little above or not much below $0^{\circ} \mathrm{C}$. The maximum temperature for the various functions lies usually between $36^{\circ}$ and $43^{\circ} \mathrm{C}$. and the death point between $50^{\circ}$ and $55^{\circ} \mathrm{C}$., but in a few plants of hot springs as well as some bacteria causing the heating of manure, etc., the optimum temperature may be about $60^{\circ}$ and the death point even as high as $75^{\circ}$ to $85^{\circ} \mathrm{C}$.

144. The death of plants by heat appears to be due to the coagulation of some of the protein constituents of the protoplasm. Since this coagulation cannot occur unless a certain amount of water is present we find that some nearly water-free structures are able to endure rather high temperatures. Thus the spores of some bacteria can be boiled for several hours before they are killed and some seeds can endure a dry heat exceeding 
$100^{\circ}$ C. Similarly dry plant parts can endure very low temperatures. Many seeds are not killed by an exposure for several hours to the temperature of liquid hydrogen (below $-250^{\circ} \mathrm{C}$ ). The latter is also true for many single-celled water plants that must contain plenty of water, e.g. diatoms, bacteria, etc. On the other hand many watery tissues are killed by a temperature that does not reach the freezing point. Just the reason for this is unknown. It is here suggested that at these low temperatures certain processes continue which result in the accumulation of poisons, while the processes that would usually destroy these poisons, are prevented by the low temperature so that in reality the death of the plant would be due to poisoning.

145. Freezing of plants may cause death in several ways: (1) the ice crystals formed may rupture the cells or disrupt the tissues; (2) the water may escape into the intercellular spaces and be frozen there and on thawing rapidly may remain outside the cells filling up the intercellular spaces and cutting off the air supply; (3) the withdrawal of water from the protoplasm by freezing may so increase the concentration of certain substances dissolved in the cell sap that the cells are killed. Upon the whole subject consiclerable uncertainty rests.

146. Effect of Poisons. Many substances are poisonous to living plant cells. The effects are almost as varied as the types of poisons. Some, like the strong acids, simply decompose the protoplasm and cell walls and so destroy life; others, like the salts of the heavier metals, coagulate the protoplasm; others even in minute quantities interfere with the nutrition of the cell in a manner not understood, and kill it. Thus one part of copper in ten million parts of water will kill certain algae and fungi. Hydrocyanic acid acts apparently by preventing the 
taking in or using of oxygen in respiration. Many parasitic plants, e.g. bacteria and fungi secrete poisons or induce activities in the cells of the host that lead to the accumulation of poisons that may destroy the life of a cell or lead it to abnormal growth or functioning.

Laboratory Studies. (a) Take a piece of the root of a living red beet. Cut out a cube a centimeter or so in diameter. Wash off the colored cell sap that has escaped from the cut cells and place the cube in a test tube of water. So long as the cells are alive their plasma membranes prevent the colored solute in the cell sap from escaping. Gently heat the test tube. When the death point of the beet tissues is reached (below $60^{\circ} \mathrm{C}$.) the plasma membranes are no longer impermeable and the color diffuses out into the surrounding water. This experiment also shows that the cell walls themselves are but slight obstacles to diffusion. Instead of by heating, similar results may be obtained by using certain poisons such as strong alcohol, etc., but care must be taken not to choose a substance that will destroy the coloring matter.

(b) Set up a series of water cultures as follows: Take glass jars (Mason jars will do) and to keep the contents dark encase each with a cylinder of pasteboard which can be removed to permit of observation. Fill these jars nearly full of the solution to be tested, leaving a small air space between the water and the cork. The cork should have at the center a hole 5 or $6 \mathrm{~mm}$. in diameter. Germinate some peas, corn, buckwheat or mustard seeds. When the radicles are 2 to $3 \mathrm{~cm}$. long, fasten one seed to each cork in such a way that the root just enters the solution and the plumule is in a position to pass up through the hole in the cork (or the seed can be fastencd outside with the root passing through the hole). Instead of a cork the jars may be nearly filled with water and melted paraffin poured upon it; after the paraffin has hardened several holes may be made through it by means of a hot metal rod. The water can now be poured out and the desired liquid poured in, nearly up to the under side of the paraffin. The germinated seeds can be set upon this paraffin cap in such a way that the radicles will pass through the holes. Expose all the jars to the same light and temperature so that as far as possible the only differences will 
be those of the composition of the solutions. Make up the following solutions and fill into the jars:

1. Distilled water

2. Complete culture solution (Sachs)

3. Complete culture solution, omitting the $\mathrm{KNO}_{3}$

4. Complete culture solution, omitting the $\mathrm{MgSO}_{4}$

5. Complete culture solution, omitting the $\mathrm{KNO}_{3}$ and $\mathrm{K}_{2} \mathrm{SO}_{4}$ and adding $\mathrm{Ca}\left(\mathrm{NO}_{3}\right)_{2}$ in place of the first.

6. Complete culture solution, omitting the $\mathrm{Ca}_{3}\left(\mathrm{PO}_{4}\right)_{2}$ and adding an equal amount of $\mathrm{Ca}\left(\mathrm{NO}_{3}\right)_{2}$

7. Complete culture solution, omitting the $\mathrm{K}_{2} \mathrm{SO}_{4}$ and $\mathrm{MgSO}_{4}$ and replacing by an equal amount of $\mathrm{Mg}\left(\mathrm{NO}_{3}\right)_{2}$

S. Complete culture solution omitting the $\mathrm{Ca}_{3}\left(\mathrm{PO}_{4}\right)_{2}$ and substituting $\mathrm{K}_{2} \mathrm{HPO}_{4}$

9. Complete culture solution omitting the $\mathrm{FeCl}_{3}$.

The Sachs' solution consists of :

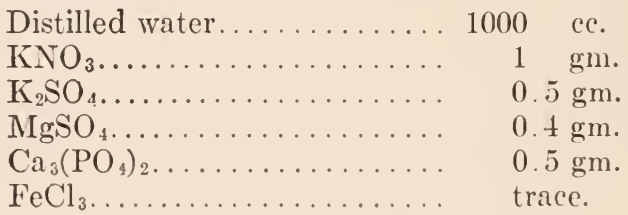

Let the plants grow for several weeks, replacing the old solutions by fresh ones of the same composition every week or so. Compare the amount of growth of both roots and stems in the different solutions, the size and color of the leaves, etc. Note when growth ceases and to what stage of development the plant proceeds before its death.

(c) Bring some Spirogyra into the laboratory and place in a dark room (not too cold) for twenty-four to thirty-six hours or until on testing some of the plants with iodine solution no starch is found. Bring the dish into the sunlight and with iodine solution test some of the plants for starch after five minutes, ten minutes, half an hour, etc.

(d) In a rather broad, deep glass dish (e.g. a wide battery jar) place some actively growing Spirogyra. Put a bit of wire netting (iron, not copper nor brass) into the bottom of a shorttubed funnel and invert over the Spirogyra submerging the 
funnel and its tube completely. Over the latter invert a test tube filled with water. Now raise the funnel as high as it will go without lifting the edge of the test tube above the surface of the water, supporting it on a small block. Place the whole in the sunlight. As photosynthesis goes on the oxygen given off by the pond scum collects in the test tube and may be tested in various ways, e.g. by carefully removing the test tube, inverting it and inserting a glowing splinter which will burst into flame if sufficient oxygen is present. The diameter of the funnel must be considerably less than that of the jar or no $\mathrm{CO}_{2}$ can reach the Spirogyra and photosynthesis will soon cease. If $\mathrm{CO}_{2}$ is passed into the water oceasionally, taking care not to let any bubbles enter the funnel, the activity of the process

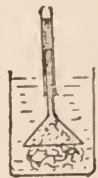

FIg. 44. Photo: synthesis experiment $(d)$. is increased.

(e) In a similar way the oxygen evolved in photosynthesis by Philotria (Elodea) may be collected by inserting the cut ends of several plants into the mouth of an inverted test tube filled with water and placing the whole dish in the sunlight. Care must be taken, however, not to confuse two phenomena here, viz. the rapid outflow of bubbles at first, due to the expansion of the gas already present in the stem as it heats, and the much slower evolution of oxygen by photosynthesis. After the first outrush of gas due to the expansion by heat is past the relative amount of photosynthesis can be told with a fair degree of accuracy by counting the number of bubbles of oxygen evolved per minute under the different conditions. Be sure, however, to keep the water well supplied with $\mathrm{CO}_{2}$. Test now the effect of placing glass plates of different colors in front of the dish containing this plant, in all cases waiting long enough to avoid the effect of the changing volume of the enelosed gas due to changes of temperature.

(f) Place two potted geranium (Pelargonium) plants, preferably with plain, not varicgated leaves, in the lark until their leaves contain no starch. Now place them under bell jars, sealing one air tight with sealing wax or by other means, first placing under the jar a dish containing a strong solution of $\mathrm{KOH}$ to absorb all $\mathrm{CO}_{2}$. Leave a small air space under the edge of the other bell jar so as to permit the cntry of air containing $\mathrm{CO}_{2}$. After an hour or so place both plants in the 
sunlight and after three or four hours test their leaves for the presence of starch as follows: Remove a leaf, immerse it in hot alcohol for a few minutes to extract the chlorophyll and then cover with a strong solution of iodine which will color the leaf blue or not according as the starch is present or absent. To aroid rupture of the sealing by the expanding air it is well to use a bell jar with an opening at the top into which is placed a cork through which a glass tube passes. This tube should be bent so that its other end is immersed in a dish of mercury. As the air expands it passes out through this tube and escapes through the mercury but the air and earbon dioxide from outside cannot enter.

(g) On a large leaf of geranium (Pelargonium), or other plant which produces starch in abundance in its leaves, clamp on the upper side a flat cork and on the lower side a little box (a wooden box such as cover glasses come in will be satisfactory) blackened inside and whose sides

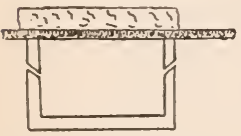

Frg. 45.-Disappearance of starch (g). have been pierced from the outside by numerous small holes running obliquely away from the leaf. These holes admit air (and $\mathrm{CO}_{2}$ ) but as they point away from the leaf any light admitted through them is absorbed by the blackened inner surface of the box. Set the plant in the sunlight for several hours then remove the leaf and treat with alcohol and iodine as in $(f)$. The spot protected from light by the cork and the little box will show no starch. To clamp two corks together on both sides of the leaf is unsatisfactory, as in that case not only is the light cut off but the $\mathrm{CO}_{2}$ as well, so that the reason for the lack of starch in that case is two fold.

(h) Reserve carbohydrate in the form of starch may be demonstrated in the tubers of potatoes, root of sweet potatoes (Ipomoea batatas), seeds of corn (Zea mays), wheat, beans, etc. In the form of cane sugar it is present in the root of the beet (especially in the sugar bect), in the stem of corn and sugar cane, etc. As hemicellulose it is present in the wood of mulberry (Morus) and elm where it may be demonstrated by treating a section with sulphuric acid followed by iodine solution. Food is stored up in the seeds of cotton, castor bean (Ricinus), flax, etc., and in the seales of onions, leaves of cabbage, etc., as fats. 
It may be demonstrated by treating with dilute osmic acid solution which turns fats black, or with alkannin solution, which stains the fat drops red.

(i) Place a geranium (Pelargonium) plant in the light for several hours until stareh has been produced in quantity in the leaves. On two or three leaves cut one or two of the main radial veins leaving the other veins intact. Cover the whole plant loosely with a bell jar to prevent these injured leaves from drying out too much and place in the dark for from twelve to twenty hours. Treat these leaves with alcohol and iodine solution as in $(f)$ to determine the location of the starch. It will be found to have disappeared except from the portions bordering on the cut veins, showing that it is through these veins (vascular bundles) that the carbohydrates are transported.

(j) Reserve protein in the form of aleuron in the seeds of beans, peas, ete., was studied in connection with cell inclusions (paragraph 24). It will be worth while to repeat these observations.

(k) Examine one of the powdery mildews (Erysiphaceae) as an example of a hysterophytic lower plant that obtains its food from living plants (i.e. is parasitic). Take a bit of infected leaf and moisten with alcohol, then mount in water or dilute potassium hydrate solution with the infected side uppermost. By eareful focusing the filaments of the fungus may be distinguished and here and there may be seen the haustoria ("suckers") which are sent into the epidermal cells of the leaf. Better developed haustoria can sometimes be found on making cross-sections of leaves or stems affected by downy mildew (Peronosporaceae) or white rust (Albugo). In these cases the whole fungus except certain reproductive parts is within the host plant, growing intercellularly and sending well developed haustoria into the cells between which it passes. In both eases note the lack of chlorophyll in the fungus.

( $l$ ) Examine a dodder plant (Cuscuta) as an example of a higher plant that is parasitic. No leaves are to be found and in most cases no chlorophyll, and the plant carries on no photosynthesis. The original root which penetrated the soil dies as soon as the plant has attached itself to its host or even before. Note the roots by which it obtains its food from the host. Sections of the stem will reveal vascular bundles, epidermis, etc., but usually no chlorophyll-bearing cells. 
(m) Place a number of fresh leaves or a short shoot with leaves in the large end of a retort with a little water and place the small end under a surface of mercury to prevent the entrance of gases. Keep in a dark moderately warm place for from twelve to twenty-four hours. Note that the volume of the gas does not seem to be changed. Carefully without allowing any air to enter run a pipette full of strong $\mathrm{KOH}$ solution into the small end of the retort or introduce a small piece of stick potash $(\mathrm{KOH})$ with a few drops of water, these rising to the surface of the mereury. As the $\mathrm{CO}_{2}$ is absorbed the mereury rises. When the ascent ceases (i.e. all the $\mathrm{CO}_{2}$ has been absorbed) introduce a strong solution of pyrogallic acid. This has the property when mixed with alkaline solutions of absorbing oxygen. Note whether the mereury rises any further. If it does so it shows that some oxygen was present. Repeat the experiment using a retort without any leaves in it. It will be found that about as much $\mathrm{CO}_{2}$ was produced by the leaves (as shown by the height to which mereury rose with the $\mathrm{KOH}$ alone) as oxygen was present (as shown in the control experiment by the distance the mercury rose with the $\mathrm{KOH}$ and pyrogallic acid). If this can be done with graduated eylinders the amounts can be measured more aceurately.

(n) That $\mathrm{CO}_{2}$ is given off by a living plant may be demonstrated in the following way also. Place a potted plant under a bell jar with a dish of $\mathrm{Ba}(\mathrm{OH})_{2}$ solution or (less preferably) $\mathrm{Ca}(\mathrm{OH})_{2}$ solution. Put in a dark place. The $\mathrm{CO}_{2}$ given off forms a crust of $\mathrm{BaCO}_{3}$ (or $\mathrm{CaCO}_{3}$ ) on the surface of the liquid while in a control experiment with no plant under the bell jar the amount of $\mathrm{CO}_{2}$ in the air (3 parts in 10,000) produces only a very small precipitate.

(o) Soak some peas over night and then place them in a tall glass jar filling it about half full, and cover with a vaselined glass plate. After a few hours remove the plate and lower a burning taper into the cylinder. It is extinguished by the $\mathrm{CO}_{2}$ which has replaced the oxygen. If the air is very still it is more striking to place a small lighted taper in the bottom of another jar and to pour the $\mathrm{CO}_{2}$ from the jar of peas into this jar, extinguishing the light.

$(p)$ Soak some peas over night. Fill a test tube with mercury and invert over a dish of mereury. Force three or four peas under the mercury so that they come under the edge of the 
test tube, when they will rise to its closed end. Respiration in its first (anaerobic) stage will go on and gas will be formed, oftentimes driving nearly all the mercury out of the tube. Introduce a strong $\mathrm{KOH}$ solution or a piece of stick $\mathrm{KOH}$ and a little water under the edge of the test tube and the gas will all be absorbed, showing that it is $\mathrm{CO}_{2}$ that was produced.

(q) Yeast plants ordinarily carry on only this first stage of respiration (called fermentation in this case).

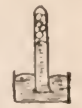

Fig. 46 . - IR espiration experiment $(d)$. To potato water (made by grating up a potato and boiling it in a little water and expressing the latter) add about 5 per cent. glucose. Place in a flask with a cork and a glass tube bent so as to lead the gas produced under water. Break up part of a cake of compressed yeast in a little water and add it to the solution in the flask and insert the cork and glass tube. In a short time gas will begin to escape in bubbles from the end of the tube. Collect some in a test tube and test in various ways such as for inflammability, absorption by $\mathrm{KOH}$, etc. It will be found to be $\mathrm{CO}_{2}$. Note what large amounts are produced. After the evolution of gas has ceased the proper chemical tests will show the presence of alcohol in the liquid. Distill the latter and collect the first part that comes over. Add to it some strong $\mathrm{KOH}$ solution and some flakes of iodine, and heat. If alcohol is present a strong odor of iodoform will be produced and if much is present this will show as a yellow precipitate.

$(r)$ The liberation of heat during respiration can be demonstrated by placing a quantity of soaked peas or a number of mushrooms just expanding in a flask with an accurate chemical thermometer bulb in their midst and placing this flask in a mass of cotton in another vessel and covering all with several layers of cloth, leaving only the thermometer tube exposed. Often the temperature within the flask will rise 3 or 4 degrees or more above that of the surrounding air. Of course this experiment must be carried on in a room where the temperature is fairly constant. If a Dewar bulb or a Thermos bottle is used, these being double walled with a vacuum between so that the loss of heat is very small, the difference of temperature is much more marked.

(s) Without special thermostats where temperatures can be controlled exactly, satisfactory experiments as to the eardinal points of temperature cannot be made. However, it will be 
helpful in the autumn to list the plants most susceptible to injury and those that suffer least from frost.

147. Growth. In the one-celled plants, or plants made up of undifferentiated cells, growth is a function of every cell. It enlarges up to a certain point and then divides into two cells which enlarge and divide, etc. In some cases the cell divides internally into many small cells which enlarge until they reach the size of the parent cell and repeat the process. The growth of a cell involves a number of factors. Among these are the increase in the amount of cytoplasm and sometimes a great increase in the amount of cell sap, also the enlargement of the cell wall in area and frequently also in thickness. These cells are meristematic in many features. In such plants we can hardly dissociate growth from reproduction.

148. In the more complex plants we find some parts that are the seat of the growth, the growing points and adjacent region and cambium layers, while the rest of the plant practically ceases to grow. The reproductive functions are carried on by special parts of the plant which have nothing to do with its ordinary growth. The growth in such plants takes place still by the process of cell growth and division, but we find that these differ considerably from the case in one-celled plants. Thus near the tips of the growing points the cells increase their cytoplasm and cell wall area so as to become perhaps twice as large, and then divide and form new cells as is the case in one-celled plants except that the cells remain attached. Gradually, however, some of these cells that by the formation of new cells have come to lie further from the tip increase more and more in size and are not so active in their division. This increase in size takes place largely by an increase in size of the vacuoles so that the cells contain proportionally less and less cytoplasm, although probably the amount of cyto- 
plasm actually does increase, or decreases but little. In other words the growth of the cell is mainly accomplished by absorbing large amounts of water, the cell wall being increased in area so as to keep pace with the increase in volume. It is possible that in some cases where the growth of the cell is very rapid the total amount of cytoplasm in the cell may actually be reduced in manufacturing the additional cell wall substance required. In this growth we can distinguish three phases which ean be more or less clearly set off, viz., formative phase, phase of enlargement and phase of differentiation or maturation.

149. Thus it comes about that at the growing root tip or tip of the stem we can distinguish an area near to the tip where growth is not very rapid but cell division is taking place abundantly (i.e. the cells are in the formative phase of growth), and another area into which the first grades, and a little distance back from it, where the cells are enlarging very rapidly and but little cell division is taking place (i.e. the cells are in the phase of enlargement). This gradually grades off into that portion of the root or stem where growth in size is no longer occurring but where the various tissue differentiations are taking place (i.e. the phase of differentiation). In the root these zones are well marked, while in the stem the elongation may persist for a long while and may become localized in nodes while the internodes cease to grow. In this case the nodes usually retain some meristem and possess the power of producing new cells as well as increasing in size.

150. There are several factors that influence plant growth. There must in the first place be sufficient food stuffs to enable the cells to manufacture the necessary new cytoplasm and cell wall. Then there must be sufficient organic substances to produce the osmotic 
pressure necessary to take in the requisite large quantities of water that increase the bulk of the cell so greatly during the phase of enlargement. Then sufficient food substances must also be present to supply in the process of respiration the energy necessary for growth. Furthermore the water supply must be ample, for growth ceases immediately if the cells of the plant are not kept strongly turgicl, hence the reason that in a dry season a plant may remain alive for months on a minimum of water, but scarcely grow at all. The temperature also has a marked influence on growth. The cardinal points of temperature for growth are often quite different from those for photosynthesis or respiration in the same plant. In some plants that come up through the snow the optimum temperature for growth may be but little above $0^{\circ} \mathrm{C}$., while in Indian corn, for example, the optimum lies between $37^{\circ}$ and $42^{\circ} \mathrm{C}$.

151. The effect of light upon growth is noteworthy. Careful records of the rate of growth with automatically recording instruments show that, given constant temperature, the growth is much more rapid in darkness than in light. If the rays from the blue end of the spectrum are excluded growth is scarcely if at all checked by light. The absence of light, however, although favoring the elongation of the plant, prevents the normal formation of leaves. This is possibly due in part to lack of food, but it seems probable that a definite stimulus on the part of light is needed before leaves will be produced in the normal form and size. Plants kept in the dark become much elongated (remaining pale in color) with only rudiments of leaves. Such plants are said to be etiolated. To a certain degree this is useful to a plant in that a tuber or seed buried too deep produces an abnormally elongated shoot which may thus be able to reach the light. 
152. The amount of growth in a given length of time varies with the plant. Some trees in dry regions, e.g. Cercocarpus parvifolius, the mountain mahogany of Colorado, may scarcely attain a height of two meters in one hundred years, while a morning glory vine (Ipomoea) may grow $17 \mathrm{~cm}$. per day, a bamboo shoot $60 \mathrm{~cm}$. per day and a stamen of wheat $1.8 \mathrm{~mm}$. per minute, i.e. at a rate of over 25 meters a day (but of course this rate of growth actually lasts only a few minutes).

153. As growth occurs in a stem or root various tensions arise owing to the unequal amount of growth in different parts. Thus the pith of many plants (especially herbaceous ones) elongates considerably when removed from the stem and the surrounding portions shorten a little. While they remain in the plant the result is that certain parts of the plant are stretched and the pith compressed, which stiffens the plant just as in a turgid cell the stretched cell wall pressing against the osmotic pressure within the cell renders the cell stiff. Bark of trees usually shows a circumferential stretching also which helps to keep the stem rigid.

Laboratory Studies. (a) Examine plants of Protococcus (one to few celled) or of Spirogyra (chain of cells). Cells of different sizes will be found but the largest cells are rarely more than twice as large as the smallest ones. Here each cell grows and divides for itself and in the case of the first the cells soon separate, forming new plants.

(b) Take a germinated seed of Indian corn, sunflower or other plant and on a rapidly growing root, using a thread dipped in India ink, mark lines $1 \mathrm{~mm}$. apart making the first mark $1 \mathrm{~mm}$. back from the tip (special markers for this purpose may be bought, but although more convenient are not indispensible). Place this seed on moist cotton with the marked root directed downward and cover with a bell jar to prevent drying out. Examine at intervals of several

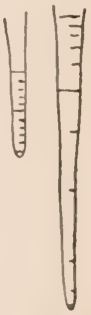

Fig. 47. - 120 o tg rowth. experiment $(b)$. 
hours to determine in what segment so marked the most rapid growth occurs. It must be remembered that this zone of most rapid growth is rapidly passing down the root all the time, keeping about the same distance back from the root tip, so that the marked root must not be left too long before examination or the conclusions will be faulty.

(c) Attach the thread of an auxanometer (instrument for measuring growth) to the tip of a leaf just growing out of an onion or hyacinth bulb or to the tip of the flower scape of such a plant, or just below the cotyledons of a sunflower seedling. If possible have the plant in a situation where

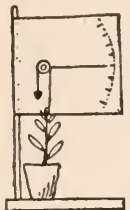

Fig. 48 Simple auxanometer $(c)$. it is almost equally lighted from all directions. If the instrument is not self-recording readings should be made every one or two hours during the day and night. If the records are automatically made the readings need not be taken during the course of the experiment but the records can be studied afterward. So far as possible keep the temperature constant. Interesting results may be obtained by varying the temperature while keeping the intensity of the light the same or by varying the light with constant temperature. The effect of keeping the soil very wet and very dry may also be compared.

(d) Observe a potato that has started to grow in a dark corner of a cellar and compare its growth with that from a tuber that has been grown in full light.

(e) Place potted plants under bell jars as follows: (1) clear white glass, (2) double bell jar with space filled with saturated $\mathrm{K}_{2} \mathrm{Cr}_{2} \mathrm{O}_{7}$ solution, (3) double jar with space filled with saturated cuprammonia solution. Compare the growth. Note also the differences in the color and development of the leaves. The cuprammonia solution is prepared by carefully adding to a copper sulphate solution sufficient ammonia to precipitate all of the copper as copper hydroxide but not adding enough ammonia to redissolve the precipitate. Filter and wash the precipitate and then dissolve it in strong ammonia using only enough of the latter to completely dissolve it. This must not be done on the filter paper as the solution thus formed dissolves cellulose.

$(f)$ The rate of growth under normal conditions can be measured by an auxanometer or with a horizontal microscope or in the case of rapidly growing plants, such as Indian corn, morn- 
ing glory vine, bamboo, ete., it can be measured every day with a ruler. Make and record such measurements night and morning for several kinds of plants.

154. Reproduction. This is the ultimate function of all plants. For many it is the final function of life, the death of the old individual occurring with the formation of the new individual. It is perhaps to be considered as the final act of growth toward which all development of the plant has been leading.

155. In many of the lower plants, especially those that are undifferentiated, reproduction is nothing more than cell division followed by separation of the cells thus produced. In the more differentiated plants, however, we find certain cells set aside for reproductive purposes. These may be at first ordinary vegetative-cells that later take up the reproductive function, or they may be destined for the latter from their beginning.

156. Very early in the vegetable and animal kingdoms two types of reproduction become recognizable, the asexual and the sexual. The former consists essentially of the division of the plant, or of the separation from it of single cells or groups of cells or even whole plant members. By further growth these parts thus produced become like the parent plant. Not to be confused with true asexual reproduction, is the development of the gametophyte from the spores produced by the sporophyte.

157. Sexual reproduction is fundamentally different from asexual reproduction in that there is requisite the union of two distinct cells (or at least their nuclei) to form a single cell, the zygote. This may develop directly into a new plant or into a mass of cells (the spore fruit), which produces only eventually the reproductive cells, which give rise to the new plants. The 
uniting cells (gametes) may come from the same or from different plants, indeed they may be sister cells, i.e. formed by the division of one cell, but this is not common. 'They may be alike (isogamous) or unlike (heterogamous).

158. As we proceed from the simple to more complex plants in the study of sexual reproduction we find entering in, the principle of "increased parental care." In the lowest plants with sexual reproduction the gametes unite outside of the parent plant, at a higher stage one gamete (the egg) is retained in the parent plant and is fertilized by the motile sperm. Still higher the egg is surrounded by special protective structures (cystocarp, archegone, etc.) and produces no longer a simple zygote but a spore fruit which may also be included in the protective envelope. A still higher stage is where the spore fruit is so highly differentiated that it becomes a separate generation (sporophyte), capable of separate existence, similar to or differing in appearance from the parent generation (gametophyte). Highest of all we find the sporophyte becoming the prevalent generation, the gametophyte being retained within its protective tissues and only developing far enough to permit sexual reproduction to occur.

159. Each gamete of the same species has the same number of chromosomes in its nucleus. The cell resulting from their union, the zygote, has double this number (diploid number). Where a zygote is formed which gives rise directly to a plant like the original one, the reduction in the number of the chromosomes from the diploid to the haploid number (see paragraphs 35 and 160), occurs with the germination of the zygote. Where a spore fruit or sporophytic generation occurs its cells retain the diploid number and the reduction divi- 
sion does not enter in until the spores are being produced, which give rise to the sexual generation (gametophyte). This latter has the haploid number of chromosomes in its nuclei. We must thus distinguish carefully between typical asexual reproduction, where the resulting plant is, as it were, but a separated part of the mother plant, and the formation of a gametophytic generation from the spore produced in the sporophytic generation. Indeed each of these generations may have typical asexual reproduction leading simply to the formation of other plants of the same generation.

160. After the union of gametes the ehromosomes from the two gametes remain separate, but usually the corresponding chromosomes from each gamete lie close together. In the reduction division the chromosomes gather at the equator of the spindle as double chromosomes, in all probability representing the two corresponding chromosomes from the two gametes. Before this stage is reached, and while the chromatin matter is found on fine threads, there is a characteristic bunching together of these threads (called the synapsis) in the course of which it is supposed that certain characters become ex-
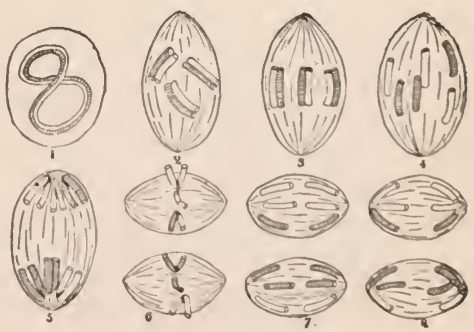

FIG. 49.-Reduction division (diagrammatic). changed in the corresponding chromosomes. These double chromosomes split apart and as single ones go to the opposite poles. There are thus entering into each daughter nucleus only as many chromosomes as were originally present in the gametes. These 
chromosomes do not, however, correspond exactly to the originals, for in the synaptic stage there has been an exchange of some characters. At the next division the nuclear phenomena are like those of the ordinary vegetative division.

161. These peculiarities of haploid and diploid chromosome number, reduction division, and ordinary (somatic) division of the nuclei, as well as other observed phenomena of heredity, have led most investigators to conclude that the chromosomes are the chief bearers of heredity. In sexual reproduction, then, is found a means of combining in the most complicated ways the minute or larger differences found in the different parents.

162. Variations. Hardly any two plants are exactly alike. The differences are of two kinds: (1) a response of the plant to slightly or greatly different environmental conditions, and (2) a difference in the constitutions of the plants that leads them to respond somewhat differently in morphological or physiological characters when exposed to the same conditions. These latter are the only ones that demand attention here. They may be slight differences that are apparently not inheritable (i.e. although the somatic or vegetative cells are somewhat different the sexual cells are not so), or there may actually have taken place a change in the constitution of the protoplasm that affects also the reproductive cells, so that the heredity carriers (probably the chromosomes) are slightly different in the different plants.

163. Gregor Mendel, in 1866, published a paper in which he pointed out that certain characters that differed in the two parents and that are mutually exclusive (i.e. that allow of no intermediate form) would appear in the second generation in a pure form in some of the plants. This is now explained by the phenomena taking 
place in connection with the reduction division, where during synapsis certain character-determining units in the chromosomes may become exchanged, so that the chances are about equal whether one or the other character from respectively one or the other parent will be present in the new cell. Mendel found that about onefourth of the second generation plants show a given character from one of the original plants and one-fourth the character from the other plant, while one-half still retains (at least potentially) both characters, although only one is visible, it being "dominant" over the other character which is "recessive." That both characters are present is shown by the fact that seeds from this half produce plants which divide up again into one-fourth, one-fourth, and one-half, etc.

164. In sexual reproduction the various differences borne by the different chromosomes, or perhaps more accurately by the unit structures of the chromosomes, will be redistributed among the daughter and granddaughter plants in new combinations. Some of these will be advantageous to the plant, and it will succeed better and be able to reproduce more freely; other combinations may be less favorable, and the plants with such combinations will have a poorer chance in the struggle for existence, and will not reproduce so freely. As a result, "Natural Selection" sorts out those whose combinations are most favorable. Thus we see that sexual reproduction forms a means by which the constantly arising individual differences (and why they arise we do not know) are made use of in the most manifold combinations, the most favorable of which are perpetuated. This is what was called by Darwin "The survival of the fittest."

165. These inheritable variations may be slight or 
they may be strongly marked. They are often called "mutations" to distinguish them from the non-inheritable variations. If the plants showing them are considerably better able to exist, they will rapidly crowd out the less favorably constituted plants, and thus a new species will replace the old. Under other environmental conditions this new feature may be less favorable and so the older form will persist. Thus we find plants with all sorts of differences or what we call "species," all over the world. Some plants have changed but little apparently from their primitive structure, as they were able to persist in that form under certain conditions, while some of their descendants, it may be, have progressed far along the evolutionary line. Thus we find the Vegetable Kingdom made up not only of the ends of long evolutionary branches but also of stragglers that have progressed only a very little way, and of those that have grown further before branching out in some other direction. It is this fact that enables us to attempt to show the probable course of evolution (phylogeny) of the Vegetable Kingdom in our arrangement of the plants now existing.

166. The conditions that favor reproduction have been worked out for a good many plants, but are unknown for the vast majority. It seems that those conditions that favor continued vegetative growth, such as an abundance of water and all foods, tend to delay or prevent reproduction. On the other hand, there must usually be a certain amount of food stuffs stored up. If these can be prevented from accumulating, or can be used up by promoting vegetative growth, reproduction will be held back. In many cases, however, the reproductive stage comes on in spite of all efforts to keep it back, showing that not all the factors are known. 
167. The breeding of plants is an application of the principles of reproduction and heredity to the production of plants with certain desirable characteristics. Instead of waiting for the chance production of a desirable type of plant, the plant breeder either grows many plants in conditions under his control and selects for further propagation those he deems most desirable (method of selection), or he takes two distinct plants, each with certain characters that he desires, and crosses them, and grows the progeny in large numbers for several generations until by the laws of chance in the distribution of the unit character determinants there appears a plant combining the desirable characters of the two parents. This is the method of hybridization or erossing. The discovery by Mendel of the segregation of characters by definite laws of numbers (see paragraph 165) has given a great impetus to this line of work.

Laboratory Studies. Not much can be done in the way of laboratory work on this subject. In the study of the different forms of plants in the later chapters of the book, the points emphasized in the foregoing paragraphs should be borne in mind. A few suggestions are made for observations on the part of the student.

(a) Find and compare earefully a dozen different plants of timothy (Phleum pratense), red clover (Trifolium pratense), ribbed plantain (Plantago lanceolata), ete. Select those plants of the same age and from as nearly as possible the same soil and growing under the same environmental conditions. Note how they differ in height; number, size and shape of leaves; size of flower heads; number of flowers in the head; amount of hairiness of various parts, ete.

(b) Compare plants of the same kind grown in sun and shade, in dry and moist soils, in barren and on fertile ground, for differences due largely to the environment. Note the differences in the times of flowering and of ripening of seeds, as well as the structural differenees. 
168. Movements. Plant movements are of four kinds: (1) hygroscopic, (2) protoplasmic, (3) turgor, and (4) growth movements. The first is a strictly physical phenomenon of deacl cells, the last three are functions of living cells or tissues.

169. Hygroscopic Movements. Cell walls have a great power of imbibition of water, and when filled with water have a greater volume than when dry. In many plant organs certain cell walls have a greater power of imbibition than others, or in some cases certain tissues on one side prevent the organs from elongating or contracting on that side. The result in either case is that as the cell walls absorb water or give it up a curvature takes place. This may be a simple bending or may consist of twisting. Mostly the organs straighten out on becoming wet and curve or twist as they dry. In some cases the differences in the moisture content of the air are sufficient to produce movements. These movements are of value to the plant in opening reproductive organs (sporangia, seed capsules, etc.) or in enabling seeds to penetrate the ground (twisting of the long awn of porcupine grass, Stipa).

170. In the case of the sporangia of the common ferns (Polypodiaceae), the cell lumen as well as the walls is filled with water. As the water evaporates through the cell wall, the cell

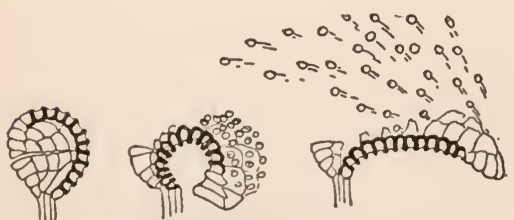

FIG. 50.-Dispersal of fern spores. contracts to compensate for the water lost. As the walls are thin and collapsible on one side only, and thick but flexible on the others, the cell contracts more and more toward the thin side until the row of cells instead of being in a nearly 
complete circle with the thin wall at the outside, is bent back into almost a reverse circle, the whole row being now under high tension. As the evaporation proceeds, further contraction becomes impossible, and the collapsed thin cell walls become dry in spots. These dry spots are permeable to air, which rushes into them and permits the whole ring to snap back with extraordinary violence, flinging the spores a comparatively long distance.

171. Protoplasmic Movements. We may distinguish two types of these, the movements of the cytoplasm within the cell and the movement of the cell as a whole, due to the motion of the cytoplasm or special parts of it (cilia or flagella).

172. The motion of cytoplasm within the cell seems to be a normal phenomenon in all living cells whose protoplasm has imbibed enough water to make it rather liquid, i.e. in all active cells. It is probably entirely absent in so-called dormant cells, such as the cells of dry seeds, etc. In many cells it cannot be distinguished except by special methods. The motion may consist of a rotation of all the cytoplasm of the cell except a thin layer against the cell wall (as in Chara and Nitella), or of large streams in which chloroplasts and cell inclu- Fia. 51. sions are swept along (as in Philotria), or in cur- Streamrents in the parietal cytoplasm and delicate toplasm strands crossing the vacuole (as in Tradescantia), cantia). or it may consist of rather local disturbances.

173. Of especial interest are those movements by which the nucleus is carried from one part of the cell to the other. Thus in a cell that is growing rapidly on one side or secreting abundantly at one side, the nucleus is of ten carried to the point of activity. The chloroplasts, too, change their position with reference to the light. If 
the light is dim, they are carried to the top or bottom of the cell, where they will get the strongest light broadside. If the light is too strong, they are carried to the sides of the cell, where the light will only strike them edgewise.

174. The locomotion of cells is accomplished mostly by the lashing movements of slender eytoplasmic projections from the surface of the naked cell. If few in number and long, they are usually called flagella. If numerous and rather short, they are called cilia. When single or few, they are usually attached at the anterior end of the cell. A few plant cells

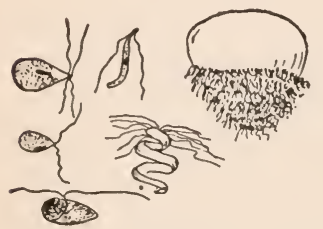

FIG. 52.-Flagellate cells, (U l o thrix, Pleurocladia, Marchantia, Struthiopteris, Zamia). move by amoeboid motion, i.e. send out processes or lobes into which the whole protoplasm flows. The cells of diatoms (Bacillarioideae) are provided with cell walls of cellulose so filled with silica as to be non-elastic and brittle. In some diatoms the protoplasm comes to the surface through a longitudinal slit, the raphe, and its longitudinal motion in this slit is probably the cause of the motion of the cell. Finally, must be mentioned the motion of some diatoms as well as desmids, and some of the blue-green algae (e.g. Oscillatoria) which is ascribed to the secretion of a slime through the cell wall. The bending of the Oscillatoria filaments, however, may be due to protoplasmic contraction.

175. All of these movements are dependent on an ample supply of oxygen, and cease very quickly in its absence. The usual cardinal points of temperature can be found for these as well as for other functions of the cell. Apparently the movements within the cell are of use in 
distributing various food products as well as other substances throughout the cell.

176. In motile cells there is observable a response in direction of the movements to various external stimuli. Thus many cells swim toward the light, or away from it (positive and negative phototaxy). Others swim toward or away from various chemical substances (e.g. food matters, acids, etc.) diffusing through the water, this being called chemotaxy. In many cases a degree of light or of concentration of a chemical that causes positive reaction, when increased beyond a certain point repels the cell. It is not always the case that harmful chemical substances (poisons) repel the cell, although usually this is the case.

Laboratory Studies. (a) Insert the point of the fruit of porcupine grass (Stipa) into a cork or fasten the fruit of eranesbill (Erodium) to a cork with a drop of sealing wax, with the main shaft of the fruit upright, and place a marker opposite the tip of the bent portion. Place a bell jar partially lined with wet filter paper over it and note how it changes its position and the direction of the motion. Remove the bell jar and note the change in the direction of motion. By spraying a fine mist on the specimen a lively movement will be obtained.

(b) Mount several ripe sporangia of a fern in a very little water without a cover glass and watch the motion as the water dries out.

(c) Examine some of the end eells of Chara or Nitella for rotatory movement of eytoplasm, the leaf of Philotria for large streams of cytoplasm carrying the chloroplasts with them, the stamen hairs of Tradescantia or the stem hairs of petunia, tomato or watermelon for more delicate strands of streaming cytoplasm.

(d) With some of the foregoing test the effect on the movement of cold (laying on a block of ice) and heat (up to $40^{\circ}$ or $45^{\circ} \mathrm{C}$.), examining again at room temperature.

(c) Place some green felt (Vaucheria) that has been growing on the surface of the ground in a dish of water. Often this will 
cause it to form its multiciliate zoospores. Study their motion. Study also zoospores of Ulothrix, Chaetophora or Draparnaldia which ean often be obtained by bringing these algae into the laboratory and leaving them over night in a dish of water. Often they will collect at the side of the glass next to the light.

(f) With sharp scissors cut off as much as possible of the mycclium (fungous threads) of Saprolegnia growing on a fly or piece of meat thrown into a dish of algae. Place it in a dish of clean water and after a few hours hang a small piece of meat in the water at one side of the dish. After a comparatively short time the zoospores produced will be found congregated around the meat (chemotaxis).

177. Turgor Movements. Many plant organs change their position or become curved by the change in turgor of the cells on one or both sides of the organ. Thus at the base of the petiole of the leaf of the sensitive plant (Mimosa pudica) there is a strongly developed mass of thin-walled cells, the pulvinus. When the cells on the lower side are turgid the leaf is held out horizontally or inclined upward. In response to various stimuli these cells suddenly allow their water to escape into the intercellular spaces, thus losing their turgor and contracting considerably. Apparently the cells on the upper side of the pulvinus take up this water very quickly, thus becoming turgid in their turn. This process takes place very rapidly and results in a quick downward bending of the leaves. It is by a similar arrangement that the two halves of the leaf of the Venus fly-trap (Dionaea muscipula) snap together quickly enough to catch insects lighting upon them, or that in the case of the sundew (Drosera), when an insect is caught by the sticky mass on one of the so-called tentacles, the adjacent ones bend over until they too touch the unfortunate victim and the whole leaf gradually closes in on it. The movement of the stamens in the flower of barberry (Berberis) is also due to turgor changes as are 
the constant movements of the lateral leaflets of the leaves of the telegraph plant (Desmdoium gyrans).

178. Some turgor movements are so-called autonomous movements; i.e. they seem to be due to internal causes and not caused by external stimuli. Such seems to be the case in the movements of the leaflets of Desmodium referred to above. The leaflets of red clover (Trifolium pratense) show a similar rising and falling, but instead of requiring only a few seconds as is the case with Desmodium, require several hours. It is possible that these so-called autonomous movements are due to external stimuli which have not yet been recognized.

179. Most turgor movements are in response to some recognized stimulus. Whereas the hygroscopic movements are the direct physical result of the increased or decreased moisture in the surrounding air, the movements in response to a stimulus are not the direct physical effects of the energy exerted by the stimulus but are due to energy stored up in the tissues which is released by the stimulus as the energy of the gunpowder is released by the chain of events between the pulling of the trigger and the discharge of the gun. As the strength with which the trigger is pulled has no influence upon the energy applied to the bullet, so the intensity of the stimulus has no direct effect upon the vigor of the movement resulting from it (except in so far as a more vigorous stimulus may reach more cells and so release more energy in that way).

180. The most frequent stimuli for turgor movements are variations in temperature and light. Examples of this are the so-called sleep movements of leaves of clover, Oxalis, Mimosa, etc., and probably all leaves that have a pulvinus at the base of the leaflets or of the petiole. On the other hand the sudden movements of the stamens 
of barberry, the rapid closing of the leaf halves of Dionaca, the closing of the leaflets and dropping downward of the leaves of Mimosa are responses to the stimulus of contact. In the case of the sundew the movement of the tentacles may take place both in response to contact or to the presence of eertain chemicals such as ammonium sulphate, proteins, etc. It is worthy of note that the stimulus may be applied at a distance even of several centimeters from the point where the ehange in turgor occurs, i.e. the plant tissues are able to transmit a stimulus for a considerable distance. None of these movements will take place except under the proper degrees of temperature, moisture, etc.

Laboratory Studies. (a) Observe a plant of Desmodium gyrans at a temperature of between $20^{\circ}$ and $30^{\circ} \mathrm{C}$. The rapidity of the rotation of the leaflets will be found to vary with the temperature, degree of illumination and other factors.

(b) Observe clover and Oxalis leaves by night and by day. Compare also the leaves of Mimosa, Robinia, etc., in light and darkness.

(c) Touch one of the three bristles on the surface of a leaf half of Venus fly-trap (Dionaea). Note the sudden closing of the leaf. The temperature and humidity must be rather high or it will not respond well.

(d) Touch a leaf of a sensitive plant (Mimosa pudica) at the under side of the pulvinus. Touch or slightly pinch other leaves of the same plant at various points. Apply the flame of a match to the end of one of the leaflets. Note in this case the progressive closing of the leaflets followed by the dropping of the whole leaf and in many cases of the nearest leaves above and below.

(e) Place a grain of sand on the tip of a tentacle of a leaf of sundew (Drosera). Note the degree of movement in the surrounding tentacles. On a tentacle on another leaf place a tiny piece of meat or a very small crystal of ammonium sulphate and note the movements of the adjacent tentacles.

181. Growth Movements. Many plant movements are the result of unequal growth on opposite sicles of an 
organ. Here again can be distinguished autonomous movements whose stimuli if external are not recognized and paratonic movements in response to recognized stimuli.

182. Probably the most widely prevalent autonomous growth movement is that called nutation. If a firm long bristle be fastened to the tip of a growing stem or root tip and its end be observed under a microscope or in some cases with the unaided eye it will be found to describe a very irregular somewhat circular figure. This is really a low spiral for the tip is advancing at the same time that it rotates. This is the form of nutation that is frequently called circumnutation. This movement is due to the fact that the zone of most rapid growth is not equal on all sides but growth takes place more rapidly at one side, this region of most rapid growth passing around the stem and slowly advancing so that it remains at a constant distance from the tip. The tip is then bent a little away from the side

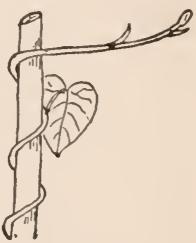

FIG. 53.-Circumnutation (Ipomoea). where the most rapid growth is occurring, hence its nutation. The opening of buds is due to greater growth on the upper than on the lower side of the leaf bases. This may be followed by the reverse and so on until finally a state of balance is reached. This is another form of nutation. The rotation of free horizontal ends of twining plants is often, perhaps not with correctness, regarded as a type of nutation. When such a rotating shoot strikes a vertical support it keeps on rotating and thus winds around the support while at the same time its negatively geotropic response (see paragraph 186) is sufficient to cause the stem to ascend spirally. Most plants rotate in a direction opposite to that of the hands of a watch when 
seen from above, but a few plants rotate in the opposite direction. Some botanists regard the whole rotary movement of such plants not as a form of nutation but as a special form of geotropic response.

183. Those growth movements due to the response to recognized stimuli are often divided into tropic movements where the organ affected is brought to lie with its axis in some definite relation to the direction of the stimulus, and nastic movements where one or the other face of a bifacial organ is placed in some relation to the direction of the stimulus. However, in view of the fact that the general phenomena concerned are the same, they need not be sharply separated here.

184. The chief tropic movements of plants are phototropism, geotropism, thigmotropism, chemotropism, being responses respectively to the stimulus of light, gravity, contact and chemical substances. Other tropisms have been distinguished but will not be discussed here. For all tropisms the point of curvature is the region where the most rapid growth usually occurs. As the result of the stimulus the growth is increased above the normal rate on one side and sometimes even retarded below the normal on the other with the result that a curvature is produced. The perceptive region for the stimulus may be distant some millimeters or even centimeters from the zone of growth.

185. Phototropism may be illustrated by the action of a plant illuminated on one side only. Usually the stem of such a plant curves toward the source of light (positive phototropism) while the leaves place themselves so as to stand with their surfaces at right angles to the source of the light (photonasty). Sometimes the curvature is away from the light as is the case with most roots and with the stems of some climbing plants, e.g. 
ivy (Hedera helix). This is negative phototropism. Too great intensity of light may cause a positively phototropic organ to become negatively phototropic. A very small amount of light scarcely perceptible to the human eye is sufficient to induce phototropic curvature in some plants. The effective rays of light are those of the blue and violet portion of the spectrum. The perceptive region may be some distance from the region of curvature. Thus in the seedlings of oats the tip of the first leaf is the perceptive region while the curvature takes place at a point near the ground.

186. Geotropism. If a seedling that usually grows upright be placed in a horizontal position for a few hours the tip of the stem will be found to be curved so as to be directed upward, while the tip of the root will have assumed a position directed downward, the remainder of the stem and roots being horizontal. If the root tip and stem tip have been previously marked with cross lines at equal distances it will be found that the curvature begins and is carried out by those regions of stem and root respectively where the growth is usually most rapid and the curvature has taken place by the more rapid growth on one side than on the other. The main root, then, is positively geotropic and the stem negatively so.

187. If the plant has been allowed to grow until horizontal lateral roots have been produced and then is placed with the main stem horizontal it will be found that not only does the main stem curve upward and the main root downward, but that the lateral roots, which are now of course some of them directed upward and some downward, will curve so as to occupy a horizontal position again. Thus it is apparent that some stimulus causes certain plant parts to grow toward, other parts away from and still others parallel to the surface of the earth. Care- 
ful experiments have shown that it is with reference to the direction of the force of gravity that these different plant parts orient themselves.

188. Experiments have shown that by attaching plants to a rapidly whirling wheel the centrifugal force has the same effect as gravity and stimulates the main root growth away from the center of the wheel, while the growth of the main stem becomes directed toward the center and that of the lateral roots at right angles to the radius. On the other hand, if the wheel to which a plant is attached be rotated very slowly with its axis horizontal so that all sides of the plant are successively exposed to the stimulus of gravity, the rotation being so slow that the centrifugal force is negligible, the different parts of the plant continue to grow in any direction they may have happened to start. It is thus apparent that the general form of the plant is largely controlled by the stimulus of gravity as well as by the stimulus of light.

189. The zone of curvature is that of most rapid growth. The perceptive region may, however, be distant some millimeters. Thus in the root it has been shown that the root cap is the region of greatest perception. It has been suggested that the cells there containing starch grains are the perceptive cells, the different position in the cell assumed by these starch grains in response to gravity as the root is pointed in various directions furnishing the stimulus which is communicated from cell to cell to the growing zone. Here certain cells on one side are stimulated to grow more rapidly than those on the opposite side until the root has assumed its proper position, when the starch grains (statoliths) will resume their normal position in the perceptive cells. The similar starch-bearing cells in the perceptive regions 
of stems have also been supposed to be such "statocysts."

190. Thigmotropism. If a tendril be touched on one side by some uneven object (not by a smooth object like a very smooth rod or a drop of water or mercury), it begins to curve very soon in the direction of that object. At the very first this curvature, which may become apparent within a few seconds, is undoubtedly due to changes in turgor on the two sides of the tendril, but in only a short time rapid growth sets in on the outside, and the tendril winds around the object. Soon thereafter the part of the tendril between the stem and the object also begins to coil in a double spiral, this also being due to unequal growth. Thigmotropism, as this phenomenon is called, is exhibited by tendrils and by other parts of plants that assume this function, such as the leaf stalk of Clematis, peduncles of some plants, and whole shoots, especially modified for this purpose, of other plants. Special papilla-like cells have been regarded by some botanists as the organs of perception. The curvature of roots toward or away from points of injury is possibly to be considered as a special form of thigmotropism. It is often called traumatropism.

191. Chemotropism. The hyphae (filaments of cells) of many fungi and the pollen tubes of seed plants show a peculiar growth response to the stimulus of various chemical substances. Thus, many pollen grains placed on a piece of moist filter paper will produce tubes growing in any direction, but if a small crystal of cane sugar be placed on the paper, some kinds of pollen tubes will change their direction of growth and turn directly toward it. Fungus hyphae show similar changes in direction of growth when they perceive various substances in solution. In both cases certain substances induce positive and others negative chemotropism. 
Of the same general class of phenomena is the so-called hydrotropism, in which roots grow away from the dry and toward the moister air.

192. In all these tropisms the stimulus must be of a certain strength, or it is not perceived. Even if strong enough to be perceived, the stimulus must act for a certain length of time before the plant has been sufficiently affected to bring about a reaction. The stronger the stimulus (up to a certain point), the shorter the time that is necessary for it to act. The reaction to the stimulus may be almost immediate, or it may not show itself for some time. In fact, the stimulus may have ceased to act upon the plant for some little time before the plant shows any response. Thus a root may be placed in a horizontal position for fifteen to twenty minutes and then restored to its normal vertical position. After a little while the root will begin to curve and will attain quite a marked curvature until the stimulus then produced by the resulting abnormal position induces the root to curve back again. In this case it usually swings too far in the other direction, and does not finally attain its normal position until it has made several such swings. Similar results can be obtained with phototropism.

193. Among the nastic movements are the opening and closing of flowers, in response to changes in temperature or illumination. These are accomplished by increased growth at the base of the petals and sepals on the inner or outer sides respectively. A change of temperature of only one or two degrees is sufficient in the case of the tulip to stimulate the flower to open or close, as the case may be. Many plants, as long as their leaves are still capable of growth, show so-called sleep movements, which are not, like those of the clover (see paragraph 180), due to changes in turgor, but to more rapid 
growth on one or the other side of the base of the petiole. Such responses to changes in light and temperature cease when the leaves have attained full growth, while those due to turgor changes in the leaves that have pulvini persist.

Laboratory Studies. (a) Fix a slender filament of glass or a stiff bristle to the rapidly growing end of a shoot of Fuchsia, geranium (Pelargonium), or verbena, using a drop of thick shellac glue. Support a plate of glass in a horizontal position, just above the tip of the pointer, and record, by making ink dots on the glass, the position of the pointer at definite intervals of time, say every ten minutes. A microscope may be focused upon the tip of the pointer and the movement observed in this way. In this and similar experiments the illumination should be as nearly equal as possible on all sides.

(b) In a similar manner, the nutatory movements of a leuf may be observed by fastening a pointer to its tip, and observing it with a horizontal microscope or by recording the position of the pointer at successive intervals on a vertical glass plate.

(c) Nutation can be demonstrated also in the long stout roots from seedlings of beans, peas, ete. These should be placed so as to point directly downward, so as to avoid geotropic curvature. The movement can be observed by placing a mirror at an angle of 45 degrees under the tip, and focusing a horizontal microscope on the tip as reflected in the mirror.

(d) Observe the rotatory movements of the horizontally bent end of a shoot of morning-glory (Ipomoea) or hop (Humulus). Note the time required to make a complete revolution. The stem also must twist one whole revolution for every turn the tip makes. Place an upright stake in the way of the shoot, and note how the climbing takes place.

(e) Germinate a mustard or sunflower seed in the dark, and after the cotyledons have escaped from the seed coat, place the seedling in a hole in a cork, so that the root projects below and the cotyledons above. Put the $\underset{(e)}{\operatorname{tro}}$

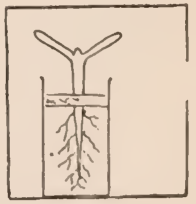

Fig. 54.-Phototropism experiment cork in a bottle so that the tip of the root dips into water, or better still, into a nutrient solution (see 
laboratory study (b) after paragraph 146). Keep in the dark until the stem and roots are both in a vertical position. Place in a box, closed on all sides, except for an opening about 10 $\mathrm{mm}$. wide at one side, and direct this opening toward a window. Note the direction of curvature of stem and roots, as well as the region where the curvature occurs.

(f) Perform experiments similar to the foregoing, placing orange-red glass or deep blue glass in front of the opening, and note the results.

(g) Sterilize some fresh horse manure in a steam sterilizer to destroy all the fungi, and inoculate with the manure mold, Pilobolus. When the sporangia of this are about to be formed, place the dish containing the culture, uncovered, in a dark box, tilting the dish at an angle of 45 degrees toward one side, where a small window about $2.5 \mathrm{~cm}$. in diameter is left open to admit light, but covered on the inside with a glass plate. Place the box in such a position that the light can enter the window. The sporangia will direct themselves toward the light and discharge their spore masses, which will stick to the glass covering the window. Only a few shots will fail to hit the "bull's eye" if the distance from the dish of the fungus to the window is not more than 10 to $20 \mathrm{~cm}$., although these are discharged with considerable accuracy much further than that. Try the effect of different colored glass on the accuracy of the aim.

(h) Germinate a number of seeds of broom-corn millet or proso (Panicum

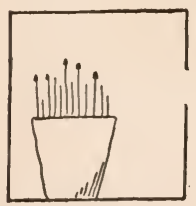

FIg. 55.-Phototropism experiment $(h)$.

( miliaceum) in the dark, in a pot of earth. When they have attained a length of 1 to $2 \mathrm{~cm}$., cap the tips of half of the seedlings with little caps of tinfoil, made over the point of a pencil, and then gently slipped over the tip of the seedling and pinched in place. Set the pot in the box used for experiment (e), and note the result. Almost as good results can be obtained by using oats.

(i) Germinate seeds of bean, sunflower, mustard, etc. After the seedlings show well-developed cotyledons, fasten several of them by their middles in a horizontal position, under a bell-jar over water, so as to keep the air moist and prevent the seeds from drying out. Keep in a dark place for a few hours and note the results. 
(j) Grow a bean seedling in water culture until some of the horizontal roots have developed a little way. Then place the main root horizontally as in (i). Note the effeet on the main and lateral roots and stem.

(k) Plant seeds of Indian corn or beans 1 or 2 $\mathrm{em}$. beneath the surface of the soil, in a completely filled flower pot. Fasten a coarse wire netting over the top of the pot, and invert it, putting it on an iron tripod, standing in a plate of water, and place a bell jar over the whole, to keep the air moist. After a few days the roots will emerge from the soil into the air in response to the stimulus of gravity, while the ism experistems grow on up into the soil.

(l) Place a flower pot with a growing plant in a horizontal position. At the same time place another one with a similar plant horizontally in a klinostat, so that it rotates slowly with the axis of rotation horizontal. Keep both in a dark room twenty-four hours during the process, and then compare the plants. (A klinostat is an apparatus worked by clock-work, which rotates a flower pot fastened to it at a

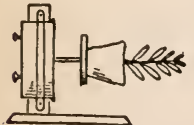

Fia. 57.-Geotropism experiment $(l)$. slow rate, being arranged so that the axis of rotation may be in any direction desired. A simple klinostat can be made by removing the longer hand of a elock and fastening to the pinion a stiff horizontal wire, supported, if need be, at the other end. At the middle of the wire may be placed a large cork, to which seedlings can be attached. With a small clock it is impossible to use a flower-pot, as it is too heavy, and so instead the seedlings will be fastened to the edge of the eork, and since they are exposed to the stimulus of gravity from successively different directions, they will show no geotropic curvature. In homemade apparatus of this kind the portion including the cork with the attached plants ought to be so enclosed that the plants will not dry out.)

( $m$ ) Place seedlings at the edge of a horizontal wheel that can be rotated very rapidly (centrifugal apparatus). When the centrifugal force much exceeds the force of gravity, the roots will grow almost directly outward and the stems almost directly inward. If both are equal, the roots will be directed downward and outward at an angle of 45 degrees, and the stem upward 
and inward at the same angle. If the wheel is rotated in a vertical plane, the effect of gravity is entirely eliminated, for it acts on all sides in succession, and it is only the centrifugal force that comes into play. (Such an apparatus with the whecl rotating in the vertical plane can be con-

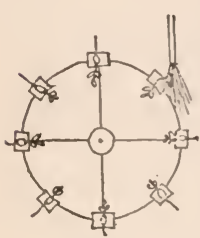

Fig. 58.--Geotropism experiment $(m)$. structed by using a stout knitting needle for an axis, the bearings being little cups of glass made by sealing and cutting off short the end of a glass tube. These are inserted into corks, fastened to two upright supports. At the center of the knitting needle is placed a large cork with short knitting needles radiating in four directions in a plane at right angles to the main axle. The ends of these hold corks, which are connected to each other by a wire, which forms the circumference of the wheel. On this wire are strung a number of small cork disks. A stream of water is directed at these disks, and causes the wheel to rotate at a high speed. Scedlings to be experimented with are pinned firmly to the cork disks.)

(n) Make a thin section of a root cap of a growing root, stain with iodine to make the starch grains more easily visible, The cells containing them are supposed by some botanists to be the perceptive cells for gravity (statocysts).

(o) On a vigorous plant of cucumber or squash or pea, make the following experiment with the tendrils. Place a very smooth glass rod in contact with one tendril, and a rough stick of the same diameter in contact with another equally developed one. Note the time in each case before the first curvature is noticeable and until the tendril has made one complete turn around the object. Note when the formation of the coils between the object and point of attachment of the tendril first begins, and observe how a twisting of the tendril is avoided as these coils develop.

$(p)$ Wet a piece of filter paper with Sachs' culture solution and sow on it fresh pollen grains of various kinds, keeping the different kinds on different parts of the paper, but all at about the same distance from the center. Cover to prevent evaporation. After a few hours, examine and if germination has occurred, place a small crystal of cane sugar at the center. Examine every two or three hours, and note when and where 
and for what kind of pollen chemotropism first becomes apparent. The experiment ean be varied by placing the stigmas of one of the flowers at the center instead of the erystal of sugar. It will attract some of the kinds of pollen tubes and have no effect on others. (The pollen grains and their germination can be observed much more easily if, in place of the filter paper, the following be used: To a measured quantity of boiling eulture solution, sift in with constant stirring enough agar powder to make a 2 per cent. solution. When thoroughly dissolved, pour it into petri dishes and cover, and allow to cool. On the jellylike mass thus produced the germination of pollen grains can be observed very easily.)

(q) In the spring bring into the laboratory buds of tulip or crocus, just about to open. In the warmer air they will soon open by increased growth on the inner surface of the bases of the petals and sepals. When fully opened, place in an ice-box or out-of-dloors on the window ledge, and very soon increased growth on the outside will cause them to close.

$(r)$ Observe growing plants of sunflower (Helianthus), lamb's quarters (Chenopodium), ete., by day and by night, and notice the different leaf positions assumed by the younger leaves. The fully developed leaves will show little or no change of position.

194. Pathology is the study of the abnormal development and functioning of a plant. It is in its widest aspect abnormal physiology. As usually studied, however, it is the determination of the cause of and means of prevention of certain plant diseases. Since most plant diseases that have been studied are caused by fungi, pathology as taught is often but a study of mycology, in which parasitic fungi alone are considered. These views of pathology are in reality only partial views, and do not take the real scope of the subject into consicleration.

195. Since abnormal functioning often leads to abnormal structural development it is necessary to study not only the abnormal functioning of a plant but also the abnormal struetures produced by the diseased conditions. Thus we can distinguish cases in which cells or tissues do 
not reach their full size or number (hy poplasy), or in which individual cells or whole tissues are enlarged above the normal size (hypertrophy), or in which the cells are abnormally increased in number (hyperplasy). In some cases cells destined to produce one kind of tissue are changed into other kinds by the pathological conditions. Furthermore, the internal structures of the cell may be modified. The chloroplasts may be increased in number and size or diminished or apparently wholly suppressed. The nucleus may be enlarged and changed in shape or caused to divide abnormally so that multinucleate cells result. The contents of the cells are often modified; acids may be increased or diminished; the tannin content may increase remarkably in some cases as also that of various coloring matters or of various enzymes.

196. These changes are in some cases the results of causes not as yet recognizable. Such troubles are spoken of as "Physiological Diseases," this being simply a name to cloak our ignorance of the true cause of the trouble. In many cases, however, the changes occur as a result of the action of parasitic organisms, either plant or animal in nature. In the case of many injuries caused by animals (e.g. biting insects) the injury is chiefly mechanical and is a subject for study from the standpoint of pathology in just the same way as the study of wounds caused by other agencies. But the punctures of some insects (e.g. plant lice, aphids) are followed by marked physiological disturbances in the cells immediately or even remotely adjacent to the punctures, leading to the type of disease called stigmonose (or puncture disease). The enormously varied structures found in insect galls as a result of the presence or punctures of various gall-producing insects, if properly understood, would doubtless throw a flood of light upon the subject of pathology and even physiology. 
In all these cases it is not the parasite but its effect upon the host that should be the subject of pathological investigation by the botanist. It must be remembered that merely to learn the name of the organism causing the pathological change in a plant is not to study pathology. It is the investigation of the actual physiological and structural changes in the diseased tissues that deserves that name.

197. By far the greater number of plant diseases hitherto investigated are those caused by parasitic plants (bacteria, fungi and flowering plants). As in the case of injury by animal parasites the effects are very varied. Thus with some parasites the injury consists of perhaps hardly more than the withdrawal of food stuffs or water from the tissues of the host. Usually, however, the case is not so simple. There is almost always some mechanical disturbance as, for example, the destruction of the middle lamella to permit the intercellular growth of a fungus hypha or perhaps the actual crushing of some of the cells of the host by the roots of some of the parasitic flowering plants. A few parasites kill the cells some distance in advance of their progress by the secretion of poisons of various kinds (as is the case with Sclerotinia libertiana), feeding then upon the more or less disorganized remains of the dead cells. In other cases, however, the parasite does not kill the host cells outright but sends little branches (haustoria) into them through which the food matters are gradually absorbed, the death of the cell perhaps being delayed for a long period during which it is constantly furnishing food to its parasite. Sometimes the diseased tissues become enlarged and richly stored with food (various fungus galls, e.g. peach leaf curl due to Exoascus deformans) which may then be used by the fungus. 
198. Death of the diseased plant or tissues may be very (arly or maly actually be postponed beyond the normal time, the fungus continuing to live in the living infected tissues after the surrounding tissues are dead. In most cases, however, the presence of the parasite so weakens the host that part of it or even the whole plant dies. The death may result from various causes. Thus a disease involving the tissues of the roots may so interfere with the absorption of water that the top of the plant dies under symptoms of wilting. It is sometimes hard to tell, however, whether the wilting is really due to reduced water supply from the roots or to poisons secreted by or whose secretion is induced by the fungus so that the cells of the top are poisoned and lose their turgor, i.e. wilt. Or again, the leaf tissues may be so destroyed by the invasion of a fungus that photosynthesis is not sufficient and the plant is weakened and dies. In some cases the mechanical rupture of the host tissues by the reproductive bodies of the parasites leads to the destructive loss of water through the wounds thus formed. This is probably why the black stem rust of grains (Puccinia graminis) is so destructive.

199. External meteorological conditions often result in harmful conditions in the plant. Thus low temperature, even when the freezing point is not approached, may so check certain functions that a plant remains dwarfed or pale (as in Indian corn in a cold spring). Excessive heat and atmospheric dryness may cause so much water loss that the plant actually dries out and dies. But asicle from these cases must be noted the diseased conditions resulting from harmful substances in the air. Thus in the vicinity of manufacturing cities some trees cannot exist, owing to the sulphur dioxide given out in the smoke and which gradually poisons some of the nutritive cells 
of the leaves. Some of the constituents of illuminating gases in the air or in the soil are frequent sources of injury and death of plants.

200. The question of the relative susceptibility of plants to attack by parasites is also comprehended in the term pathology. As yet it is not clear why certain plants are nearly immune and other plants of the same species are very susceptible to a certain disease. Apparently the difference is due partly to differences in structure and partly (perhaps chiefly) to slight differences in the chemical composition of the protoplasm or cell sap. The question of induced immunity, the effect of changed external conditions upon susceptibility to injury, etc., are very important fields of study that are as yet almost uninvaded.

201. The study of a plant disease would require then that the student determine the answers to the following questions, and perhaps others as well: (1) What are the pathological symptoms, both structural and physiological? (2) Is the disease caused by a parasite?

(3) If not caused by a parasite, what is the cause?

(4) If caused by a parasite, what is its life history, particular attention being given to the time and mode of entry into the host, method of propagation, over-wintering, etc.? (5) What are the external conditions, meteorological or cultural, that favor or check the spread of the disease?

(6) What differences in susceptibility to the disease are found in different individuals or strains of the host? (7) What is the history of the disease, its distribution, loss caused by it, etc.?

In view of the foregoing, how can the disease best be controlled?

Laboratory Studies. It is impossible for a student in this stage of training to undertake laboratory or field studies of any plant diseases. It may not be amiss, however, to have him 
collect and examine as many different types of plant diseases as he ean find, for the mere ability to recognize diseased conditions is of great value.

\section{REFERENCE BOOKS}

C. R. Barnes, Physiology (in Text-book of Botany by Coulter, Barnes \& Cowles), Chieago, 1910.

L. Jost, Lectures on Plant Physiology (Engl. Ed., Oxford, 1909).

W. Pfeffer, The Physiology of Plants (Engl. Ed., Oxford, 19001906).

B. M. Duggar, Plant Physiology, 1911, New York.

R. J. Pool, Suggestions for Experiments in Plant Physiology, 1914, Lincoln.

For the chemical aspects of this chapter and especially for the following ehapter the following books are useful.

HaAS AND Hill, Introduction to the chemistry of Plant Products 1913, New York.

F. Czapek, Biochemie der Pfanzen, 1913, Jena. 


\section{CHAPTER V}

\section{THE CHEMISTRY OF THE PLANT}

In these paragraphs are brought together the commoner plant constituents and products, giving the name, chemical formula and occurrence of each, so far as these are known.

Substance and Formula

Water

$\mathrm{H}_{2} \mathrm{O}$

Inorganic Acids and Salts

Sulphuric

$\mathrm{H}_{2} \mathrm{SO}_{4}$

Nitric

$\mathrm{HNO}_{3}$

Hydrochloric

$\mathrm{HCl}$

Phosphoric

$\mathrm{H}_{3} \mathrm{PO}_{4}$ (and other forms)

\section{Occurrence}

In all parts of the plant; the chief solvent.

These acids are present almost exclusively as the neutral or acid salts of various metals, especially $\mathrm{Ca}, \mathrm{K}, \mathrm{Na}$ and $\mathrm{Mg}$. They are largely absorbed by the plant from the surrounding water in the forms in which they are present in the plant, or a shifting of the bases occurs after their absorption.

Chiefly as the Ca salt in some crystals.

As various salts in the cell sap.

Chiefly as $\mathrm{K}$ or Na salts in the cell sap of plants, especially those of salty soil, or in marine algae.

In the cell sap as $\mathrm{Ca}, \mathrm{Na}$ or $\mathrm{K}$ salts. 
Carbonic

$\mathrm{H}_{2} \mathrm{CO}_{3}$

Silicic (of various forms) $\mathrm{Si}(\mathrm{OH})_{4}$, ete.

Organic Acids.

Formic

Acetic

$\mathrm{C}_{2} \mathrm{H}_{4} \mathrm{O}_{2},\left(\mathrm{CH}_{3} \mathrm{COOH}\right)$
$\mathrm{CH}_{2} \mathrm{O}_{2},(\mathrm{HCOOH})$

As $\mathrm{CaCO}_{3}$ in eystoliths of Ficus, and as deposits in or upon the cell walls of many algae and fungi.

These are absorbed in the $\mathrm{K}$, $\mathrm{Na}$ and $\mathrm{Al}$ salts and are sometimes deposited in undetermined composition in cell walls, e.g. diatoms, scouring rushes (Equisetum), etc.

These occur in all parts of the plant, either free or as esters or as salts of metallic bases. They are present as reserve food, as waste products, as substances to increase the osmotic pressure, to increase acidity, etc.

As free acid in stinging hairs of nettles, in some fruits, etc., and sometimes as salts of various metals.

As salts of various metals in the cell sap. Formed as free acid by the fermentation of ethyl alcohol by various bacteria. Produced in dry distillation of wood.

Butyric (normal) As esters in various Apiaceae.

$\mathrm{C}_{4} \mathrm{H}_{8} \mathrm{O}_{2},\left(\mathrm{CH}_{3}-\mathrm{CH}_{2}-\mathrm{CH}_{2}-\right.$ $\mathrm{COOH})$.

Isobutyric

$\mathrm{C}_{4} \mathrm{H}_{8} \mathrm{O}_{2}$,

Free in fruit of St. John's $\left\{\begin{array}{c}\mathrm{CH}_{3} \\ \mathrm{CH}_{3}\end{array} \mathrm{CH}-\mathrm{COOH}\right)$ in various other plants.

Palmitic, Stearic and Oleic (see below under fats).

Gilycollic

In unripe fruits and leaves of $\mathrm{C}_{2} \mathrm{H}_{4} \mathrm{O}_{3},\left(\mathrm{CH}_{2}(\mathrm{OH})-\mathrm{COOH}\right)$ the grape. 
Lactic

$\mathrm{C}_{3} \mathrm{H}_{6} \mathrm{O}_{3}\left(\mathrm{CH}_{3}-\mathrm{CH}(\mathrm{OH})-\right.$ $\mathrm{COOH})$

Oxalic

$\mathrm{C}_{2} \mathrm{H}_{2} \mathrm{O}_{4}(\mathrm{COOH}-\mathrm{COOH})$

Formed by the bacterial fermentation of milk sugar (lactose), also by bacterial fermentation in sauer kraut and ensilage.

Free or as acid or neutral salts of $\mathrm{Ca}, \mathrm{K}$ or $\mathrm{Na}$ in Oxalis, Rumex, Rheum, etc. Very abundant as $\mathrm{Ca}$ salt in the form of crystals.

Succinie

In green grapes, and in $\mathrm{C}_{4} \mathrm{H}_{6} \mathrm{O}_{4}\left(\mathrm{COOH}-\mathrm{CH}_{2}-\mathrm{CH}_{2}\right.$ various Papaveraceae and $\mathrm{As-}$ $-\mathrm{COOH})$

Dextro-tartaric terales.

Free and as acid salt of $\mathrm{K}$ in $\mathrm{C}_{4} \mathrm{H}_{6} \mathrm{O}_{6}(\mathrm{COOH}-\mathrm{CH}(\mathrm{OH})$ - fruit of grapes and in other $\mathrm{CH}(\mathrm{OH})-\mathrm{COOH})$

Malic $\mathrm{C}_{4} \mathrm{H}_{6} \mathrm{O}_{5}\left(\mathrm{COOH}-\mathrm{CH}_{2}-\mathrm{CH}-\right.$ $(\mathrm{OH})-\mathrm{COOH})$

Citric

$\mathrm{C}_{6} \mathrm{H}_{8} \mathrm{O}_{7}\left(\mathrm{CH}_{2}(\mathrm{COOH})-\mathrm{C}\right.$ $\left.(\mathrm{OH})(\mathrm{COOH})-\mathrm{CH}_{2}(\mathrm{COOH})\right)$ berry, ete.

\section{Benzoic}

$\mathrm{C}_{7} \mathrm{H}_{6} \mathrm{O}_{2}\left(\mathrm{C}_{6} \mathrm{H}_{5}(\mathrm{COOH})\right)$

Salicylic

$\mathrm{C}_{7} \mathrm{H}_{6} \mathrm{O}_{3}\left(\mathrm{C}_{6} \mathrm{H}_{4}(\mathrm{OH})(\mathrm{COOH})\right)$

Gallic

$\mathrm{C}_{7} \mathrm{H}_{6} \mathrm{O}_{5}\left(\mathrm{C}_{6} \mathrm{H}_{2}(\mathrm{OH})_{3}(\mathrm{COOH})\right)$

Gallotannic (tannin)

$\mathrm{C}_{14} \mathrm{H}_{10} \mathrm{O}_{9}$ (= two molecules of plants; the chief tanning subgallie acid united, less $\mathrm{H}_{2} \mathrm{O}$ ) stance.

Alcohols.

Methyl

$\mathrm{CH}_{4} \mathrm{O}\left(\mathrm{CH}_{3}(\mathrm{OH})\right)$

Ethyl

$\mathrm{C}_{2} \mathrm{H}_{6} \mathrm{O}\left(\mathrm{CH}_{3}-\mathrm{CH}_{2}(\mathrm{OH})\right)$ fruits.

Very widely distributed as free acid in fruits, e.g. apple, barberry, grape; in leaves of Crassulaceae, etc.

Free in fruits of Citrus (orange, lemon, etc.), gooseIn fruit of cranberry and in various gums.

In flowers of Ulmaria and as

an ester in Wintergreen.

In insect galls, tea, etc.

In great abundance in many

As an ester in some fruits; produced by dry distillation of wood.

Produced in the anaerobic stage of respiration of glucose. The chief product (together with $\mathrm{CO}_{2}$ ) of fermentation of glucose by yeasts. 
Higher Alcohols.

Normal propyl

These are grouped under the name "fusel oil" and are produced in small quantities during the fermentation processes that lead to the production of ethyl alcohol. The commonest are the following.

$\mathrm{C}_{3} \mathrm{H}_{8} \mathrm{O},\left(\mathrm{CH}_{3}-\mathrm{CH}_{2}-\mathrm{CH}_{2}-\right.$ $(\mathrm{OH}))$

Normal butyl

$\mathrm{C}_{4} \mathrm{H}_{10} \mathrm{O},\left(\mathrm{CH}_{3}-\mathrm{CH}_{2}-\mathrm{CH}_{2}-\right.$

$\mathrm{CH}_{2}(\mathrm{OH})$ )

Isobutyl

$\mathrm{C}_{4} \mathrm{H}_{10} \mathrm{O}$,<smiles>CC(C)CO</smiles>

Isobutyl carbinol

Also found in Roman camo$\left.\mathrm{C}_{5} \mathrm{H}_{12} \mathrm{O},\left\{\begin{array}{l}\mathrm{CH}_{3} \\ \mathrm{CH}_{3}\end{array}\right\rangle \mathrm{CH}-\mathrm{CH}_{2}-\mathrm{CH}_{2}(\mathrm{OH})\right)$

Glycerine

See under fats, below.

$\mathrm{C}_{3} \mathrm{H}_{8} \mathrm{O}_{3},\left(\mathrm{CH}_{2}(\mathrm{OH})-\mathrm{CH}-\right.$

$\left.(\mathrm{OH})-\mathrm{CH}_{2}(\mathrm{OH})\right)$

Mannite

$\mathrm{C}_{6} \mathrm{H}_{14} \mathrm{O}_{6},\left(\mathrm{CH}_{2}(\mathrm{OH})-\mathrm{CH}-\right.$

In leaves of lilac and celery, $(\mathrm{OH})-\mathrm{CH}(\mathrm{OH})-\mathrm{CH}(\mathrm{OH})$ $\left.-\mathrm{CH}(\mathrm{OH})-\mathrm{CH}_{2} \mathrm{OH}\right)$ in sugar cane, especially in the manna ash (Fraxinus ornus) and in many fungi.

Dulcite (formula as for man- In Euonymus, Melampyrum, nite). etc.

Sorbite (formula as for mannite) In service berries.

Perseite

$\mathrm{C}_{7} \mathrm{H}_{16} \mathrm{O}_{7},\left(\mathrm{CH}_{2} \mathrm{OH}\right)-(\mathrm{CH}-$ $\left.(\mathrm{OH}))_{5}-\mathrm{CH}_{2}(\mathrm{OH})\right)$

Fats and Fatty Oils.

In seeds of the avocado, (Persea gratissima).

These are distinguished readily from the so-called ethereal or aromatic oils in that the former leave grease spots on paper while the spots formed by the latter disappear on evaporation. The chief fats and fatty oils are esters of the 
Fats and Fatty Oils.-Con.

alcohol glycerine and various fatty acids. They are mostly liquid (i.e. oils) in plants but in some tropical plants are solid at ordinary temperatures. Usually they are mixtures of several fats, the three most common ones being the same as the commonest animal fats, viz.: the first three named below. Upon the proportions of the three depends whether the fat will be solid or liquid. The acids coneerned are:

Palmitic acid

$\mathrm{C}_{16} \mathrm{H}_{32} \mathrm{O}_{2},\left(\mathrm{C}_{15} \mathrm{H}_{31}-\mathrm{COOH}\right)$

Stearic acid

$\mathrm{C}_{18} \mathrm{H}_{36} \mathrm{O}_{2},\left(\mathrm{C}_{17} \mathrm{H}_{35}-\mathrm{COOH}\right)$

Oleic acid

$\mathrm{C}_{18} \mathrm{H}_{34} \mathrm{O}_{2},\left(\mathrm{C}_{17} \mathrm{H}_{33}-\mathrm{COOH}\right)$

Ricinoleie acid

$\mathrm{C}_{18} \mathrm{H}_{34} \mathrm{O}_{3}$

Linoleic acid

$\mathrm{C}_{18} \mathrm{H}_{32} \mathrm{O}_{2}$

Crotonic acids

$\mathrm{C}_{4} \mathrm{H}_{6} \mathrm{O}_{2}$

Aromatic Oils and Camphors.
Forming with glyeerine a solid fat, palmitin.

Forming with glycerine a solid fat, stearin.

Forming with glyeerine a liquid oil, olein.

Forming with glycerine a liquid oil (castor oil).

Forming with glyeerine a liquid oil (in linseed oil).

Of which several isomeres are known, are found in their glycerine esters in croton oil.

These are oily liquids or crystalline solids, mostly "benzene derivatives," occurring in fruits, leaves and stems of many plants. The oily spots made by the oils disappear on evaporation. Very many are known but in many eases the composition is not satisfactorily worked out. Chemically they are very variable. Those mentioned below are all very closely related to each other. 
Pinene

$$
\mathrm{C}_{10} \mathrm{H}_{16}
$$

d-Limonene

$\mathrm{C}_{10} \mathrm{H}_{16}$

Cineol (Eucalyptol)

$$
\mathrm{C}_{10} \mathrm{H}_{18} \mathrm{O}
$$

Linalool

$$
\mathrm{C}_{10} \mathrm{H}_{18} \mathrm{O}
$$

\section{Citral}

$$
\mathrm{C}_{10} \mathrm{H}_{16} \mathrm{O}
$$

Tanacetone

$$
\mathrm{C}_{10} \mathrm{H}_{16} \mathrm{O}
$$

Camphor

$$
\mathrm{C}_{10} \mathrm{H}_{16} \mathrm{O}
$$

Menthol

$$
\mathrm{C}_{10} \mathrm{H}_{20} \mathrm{O}
$$

Caoutchouc

$\left(\mathrm{C}_{10} \mathrm{H}_{16}\right)_{\mathrm{n}}$

Gutta Percha

$\left(\mathrm{C}_{10} \mathrm{H}_{16} \mathrm{O}\right)_{\mathrm{n}}$

Carbohydrates.
Chief constituent of turpentine.

The chief oil of the orange rind, also of oil of dill, oil of erigeron. Together with pinene it forms oil of citron.

In oil of Eucalyptus.

In oils of lavender and geranium.

In oil of bergamot.

In oil of tansy.

In all parts of the camphor tree.

Chief constituent of oil of peppermint.

Produced in the latex of many plants, especially Apocynaceae and Euphorbiaceae.

In the latex of Isonandia gutta and many other Sapotaceae.

The compounds grouped under this head are in their nature in some cases aldehydes, in others ketones. They may be combined into more complex anhydrides or ethereal derivatives. They consist of carbon, hydrogen and oxygen in the proportion $\mathrm{C}_{\mathrm{x}} \mathrm{H}_{2 \mathrm{y}} \mathrm{O}_{\mathrm{y}}$ in which $\mathrm{x}$ and $\mathrm{y}$ may be equal, or y may be one or more less than $\mathrm{x}$ (e.g. $\mathrm{C}_{6} \mathrm{H}_{12} \mathrm{O}_{6}, \quad \mathrm{C}_{12} \mathrm{H}_{22} \mathrm{O}_{11}$, etc.). Mostly $\mathrm{x}=6$ or a multiple of 6 . The forms with low value for $\mathrm{x}$ ( 5 or 6 or 12) are soluble in water and sweet to the 
Carbohydrates.-Con.

Monosaccharids.

Arabinose

$\mathrm{C}_{5} \mathrm{H}_{10} \mathrm{O}_{5},\left(\mathrm{CH}_{2}(\mathrm{OH})-(\mathrm{CH}-\right.$ $\left.(\mathrm{OH}))_{3}-\mathrm{CHO}\right)$

d-Glucose (grape sugar, dex- This is the commonest sugar. trose)

$\mathrm{C}_{6} \mathrm{H}_{12} \mathrm{O}_{6},\left(\mathrm{CH}_{2}(\mathrm{OH})-(\mathrm{CH}-\right.$ $(\mathrm{OH}))_{4}-\mathrm{CHO}$ ) with $\mathrm{C}_{6}$ (or $\mathrm{C}_{5}$ ) are called monosaccharids; with $\mathrm{C}_{12}$, disaccharids or bioses; $\mathrm{C}_{18}$, trisaccharids or trioses; $\mathbf{C}_{24}$, tetrasaccharids or tetroses; those with larger value of carbon are often termed polysaccharids. They usually have the formula $\left(\mathrm{C}_{6} \mathrm{H}_{10} \mathrm{O}_{5}\right)_{n}$.

Only the commoner forms will be mentioned.

Obtained by treatment of various gums with dilute boiling $\mathrm{H}_{2} \mathrm{SO}_{4}$.

It is in most cases the first carbohydrate produced in photosynthesis. It occurs abun- taste and dialyze easily. The solubility and sweetness as well as power to dialyze decrease as the number of carbon atoms increases. Those dantly in most sweet fruits. It is the form in which carbohydrates are translocated.

d-Galactose (formula as for glu- Produced by the splitting of cose)

the lactose, raffinose, or manneotetrose molecule by weak acids, therefore one of the constituents of these sugars.

d-Mamnose (formula as for glu- Produced by the splitting of cose) the molecule of certain (reserve) celluloses by weak acids and therefore one of the constituents of those carbohydrates.

d-Fructose (fruit sugar or levu- This sugar is abundant in lose)

$\mathrm{C}_{6} \mathrm{H}_{12} \mathrm{O}_{6},\left(\mathrm{CH}_{2}(\mathrm{OH})-(\mathrm{CH}-\right.$

$(\mathrm{OH}))_{3}-\mathrm{CO}-\mathrm{CH}_{2}(\mathrm{OH})$ ) 
Sorbinose (formula as for In juice of the fruit of the d-fruetose)

Disaccharids.

Saceharose (Cane sugar) d-glucose $+d$-fructose

Trehalose (Fungus sugar) d-glucose + d-glucose

Maltose (Malt sugar) d-glucose + d-glucose

Lactose (Milk sugar) d-glucose +d-galactose Trisaccharids.

Raffinose $d$-fructose $+d$-galactose $+d$ fructose

Tetrasaccharids.

Manneotetrose

$\mathrm{C}_{24} \mathrm{H}_{44} \mathrm{O}_{22}$, d-fructose $+d$ glucose $+\mathrm{d}$-galactose $+\mathrm{d}-$ galactose. service-berry.

These are to be looked upon as formed by the union of two (not necessarily similar) molecules of monosaccharids with the loss of $\mathrm{H}_{2} \mathrm{O}$. Their arbitrary formula is $\mathrm{C}_{12} \mathrm{H}_{22} \mathrm{O}_{11}$. The exact arrangement of the groups within the molecule is still disputed, so that no attempt will be made to show it. The component monosaccharids are given in each case. Very abundant in the higher groups of plants in stems, roots and fruits. Found in sugar beet, sugar cane, Indian corn, maple, birch, and various palms, etc.

Abundant in fungi.

In germinating starehy seeds.

Common in milk but only rarely in plants.

These have the arbitrary formula $\mathrm{C}_{18} \mathrm{H}_{32} \mathrm{O}_{16}$ and are looked upon as composed of three monosaccharid molecules joined with the loss of $2 \mathrm{H}_{2} \mathrm{O}$. Occurs in the sugar beet (abundant in beet molasses), cotton seeds, etc.

These are formed by the union of four monosaccharids with loss of water.

In gum of the Manna ash (Fraxinus ornus). 
Polysaccharids.

Starch (Amylum).

Glycogen (Liver starch)

Inulin

Celluloses
The following earbohydrates have an arbitrary formula corresponding nearly if not exactly to $\left(\mathrm{C}_{6} \mathrm{H}_{10} \mathrm{O}_{5}\right)_{n}$ in which $\mathrm{n}$ may be different for the different forms. They are looked upon as composed of $\mathrm{n}$ molecules of monósaccharids with loss of some $\mathrm{H}_{2} \mathrm{O}$. They are mostly little if at all soluble in water and are correspondingly $\mathrm{lacking}$ in sweetness. They are the commonest forms of reserve carbohydrates.

Hydrolyzes ultimately to $\mathrm{d}$ glucose. The commonest form of reserve carbohydrate for green plants. Always produced in plastids (chloroplasts or leucoplasts). Usually formed in grains of alternating denser and less dense concentric layers. Occurs in many modifications (i.e. there are many starches). Hydrolyzes to d-glucose. Very abundant in fungi. Is the storage carbohydrate of animals also.

Hydrolyzes to d-glucose. Stored in solution in roots and tubers of Asterales (e.g. Dahlia).

These are water-insoluble compounds which form the cell walls of most plants. Many forms have been distinguished, differing in their solubility in weak acids and 
Glucosides.

Amygdalin

$\mathrm{C}_{20} \mathrm{H}_{27} \mathrm{NO}_{11}$

Solanin

$\mathrm{C}_{28} \mathrm{H}_{47} \mathrm{NO}_{11}$

Saponin

$\mathrm{C}_{32} \mathrm{H}_{52} \mathrm{O}_{17}$

Coniferin

$\mathrm{C}_{16} \mathrm{H}_{22} \mathrm{O}_{8}$ alkalies and in the form of monosaccharids produced on hydrolysis. We can distinguish the celluloses proper (insoluble in weak acids and alkalies, but soluble in ammoniacal copper oxide solution and hydrolyzing with difficulty) and the hemi-celluloses (reserve celluloses are of this type), pectoses, etc., with all gradations to the plant gums which are pectic in nature and soluble in water.

These are compounds of glucose with various other, often not, closely related, substances from which the glucose is set free by the action of enzymes or acids. The most important are:

This occurs in the leaves, bark and kernels of peach, bitter almond, cherry, etc. Under the influence of the enzyme emulsin it breaks up into d-glucose, oil of bitter almonds $\left(\mathrm{C}_{6} \mathrm{H}_{5}-\mathrm{CHO}\right)$ and hydrocyanic acid (HCN).

In green portions and seeds of the potato and other Solanaceae.

In soap bark (Sapindus) and many other plants.

In young wood of Conifers (see below under hadromal for discussion). 
Hesperidin

$\mathrm{C}_{22} \mathrm{H}_{26} \mathrm{O}_{12}$

Aesculin

$\mathrm{C}_{15} \mathrm{H}_{16} \mathrm{O}_{9}$

Arbutin

$\mathrm{C}_{12} \mathrm{H}_{16} \mathrm{O}_{7}$

Salicin

$\mathrm{C}_{13} \mathrm{H}_{18} \mathrm{O}_{7}$

Alkaloids.
Caffeine (Theine)

$\mathrm{C}_{8} \mathrm{H}_{10} \mathrm{~N}_{4} \mathrm{O}_{2}$

Theobromine

$\mathrm{C}_{7} \mathrm{H}_{8} \mathrm{~N}_{4} \mathrm{O}_{2}$

Piperin

$\mathrm{C}_{17} \mathrm{H}_{19} \mathrm{NO}_{3}$

Abrotanin

$\mathrm{C}_{21} \mathrm{H}_{22} \mathrm{~N}_{2} \mathrm{O}$

Aconitin

$\mathrm{C}_{33} \mathrm{H}_{45} \mathrm{NO}_{12}$
In green oranges.

In bark of horse chestnut (Aesculus).

In leaves of bearberry (Aretostaphylos).

In the willow.

These are organic compounds, acting as bases in the presence of acids, and usually bitter to the taste. Under this name are grouped a variety of unrelated substanees although the tendency now is to limit the name to derivatives of the pyridin group which would exclude the first two in the list below of the commoner alkaloids. Many if not most alkaloids are poisonous. They may be in some eases reserve foods but possibly in other cases are waste products or even special defences against herbivorous animals.

In leaves of tea, "berries" of coffee and in many other plants (e.g. Cola nut).

In seeds of the eacao.

In pepper (Piper nigrum).

In wormwood (Artemisia abrotanum).

In monkshood (Aconitum). 
Atropine

$$
\mathrm{C}_{17} \mathrm{H}_{23} \mathrm{NO}_{3}
$$

Berberin

$$
\mathrm{C}_{20} \mathrm{H}_{17} \mathrm{NO}_{4}
$$

Brucine

$$
\mathrm{C}_{23} \mathrm{H}_{26} \mathrm{~N}_{2} \mathrm{O}_{4}
$$

Cocaine

$\mathrm{C}_{17} \mathrm{H}_{21} \mathrm{NO}_{4}$

Coniine

$\mathrm{C}_{8} \mathrm{H}_{17} \mathrm{~N}$

Cytisin

$\mathrm{C}_{11} \mathrm{H}_{14} \mathrm{~N}_{2} \mathrm{O}$

Hydrochinin

$$
\mathrm{C}_{20} \mathrm{H}_{26} \mathrm{~N}_{2} \mathrm{O}_{2}
$$

Hyoscyamine

$\mathrm{C}_{17} \mathrm{H}_{23} \mathrm{NO}_{3}$

Lupinin

$$
\mathrm{C}_{10} \mathrm{H}_{19} \mathrm{NO}
$$

Morphine

$$
\mathrm{C}_{17} \mathrm{H}_{19} \mathrm{NO}_{3}
$$

Nicotine

$$
\mathrm{C}_{10} \mathrm{H}_{14} \mathrm{~N}_{2}
$$

Quinine

$$
\mathrm{C}_{20} \mathrm{H}_{30} \mathrm{~N}_{2} \mathrm{O}_{2}
$$

Strychnine

$$
\mathrm{C}_{21} \mathrm{H}_{22} \mathrm{~N}_{2} \mathrm{O}_{2}
$$

Taxin

$$
\mathrm{C}_{37} \mathrm{H}_{52} \mathrm{NO}_{10}
$$

Veratrine

$$
\mathrm{C}_{22} \mathrm{H}_{42} \mathrm{NO}_{9}
$$

Protein Group.
In leaves of Atropa belladonna.

In Berberidaceae, Ranunculaceae, Papaveraceae, etc.

In the seeds of nux vomica (Strychnos nux-vomica.)

In leaves of coca (Erythroxylon coca).

The poisonous principle of the hemlock (Conium maculatum).

In various Fabaceae, e.g. Cytisus, Laburnum, Sophora, Thermopsis, Baptisia, Ulex, etc.

In Cinchona bark.

In henbane (Hyoscyamus niger).

In seeds of various lupines.

The chief of many alkaloids in opium, the coagulated latex of Papaver somniferum.

In tobacco.

In the bark of Cinchona.

In the seeds of nux vomica (Strychnos nux-vomica).

In twigs, leaves and fruit of the European yew (Taxus baccata).

In Veratrum album.

This embraces a vast number of very complex compounds 
whose true composition is in great part not yet clear. They contain $\mathrm{C}, \mathrm{H}, \mathrm{O}$ and $\mathrm{N}$ in fairly large amounts and usually some $S$ and often $P$. They may also have in combination certain metallic bases, but this is not proved. They are probably built up of combined chains of amino-acids. Possibly hydrocyanic acid is one of the steps, for it is abundant in many plants when proteinsynthesis is active. Possibly carbohydrates also are of importance in the framework of the molecule. The molecule is very large and in the more complex forms dialysis does not occur or only feebly, but in forms like peptones it readily takes place. The higher forms lead to the Protoplasms which are chemically to be regarded as very complex protein compounds in which probably various metallic bases are combined and which perhaps have one or more carbohydrate nuclei in the molecule. They are very labile compounds, easily destroyed by external influences of varied nature. The protoplasm and higher protein compounds (Albumens) are usually easily coagulable by heat and by salts of $\mathrm{Cu}, \mathrm{Hg}$, $\mathrm{Ag}$, etc. By hydrolysis with certain enzymes these compounds are broken down into 
Protein Group.-Con.

Enzymes.

Invertase

Cytase the less complex, soluble, dialyzable Albumoses (to which the peptones belong). Other related groups are the $A l b u$ minoids, some of which are crystallizable. All of these groups have innumerable forms differing from one another in solubility in acids, alkalies and salt solutions; in their coagulability with heat, salts, acids and alkalies and enzymes; in their power to dialyze, and in the forms of enzymes that can attack them and the forms of the products of such enzymatic action.

These are substances showing many of the characteristics of the protein compounds (e.g. destruction of activity by heat or salts of heavy metals, etc.), but not so complex. They are very numerous, even in the same plant, and perform many of its important functions. They are in a sense "catalyzers," in that they start or intensify chemical processes without themselves being used up (or only in relatively small degree).

The more important plant enzymes and the substances acted upon by them are as follows:

Hydrolyzing saccharose to dglucose and d-fructose.

Hydrolyzing hemicelluloses to monosaccharids. 
Pectase

Amylase (diastase)

Zymase

Emulsin

Lipase

Pepsins and trypsines

Oxidases and peroxidases

Catalase

Reductase

Miscellancous substances.

Methane $\mathrm{CH}_{4}$

Heptane $\mathrm{C}_{7} \mathrm{H}_{16}$

Methylamine $\mathrm{CH}_{5} \mathrm{~N},\left(\mathrm{CH}_{3} \mathrm{NH}_{2}\right)$

Tri-methylamine $\left.\mathrm{C}_{3} \mathrm{H}_{9} \mathrm{~N},\left(\mathrm{CH}_{3}\right)_{3} \mathrm{~N}\right)$

Formaldehyde $\mathrm{CH}_{2} \mathrm{O},(\mathrm{H}-\mathrm{CHO})$
Hydrolyzing pectin compounds to monosaccharids. Hydrolyzing starch to d-glucose (probably several steps, involving perhaps several enzymes).

Splitting d-glucose into ethyl alcohol and $\mathrm{CO}_{2}$.

Hydrolyzing amygdalin to HCN, d-glucose and oil of bitter almonds.

Acting on fats, saponifying and emulsifying them.

Hydrolyzing protein compounds to different degrees of simplicity.

Many kinds, bringing about numerous oxidations within the plant.

Decomposing peroxides in the plant.

Bringing about reducing processes in the plant.

Under this head are grouped a number of totally unrelated substances that do not come under any of the foregoing heads and that are not numerous enough to form classes by themselves.

Produced by bacterial fermentations of celluloses.

In the oil from the seeds of some pines.

In Mercurialis perennis and M. annua.

In Chenopodium, in blossoms of Crataegus, and of pear, etc. Apparently one of the first steps in the photosynthesis of $\mathrm{CO}_{2}$ and $\mathrm{HO}_{2}$ to form carbo- 
Formaldehyde-Con.

Asparagin

$\mathrm{C}_{4} \mathrm{H}_{8} \mathrm{~N}_{2} \mathrm{O}_{3},\left(\mathrm{CO}\left(\mathrm{NH}_{2}\right)-\mathrm{CH}_{2}\right.$ $\left.-\mathrm{CH}\left(\mathrm{NH}_{2}\right)-\mathrm{COOH}\right)$.

Chitin

$\mathrm{C}_{18} \mathrm{H}_{30} \mathrm{~N}_{2} \mathrm{O}_{12}$

Vanillin

$\mathrm{C}_{8} \mathrm{H}_{8} \mathrm{O}_{3}$ hydrates. Found free in minute quantities in leaves when active photosynthesis is occurring.

This is found, especially in the growing regions, in many plants, e.g. asparagus, peas, beans, vetches, beet roots, potatoes, etc.

This forms part of, or in some cases is the chief constituent of, the cell wall of many of the lower plants, e.g. Myxophyceae, Mucorales, Carpomyceteae. It was long considered a form of cellulose ("fungus cellulos e"). It forms the body wall of insects, crustaceans, etc.

Formed by the fermentation of the seed pods ("beans") of the Vanilla plant, whence it is extracted by alcohol. It is present in most if not all lignified cell walls and is possibly one of the substances giving the cell wall the characters that we call "lignification" (see hadromal).

Hadromal (composition uncer- This is a substance separated tain) by Czapek from lignified cell walls and believed by him to be what gives them their "lignified" character. On the other hand many botanists do not consider this as the important body and ascribe lignification to the presence in the cell walls of coniferin and vanillin (q.v.) and perhaps other substances. 
Suberin

Cutin

Chlorophyll (chlorophyllan)

Carotin (Xanthophyll) $\mathrm{C}_{26} \mathrm{H}_{38}$
This is the name applied to what is probably a mixture of several fatty acids including the following: Phellonic, phloeonic and suberic $\left(\mathrm{C}_{8} \mathrm{H}_{14} \mathrm{O}_{8}\right)$. Their presence in the cell walls waterproofs them.

This is a fatty substance or substances related to the foregoing and waterproofing the epidermal cell walls in which it is deposited.

This is a blue-green pigment occurring only in chloroplasts (or in such Myxophyceae as lack definite chloroplasts in minute particles in the cytoplasm). It is the most important plant pigment, absorbing certain light rays and transforming the energy into the chemical energy used in photosynthesis. It is formed (with rare exceptions) only in the light and is itself quickly destroyed by bright light. It contains no iron but the plant requires iron for its production. Its chemical composition is not exactly known but it secins to be closely related to haemoglobin. It is insoluble in water but soluble in alcohol, ether, petroleum ether, gasoline, etc. Probably "chlorophyll" is not one but a group) of closely similar compounds. Under the name Xanthophyll this substance is associated in small or large proportions with chloophyll wherrever the latter occurs, the mixture giv- 
Phycocyanin

Phycophaein

Diatomin

Phycoerythrin ing the characteristic "grass green" color to the chloroplasts. It is present without chlorophyll in autumn leaves and in many parts of some plants. The autumn coloration of leaves is due to various chemical changes of carotin and chlorophyll and other substances present in the cells. Carotin is of itself yellow to orange when in solution, forming orange-red to red crystals. It is insoluble in water, petroleum ether and gasoline, but soluble in alcohol, ether, etc.

Other plant pigments, of unknown composition, may be associated with the two preceding pigments, giving charatceristic colors to the chloroplasts. Their function is not proved, but in some cases they probably change the quality of light to that most favorable for absorption by the chlorophyll. In the Myxophyceae, blue, water soluble.

In the Phacophyceae, brown.

In Bacillarioideae (diatoms) brown, water soluble.

In Rhodophyceae and a few Siphonophyceae, violet-red, water soluble.

Anthocyanin is a red (in acid cell sap) or blue (in alkaline cell sap) coloring matter in the cell sap of many brightly colored leaves and other plant parts, occurring especially in the epidermal cells. It is apparently a nitrogen-free glucoside. 


\section{CHAPTER VI}

\section{THE CLASSIFICATION OF PLANTS}

202. We now come to that part of the subject in which we are to consider the different kinds of plants to be found in the world. Botanists now know over 233,000 kinds, a number which is too vast to be remembered in detail by any one and yet even the beginner may learn much about them by taking up their study properly.

\section{Of Relationship}

203. It is now known that all the kinds of plants are related to one another. $\mathrm{By}$ this we mean that traced back far enough all plants have a common ancestry, in other words they have descended from earlier identical or similar forms. This is what we know as Evolution, and in thinking of the great numbers of plants we regard them as related to one another because they have descended recently or remotely from common ancestors.

204. In Botany we try to group plants according to their relationships, much as we group people by their relationships. This requires that as we study plants we should constantly keep in mind the fact that they are less or more alike just as their relationship is remoter or nearer. And this is what we call Phylogeny, that is, the racial history of the groups of plants. So what follows in Chapters VII to XX is an attempt to present selected representatives of the groups of plants in such a sequence as will suggest their relationship and path of development.

205. It must be remembered that plants have been in existence for a very long time, and that many, or possi- 
bly all of the earliest kinds have disappeared. If we had before us all of the plants that ever existed the task of arranging them so as to show their relationship would still be a difficult one, but with many forms irretrievably lost the difficulty of the task is very greatly increased. Some lower plants are probably still much like their primitive ancestors, while others have been greatly modified. We may think of the plants that we now see as having developed through shorter or longer distances; some perhaps have stood still in their original places, others have moved forward short distances to where we now find them, while still others have gone much farther along their evolutionary pathway to their present positions.

\section{Of Species and Genera}

206. In studying plants we notice that they exist as kinds, and there has been a general agreement to speak of each recognizable kind as a "species." Thus we speak of the species of Oaks, Elms, Ashes, Magnolias, etc., meaning the kinds of Oaks (White Oak, Red Oak, Black Oak, etc.), or Elms (White Elm, Slippery Elm, Cork Elm, etc.), or Ash (White Ash, Green Ash, Black Ash, etc.), etc., etc., and in all these cases we recognize that we refer to a quite definite kind-a species. While in many cases the distinctions are less definite, it is still true that in any particular locality plants are recognizable as kinds (species). Now these species are sufficiently stable so that under constant conditions, in any particular locality they change slowly, if at all, while they are sufficiently plastic so that under changed conditions, as when they are carried to other habitats, they change more or less, and this may be great enough so that we regard them as different species. 
207. For our own convenience we group similar species into genera. Thus we group all the species of oaks into one genus Quereus, the old Latin name for all the Oaks, and in like manner all the Elms are grouped under Ulmus, the Latin name for the Elms. So we have Quercus alba, Quercus rubra, Quercus nigra, etc., and Ulmus americana, Ulmus fulva, Ulmus racemosa, etc., in all of which cases the first name is that of the genus, and the second that of the species and these constitute the names of these plants. The name of the plant comes thus from its classification.

\section{Higher Groups}

208. For further convenience all genera are gathered into their appropriate families, all families into orders, all orders into classes, and finally all classes into phyla. Lastly all the kinds of plants in the world are said to constitute the Vegetable Kingdom.

We may arrange these as follows:

Species consist of individual plants

Genera are composed of species

Families are collections of genera

Orders are collections of families

Classes are collections of orders

Phyla are collections of classes

The vegetable kingdom is a collection of phyla.

From this it follows that:

Every plant belongs to some species

Every species to some genus

Every genus to some family

Every family to some order

Every order to some class

Every class to some phylum

All phyla to the Vegetable Kingdom. 
So the Vegetable Kingdom contains

Phyla

Classes (also Sub-classes)

Orders (also Super-orders, and Sub-order's)

Families (also Sub-families)

Genera

Species.

The foregoing may be called the framework of the classification of plants used in this book.

209. It must be borne in mind that in this classification we are dealing with individuals as the only actually existent things. For our own convenience we form a mental concept of an aggregation of similar individuals, and this we hold as "kind" ("species"). So also we form a mental picture of an aggregation of similar species, and this is what we call the genus. Quite similarly we form a concept of aggregated genera, and call it a family, and so on for orders, classes and phyla.

\section{Evolution}

210. For the present purpose the more important points included in the general doctrine of evolution may be summarily stated as follows:

1. The first species were lower plants, and these gave rise to higher plants.

2. Evolution while generally upward (progressive) is often downward (retrogressive).

3. Evolution does not necessarily involve all organs of the plant equally in any particular period, and one organ may be progressing at the same time that another is retrograding.

4. Hysterophytic retrogression of plants is persistent, and the hysterophytic phylum does not afterward become holophytic. 
5. All plant relationships are genetic, and these relationships are up and doun the genetic lines.

\section{Origin of Phyla}

211. If now we inquire as to the origin of phyla we may formulate our answer in several ways. Stated philosophically we may say that a phylum originates with the incoming of a new idea. Stated structurally, it has its beginning with the development of a dominant morphological peculiarity. Stated taxonomically, its initial point is indicated by the appearance of a new character. So every phylum is the result of a development which differs from that which preceded it because of the incoming of a new idea: this dominant idea was manifested structurally by a divergence from the previous lines of evolution and this point of divergence became the actual origin of the new phylum. As long as this idea and its structural expression dominate, so long does the phylum extend, and when a still newer idea comes in and attains dominance, a still newer phylum has its beginning. So we say that a phylum originates with a divergence which is the expression of a new idea, or in other words a "tenclency" ; and this in taxonomy we call a "new character."

\section{The Place of Plants in Tine}

212. As stated above, plants have been in existence a very long time, and as some references will be made in the following chapters to particular periods of time it is necessary here to give a table showing the divisions of earth time ("geologic time") as recognized in recent treatises, with suggestions as to their vegetation. In this table no attempt is made to indicate the relative longths of different periods. 
General Table of Geologic Time Divisions

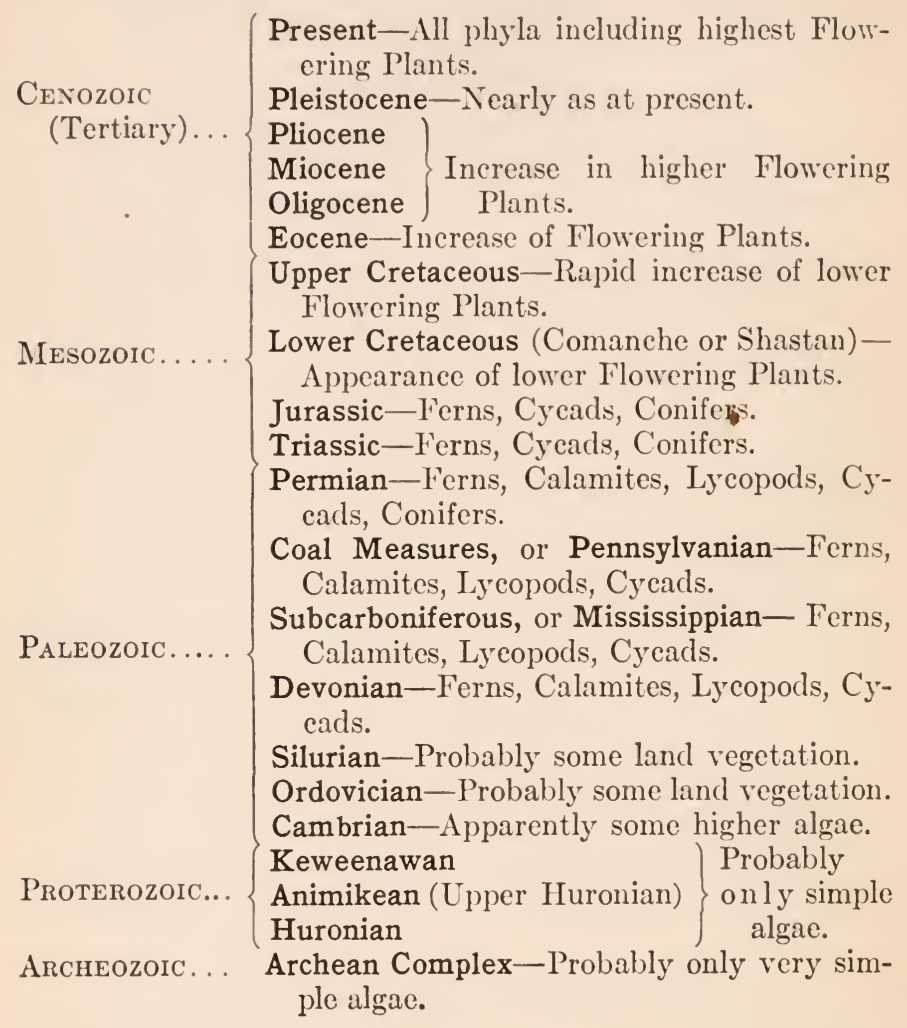




\section{PHYLUM I. MYXOPHYCEAE}

\section{THE SLIME ALGAE}

213. The Slime Algae are the lowest and simplest plants, and are often so minute as to require the highest powers of the microscope for their study. Some of them are single cells, while others are rows or masses of similar or slightly different cells. In most Slime Algae the cells are poorly developed, the walls being soft and easily gelatinized and usually containing chitin, the nuclear matter diffused and not bounded by a nuclear membrane, and the cytoplasm containing no plastids.

214. The dominant coloring matter of the cells, phycocyanin, which is blue, is mostly distributed throughout the protoplasm, and mixed with the chlorophyll and more or less carotin give the blue-green, brown-green, or smoky color found in this group. In the hysterophytes these are wanting.

215. They reproduce asexually by fission, and the formation of spores, and in the filamentous forms by the breaking of the filaments into short segments (hormogones) each of which then grows into a long filament. No sexual reproduction is known.

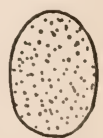

Fig. 59.A cell of the Myxophyceae.

216. The Slime Algae mostly live in the water, getting their nourishment from the solutions it contains. The green plants (holophytes) are able to use carbon dioxide, but those not green (hysterophytes) are typically parasitic or saprophytic. 
217. In this Phylum the dominant idea is the simple nucleus, typically not limited by a nuclear membrane, asexual reproduction, and blue-green color.

There are two classes:

I. Nucleus not definitely outlined, no nuclear membrane; no plastids.

Class 1. Archiplastideae.

II. Nucleus definitely outlined, with a nuclear membrane; plastids present.

Class 2. Holoplastideae.

\section{Class 1. ARCHIPLASTIDEAE (CYANOPHYCEAE)}

\section{The Blue Greens}

218. In these plants (numbering about 2000 species) there is no limiting membrane around the primitive nucleus, and yet there is a simple karyokinetic process in cell division. In the absence of plastids the coloring matter is diffused throughout the cell.

order coccogonales. Unicellular Blue Greens

219. Here the plants are strictly unicellular, although they may be aggregated into colonies in which the cells are included in a gelatinous matrix due to the softening of their walls.

220. These are the lowest and simplest of plants; they 0 live as single cells in the water, or they may 00 be aggregated into slimy films on sticks and stones. The principal family is Chroococcaceae, represented by minute species Fig. 60.- of Chroococcus, Gloeocapsa, Aphanocapsa, Me ris mopedia, Merismopedia and other genera. Each cell Gloeocapsa. divides into two, and these soon divide again, and so on. In Merismopedia the successive divisions are in two planes, resulting in quadrate colonies of regularly arranged cells. 
ORder hormogonales. Filamentods Blue Greens

221. These plants consist of simple or branched rows (filaments) of cells, which are usually enclosed in a sheath. There are half a dozen families, the lowest of which is Oscillatoriaceae, with cylindrical filaments of uniform cells. There are many genera, as Microcoleus, Lyngbya, Spirulina, Oscillatoria, etc., which occur in quiet waters. Oscillatoria and Spirulina are interesting because of their marked motility.

222. The Nostocs (Family Nostocaceae) are filamentous with more or less spherical cells, some of which are larger (rarely smaller) than the others and have thickened, cellulose walls (heterocysts). Spores are common as larger, denser cells which serve to carry the species through adverse conditions. The genera Nostoc, Anabaena, and Cylindrospermum are common.

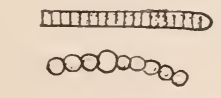

Fig. 61.-Oscillatoria and Nostoc.

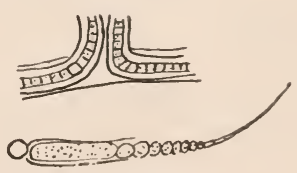

Fig. 62.- Seytonema and Rivularia.

223. The Scytonemas (Family Scytonemataceae) have cylindrical (often branched) filaments which contain heterocysts also. Scytonema and Tolypothrix are common genera.

224. The Rivularias (Family Rivulariaceae) are tapering filaments with a heterocyst at the base. They usually occur in jelly-like masses. The principal genus is Rivularia.

225. The Stigonemas (Family Stigonemataceae), while filamentous, have their larger filaments composed of more than one row of cells. Haplosiphon and Stigonema are common genera. 


\section{ORDER BACTERIALES. The Bacteria}

226. The Bacteria, which are here regarded as degenerated chlorophyll-less Blue Greens, are so important that they require a somewhat fuller treatment. They are the smallest of living things, some being as small as 0.0005 millimeters $(1 / 50,000$ inch), or even smaller. Although typically filamentous they break up easily into one-celled or few-celled forms, in which condition they are most commonly found. In some species they occur as minute rounded cells ("cocci"), in others elongated (then called "rods"), and in still others they are more or less curved. They are frequently provided with one or more cilia or flagella by means of which they are motile.

227. Bacteria are found in great numbers in the watery parts of decaying organic matter, causing various kinds

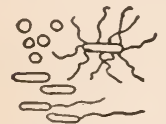

Fig. 63.--Several bacteria. of fermentation, and in fact they occur so generally in Nature that their presence is almost universal. They reproduce by fission with such astonishing rapidity that in a short time they swarm in any exposed substance which is capable of furnishing them with food. Some of the species live in the watery juices of plants and animals, causing various diseases. However, of the hundreds of species known, the great majority are harmless, or actually beneficent.

228. Some bacteria can endure high temperatures, especially in the spore state, and frequently appear in tightly closed vessels whose contents have been boiled. Some people have been led to explain their appearance under such circumstances by "spontaneous generation"; but thus far the facts are capable of other explanation.

229. The proper spores of bacteria (endospores) are produced singly within the cells, and are thick-walled, rounded bodies. By the breaking of the filaments into 
their component cells other reproductive bodies (hormogones) are formed.

230. On account of their minuteness, bacteria may be picked up by currents of air and borne long distances, and in this way they are doubtless often carried from place to place. When a pool of putrid water dries up, the bacteria with which it swarmed are blown away with the dust and dirt, dropping everywhere into pools, upon plants and animals living and dead, and even entering our lungs with the air we breathe.

\section{Class 2. HOLOplastideaE}

\section{The Higher Blue Greens}

231. This little class, of about 20 species, includes Slime Algae, in which the nucleus is defined by a nuclear membrane, and the coloring matter is concentrated in one or more plastids. There is but one order, the Glaucocystales, and a single family (Glaucocystaceae) of unicellular plants. The type genus is Glaucocystis.

Laboratory Studies of the Myxophyceae. With the foregoing general statements of the structure and life of the Slime Algae including the Bacteria, the student must now make some examination of them by means of a good compound microscope in the laboratory. In his examination he should make careful drawings accompanied by brief, necessary descriptions. It is a good rule in the study of plants never to make a needless drawing, nor write an unnecessary description. A second rule of still greater importance insists upon the absolute truthfulness (accuracy) of both drawings and descriptions.

The following studies are suggested as useful.

(a) Scrape off a little of the greenish slimy matter from a damp wall, mounting it in water; examine under a high power. Some small blue-green or smoky-green cells will be found belonging to the Blue-green Slimes (Chroococeus, etc.); of 
these some will probably be found in process of fission. Larger br ght-green eells filled with granular protoplasm will also be found; these are species of Protoeoceus belonging to the next phylum.

(b) In midsummer look along the water-line of fresh-water lakes and ponds for soft, amber-colored, round masses from the $s$ ze of a pea to that of a hickory-nut. By mounting a small $\mathrm{sl}^{\circ}$ ee of one of these it will be seen under the microscope to be composed of myriads of filaments of Nostoc. Oecasionally a filament may be seen with a heteroeyst; its function is not known.

(c) Secure a handful of the dark-green filamentous growth which is common on the wet sides of watering-troughs and place it in a dish of water. If an Oscillatoria, it will rapidly disperse itself, a few minutes being long enough to show quite a ehange in position. Now mount a few filaments in water and examine under a high power. They will be seen to sway from side to side while moving quite rapidly across the field of the m:eroscope.

(d) In midsummer scrape off one of the small jelly-like masses of Rivularia, so eommon on the submerged stems of water-plants; mount in water, crushing or eutting the mass so as to show the individual filaments. Each filament tapers from the eenter of the mass outward, and at its larger (inner) end there is generally a heterocyst.

Some elementary studies of bacteria may be made very easily, but their profound study (Bacteriology) involves a technique which is unattainable by the beginner in Botany. The following may be attempted.

(e) Boil a pinch of eut hay or any other similar vegetable substance for a few moments, and put into a glass of water; keep in a warm room for a couple of days, or until it becomes turbid (from the abundanee of bacteria); examine a minute drop with the highest powers of the microscope, for active bacteria. The bacterial growth originates from the spores which were not killed by the short boiling. The eommonest form thus obtained is Bacillus subtilis.

(f) Put a bit of fresh meat into water, and study the bacteria which will appear in it. Spiral forms (especially Spirillum) may often be found in such a preparation.

(g) Examine the juices of decaying fruits and regetables. 
(h) Among the many bacteria of especial interast to us are the following:

1. Clover-nodule bacteria (Pseudomonas leguminosarum), which enrich the soil by the production of nitrogen compounds.

2. Sulphur-bacteria (Beggiatoa alba), which occur as large motile filaments in refrigerator drains.

3. Apple and pear blight bacteria (Bacillus amylovorus), eausing the blight in apple and pear trees.

4. Cucumber-wilt bacteria (Bacillus tracheiphilus), causing the "wilt discase" of eucumbers, and other cueurbits.

5. Crown-gall bacteria (Pseudomonas tumefaciens), causing the crown galls in the roots and stems of many plants.

6. Typhoid fever baeteria (Bacillus typhosus), eausing typhoid fever.

7. Tuberculosis bacteria (Bacterium tuberculosis), causing tubereulosis.

8. Diphtheria baeteria (Bacterium diphtheriae), eausing diphtheria.

9. Influenza bacteria (Bacterium influenzae), causing influenza ("Grippe").

10. Anthrax bacteria (Bacterium anthracis), causing anthrax.

11. Cholera bacteria (Microspira comma), eausing cholera.

12. Colon bacteria (Bacillus coli) in the large intestines of most mammals.

\section{LITERATURE OF MYXOPHYCEAE}

Here as elsewhere only the most necessary works are mentioned, in the order of their desirability for the beginner in Botany.

G. S. West, A Treatise on the British Freshwater Algae, Cambridge, 1904.

Josephine E. Tildex, The Myxophyceae of North America and Adjacent Regions (Vol. I of Minnesota Algae), Minneapolis, 1910.

G. B. De Toni, Sylloge Algarum, Vol. 5, Padua.

E. F. Surth, Bacteria in Relation to Plant Diseases, Washington, I, 1906 ; II, 1911.

IV. D. Frost and L. F. CAmpreli, A Text-book of General Bacteriology, New York, 1910. 


\title{
CHAPTER VIII
}

\section{PHYLUM II. CHLOROPHYCEAE*}

\author{
THE SIMPLE ALGAE
}

232. The plants of this phylum while still small, and mostly microscopic and consisting of single cells, filaments or rarely plates of cells, show a considerable advance over the Slime Algae in having well-defined nuclei, definite plastids, a dominant yellow-green color (chlorophyll and earotin), and in many genera

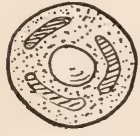

Fig. 64.-A cell of the Chlorophyceae. sexual reproduction. The cells are much better developed, the walls are composed of cellulose, and are usually firmer. The nuclear matter of the cell is collected into a definite nucleus which is surrounded by a membrane. A portion of the protoplasm is set off as one or more distinet plastids (chloroplasts) which are stained green by chlorophyll.

233. Here the dominant idea is the definite nucleus limited by a nuclear membrane. With this are associated the definite plastids, true chlorophyll, firm cell wall, motile reproductive structures (zoospores and gametes), and the still simple plant body.

234. The Simple Algae, of which there are about 1100 species, are mainly fresh-water plants, living on wet rocks, moist walls or tree-trunks, etc., or floating or attached in the deeper waters. A few have become degenerated through parasitism.

* This name is here used in the narrower sense, excluding the plants of the phyla Zygophyceae and Siphonophyceae. 
235. This phylum has been unusually productive of other phyla of primary and secondary rank, and the suggestion is hazarded that also from it (near Protococcoideae) a phyletic line gave rise to the Animal Kingdom. There are two classes:

I. Plants unicellular, or in colonies.

Class 3. Protococcoideae

II. Plants pluricellular, in filaments (or plates).

Class 4. Confervoideae

\section{Class 3. PRotococcoideae. Green Slimes}

236. These plants (of about 450 species) are nearly all microscopic, and are unicellular, or in a few cases aggregated into definite colonies. They propagate (reproduce by asexual reproduction) by (1) cell division, (2) ciliated zoospores, (3) and thick-walled spores (chlamydospores), and generate (reproduce by sexual reproduction) by the union of equal, motile gametes (isogametes) to form a single cell (zygote) which often becomes a thick-walled spore. Generation is not known for all of the species.

\section{ORDER PALMELLALES}

237. These unicellular plants are not aggregated into colonies, although they may remain attached together in irregular masses for some time after cell division. They are common in water, and in moist or wet places, as the sides of walls, trees, posts, etc., where they often form dense, green layers. The spherical forms growing on trees, walls, etc., which produce no zoospores are species of Protococcus,

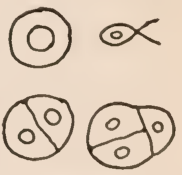

FIg. 6.5. Protococcus. while those with zoospores may be Chlorococcum. Near relatives of these have become unicellular para- 
sites (Family Synchytriaceae) in the tissues of other algae, or even land plants, and are known as Gall-fungi.

\section{ORDER COENOBIALES}

238. The cells or coenocytes in these plants are aggregated into colonies, the most common of which are the

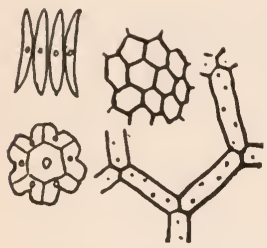

Fig. 66.-Scenedesmus, Pediastrum and Hydrodictyon. pretty species of Scenedesmus, in which four spindle-shaped cells lie side by side. Less common is the very regular plate-colony of Pediastrum with usually a dozen or more regularly arranged cocnocytes. Related to these is the Water Net (Hydrodictyon) with its many long coenocytes arranged in a hollow, reticulated colony 20 to 30 centimeters long. Ciliated zoospores and isogametes occur in Pediastrum and Hydrodictyon.

239. Here are commonly placed certain doubtful organisms, the Volvoces (Volvox, Pandorina, and related genera), with the color of plants but the structure of animals. Most botanists still claim them on account of their color, but many zoologists emphasizing the importance of their structure regard them as animals (Flagellata). The explanation here given is that at about this point in the Vegetable Kinglom the animal type became differentiated from the plant type by an increase in the motility of the cells, and in the Volvoces we have the organisms on the pathway leading from plants to animals. In the opinion of the authors they have already passed the frontier of the Plant Kinglom, and entered that of Animals, although they have not yet abandoned their use of chlorophyll.

240. On the same ground should be excluded the "red 
snow plant" of high mountains and polar regions, a unicellular eiliated organism (Chlamydomonas) which is usually of a red color, and some more common but similar, often red, organisms (Haematococcus) found in pools and on wet earth. They are all more like animals than plants.

\section{Class 4. CONFERvoldeaE. Confervas}

241. The Confervas are simple or branched filaments of cells, or a sheet (plate) of cells, and number about 640 species. They propagate by (1) the fracture of the filaments (into hormogones), (2) ciliated zoospores, (3) thick-walled spores (chlamydospores), and generate by the union of isogametes or heterogametes, to form a zygote which often becomes a thick-walled spore. They are mostly fresh-water plants, in ponds and in running waters.

242. The simplest of the Confervas are small unbranched filaments (species of Ulothrix) which are usually attached by a basal cell ("root"). They propagate by 2- or 4-ciliated zoospores, and generate by the union

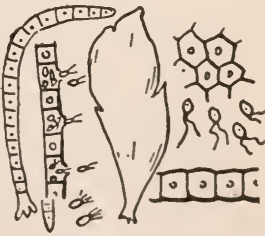

FIG. 67.- Tlothrix and Ionostroma. of 2-ciliate gametes.

243. The very similar, much-branched and rooted Draparnaldia and Chaetophora present a slightly higher development of the same type. They are common in running fresh water.

244. Related to these are the Sea-Lettuces common on stones, wharf-timbers, etc., along the coast and in brackish waters, and resembling small lettuce leaves. Each plant consists of a single layer of cells (Monostroma) or two layers (Ulva), and nearly every cell is capable of 
producing 4-ciliate zoospores, or 2-ciliate gametes. The irregularly tubular Enteromorphas resemble the Sea Lettuces and are common in brackish ponds.

245. In the Oedogoniums (Ocdogoniaceae) the plants are attached below, and are simple or branched above. They propagate by means of multiciliated zoospores which are formed singly in the cells, and generate by heterogametes, consisting of small multiciliated sperms, and

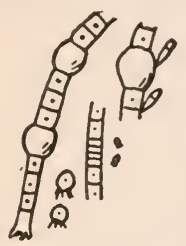

FIG. 68. Oedogonium. large non-ciliated eggs. The sperms are formed (1) in certain cells in the filament which produces the eggs, or (2) in somewhat smaller filaments, or (3) in very small, few-celled filaments ("dwarf males"). The eggs are formed singly in oogones that are merely transformed and considerably enlarged vegetative cells. When the egg reaches maturity the oogone wall opens to admit the sperm, after which the egg becomes a thick-walled resting spore. In germination the resting spore divides into four multiciliated zoospores which soon come to rest and develop into ordinary vegetative filaments.

246. The little Disk Algae (Coleochaetaceae) are minute branching plants closely related to the Oedogoniums, whose radiating filaments usually fuse laterally into small disks or eushions, a millimeter or so in diameter, and occurring on the stems and leaves of larger water plants. They propagate by biciliated zoospores formed singly in the cells, and generate by heterogametes. The biciliated sperms are formed singly in the antheridial cells. The oogones are terminal and each contains

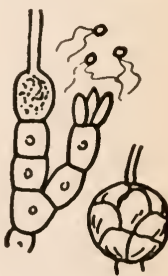

FIG. 69. Coleochaete. a single egg, and is supplied with a tubular prolongation, the "trichogyne." 
247. Fertilization is effected by a sperm uniting with the egg in the oogone, usually by passing into the open end of the trichogyne. After fertilization the egg increases considerably in size, and forms a cellulose coat of its own. The cells which support the oogone send out lateral branches, which grow up and closely surround it, finally covering it entirely (excepting the trichogyne) with a cellular thick-walled "pericarp." The whole mass, including the fertilized oogone and its investing pericarp, constitutes the simplest form of spore-fruit (sporocarp).

248. The further growth of the spore-fruit takes place the next spring by the swelling of the protoplasmic contents, and the consequent rupture of the pericarp; the inner portion divides into several cells (the proper fruitspores), which give rise to zoospores closely resembling those developed from the vegetative cells. From each zoospore a new plant eventually arises.

There is but one genus (Coleochaete) including a few widely distributed species.

Laboratory Studies. (a) Scrape off a little of the green, paint-like coating from a flower-pot, a damp wall, or a sidewalk plank, and examine under a high power for common Green Slime (Protococcus, ete.).

(b) Gall-fungi may sometimes be found in Spirogyra and Desmids, and in the leaves of evening primroses, plantains, mints, and some leguminous plants.

(c) Examine the green plants collected from ponds and ditches for Scenedesmus and Pediastrum. The former may often be found in great numbers on the glass sides of jars or aquaria.

(d) In midsummer search quiet pools for Water Nets. With a fine scissors cut out a piece of one and mount carefully in water. Study with a low power of the microscope. Some of the coenocytes will be found producing zoospores. Search for young nets forming within the old coenocytes.

(e) Collect fresh specimens of Sea Lettuce, put into a jar of 
water, and wateh the produetion of zoospores. Enteromorpha, which is common in brackish waters in the interior, may be substituted for Ulva.

(f) Study Ulothrix in like manner. It may be grown in an acquarium very easily, so as to be obtainable at any time, even in the winter. Draparnaldia may be found in running fresh water.

(g) Specimens of Oedogonium may be obtained by examining the small sticks and stems of aquatic plants from quiet waters. They may be recognized by the enlarged oogones.

(h) The Disk Algae occur in fresh-water pools as little green masses adhering to leaves, sticks, the stems of living plants, etc., where they should be sought. The sexual process and the development of the sexual organs occur in May, June, and July.

\section{LITERATURE OF CHLOROPHYCEAE}

Frank S. Collins, The Green Algae of North America, Tufts College, 1909.

G. S. West, A Treatise on the British Fresh-water Algae, Cambridge, 1904. 


\section{CHAPTER IX}

\section{PHYLUM III. ZYGOPHYCEAE}

\section{THE CONJUGATE ALGAE}

249. These plants are typically unbranched, unattached filaments, which easily fragment into short segments, or single cells. They are green, with chlorophyll, but in many cases this is obscured by the presence of a yellow-brown pigment in the cells. They propagate by the fission and ultimate separation of cells (hormogones) or by the formation of spores, but are wholly destitute of zoospores. They generate by the union of the protoplasm of pairs of ordinary cells (isogametes).

250. The dominant idea in this phylum is the physiological sluggishness of the cells, resulting in the feeble attachment of the cells to one another and the easy and usually early fragmentation of the filament, the absence of zoospores, and the reduction of the sexual reproduction to the sluggish union of the scarcely modified protoplasms of two vegetative cells. This is a phylum on the down-grade, and all of its members show more or less structural degeneration.

There are two classes:

I. Chlorophyll green plants with cellulose walls.

Class 5. Conjugatak.

II. Mostly yellowish-brown plants, with silicified walls. Class 6. Bacillarioideat. 


\section{Class 5. CONJUgataE}

In this class the lowest type is that of the filamentous Pond Scums, well represented everywhere by species of Spirogyra. In this genus the ribbon-shaped chloroplasts are longer than the cells, and are therefore more or less spirally coiled. In generation two cells unite by pushing out short opposing tubes until they come in

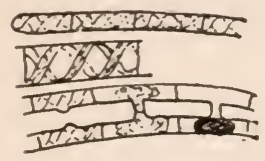

FIG. 70.-Spirogyra. contact; the contact walls then are absorbed leaving an open channel from cell to cell, and through this the protoplasm from one cell slowly passes to the other, the two protoplasms uniting into one mass, which rounds up and covers itself with a thick wall, thus forming a resting spore. The resting spore thus formed is set free by the decay of the dead cell-walls of the old filament surrounding it; it then falls to the bottom of the water, and remains there until the proper conditions for its growth appear.

251. More commonly this sexual union takes place between cells of different filaments, as described, but in some species such a union takes place between contiguous cells in the same filament, the tubes forming at the contiguous ends.

252. The germination of the resting spore is a simple process. The inner mass enlarges and bursts the outer hard coat; it then extends as a cylindrical cell, in which after a while a transverse partition forms, and this is followed by another and another, until an extended filament is produced.

253. In the Desmids the filaments usually fragment easily into single cells, which then grow more or less after separation. However in the lower Desmids the cells are still in filaments (Family Desmidiaceae). In the second 
family (Closteriaceae) the elongated cylindrical cells separate early and become more or less attenuated, as in Closterium. In a third family (Cosmariaceae) the flattened, more or less constricted cells separate very early, and in many cases become terminally much lobed or otherwise modified. Of the less modified desmids the species of Cosmarium are good examples, while those of Euastrum and Micrasterias are

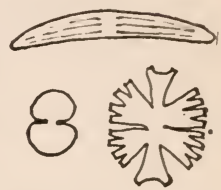

FIG. 71.-Desmids: Closterium, Cosmarium, and Micrasterias. greatly modified, the cells of the latter being divided into many pointed lobes.

254. In generation the desmid cells break open at the middle (where there is commonly a joint in the wall) and the two protoplasms (isogametes) unite into a zygote, which eventually becomes a thick-walled resting spore. After some time the resting spore germinates by rupturing its wall and dividing the contents into two, four or eight new non-ciliated cells which eventually become like the parent cells.

255. Desmids are fresh-water plants, floating free in the waters of quiet pools, or entangled with mosses or other aquatic plants.

\section{Class 6. BACILLARIOIDEAE}

256. The plants of this class are the Diatoms, numbering about 5700 species, or even as many as 10,000 species in the opinion of some botanists. Some diatoms are filamentous, but in the greater number the filaments fragment early into single cells. The cells contain chlorophyll, which is commonly hidden by the addition of diatomin, a yellow-brown pigment. A few diatoms are colorless, and hysterophytic, and therefore are "fungi." 
257. The cellulose walls in most diatoms soon become more or less silicified and rigid, and incapable of further expansion. 'This is probably a protective device, many diatoms living at or near the surface of the ocean waters where softer walls would be likely to be crushed. This rigidity of their walls has brought about some structural details that are peculiar to this group of plants, and which are quite puzzling to the beginner if not considered in connection with the origin of diatoms and their relationship to the filamentous types.

258. In order to understand the structure of any diatom it is necessary to consider it as one cell of a cylindrical, angled, or flattened filament. These cells are usually short (measured along the axis of the filament), so that when separated from the other cells they lie with one end up, and thus show a cross-section of the filament. Compare this with the end view of the cells in a filamentous plant like Ulothrix or Spirogyra. As in Desmids, the cells of the Diatoms are transversely jointed, allowing the two halves (really the two ends of the cells) to move apart, and thus enlarge the cell cavity. Each half of the silicified wall is shaped like a paper box cover, the flat surface corresponding to the "valve" and the curving ring to the "girdle." Sometimes there are

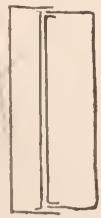

FIg. 72.Propagation of a diatom. additional rings known as "interzones," giving a good deal of flexibility to the diatom cell wall.

259. Diatoms propagate (1) by the enlargement of the protoplasm of the cell resulting in its elongation, and the formation of two walls in the plane of the joint which become the ends of the two new cells ("fission"); (2) by the separation of the two halves of the cell allowing the escape of the protoplasm which then rapidly grows into a 
larger new cell ("rejuvenescence"). They generate by the eseape and union of the protoplasms of two contiguous cells whose half-cells have separated, resulting in the formation of one or two new and usually much larger cells. Small biciliate isogametes have been doubtfully reported in some marine diatoms.

260. There are two general kinds (orders) of Diatoms, namely, the Round Diatoms (Eupodiscales) with the eells mostly round in end view, and the Flat Diatoms (Naviculales) with the filaments flattened in end view.

261. The Round Diatoms are mostly marine and fossil. The ends of the cells are usually marked radially with lines or rows of dots, as in Melosira, Coscinodiscus, Actinodiscus, etc. Some Round Diatoms

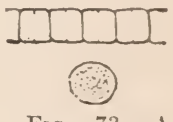

FIG. 73.-A Round Diatom; IIelosira. form long filaments (Melosira).

262. The Flat Diatoms occur abundantly as freshwater, marine, and fossil plants. The ends of the cells

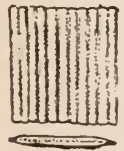

Frg. $74 .-\mathrm{A}$ Flat Diatom; Bacillaria.

(transection of the flat filament) are often marked transversely or pinnately by dots or lines. In many of our most common Flat Diatoms (e.g. Naviculaceae) there is a median longitudinal slit ("raphe") in the end wall, which probably has to do with the motility exhibited by these plants (Par. 174).

263. Origin of Zygophyceae. It may be assumed that the plants of this phylum have been derived from other filamentous plants, and that the adhesion of cell to cell, and the consequent formation of a multicellular plant body, had become a well established habit long before the peculiarties arose which set them off as Zygophyceae. We must search among the Confervoideae of the preceding phylum for the ancestral types from which the Conjugate Algae may have descended. Such plants as 
Microspora and Ulothrix could very well serve as the originals which have been modified successively into the Pond Scums, the Desmids and the Diatoms. The limited fragmentation of the filament in Ulothrix is so much increased in the Conjugate Algae as to render the production of zoospores unnecessary. In like manner the sluggish protoplasm of the Conjugate Algae is correlated with the disappearance of the freely motile gametes and the degeneration of the sexual process into a sluggish conjugation, which in some Desmids and Diatoms resulte in the partial (if not complete) suppression of the sexual act. According to this view "conjugation" is the result of degeneration. It is sexual reproduction on its way toward disappearance. Instead of affording an example of the beginning of sexuality, as has so often been suggested, these plants show sexuality on its way to disappearance. Furthermore, it is obvious that the Conjugate Algae constitute a lateral phylum which is related to other phyla only in its lower members, and that its higher members depart more and more widely from all other forms of plants.

Laboratory Studies. (a) Collect a quantity of bright green pond scum, which always abounds in shallow ponds and pools in the spring, summer and autumn, and preserve in a dish of water. Collect, also, some which has begun to turn yellow and brown. Upon mounting a little of the first in water and examining with a high power it will be found to consist of threads of cylindrical cells, each containing one or more spiral chloroplasts (Spirogyra) or star-shaped chloroplasts (Zygnema). Upon mounting some of the second collection, here and there the formation of resting spores may be observed. In all cases care must be taken not to mount too great a quantity of the material, nor to injure the plants by rough handling.

(b) Collect a quantity of pond scum and other aquatic vegetation. Mount portions of this material and search for desmids, using a low power objective. Two-lobed desmids 
(Cosmarium) of a bright green color may frequently be found. The large lunate desmids (Closterium) are of ten more common. In the latter the clear protoplasm at each end is always streaming rapidly.

(c) Round Diatoms may be obtained of dealers in laboratory material, or mounted slides may be used. A few Round Diatoms may be found occasionally in fresh-water ponds, and they often occur on the surfaces of marine seaweeds.

(d) Collect a little of the brownish-yellow scum which in early spring gathers on the top of the water of brooks, ditches, and pools. Mount in water and examine with a high power. Hundreds of Flat Diatoms may be seen moving rapidly in every direction across the field. In any such preparation many species of various shapes will be found. The prevailing forms, however, are much flattened and somewhat dianond shaped in end view.

(e) Study in like manner the slimy coating upon dead leaves and twigs in water in the summer for diatoms. On some of these very fine markings may be found.

(f) Here again mounted slides of Flat Diatoms may be used with profit, but it is well to study living specimens so as to be able to observe their motility.

(g) For future study in the laboratory the Conjugate Algae should be preserved in bottles of water containing just enough alcohol, glycerine, formaldehyde or carbolic acid to prevent their decay. One-fourth or fifth of the first and second, onetenth of the third, and enough of the last to give a decided odor, will usually do well enough. A 2 per cent. solution of potassium acetate made light blue by addition of copper sulphate will preserve the green color of these plants, if kept in the clark.

\section{LITERATURE OF ZYGOPHYCEAE}

G. S. West, A Treatise on the British Fresh-water Algae, Cambridge, 1904.

Frank S. Collins, The Green Algae of North America, Tufts College, 1909.

G. B. De Toxi, Sylloge Algarum, Vol. II, Padua 1891-1S94.

H. Van Heurck. A Treatise on the Diatomaceae (Engl. trans.), London, 1896. 


\section{CHAPTER X}

\section{PHYLUM IV. SIPHONOPHYCEAE}

THE TUBE ALGAE

264. These plants are filamentous, saccate or erectdendroid, and are composed of coenocytes instead of distinct cells. In the first (primitive) forms the plant body consists of a row of long bi- or poly-nucleated segments (coenocytes) arranged in a simple or branched filament, which is more commonly rooted below. When the filament has cross partitions it is said to be septated. In many Tube Algae there are no partitions in the vegetative portions of the plant, and such are said to be continuous.

265. They are propagated (1) by the internal division of the protoplasm of a coenocyte (sporangium), or even of the whole plant into spores (ciliated zoospores in the water-walled spores in the air); (2) by the condensation of definite masses of protoplasm directly into thick-walled spores (chlamydospores). Their generation shows all gradations including the union of (1) ciliated isogametes; (2) ciliated heterogametes; (3) ciliated sperms, with eggs; (4) antherid nuclei, with eggs - in all cases producing zygotes, which usually become thick-walled resting spores.

266. The dominant idea here is the development of coenocytes instead of distinct cells, and this has been consistently adhered to even when the plant body has shown otherwise a considerable amount of differentiation. 
267. 'They are typically aquatic, green plants (holophytes), but many have become parasites or saprophytes, and suffered degradation into "fungi" (hysterophytes). The number of species now known is about 1260. The holophytes are readily separated into two classes, the Lower Tube Algae (Vaucherioideat) and the Higher Tube Algae (BryopsidoideaE), and from the first have been derived a considerable number of hysterophytes which may be separated as a class of Tube Fungi, or Lower Fungi (Phycomyceteae).

268. Water Flannel (Cladophora) is one of the commonest genera of the Lower Tube Algae, occurring in large tangled masses of stout branched filaments in fresh-water streams, or even in salt waters. Its coenocytes have thick walls, with two to many nuclei. In their propagation and generation they so closely resemble Ulothrix and Microspora that they were formerly included in the same family.

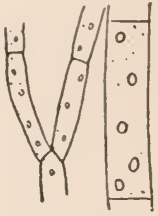

FIg. 75.

Cladophora. Zoospores with two or four cilia escape from the segments and after a free-swimming period come to rest and grow directly into new plants. Likewise biciliated isogametes issue from similar segments, and fuse into zygotes.

269. The Green Felts (Vaucheria) are good representatives of one of the families in which the plant body

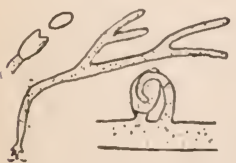

FIg. 76.- Vaucheria. is a continuous coenocyte. 'They are coarse, green, tubular, branching and rooted plants which grow in abundance on the moist earth in the vicinity of springs, and in shallow running water, forming dense felted masses.

270. They propagate by large compound motile zoospores, formed in the ends of the branches. Each zoo- 
spore eventually forms a wall around itself, and then proceeds to elongate into a new plant-body.

271. Generation takes place in special, usually lateral, segments. Both antherids and oogones develop as protuberances upon the stem. The antherid is long and rather narrow, and soon much curved; its upper portion becomes cut off by a partition, and in it very small biciliated sperms are developed in great numbers. The oogone is short and ovoid in outline, and usually stands near the antherids. In it a partition forms at its base; the upper portion becomes an oogone, and its protoplasm condenses into a rounded body, the egg. At this time the wall of the oogone opens, and permits the entrance of the sperms which were set free by the rupture of the antherid wall.

272. Upon coming into contact with the egg one sperm fuses with it; the fertilized egg (zygote) immediately begins to secrete a wall of cellulose about itself, and it thus becomes a resting spore. After a period of rest the thick wall of the resting spore splits, and through the opening a tube grows out which eventually assumes the form and dimensions of the full-grown plant.

Here must be placed half a dozen families of hysterophytic plants, the "Tube Fungi," often known as the

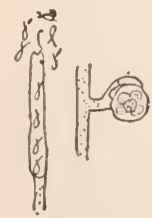

FIG. 77.

Saprolegnia. "lower fungi," and to be regarded as degenerate descendants of some such holophytic form as Vaucheria.

273. The Water-molds (Saprolegniaceae) are colorless saprophytes or parasites. They are generally to be found in the water, attached to the bodies of living or dead fishes, crayfishes, etc., or in decaying animal or vegetable matter, in or out of the water. The plantbody is greatly elongated and much branched, and is 
basally rooted. All its vegetative portion is continuous; the reproductive portions only are separated from the rest of the plant-body by partitions.

274. The propagation is very much the same as in Green Felt. It may be briefly described as follows for Saprolegnia: The protoplasm in the end of a branch becomes somewhat condensed, a partition forms, cutting off this portion from the remainder of the filament, and the whole of its contents becomes converted by internal cell division into zoospores provided with two cilia. These soon escape from a fissure in the wall and are active for a few minutes, after which they come to rest and their cilia disappear. In one or two hours they germinate by sending out a filament, from which a new plant is quickly produced.

275. The sexual organs also bear a close resemblance to those of Green Felt. The oogones are spherical, or nearly so (in most of the species), and contain from one to many eggs, which are fertilized by means of antherids, which usually develop as lateral branches just below the oogones. Fertilization takes place by the direct contact of the antherid and the passage of its contents into the oogone by means of a tubular process from the former. In some species there is no transfer of the contents of the antherid, and in others again there are no antherids. These eggs must therefore develop without fertilization, indicating that sexuality is disappearing in these plants. Eventually each egg becomes covered with a wall of cellulose and is thus transformed into a resting spore, which later germinates by sending out a tube, as in Green Felt.

276. The Downy Mildews (Peronosporaceae) and White Rusts (Albuginaceae) live parasitically in the tissues of higher plants. They are composed of long 
branching tubes, whose cavities are continuous throughout. They usually grow between the cells of their hosts, and draw nourishment from them by means of little

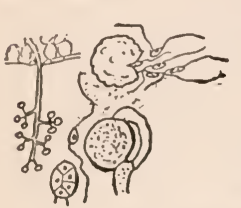

branches (haustoria), which thrust themselves through the walls.

277. The asexual spores (eonidia) are produced upon branehes (conidiophores) which protude through the epidermis of Fis. 78.-Plasmopara the host. In the Downy Mildews (Per. viticola.

onospora, Phytophthora, Plasmopara, etc. ) these branches find their way through the breathing-pores and bear their spores singly upon lateral branchlets; in the White Rusts (Albugo) the conidia-bearing branches collect under the epidermis and rupture it. Here the conidia are borne in chains or bead-like rows.

278. In some genera the relationship to the Water Molds is shown by the fact that these conidia upon falling into water become true sporangia, within which few to many zoospores

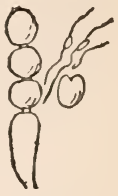

Fig. 79. Albugo. are produced. These after a free-swimming period become motionless and germinate by means of a tube which bores its way into the host. In two genera, however (Bremia and Peronospora), the conidia themselves germinate directly by a tube.

279. The sexual reproduction takes place in the intercellular spaces of the host. Lateral branches of two kinds appear upon the hyphae; those of one kind (the young oogones) beeome greatly thiekened and finally assume a globular shape; the other branches (the young antherids) become elongated and club-shaped, both becoming separated from the main filament by eross partitions. The antherid comes in contact with the oogone which it penetrates by a tube, through which fertilization occurs, 
and thereupon the egg secretes a thick double wall, and becomes a resting spore.

280. The resting spores remain in the tissues of the host until the latter decay, which is generally in the spring. Germination then takes place, in some species by the production of a tube (either germ-tube, or conidiophore), in others by the division of the protoplasm into zoospores whose subsequent development is like that deseribed above in case of the conidia.

281. The Black Molds (Mucoraceae) are saprophytic and sometimes parasitic plants; they are composed of long branching non-septate filaments (hyphae), which always form a more or less felted mass, the mycelium. The protoplasmic contents of the filaments are more or less granular, but they never develop chlorophyll. The cell walls are colorless, except in the fruiting filaments, which are often dark-colored or smoky (fuliginous); hence the name of Black Molds.

282. The mycelium sometimes develops exelusively in the interior of the nutrient medium; in other cases it develops partly in the medium and partly in the air. In some species the mycelium may attack the filaments of other plants of the same order, and even exhibit a weak parasitism upon higher plants.

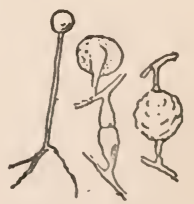

Fig. 80.-Mucor.

283. The reproduction of black molds is asexual and sexual. In the asexual reproduction (propagation) the mycelium sends up erect filaments, which produce few or many separable reproductive cells-the spores. The method of formation of the spores in a common black mold (Mucor) is as follows: The vertical filaments, which are filled with protoplasm, become enlarged at the top, and in each an arched partition forms, constitut- 
ing the so-called columella. The protoplasm in the enlarged terminal segment (sporangium) divides into a large number of minute masses (spores) each of which surrounds itself with a cell wall.

284. The spores are set free in different ways: in some cases the wall of the sporangium is entirely absorbed by the time the spores are mature; in other cases only portions of the wall are absorbed, produeing fissures of various kinds. The spores germinate readily when on or in a substance eapable of nourishing them, by sending out one or two filaments, which soon branch and give rise to a mycelium. If kept dry, the spores may retain their vitality for months.

285. Sexual reproduction (generation) may take place after the production of asexual spores, but it appears to be of rare occurrence in our commonest species. Two filaments in the air or within the nutritive medium, in contact send out small branches (here regarded as reduced sexual organs, the one an antherid, and the other an oogone); these elongate and become club-shaped, and at the same time become more closely united to each other at their larger extremities; a little later a transverse partition forms in each at a little distance from their place of union; the wall separating the new terminal segments is now absorbed, and their protoplasmic contents unite into one common mass (the zygote); the last stage of the process is the secretion of a thick wall around the new mass, thus forming a zygospore, i.e. a resting spore, which eventually germinates and sooner or later gives rise to a new plant.

286. In some Black Molds both gametes are formed upon different branches of the same mycelium (homothallic forms, monoecious). In many, however, the plants are of two kinds (dioecious), and sexual reproduc- 
tion occurs only when hyphae of the two kinds come into contact (heterothallic forms).

287. The Insect-fungi (Entomophthoraccae) are well represented by the Fly-fungus (Entomophthora muscae), which in the autumn is destructive to house-flies. It consists of small tubular coenocytes which grow in the moist tissues of the fly, and at last pierce the skin, producing minute terminal spores, which give the fly a powdery appearance. These spores (called, also, conidia) may be seen as a whitish halo surrounding the spot to which the fly (now dead) has attached itself. Round and thick-walled resting spores (formed by the union of gametes similar to those of Black

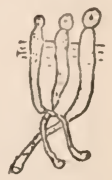

FIG. $81 .-$ Entomophthora. Molds) have been observed in some species, and may be studied in the Grasshopper Fungus (Entomophthora grylli), which destroys great numbers of grasshoppers every autumn.

The Sexual Organs of the Water Molds, Downy Mildews, Black Molds, and Insect Fungi show a progressive degeneration from the typical structure occurring in the Green Felts. In the Water Molds there is a suppression of the sperms, the antherid protoplasm being transferred directly to the egg. This is continued with little change throughout the Downy Mildews and White Rusts, which being non-aquatic could scarcely make use of motile sperms. The sexual organs of the Black Molds are apparently of the same general type as those of Water Molds and Downy Mildews, each being an end cell cut off from a reproductive filament, but in Black Molds these filaments show little differentiation. They unite prematurely, before the oogone has developed an egg, and before the other filament has developed its antheridial protoplasm. They are physically under-developed 
sexual organs, and are to be regarded as mere vestiges of the fully developed antherids and oogones of the Green Felts. They are sexual organs on the road to extinction. In the Insect Fungi the sexual organs are still more degenerated and vestigial in structure.

288. The commonest example of the Higher Tube Algae is the little Bladder Alga (Botrydium), found on

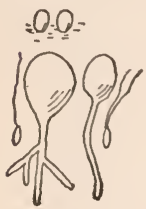

FIG. 82.Botrydium and Protosiphon. moist ground. It is a globular coenocyte a millimeter or two in diameter, with a branching root below. When in good vegetative condition it is bright green, but later it may be dull red. It is known to propagate by uniciliated zoospores, and thick walled chlamydospores. Its generation was long supposed to be by the union of biciliated isogametes, but these are now thought to belong to Protosiphon, a similar plant with an unbranched root.

289. In the shallow waters of the ocean there are larger Bladder Algae (Valonia) that when young are single globose or club-shaped coenocytes, firmly rooted below. They may reach several centimeters in height, and ultimately become more or less divided into segments. Their propagation and generation appear to be much like that of the little Bladder Algae.

290. The Sea Ferns (Bryopsis) are erect, slender, cylindrical, single coenocytes, rooted below, and pinnately branched above, and look like little trees, or fern-leaves. They

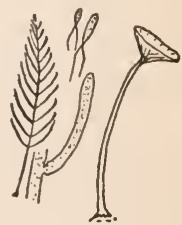

Fig. 83.-Bryopsis and Acetabularia. generate by biciliated heterogametes. They occur along the shores of the warmer oceans.

291. The pretty Sea Umbrellas (Acetabularia) are also erect, slender, cylindrical, single coenocytes, rooted 
below; but here the branches are in one terminal whorl and are united into an umbrella-like structure. They generate by biciliated isogametes. They occur in shallow tropical or sub-tropical marine waters.

292. In the Stoneworts (Charales) we find the highest development of the coenocytic structure. The plants are erect, slender, cylindrical rows of coenocytes, rooted below, and bearing many whorls of free branches. The stems are often corticated with a parallel layer of smaller coenocytes. They occur in the fresh or brackish waters of ponds and lakes.

293. The generation of Stoneworts is heterogamous, that is by the union of biciliated sperms, with non-ciliated

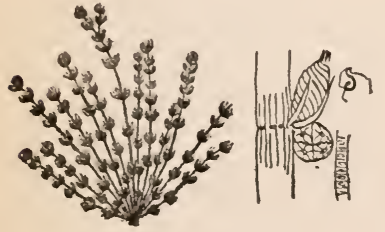

FIG. 84.-Chara. eggs. The sperms are produced in compound antherids which are globular manycelled bodies, in the interior of which certain multicellular filaments (the antherids) produce the sperms singly in the cells. Each sperm is a spiral thread of protoplasm, provided with two long cilia at one end, by means of which it swims rapidly through the water.

294. The oogone is a single cell, which soon becomes covered (corticated) by the growth from below of a layer of five spirally wound coenocytes, which are prolonged into a 5- or 10-celled erown. This covering, which here develops before fertilization, is analogous to the protective covering which in Coleochaete, forms after fertilization has taken place. In the oogone is the egg, which is non-ciliated, and very much larger than the sperms.

295. The sperms enter the opening at the apex of the oogone and one of them entering the egg fertilizes it. 
The oogone and its covering now become thicker-walled and constitute a spore-fruit. The latter soon drops off and falls to the bottom of the water, where it remains at rest for a time and later germinates by sending out a jointed filament, which eventually gives rise to a branching plant like the original.

296. About 160 species of Stoneworts are known, all included in the single order Charales. The two families, Nitellaceae and Characeae are separated by the structure of the crown, which is 10-celled in the former, and 5celled in the latter. The principal genus of the first family is Nitella, and of the second Chara; each contains in this country a dozen or more widely distributed species.

297. Summary. The attempt has been made in the foregoing pages to treat the coenocytic plants in accordance with the theory that they have been derived from the many-celled filamentous algae of the Ulothrix type in the Phylum Chlorophyceae, where the segments of the filaments are true cells, each having a single nucleus. And it is regarded as probable that the coenocytic structure was gradually attained by the formation of fewer and fewer partitions in the succession of filamentous plants.

298. Accordingly the Cladophoraceae are given place at the beginning of the phylum, and they are regarded as having given rise to two general lines of development, one of which is characterized by the retention of a distinctly filamentous structure, while in the other the coenocyte undergoes great differentiation into "root," "stem" and "leaves." If we designate these lines by their highest holophytic representatives, we may call them (1) the Vaucheria line, and (2) the Chara line.

299. In passing from Cladophoraceae to Vaucheriaceae 
the plant body has become almost completely non-septate and the sexual reproduction has become heterogamic. This plant body and heterogamic generation have been bequeathed to the hysterophytes of this line (Class Phycomyceteae), and both suffer marked degeneration in passing from family to family.

300. So also we may trace an evolutionary line from Cladophoraceae to Valoniaceae (and Botrydiaceae), Bryopsidaceae, Dasycladaceae, and the Charales, in all of which the erect, rooted and regularly branched plant body becomes more and more marked. Here there is again a passage from isogamy to heterogamy.

Laboratory Studies. NотE: In addition to those mentioned below many marine forms, as Codium, Penicillus, Halimeda, Udotea, etc., occur in warm seas, and may be studied with profit. (a) Collect a quantity of Water-flannel (Cladophora) and put it into a large dish of water, leaving it over night. Next morning the side of the dish which is nearest to the light will show a green band at the water's edge, due to the myriads of zoospores which escaped during the night. Mount a drop of water and search for zoospores. Occasionally the escape of zoospores may be seen by mounting a number of filaments and searching carefully.

(b) Collect a quantity of terrestrial Green Felt (Vaucheria) and preserve it in a dish of water. After a few hours a large number of zoospores may be observed collected at the edge of the water nearest to the light.

(c) Examine carefully mounted specimens of the bright green filaments, and look for the thickened branches which produce the zoospores.

(d) Select some of the oldest, yellowish filaments. Mount and examine with a low power for the sexual organs. In collecting specimens for the study of the sexual organs it is usually necessary to take those masses which are yellowish and appear to be dying or dead.

(e) Kill a few flies in strong alcohol and place them in a dish containing algae freshly gathered from some ditch or pool. After a day or two the flies will usually be found to be covered 
with whitish masses of radiating hyphae of Saprolegnia or related genera. Remove some of these hyphae and examine for zoospore formation. Somewhat later oogones and antherids may often be found. A water mold (Saprolegnia ferax) frequently occurs upon the bodies of young fishes, especially in fish-hatcheries where it is occasionally very destructive.

(f) In the Spring the leaves and stems of shepherds'-purse and peppergrass may of ten be found covered underneath with a white mold-like growth (Peronospora parasitica). Carefully scrape off a little of this growth and mount first in alcohol, afterward adding a little potassium hydrate. The irregularly branching filaments will be seen to bear here and there white, broadly ellipsoidal conidia. Similar studies may be made of the Grape-mildew (Plasmopara viticola) on grapc-leaves in autumn, and the Lettuce-mildew (Bremia lactucae) on cultivated and wild lettuce from spring to autumn.

(g) Make very thin cross-sections of a leaf affected with a Downy Mildew, when the latter has passed the period of its greatest vegetative activity. Mount in alcohol (to drive out air-bubbles), then add potassium hydrate, and look for the resting-spores, which in some species are of a dark brown color.

(h) White Rusts occur on many plants: one (Albugo candida) on shepherd's-purse, peppergrass, radish, etc.; another ( $A$. bliti) on Amaranthus; and another (A. portulacae) on purslane. For conidia make very thin cross-sections of leaves, through a white-rust spot, and mount as above. The resting spores (which are dark brown) are easily obtained in the leaves of Amaranthus and purslane and in the distorted stem of the radish.

(i) In the study of Black Molds it is mostly necessary to make use of alcohol for freeing the specimens of air; afterward they usually require to be treated with a dilute alkali (as a weak solution of ammonia or potassium hydrate), which causes the filaments to swell up to their original proportions.

(j) Cut a lemon in two, and, squeezing out most of the juice, expose the two halves to the air af an ordinary laboratory or living-room for a few days, when various molds will begin to develop. Under favorable circumstances Black Mold (Mucor) will predominate. It can be told by its dark color and the minute round black sporangia on the ends of the erect filaments. 
Mount a few filaments (as directed in $i$ above) and examine filaments, sporangia, and spores.

(k) Moisten a piece of bread and then sow here and there on its surface a few spores of Black Mold; cover with a tumbler or bell glass. In a few hours a new crop of Black Mold will begin developing. The nutritive mycelium may be studied by teasing out small bits of the newly infected bread.

(l) Place several clean glass slides in contact with a culture of black mold, as described in $(k)$. By removing these at different times the various stages of growth of the mold may be easily studied.

$(m)$ Collect a number of large fleshy fungi (Boletus, Lactaria, Agaricus, etc.) and place under bell jars for a couple of days. Usually a cream-colored mold (Sporodinia grandis) will begin to develop upon some of these. Transfer it to pieces of bread as in $(k)$ and study in a similar way. After a few days the zygospore formation will be observed, as this species is homothallic.

(n) In the latter part of summer and in the autumn examine the dead flies which adhere to windowpanes, door-casings, and especially to wires and strings hanging from the ceiling. The whitish powder around the fly will indicate the presence of the Fly-fungus (Entomophthora muscae). Mount some of this white powder in water and examine under a high power. Tear out small bits of the distended abdomen of the fly, and examine for internal portions of the parasite.

(o) In the autumn look for dead grasshoppers attached to the tops of weeds and grasses. Examine their interior tissues for thick-walled resting spores of Entomophthora grylli.

(p) In damp weather in the summer look for Botrydium on the hard, smooth ground of unused paths. It often appears on compact soil in greenhouses in the winter.

(q) Specimens of Valonia, Bryopsis, Caulerpa and Acetabularia may be obtained of dealers in laboratory material for study and examination.

$(r)$ Search the sandy margins of ponds, lakes, and slow streams for Stoneworts (Charales). They are generally found in water from a few centimeters to one or two meters in depth. Preserve such specimens temporarily in water which is frequently changed, but for future use preserve in alcohol. Study as follows. 
(s) Mount carefully a considerable portion of a fresh plant, and examine its structure under a low power. Note that in some species the stem is composed of a row of large coenoeytes surrounded by a coat of smaller ones. Look for the rapid movement of protoplasm which is so marked in these plants.

$(t)$ Mount several spore-fruits in various stages of development. Note the eovering layer of spirally coiled cells surrounding the oogone (in young specimens) or the resting spore (in older specimens).

(u) Mount several full-grown compound antherids. Carefully crush them and look for sperms, which are produced in chains of cells (antherids).

\section{LITERATURE OF SIPHONOPHYCEAE}

Frank S. Collins, The Green Algae of North America, Tufts College, 1909.

G. S. West, A Treatise on the British Fresh-water Algae, Cambridge, 1904.

F. E. Clements, The Genera of Fungi, Minneapolis, 1909.

W. Migula, Die Characeen, etc., in Rabenhorst's Kryptogamen Flora von Deutschland, Oesterreich u.d.Schweiz, Vol. V, Leipzig, 1897. 


\section{CHAPTER XI}

\section{PHYLUM V. PHAEOPHYCEAE}

\section{THE BROWN ALGAE}

301. The Brown Algae which are almost wholly marine plants of shallow waters, numbering about 1000 species, are all truly cellular, and range from small filamentous few eelled plants, to large massive organisms differentiated into roots, stems and leaves. They are browngreen in color, and contain other coloring matters in their cells in addition to chlorophyll. They are propagated mostly by laterally biciliated zoospores, and generated in the lower families by isogametes, and in the higher families by heterogametes, their union in all cases producing a simple zygote. The gradations in the sexual union of the gametes inclucle (1) biciliated isogametes, (2) biciliated heterogametes, (3) biciliated (or uniciliated) sperms and non-ciliated eggs.

302. In this phylum the dominant feature is the addition of the brown pigment, phycophaein, to the chlorophyll of the cells. With this character must be associated the typically motile, usually biciliated gametes, producing simple zygotes upon uniting, and the rooted plant body (from filamentous and small, to massive and large.)

303. Brown Algae probably originated in the vicinity of Ulotrichaceae in the Chlorophyceae. The phylum constitutes a "side line" diverging from the main evolutionary stem or current. 
304. Among the commonest of the smaller Brown Algae are the species of Ectocarpus in which the plant body is composed of simple or branched filaments which may

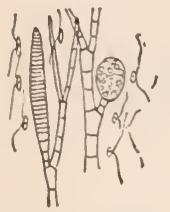

Frg. 85.

Ectocarpus. attain a length of many centimeters. They are firmly rooted below, and their tufted filaments float as dark brown masses in the ticle currents near the shore. They are propagated by zoospores produced in onecelled sporangia which occur on the sides of the filaments. These zoospores are oval, pointed anteriorly, and have two long cilia which are attached near together at one side. Generation takes place by the union of isogametes, resembling the zoospores, but originating in many-celled sporangia (gametangia) also occurring on the sides of the filaments. This union takes place in the water after both gametes have escaped from the sporangia, and it results in the formation of a zygote, which soon germinates and gives rise to a new plant.

305. The Kelps (Laminariaceæ) while large massive plants are still of a low type. In the Flat Kelps, or Devil's Aprons (Laminaria), there is a stout stem a centimeter or so thick, and a decimeter to nearly a meter long, firmly rooted below, and flattened into a broad "leaf" above. The whole plant may be a meter or even several meters in length, and the "leaf" a few centimeters to half a meter in breadth. On the surface of the "leaf" there develop

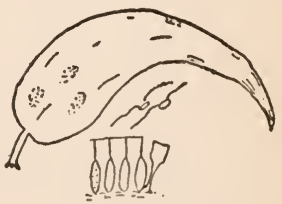

FIG. 86.-Laminaria. patches of 1-celled sporangia that produce zoospores like those in Ectocarpus. Gametes are not certainly known to occur in the Kelps.

306. Other kelps that are common on the Atlantic or 
Pacific coasts are the Sea Girdle (Cymathere) with a narrow beautifully ribbed "leaf"; the Sea Tree (Lessonia) with a stout branching stem bearing many small leaves; the Sea Palm (Postelsia) with an unbranched stem bearing a tuft of leaves at the top; the Bladder Kelp (Nereocystis) with a long, cord-like stem, often 10 to 15 meters long and bearing an air bladder at the top, to which is attached a tuft of large leaves; the Giant Kelp (Macroeystis) with a long, slender, cord-like stem, sometimes 50 to 75 meters long and bearing a row of large leaves toward its extremity, each with a basal air bladder; the Leafy Kelp (Egregia) with a flat stem which bears innumerable lateral leaflets and air bladders.

307. The highest of the Brown Seaweeds are the Rockweeds and Gulfweeds (Fucales) in which the plant body is of medium size (usually from a decimeter to a meter in length), rooted below, and massive and branching above. Their tissues, too, show a considerable differentiation; the cells are arranged in cellmasses, and these are differentiated into several varieties of parenchyma, and other

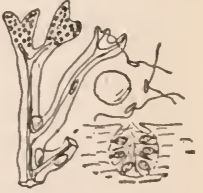

FIG. 87.-Fucus. tissues approaching, in some instances, to the condition which prevails in higher plants. Some species develop air bladders in their tissues.

308. With the foregoing there is found a marked differentiation of portions of the plant body into general reproductive organs, analogous to the floral branches of higher plants. The sexual organs are developed upon modified branches, which differ more or less in shape and appearance from those destitute of such organs.

309. In all Rockweeds the asexual reproduction ("propagation") has been suppressed, the emphasis being placed upon the sexual reproduction ("generation"). 
310. In common Rockweeds (Fucus) of the seashore the sexual organs are found in the thickened ends of the lateral branches. They occur on the walls of cavities (conceptacles), which are spherical, with a small opening at the top. The conceptacles are at first portions of the general surface, and afterward become depressed and walled in by the overgrowth of the surrounding tissues; they are thus in reality portions of the general surface.

311. The walls of the conceptacles are elothed with pointed hairs, which in some species project through the opening, and among these are found the sexual organs. The antherids are produced as lateral branches of hairs; each antherid is a thin-walled structure containing a large number of biciliated sperms, which escape by the rupture of the surrounding wall. Before rupturing, however, the antherids detach themselves and float in the water with their contained sperms.

312. The oogone is a globular or ovoid short-stalked body containing eight eggs. These escape from the oogone and float out through the opening of the conceptacle, into the open water. The sperms, which are liberated at about the same time, gather around the inactive eggs in great numbers, and by the vigor of their movements sometimes actually give them a rotary motion. Fertilization results from the union of one of these sperms with the egg, the zygote thus produced secreting a wall of cellulose about itself.

313. In germination the zygote lengthens and undergoes division into numerous cells; at the same time it elongates below into root-like processes, which serve to hold fast the new plant.

314. In the nearly related Gulfweeds (Sargassum) the plant body is composed of a distinct stem, rooted below, and bearing leaves above. The stem bears also many 
stalked air bladders which buoy up the plant when rooted, and float it when torn free. The short, thickened, elongated and clustered axillary branches (receptacles) which contain the conceptacles may be distinguished easily from the spherical air bladders. There are many species, one of which (Sargassum vulgare) is common along our eastern coast as a low-tide plant, half a meter to a meter long. Another smaller species (Sargassum bacciferum) floats in considerable

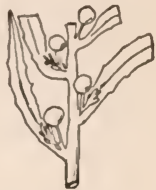

FIG. 88. Sargassum. quantities in the so-called "Sargasso Sea" of the central Atlantic Ocean. Its proper home is in the West Indian region, where it grows attached to rocks.

Laboratory Studies. Probably the best Brown Algae for the beginner to take up are Ectocarpus, Laminaria, and Fucus.

(a) Good material of Eetocarpus for study may be obtained of dealers in laboratory supplies. The specimens should be examined with reference to the general form and appearance of the plant body, and especially for the 1-celled, and the manycelled sporangia.

(b) Where fresh material cannot be secured, the Kelps may be studied very well from preserved specimens, which can also be obtained from dealers in botanical supplies.

(c) Study the tissues of Laminaria and other Kelps in cross and longitudinal sections.

(d) Make sections through the fruiting patches and examine the sporangia and "paraphyses," that is, the elongated, intervening protective cells.

(e) It is helpful to have jars of other Kielps, as Sea Palms, Bladder Kelps, Giant Kelps, Leafy Kielps, etc., for macroscopic observation.

(f) Sccure specimens of Rockweeds, fresh, alcoholic, or dry. Fresh ones may easily be found along the beach of the ocean after a storm. Alcoholic and dry speeimens and even living material ean easily be procured by purchase or exchange. Make thin cross-sections through the eonceptacles in the thickened ends of the branchlets. When mounted in water, even the 
sections from the dry specimens will frequently show the sexual organs quite well. It must be remembered that some species are dioecious, i.e. have the antherids on one plant and the oogones on another.

(g) Make very thin cross and longitudinal sections of different portions of the plant body, and study the tissues. Note particularly the boundary tissue (epidermis), and the cells constituting the mid-ribs and harder portions of the stems and leaves.

(h) Secure in like manner specimens of Gulfweed, and make macroscopic examination of the plant body, then if there is time available make cross-sections of the air bladders and the receptacles.

\section{LITERATURE OF PHAEOPHYCEAE}

George Murray, An Introduction to the Study of Seaweeds, London, 1895.

G. B. De Toni, Sylloge Algarum, vol. III, Padua, 1895.

W. G. FArLow, Marine Algae of New England and Adjacent Coast, Washington, 1881. 


\section{CHAPTER XII}

\section{PHYLUM VI. RHODOPHYCEAE}

\section{THE RED ALGAE}

315. The Red Algae are almost wholly marine plants, in structure ranging from small, simple, cellular, attached filaments to stout, massive, rooted plants which may attain considerable dimensions (half a meter or more). The smaller plants are often diffusely and beautifully branched into quite intricate patterns, rising from a short basal stem which is rooted below, while in the larger forms there may be a thick, rooted stem which bears one or more flat leaves above.

316. The cell walls of the Red Algae are more or less gelatinous in nature and swell greatly in fresh water, even dissolving. The cells usually are connected with one another by visible openings in their walls, so that the protoplasm is continuous from cell to cell.

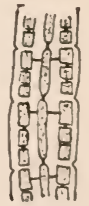

FIG. 89.

Connected cells.

317. The cells contain chloroplasts, but their green color is masked by the presence of a red or purple coloring matter (phycoerythrin) and sometimes a blue coloring matter (phycocyanin), so that the plants appear red or purple, instead of green, although in fact they are green; but lit must not be overlooked that a few species are parasitic, and therefore devoid of coloring matter!

318. The Red Algae are propagated by non-ciliated, naked cells which are separated from the plant, cither 
singly ("monospores") or in groups of fours ("tetraspores"); these float away and on germination give rise to new plants. They are generated heterogamically by the union of non-motile sperms with enclosed eggs, usually resulting in the growth of branching, sporebearing filaments, mostly covered, and constituting a primitive many-spored fruit ("cystocarp").

319. In those species (by far the greater number of the Red Seaweeds) in which tetraspores are produced, these

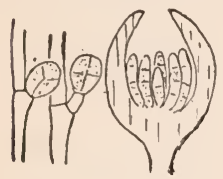

Fra. 90.-Tetraspores. give rise to the sexual plants which are mostly dioecious. The carpospores from the latter give rise, in their turn, to the tetrasporic plants. The nuclei of the latter possess the diploid number of chromosomes; thase of the former the haploid number, the reduction of chromosomes taking place during the divisions leading to the production of the tetraspores.

320. Here the dominant characters are the reddish pigment added to the chlorophyll of the cells, and the development of the zygote into a sporiferous, usually covered, tissue (the spore fruit; cystocarp). The important secondary characters are the definite and final attainment of heterogamy, and the mostly symmetrically branched and basally rooted plant body.

For the most part the Red Algae grow at very considerable depths in the waters of the ocean, although a few occur near the shore, and a very few live in fresh water. They are more abundant in the warmer waters, and become less frequent as we go toward the poles. The number of known species is about three thousand.

321. This phylum as a whole is poorly understood. Very little consideration has been given to the physical modification these plants have suffered through living 
(1) at such depths (where the light is greatly modified), and also (2) in waters of such considerable salinity. It is probable that this modification has masked their true relationship to other plants, as well as to one another.

322. One of the lowest of the Red Algae is the common "Laver" (Porphyra), of the class BANGioideae, of all coasts, in which the erect, deep purple, leaf-like, and basally rooted, plant body is composed of a single layer of cells. They propagate by monospores borne in the cell layer. In their very simple generation certain cells of the cell layer divide into non-ciliated sperms, while others become very slightly modified into oogones, each containing a single egg. The latter is fertilized by the entrance of the sperm through an opening in the cell wall, after which the zygote develops into usually eight spores. The fruit is thus of very simple structure.

323. In Nemalion (which with the succeeding plants belongs to the class FLORIDEAE), a branching, filamentous marine Red Alga, the clustered antherids produce small spherical, non-ciliated sperms. The oogone is prolonged into a slender structure, the trichogyne, and to this latter the sperm adheres and fertilizes the egg. After fertilization the egg divides, and each new eell sends out short crowded

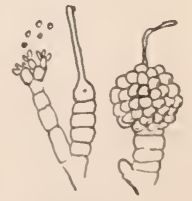

Fig. 91. Nemalion. branches which bear terminal spores. Here no protective envelope covers the spores, the fruit being very simple. Asexual reproduction is not known.

324. Here may be noted briefly the Corallines (Corallina) which are filamentous Red Algae which become so heavily coated with lime as to effectually hide their cells. This lime coating is like an ancient coat of mail with its flexible joints at intervals. The antherids and oogones are in separate terminal cup-shaped structures, those con- 
taining the oogones becoming the fruit after fertilization. Tetraspores occur in similar cup-shaped structures.

325. Polysiphonia contains plants in which the branching, filamentous plant body is composed of more than one row of cells, usually of a central row surrounded by an outer layer, completely covering it. These shallowwater plants are often of marked beauty both in structure and coloring. The tetraspores are

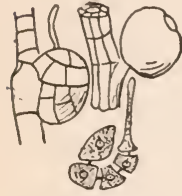

Fig. 92. Polysiphonia. produced in unmodified or slightly swollen branches, and originate within the tissues, but with the increase in size of the tetrasporangia they eventually reach the surface and slip out as large, deeply colored naked cells. The special antheridial branches consist of a central axis with numerous short, crowded, radiating branchlets whose extremities (antherids) abstrict the naked, colorless sperms. The oogone possesses a trichogyne, and is surrounded by a few protective cells. The sperms carried by currents of water come in contact with the trichogyne, and attach themselves to it and form cell walls. The nucleus of one passes into the trichogyne, and unites with that of the oogone. The oogone now fuses (for nutritive purposes, as there are no nuclear fusions) with a large nearby cell (the auxiliary cell) into which the zygote nucleus passes, and from which arise the filaments which produce the carpospores. In the meantime the surrounding cells produce an urn-shaped structure (pericarp) with an opening at the top from which the naked carpospores escape at maturity.

326. Irish Moss (Chondrus) is so easily obtained at the apothecaries that it may well be cited as one with a parenchymatous, much branched plant body. The oogones and afterward the spore fruits are immersed in 
the substance of the plant body. The plants are collected, washed and dried and so preserverl for human food (blanc mange) and especially as a food for convalescents. The structure of Callymenia is similar to that of Chondrus.

327. Among the very commonly collected Red Algae on either coast are specimens of Plocamium remarkable for the beauty of its color and the regularity of its branching.

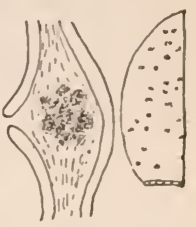

FIg. 93.

Callymenia.

Laboratory Studies. (a) It is better for the student to study the living plants of this phylum at the seashore, but the beginner should not fail to make a study of such specimens as may be accessible. Specimens for the study of structure should be preserved in alcohol or formalin, using sea-water instead of fresh water. However, much may be made out by the careful examination of dried specimens which may be obtained from dealers. Red Seaweeds may often be obtained "in the rough" which can be moistened and then pressed out and dried for study. Such material will often yield quite good specimens. Good mounted microscopic specimens may sometimes be obtained showing the structure of the plant as well as of the sexual and asexual reproductive organs.

(b) Make careful microscopical examination of Polysiphonia using alcoholic or formalin material. Such mounts should be made in sea-water or a 3 per cent. salt solution to avoid the swelling of the cell walls. In the course of the study the following should be noted: (i) the cellular structure of the plant body, (ii) the tetraspores, (iii) the antherids, (iv) the oogones (difficult to find), (v) the cystocarps with their spores (carpospores). The closely related Dasya may be substituted for Polysiphonia.

(c) Study the tissue of Chondrus.

(d) Dried specimens of some or all of the following genera, mounted on heavy white paper, or cardboard, should be available for macroscopic examination.

Porphyra, Batrachospermum, Corallina, Grinncllia, Nitophyllum, Polysiphonia, Dasya, Chondrus, Callophyllis, and Plocamium. 


\section{LITERATURE OF RHODOPHYCEAE}

George Murray, An Introduction to the Study of Seaweeds, London, 1895.

G. B. De Toni, Sylloge Algarum, Vol. IV, Padua, 1S97-1905.

W. G. Farlow, Marine Algae of New England and Adjacent Coast, Washington, 1881. 


\section{CHAPTER XIII}

\section{PHYLUM VII. GARPOMYCETEAE}

\section{THE HIGHER FUNGI}

328. The plants here brought together are all hysterophytes, being destitute of chlorophyll or any other similar coloring matter with physiological significance. In accordance with the theory underlying the treatment of all plant phyla in this book these hysterophytes must have been derived from some of the preceding holophytes, and it seems most probable that they came from the plants in the phylum immediately preceding this one. In other words, it is here assumed that the Higber Fungi are allied in structure to the Red Algae, and that the striking differences between them are correlated principally with the change from the holophytic to the hysterophytic habit, but it must be remembered also that the Red Algae are aquatic plants, while nearly all the Higher Fungi have adapted themselves to terrestrial or aerial (non-aquatic) conditions.

329. The Higher Fungi may be characterized as follows: They are filamentous plants, whose cells are always without chlorophyll. Visible protoplasmic connections between cell and cell are common. The filaments are mostly isolated, but sometimes they are compacted into parenchymatous masses, yet in few cases is there a conspicuous plant body comparable to the body of the related chlorophyll-bearing plants. This obsoleseence of the plant body results from the abandonment of the holophytic habit, which has rendered chlorophyll-bearing 211 
cells unnecessary. The vestiges of the plant body are present mainly as root-like absorbing organs, which directly bear the reproductive structures.

330. The Higher Fungi are propagated mainly by (1) the separation of special terminal cells (conidia), and (2) the separation of considerable fragments of the original plant body. Zoospores are unknown in this phylum. They generate by the union of the protoplasm of an antherid with the egg in an oogone, resulting in the production of a spore-fruit (sporocarp) consisting of (1) sporogenous and (2) sterile tissues. In the fertilization of the egg no instance is known of the production of motile sperms.

331. Because of the reduction of the plant body the spore-bearing structures, asexual and sexual, appear to be relatively large. Moreover, because of the dependent habit of the Higher Fungi it is necessary that many spores should be produced, so that correlated with their dependence is the great increase in the number of spores, and the size of the spore-bearing structures. Thus it happens that in many cases there is an actual increase in the size and development of the spore-bearing structures, especially of the spore fruits. In many Higher Fungi no sexual organs have been found, and it is thought that they may have disappeared through the degradation of the plant body.

332. This phylum contains about 64,000 known species, and these may be arranged under three classes, with an additional group of poorly understood, and unassorted plants.

A. Spore fruits containing one or more asci, with ascospores.

Class Ascosporeat.

B. Spore fruits containing one or more basidia, with basidiospores.

Class Basidiosporeat. 
C. Spore fruits much reduced, containing teliospores.

Class Teliosporeae.

D. Asci, basidia or teliospores unknown (artifieial group).

Fungi IMPERFECTI.

Class 14. Ascosporeae. The Ascus Fungi.

333. This large class includes chlorophyll-less plants which differ much in size and appearance, but which agree in producing their fruit-spores (carpospores) in sacs (asci), and because they are in sacs they are called sac-spores or ascospores. These spore-bearing sacs (singular, ascus; plural, asci) are endcells in the sporogenous tissue of the fruit of the fungus, and they tend to develop in a layer of uniform height-

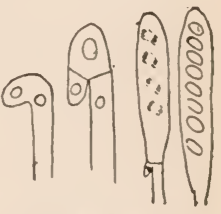

Fig. 94.-Development of asci and ascospores. the so-called "hymenium."

334. The sexual organs where known consist of oogones and antherids, and, after fertilization, produce a sporefruit (sporocarp) which includes the saes and sac-spores (ascospores). The most common number of ascospores is eight in each ascus; but it sometimes exceeds, and frequently falls short, of this number, there being sometimes no more than one or two.

335. In addition to the ascospores there are generally one or more other kinds of spores which are developed asexually. Some of these are doubtless to be regarded as the equivalents of the conidia of the lower groups, and accordingly will be so named here.

336. The Ascus Fungi include about 29,000 species, representing 15 orders and 86 families. In the treatment here a selection has been made of representative forms. 


\section{The Disk "Lichens" (ORDER DISCOLICHENES)}

337. The primitive Ascus Fungi (Ascosporeae) appear to have been parasitic on small, green algae (MYXOPHYCEAE and KHLOROPHYCEAE), and indeed this may have first taken place in the water. It is known that some of the proper Red Algae are parasitic, and the view here taken is that in the Disk Lichens we have a group of plants in which the parasitism has gone further, and has resulted in so great a modification of the plant body as to place them in another phylum.

338. The Disk Lichens abound almost everywhereon tree-trunks, rocks, old roofs, and in many regions upon the ground. They are for the most part of a greenishgray color, and hence are often called "Gray Mosses." Other colors, as black, purple, yellow, and white, are also common.

339. The plant-body of a Disk Lichen is composed of jointed, branching, colorless filaments, similar to those in

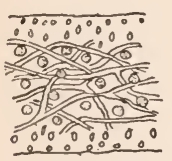

Fig. 95.-Section of a Disk Lichen. the other fungi, but usually more or less compacted together into a thallus, or even a branching stem. They obtain their nourishment from little green Myxophyceae or Chlorophyceæ to which the filaments attach themselves parasitically. These little hosts, which at first live free in water or on moist surfaces, eventually come to live in the midst of the moist tissues of the fungus parasite. They were formerly supposed to be parts of the lichen itself, and were called "gonidia," an objectionable term which is still in common use.

340. Disk Lichens are all of rather small size, varying from a millimeter or so, to 20 or 30 centimeters in length. For the greater part the plant-body is flattish, and adherent to the surface upon which it grows, but 
some species have more or less elongated branching stems.

341. Lichens propagate by the escape of some of the algal cells, with attached fungal filaments by means of eruptive areas ("soredia") on the plant body. When one of these comes to rest upon a favorable substratum it grows directly into a lichen plant body like the original. Ascxual spores appear to be wanting.

342. The sexual organs as far as known remind one of those of the Red Algae. The oogone, which is a spiral coil of cells, sends up a slender trichogyne to the surface of the plant body. Fertilization takes place by means of minute non-ciliated sperms which are produced in countless numbers in nearby cavities (spermogones) in the plant body. The sperms come in contact with the projecting trichogyne (doubtless aided by water) and fertilize the oogone, the result of which is the rapid upward

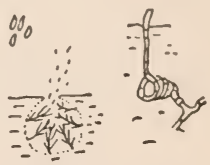

Fig. 96.-Sexual organs of Collema. growth of filaments, the enlarged terminal cells of which become asci. Mingled with the asci are long sterile cells (paraphyses) for the protection of the asci and ascospores in the hymenial layer, which forms a more or less diskshaped, or cup-shaped fruit. Such open fruits are known as "apothecia," in contrast with the closed fruits ("perithecia") of many of the fungi to be taken up later.

343. The ascospores germinate by sending out one or more tubes which develop directly into the ordinary filaments of the lichen-body. Experiments have shown that these filaments will not grow for any great length of time unless they come into contact with green algae of the proper species, to which they become attached, growing rapidly and surrounding them. On the other hand, in the moist tissues thus formed the green algae find protec- 
tion and ample opportunity for growing. There is thus an association between these plants which is mutually beneficial (symbiosis); the fungus lives parasitically upon the green algae, to which in return it furnishes shelter and moisture.

344. Among the Disk Lichens one of the simplest is the Thread Lichen (Ephebe) found on wet rocks. In it the fungus filaments grow over and around the cells of Scytonema or Stigonema filaments.

345. Some other Disk Lichens are parasitic

FIG. 97. Ephebe (parasitic on Scytonema). upon Nostoc colonies, as in the Jelly Lichens (Collema, Leptogium), while for the greater part they are parasitic on species of Protococcus, as is the case with the great majority of common lichens-Cladonia, Theloschistes, Physcia, Parmelia, Ramalina, Usnea, etc.

\section{The CUp-Fungi (ORDER PEZIZALES)}

346. The common Cup-fungus of the woods is a typical representative of this order. The familiar cup- or saucershaped growth is in reality the spore-fruit ("apothecium"), while the plant itself is out of sight. The plant consists of whitish, septate filaments which grow on or in the ground or in rotten wood, drawing their nourishment from decaying vegetable matter. These plants are therefore saprophytes. Some Cup-fungi, however, are known to be parasites.

347. But little is known as to the asexual reproduction of the Cup-fungi, but in some species conidia have been observed.

348. The sexual organs of Pyronema ("Peziza") are produced by the swelling up of the ends of certain of the filaments of the plant into globular or ovoid cells, the oogones, each having a projection (trichogyne). From below each 
oogone a slender branch grows out, and becomes the antherid, which soon comes into contact with the trichogyne. Fertilization is effected by the passage of the nuclei from the antherid into the trichogyne and from thence into the oogone. As a result numerous branches start out from the oogone, forming the ascogenous hyphae. At the same time their arise numerous sterile hyphae, from the tissues beneath the oogone, and these grow upward inter-

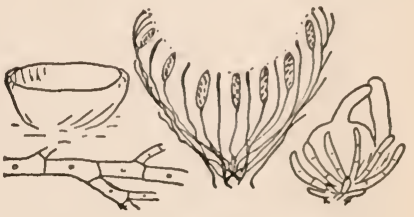

Fig. 98.-Peziza, and Pyronema. mingling with the ascogenous hyphae, forming a dense felted mass, which gradually takes on the size and form of the spore fruit. The upper ends of the ascogenous hyphae become enlarged into asci in which spores are developed, while the sterile hyphae make up the remainder of the apothecium, some of them standing among the asci as the so-called paraphyses. The asci and paraphyses all reach the same height, and make up the inner surface of the cup (the "hymenium"). Upon escaping from the asci, the spores germinate and produce the filamentous plants.

\section{The Morels (ORDER HELVELlaleS)}

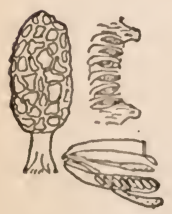

FIG. 99.

Morchella.

349. Morels are related to the Cupfungi, and like them are filamentous saprophytes living in the ground. The conical fruit is stalked, and its upper surface is studded with hymenial areas in which are asci and paraphyses similar to those of the preceding order. A common species is Morchella esculenta, in which the whitish fruit is 
from 7 to 12 centimeters high. It is edible and bears the name of Mushroom in the central United States.

350. The Plum-pocket fungus (Exoascus), which dis-

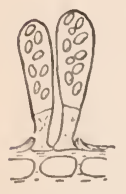

FIG. 100 . Exoascus. torts the young plums in spring and early summer, is a greatly reduced parasitic sac fungus (Order ExoAscales). Here the plant consists of delicate threads which penetrate the tissues of the plum, eventually producing on the surface poorly developed asci which are not aggregated into cups.

351. Two additional orders of lichens - the Slit Lichens (Graphidales) and Closed Lichens (Pyrenolichenes) are abundantly represented by species of Arthonia, Graphis, and Endocarpon. In the first order the apothecia are so nearly closed as to leave only a narrow slit, and in the second the asci are wholly enclosed, the fruits being perithecia, with only a minute pore or none at all.

352. The Slit-fungi (Order Hysteriales), are to be associated with the Slit Lichens, and may be illustrated by the Black Slit-fungus (Hysterographium) whose saprophytic filaments ramify through bark or old wood and eventually produce small, black, narrow, elongated, sessile apothecia, whose edges approximate, leaving only a narrow slit. Each ascus contains eight muriform,

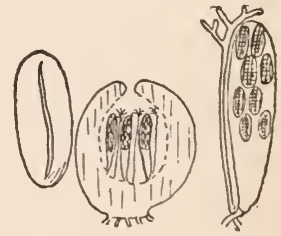

Fig. 101.-IIysterographium. elongated spores, and the asci are intermixed with branched paraphyses.

\section{The Closed Fungi (ORDER PyRenomycetales)}

353. The plants of this order are parasitic or saprophytic filaments, and their spore-fruits, which are simple or compound, are usually hard and somewhat coriaceous. 
354. A good illustration of the plants of this order is the Black Knot (Plowrightia morbosa), which attacks the plum and cherry. In the spring the parasitic filaments, which the previous year penetrated the young bark, multiply greatly, and finally break through the bark, and form a dense tissue. The knot-like mass grows rapidly, and when full-sized is usually from 2 or 3 to 10 or 15 centimeters long, and from 1 to 3 centimeters in thickness; it is solid and but slightly yielding, and is composed of filaments intermingled with an abnormal development of the bark-tissues of the host-plant.

355. The knot at this time is dark-colored, and has a velvety appearance, which is due to the fact that its surface is covered with myriads of short, jointed, vertical filaments, each of which bears one or more conidia. The conidia, which fall off readily, are produced until the latter part of summer, when the filaments which bear them shrivel up and disappear.

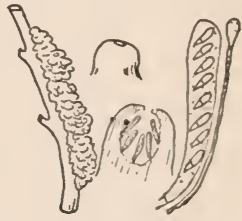

FIG. 102 .

Plowrightia.

356. During the autumn asci are produced, but require the greater part of winter to come to perfection. The asci grow in the cavities of minute papillie (perithecia), and are intermingled with slender filaments (paraphyses). Each ascus contains eight spores, which eventually eseape through an apical pore. These spores germinate by sending out a small filament, or sometimes two.

357. No sexual organs have as yet been observed. Possibly they exist in the dense tissues of the knot, and fertilization may occur in the spring or early summer, but they may have disappeared through the excessive parasitism of these plants.

358. The parasitic filaments of each year's knot gener- 
ally penetrate downward some centimeters into the uninjured bark, and remain dormant there until the following spring, when they begin the growth which results in the production of a new knot, as described above.

359. To this order belongs the Ergot (Claviceps), a common parasite upon heads of rye, and also many of the black growths upon the bark and wood of trees. Many species produce black spots upon living leaves, while many others occur upon dead leaves and twigs.

360. The Closed Fungi include a large number of exceedingly injurious species; they often attack and destroy not only plants, but also insects, upon which their ravages are sometimes very great.

\section{The Mildews (ORDeR PeRISPoRIaleS)}

361. These plants, which are mainly parasitic, are composed of branching septate filaments (hyphae) which form a white or dark web-like film upon the surface of the leaves and stems of their hosts. There are both sexual and asexual spores, and of the latter there are in some cases two or three different kinds, which are produced earlier than those that result from a fertilization.

362. In the Powdery Mildews (Family Erysiphaceae), which are all parasitic, the jointed filaments closely

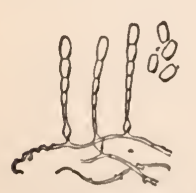

FIG. 103.-Conidia of Erysiphe. cover the leaves and other tender parts of many plants, and draw nourishment from them by means of suckers (haustoria), which project as irregular outgrowths from the side next to the epidermis. These suckers apply themselves closely to the epidermal cells, and penetrate them.

363. The crossing and branching filaments soon send up many vertical branches, which continue to form new 
cells below by cross partitions. The cells thus formed are at first oblong and cylindrical, with flattened ends; but the topmost ones soon become rounded at their extremities, thus giving rise to a row of cells, the spores, or conidia. These fall off successively and germinate at once by pushing out a tube, which gives rise to a new plant.

364. The sexual process (generation) in most species takes place late in the season. Two filaments crossing each other or coming into close contact swell slightly and send out from each a short branch; one of these becomes the oogone, and the other the antherid, both organs being very much reduced.

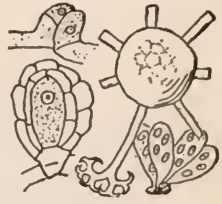

FIG. 104.-Generation of Erysiphaceae.

365. Fertilization is effected by the direct union of protoplasm. Eight or ten branches then bud out below the oogone, and growing upward soon completely enclose it in a cellular coat which eventually becomes hardened and turns brownish in color, constituting the spore-fruit (perithecium).

366. The oogone inside of the perithecium gives rise, by branching, to one or more large cells (young asci) filled at first with granular protoplasm, which soon forms two to eight spores (ascosporcs). Upon its outer surface the spore-fruit develops long filaments (known as "appendages"), probably for holdfasts. In some genera these terminate in hooks; in others they are dichotomously branched; in still others, needle-shaped; while in many species they end irregularly. The spore-fruits remain during the winter upon the fallen and decaying leaves, and finally, by rupturing, permit the asci, with the contained spores, to escape.

367. The Herbarium-mold (Aspergillus) is related to the Mildews and belongs to the order of Little Tubers 
(Aspergillales). It is common on poorly dried specimens in the herbarium, and also on moldy hay and decaying vegetation generally. It sends up vertical branches, which swell at the top and bear a great number of small protuberances (the sterigmata), each of which produces a chain of conidia.

368. The sexual organs appear a little later than the conidia. The end of a branch of the plant becomes coiled into a hollow spiral which con-

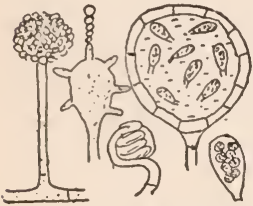

Fig. 105.-Aspergillus. stitutes the oogone. From below the spiral an antherid grows upward, and brings its apex into contact with the upper cells of the oogone. After fertilization other branches grow up around the oogone, and finally completely enclose it, as in the Mildews, described above. In the meantime from the cells of the enclosed oogone branches bud out, and finally produce many eight-spored asci on their extremities; later the asci are dissolved, and the spore fruit, now of a sulphuryellow color, contains a multitude of loose spores.

369. The Blue Molds (species of Penicillium) are related to Aspergillus. The conidial stage is a common Blue Mold on decaying fruit and pastry. The sexual organs resemble those of the herbarium-mold, and the spore-fruit is a minute truffle-like body as large as a coarse sand-grain.

370. Yeast-plants. A still greater degradation of the sac-fungus type is reached in the minute plants which occur in yeast. If a bit of yeast be placed upon a glass slip and carefully examined under high powers of the microscope, there will be seen very many small roundish or oval cells, of a pale or whitish color. They have a cell-wall, but generally the nucleus is indistinct. These 
little cells are Yeast-plants, and bear the name of Saccharomyces cerevisiae.

371. They reproduce by a kind of fission, called "budding." Each cell pushes out a little projection which grows larger and larger, and finally a cell-wall forms between it and the old cell and these sooner or later separate from one another. Under favorable circumstances certain cells form spores internally, and these are now regarded as asci, homologous with the asci of the higher sac-fungi. Yeast-plants are, therefore, to be considered as greatly simplified Sac-fungi, and they are members of

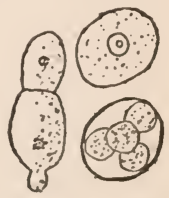

FIG. 106.-Saccharomyces. the family Saccharomycetaceae (of the Order Hemiascales) which has experienced what is probably the greatest reduction suffered by any plants of the Ascosporeae.

372. Yeast-plants are saprophytes, and live upon the starch of flour. They break up the starch, and in the process liberate considerable quantities of carbon dioxide which appears as bubbles upon the surface of the yeast. Another result of the breaking up of the starch is the formation of alcohol; hence the growth of yeast-plants in a starchy substance is always accompanied by what is known as alcoholic fermentation. The housewife and baker use yeast-plants for the carbon dioxide gas which they evolve, to give lightness to the bread, while the brewer and distiller use the same plants for the alcohol produced by their activity. (See Chapter IV, paragraph 139.)

373. The Truffles (Order Tuberales) are well known from their large underground spore-fruits, which are edible. Internally there are narrow tortuous channels on whose walls asci develop, each containing a number of spores. Little is known of their round of life, and the 
sexual organs have not been discovered. The part of the truffle that we eat is the large spore-fruit. These are collected in Europe by experts and preserved for the market, where they command high prices.

Laboratory Studies. (a) Collect fruiting specimens of the common fruticose lichen (Usnea), which grows upon branches of trees in forests. Make thin cross-sections of the stem, mount in alcohol, afterward adding dilute potassium hydrate. Study the filaments and their relation to the algae. Isolate some of the algae by tapping on the cover-glass, and note their resemblance to Green Slime (Protococcus).

(b) Make thin vertical sections through one of the fruiting disks, mount as above, and study asci, ascospores and paraphyses.

(c) Collect some of the small, flat, many-lobed lichens which grow on the bark of apple-, maple-, and oak-trees, and which have small blackish fruit-disks. Make careful sections of the plant-body through the fruit-disks, and study the whole structure, ascospores, asci, paraphyses, filaments, and algae.

(d) Search for cup-shaped fungi, in the spring, about old hot-beds and upon well-rotted barnyard-refuse. A common cup fungus of an amber color often to be met with in such localities is one of the best for the study of ascospores and asci. Make very thin sections at right angles to the inner surface.

(e) Collect the bright red saucer-shaped cup-fungus (Sarcoscypha coccinea) growing in the woods upon decaying sticks and having a diameter of 1 to 4 centimeters. Make similar sections.

(f) Collect a few Morels (Morchella esculenta), and make sections at right angles to the surface of the pits which cover the upper portion and examine for ascospores and asci.

$(g)$ Collect fresh specimens of Plum Pockets, and preserve them in alcohol. Study the fungus by making very thin sections at right angles to the surface. Each ascus will be found to contain several rounded ascospores.

(h) Collect Slit-fungi (Hysterographium) on the bark of oak or ash trees, or on dead twigs of sumach, and other shrubs. The apothecia are black and carbonaceous, and are about a millimeter long. 
(i) In early summer examine the choke-cherry and plum trees (wild and cultivated) for the young stages of Black Knot. Watch the development until the knot becomes velvety in appearance (about midsummer). Now make very thin crosssections of the knot and examine for conidia. The several stages may be readily preserved in alcohol for future study.

(j) Late in autumn and in early winter examine the knots on the same trees. Note the young perithecia, i.e. hollow papillae. Make very thin vertical sections through some of these. No perfect aseospores can be found at this time.

(k) Collect fresh knots in midwinter and make similar examinations, when the asci and ascospores may be found.

( $l$ ) In the autumn collect a quantity of leaves of the lilac which are covered with a whitish mold-like growth, the Lilacmildew (Microsphaera alni). Scrape off a bit of this Mildew after moistening with a drop of alcohol; mount carefully, adding a little potassium hydrate. Look for conidia and haustoria. Look also for spore-fruits, which appear like minute dark dots to the naked eye. Carefully crush the spore-fruits and observe the asci (four to seven) with their contained ascospores (6). Note the beautifully branched tips of the appendages.

$(m)$ Collect and study the mildews to be found on hops (Sphaerotheca castagnei), on cherry- and apple-leaves (Podosphaera oxyacanthae), on hazel- and ironwood-leaves (Phyllactinia suffulta), on willow-leaves (Uncinula salicis), on leaves and fruit of grapes (U. necator), on wild sunflowers, verbenas, etc. (Erysiphe cichoraccarum), on peas, grass, anemones, buttercups, etc. (E. communis).

(n) Place a few slips of green twigs in an ordinary plant-press, allowing them to remain until they become (1) moldy (conidial state), and (2) eovered with minute yellow globular bodies (the spore-fruits). These are known as the Herbarium-mold (Aspergillus herbariorum). Study as in the case of the Mildews. This can frequently be obtained by placing a piece of almost dry bread under a bell jar for a few days.

(o) Blue Mold may be obtained from decaying fruit, pastry, ete.

$(p)$ Place a minute piece of "compressed" yeast upon a glass slide, add a little water, cover with a cover-glass, tapping it down gently. After a short examination under a high power of 
the microscope add iodine, which will stain the starch-grains blue or purple, and the yeast-plants yellowish. Many of the latter will be found in process of budding.

(q) Repeat experiment $q$ on page 103 for production of earbon dioxide by yeast.

( $r$ ) Spread a little "compressed" yeast on a fresh-cut slice of potato or carrot; cover with a tumbler or bell-jar to keep it moist; after a few clays (four to eight) examine for cells which are producing ascospores.

(s) Commercial Truffles are natives of Europe, but they may be obtained for study in our markets. Make thin crosssections of the large spore-fruit and examine the ascospores and asci.

\section{Class 15. BASIDIOSPOREAE}

The Basidium Fungi

374. The plants, or rather the fruits, of this class are among the largest and most conspicuous of the fungi. They are mostly saprophytes whose abundant vegetative filaments (mycelium) ramify through the nourishing substance, and afterward give rise to the conspicuous spore fruits. The spores are produced usually in 4's upon slender outgrowths from the ends of enlarged cells ( $b a$ sidia), the latter usually arranged parallel to each other so as to form a spore-bearing surface (hymenium), which

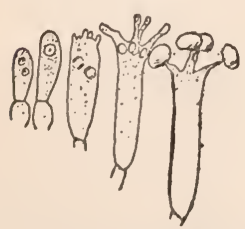

FIg. 107.-Development of basidia and basidiospores. may be external (as in Toadstools) or internal (as in Puff-balls).

375. The basidia in this class are here regarded as homologous with the asci of the Ascosporeae. The difference between them is that in the asci the spores in their development remain inside of the ascus cavity, while in the basidia the spores as they develop push out so as finally to become external. It is obvious that the ascus is the 
more primitive structure, and that the basidium is a later and a higher structure, probably derived from it.

376. There are about 14,000 species, which may be separated into nine orders, and about twenty-five families. A few only of these will be taken up here.

377. The lowest of the Basidium-fungi, the False Tubers (Order Hymenogastrales) are subterranean plants, with subterranean truffle-like, fleshy fruits, which like the truffles are edible and wholesome. They are distinguished from the truffles by the fact that they contain basidia instead of asci.

378. The Puff-balls (Order Lycoperdales). The plants of this order are saprophytes, whose spore fruits are often of large size, and usually more or less globular in form. The basidiospores are always borne in the interior of more or less regular eavities, and from these they escape by the deliquescence, and subsequent drying and rupture of the surrounding tissues.

379. The vegetative filaments of Puff-balls penetrate the substance of decaying wood, and the soil filled with decaying organic matter. They usually aggregate themselves into cylindrical root-like masses. After an extended vegetative period the filaments produce upon their rootlike portions small rounded bodies,

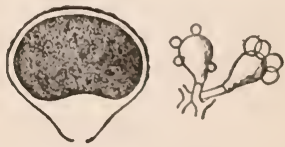

Fia. 108.-Puff-ball and basidiospores.

the young spore fruits, which increase rapidly in size and assume the forms characteristic of the different genera.

380. No sexual organs have yet been discovered, but analogy points to their possible existence upon the vegetative filaments just previous to the first appearance of the spore fruits. The spore fruits are composed of interlaced filaments loosely arranged in the interior, and an external more compact limitary tissue forming a rind 
(peridium). The basidia develop in a portion of the interior (the gleba), the remainder being sterile.

381. Many common puff-balls belong to the genus Lycoperdon, the type of the family Lycoperdaceae, of which there are a good many species. The genus Calvatia contains the Giant Puff-ball (C. maxima), whose spore fruit is sometimes 30 centimeters or more in diameter. Here it must be remembered that the proper plant lives underground, obtaining its food from decaying vegetable matter, while the great ball is a fruit containing basidia and basidiospores.

382. The Bird-nest fungi (Order Nidulariales) are so noticeable that they should be examined here. These little fruits usually grow on twigs and sticks, and are closed at first, and then open and cup shaped. They are a centimeter or less in height and width, and when mature contain several small brownish spore packets (the "eggs" of the little "nests"). When young these "eggs" are small eavities lined with basidia and surrounded by a dense layer of hyphae. When the tissues about them deliquesce these spore-bearing cavities persist as hard walled bodies.

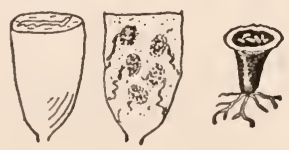

FIG. 109.-Development of bird-nest fungi.

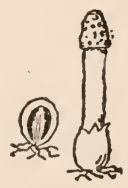

Fig. 110.-Development of stinkhorn.

383. The Stink-horns (Order Phallales) live as saprophytes, feeding upon decaying organic matter in the ground, or less frequently as parasites in the roots of various plants, eventually developing globose subterranean fruits. These fruits produce their spores in a circu- 
lar layer, and when mature become ruptured by the rapid growth of their central tissues, resulting in the formation of a stalk which earries up the slimy mass of spores to some distance above the ground. The intolerable odor of most of the species has earned for them their inelegant but quite appropriate common name.

384. The Toadstools (Order Agaricales). The fruits of these plants in some respects are the highest of the Carpomyceteae. They are not only of considerable size (ranging from 1 to 20 centimeters, or more, in height), but their structural complexity is so much greater than that of the other orders that they must be regarded as the highest of the fungi. Like the Puff-balls, they produce an abundance of vegetative filaments (mycelium) underground or in the substance of decaying wood. These filaments are loosely interwoven, becoming in some cases densely felted into tough masses or compacted into rootlike forms. While mostly saprophytic some appear to be parasitic, especially on the woody tissue of trees which are rotted by them. Sooner or later these underground filaments produce the spore fruits, which are mostly umbrella-shaped, as in common Toadstools and Mushrooms, or of various more or less irregular shapes, as in the Pore fungi, Coral fungi, etc.

385. The Mushrooms of the markets (Agaricus campestris) so commonly cultivated by gardeners, may illustrate the mode of development of the Toadstools (Family Agaricaceae). The vegetative filaments compose the socalled "spawn" which grows through the decaying matter from which it derives its nourishment. Upon this at length little rounded masses of filaments arise, which become larger and larger and are the young fruits. The circular spore-bearing layer is first internal and subterranean as in the Stink-horns, but it is brought above 
ground by the rapid growth of a central mass of stalk tissue, and later by a rupture of tissues the hymenium becomes external.

386. At maturity the spore fruit of the Mushroom consists of a short thick stalk, bearing an expanded um-

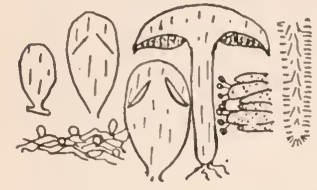

FIG. 111.-Development of mushroom. brella-shaped cap, beneath which are many thin radiating plates, the gills. Each gill is a mass of filaments whose enlarged end-cells (basidia) come to, and completely cover, both of its surfaces. The basidia produce spores in the usual manner for plants of this class, that is, upon slender stalks.

387. In the Pore fungi (Polyporaceae) the basidia line the sides of pores; in the Prickly Fungi (Hydnaceae) and Coral fungi (Clavariaceae) they cover the surface of spines and branches; while in the Leathery fungi (Thelephoraceae, Stereum, etc.) they form a smooth surface.

388. Nothing is yet known as to their sexual organs. Several botanists have described such supposed organs upon the vegetative filaments before the formation of the spore fruit, but there are grave doubts as to the correctness of the observations, and it is the general opinion that these organs have become obsolete.

389. The vegetative filaments (mycelium) of some species of this order (as Fomes fomentarius, etc.) often form thick, tough, whitish masses of considerable extent in trees and logs.

390. We know but little as to the germination of the spores and the subsequent development of the vegetative filaments.

391. Several families of more or less reduced basidium fungi which probably have been derived from the foregoing families, as the Ear Fungi (Auriculariales), Jelly 
Fungi (Tremellales) and the still more reduced Exobasidiales are probably to be placed here.

Laboratory Studies. (a) Colleet specimens of puff-balls in various stages of growth. Make very thin sections of the young spore fruit, and look for the cavities lined with spore-bearing cells (basidia).

(b) Mount in alcohol some of the dust which eseapes from a dry puff-ball. Examine with a high power, and note the spores and fragments of broken-up filaments.

(c) Dig up the earth under a cluster of young puff-balls, and observe the vegetative filaments. Examine some of these filaments under the microscope.

(d) In the summer look for Earth Stars (Geaster) in which the outer peridium is rolled back (open) when wet, and elosed when dry.

(e) Stalked Puff-balls (Tylostoma) may often be found with a stalk 3 to 10 or more centimeters long holding the spore cavity aloft.

(f) Look for Bird-nest fungi in fruit on sticks and twigs on damp ground. Note that when young the fruits are closed and solid, and that as they become older much of the internal tissue deliquesces, leaving the little egg-like spore packets.

(g) Collect specimens of Stink-horns in various stages of development and preserve in formalin. Make vertical sections of the immature (globose) spore fruit and note the circular spore layer. Study the basidia and basidiospores under a high power.

(h) Collect a few toadstools in various stages of development, securing at the same time some of the subterranean vegetative filaments. Note the appearance of the young spore fruits, and how they develop into the mature toadstool.

(i) Select a mature (but not old) spore fruit with darkcolored spores, cut away the stem, and place the top (pileus) on a sheet of white paper, with the gills down. In a few hours many spores will be found to have dropped from the gills upon the paper; these are the so-called "spore-prints".

(j) Examine the minute structure of various parts of the spore fruit and the vegetative filaments, and observe that they are composed of rows of cylindrical colorless cells joined end to end. 
(k) Make very thin cross-sections of several of the gills and carefully mount in water or alcohol. Note the layer of sporebearing cells (hymenium), with basidiospores borne upon little stalks.

(l) Examine the pores of fresh polypores in transection, looking for the basidia and basidiospores in the pores.

(m) In like manner make transections of Prickly Fungi, Coral Fungi, and Leathery Fungi, but in these look for basidiospores on the outer surface of the sections.

\section{Class 16. TeliosporeaE. The Brand-Fungi}

392. Here are collected a considerable number $(4200$ species) of extremely parasitic fungi, certainly related to the fungi of the two preceding classes. On account of their excessive parasitism they are structurally much reduced and degraded and this has served to hide their true relationship.

393. The plant body consists of branching septate filaments which run through the green tissues of higher plants, eventually producing usually erumpent spore clusters (sori), but no definite spore fruits (perithecia, or apothecia). Conidia of one or two kinds are usually present, and precede the formation of teliospores.

394. The Rusts (Order Uredinales) are minute,

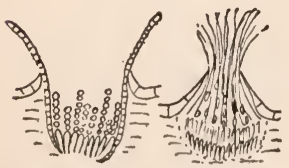

Fia. 112.-Development of aeciospores and pyeniospores. parasitic, greatly degraded fungi which grow in the tissues of higher plants.

395. A common Wheat rust (Puccinia graminis) may be taken as an illustration of the order. It is common wherever wheat is grown, and often greatly injures and sometimes entirely destroys the crop. Its round of life shows four wellmarked stages, as follows: (I) In the spring clusters of minute yellowish cups occur on the leaves of the 
Barberry. These eups are at first internal rounded bodies, in which spores (conidia) develop in chains, at length bursting through the lower epidermis. The spores quickly drop out and are carried away by the winds. This stage is known as the cluster-cup stage, and the spores as aecidiospores, or aeciospores.

396. Associated with this eluster-cup stage there are usually flask-shaped structures known as spermogones or pycnia, in which minute spores or spore-like bodies (pycniospores) are produced. They resemble the structures which produce sperms in the Disk Lichens. If they have a similar function in the rusts it has not yet been demonstrated.

397. (II) The aeciospores falling upon a wheat plant germinate there and penetrate its tissues, through the stomata, sending haustoria into the eells. After a few days, if the weather has been favorable, the parasite has grown sufficiently to begin the formation of large reddish spores (uredospores, or urediniospores) just beneath the epidermis, which is soon ruptured, exposing the spores in reddish lines or spots upon the stems and leaf sheaths. This is the Red-rust stage, so common before wheat-harvest. These red spores fall easily, and quickly germinate on wheat again, producing more Red rust, and so rapidly inereasing the parasite.

398. (III) Somewhat later in the season the parasitie filaments which have been produeing Red-rust spores begin to produce the dark-colored, thick-walled,

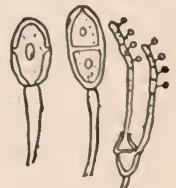

Fig. 113.-Ureaiospore, teliospore, and sporids. 2 -spored bodies characteristic of the Black Rust. Each 2-spored body consists of a continuous wall tightly enelosing the two spores, here called "teliospores." Being thick-walled, these spores endure 
the winter without injury, and when spring comes (IV) they germinate on the rotting straw forming a 4-celled "promycelium" and producing several (usually four) minute spores, called sporids. This is the fourth and last stage of the rust. Such sporids as fall upon Barberry-leaves germinate, and enter directly through the epidermis, giving rise to cluster cups again.

399. These stages (I, II, III) are so different in appearance that for a long time they were regarded as distinct plants, and received different names. Thus the first stage was classified as a species of Aecidium, the second as a species of Uredo, and the third as a Puccinia. We still preserve these names by sometimes calling the spores of the first accidiospores (or aeciospores) and of the second uredospores (or urediniospores), while the third name is retained as the scientific name of the genus.

400. For a long time many botanists did not believe the statement that this Wheat rust lives for a part of its life upon one host (barberry), and later upon another (wheat), but now this fact (known as "heteroecism") is well established not only for Wheat rust, but also for many other species.

401. The sporids cannot ordinarily produce rust directly upon wheat, probably because of the toughness of the epidermis; but it has been claimed (by Plowright) that when sporids germinate upon very young leaves of wheat-seedlings they penetrate the epidermis and then soon give rise to a red-rust stage. In such cases the cluster-cup stage is omitted. Possibly the rusts upon the spring wheat, oats, and barley in the Mississippi Valley and on the Great Plains where barberry is rare are sometimes propagated in this way. It has been shown also that on the Great Plains the red rust lives through the winter on the little wheat plants, and that 
its spores blow to the north in the spring from field to field, and back to the south in the autumn. Probably this is the more common mode of propagation upon the Plains. Recently it has been found also that teliospores occur on and in wheat kernels, and it is thought that young plants may be infected directly from these.

402. There are many kinds of rusts, distinguished mainly by their teliospores, which are single (Uromyces and Melampsora), in twos (Puccinia and Gymnosporangium), or several (Phragmidium). In many species the round of life is similar to that in the Wheat rust described above (heteroecious), the hosts, however, being different, but in others there appears to be a constant omission of certain stages. Moreover, in many species all the stages develop upon the same host plant (autoecious).

403. Cell fusions which are now regarded as having a sexual significance, and whose ultimate result is the production of teliospores, have been observed in the mycelium of some of the rusts. The simple sexual organs (usually end cells of adjacent filaments) coalesce into binucleate cells, which develop short hyphae of cells also binucleate. In some cases these produce directly one or more teliospores; in others one or two additional spore forms are intercalated as aeciospores and uredospores. Thus we may have either aecia or uredinia or both forming as the first result of the sexual act, but in any event the ultimate result is the production of teliospores. Accordingly these several spore forms are all primarily binucleated, but the two nuclei unite early in the young teliospore, and therefore the promycelial cells and sporids are uninucleate.

404. The Smuts (Order Ustilaginales). The plants which compose this order are all parasites living in the 
tissues of Flowering Plants. Like the Rusts, they send their parasitic threads through the tissues of their hosts, and afterward produce spores in great abundance which

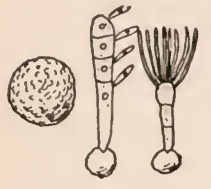

FIg. 114.-Teliospore and sporids. usually burst through the epidermis. There is a still greater structural degradation in the plants of the present order than in the Rusts, probably due to their excessive parasitism.

405. The parasitic threads of the Smuts are well defined, and consist of thick-walled, cellular, branching filaments, which are generally of very irregular shape. They grow in the intercellular spaces and cell cavities of their hosts, and some send out suckers (haustoria), which penetrate the adjacent cells much as in the Mildews. The parasite generally begins its growth when the host plant is quite young (meristematic) and grows with it, spreading into its branches as they form, until it reaches the place of spore-formation. In perennial plants the parasite may be perennial, reappearing year after year upon the same stems, or upon the new stems grown from the same roots; in annuals it must obtain a foot-hold in the young plants as they grow in the spring.

406. The life history of the Smuts has been made out for but few species. Three kinds of spores (conidia, teliospores and sporids) have been observed in many species, and their germination has been carefully studied, but the sexual organs (if any exist) have not yet been discovered.

407. The Smut of Indian corn (Ustilago maydis) is very common in autumn. The parasitic filaments are found in various parts of the host, and at last those which reach the young kernels or other succulent parts become semi-gelatinous and form spores internally. There is 
much crowding and distortion of these soft-walled sporebearing filaments, but here and there this structure may be made out. When the spores are ripe, the gelatinous walls dissolve and, the watery portions evaporating, leave a dusty mass of black spores. The spores germinate by sending out a short septate filament (promycelium) upon which minute sporids are formed laterally, much as in the Wheat rust. Like other smuts, that of Corn is capable of growing as a saprophyte in the decaying vegetable matter of the soil, producing an abundance of conidia. It has been found that when the sporids or the conidia germinate upon the meristematic parts of the growing plant or the projecting styles of the developing ears they penetrate the surface layers, and thus secure admission to the tissues of their host.

408. Other Smuts, as Wheat smut or Black Blast (Ustilago tritici) of wheat, Oat smut (U. avenae), Barley smut (U.hordei), etc., have a structure and mode of development closely resembling the foregoing, but with most of these the hosts can be infected only when very young, i.e. during or shortly after germination, or through their stigmas at the time of flowering.

409. The Bunt or Stinking smut of wheat (Tilletia tritici and $T$. foetens) represent an allied family (Tilletiaceae) in which the sporids are formed in a whorl at the end of the non-septate promycelium.

Laboratory Studies. (a) Collect specimens of cluster cups (from barberry, buttercups, or evening primroses, etc.); examine first under a low power without making sections. Note the cups filled with yellowish or orange conidia (aeciospores). Note spermogones (minute dark spots) generally on the opposite side of the leaf.

(b) Make very thin cross-sections through a mass of cups so as to obtain vertical sections of the cups and the spermogones.

(c) In May, June or July collect leaves of wheat, oats, or 
barley, bearing lines or spots of Red rust. First examine a few of the spores mounted in alcohol, with the subsequent addition of a little potassium hydrate. Then make very thin cross-sections through a rust spot, and mount as before, so as to see the parasitic filaments in the leaf, bearing the Red-rust spores upon little stalks.

(d) In July, August, or September collect stems of wheat, oats, or barley bearing lines or spots of Black rust. Study the teliospores as above, and afterward make cross-sections also.

(e) In early spring collect and examine the Black rust on wet stems of rotting straw. Look for germinating teliospores and sporids, which sometimes may be found.

(f) Examine microscopically the gelatinous prolongations on "cedar-apples," and observe the teliospores, which resemble those of Wheat rust. "Cedar-apples," which are common in the spring on red-eedar twigs, are in reality species of rust of the genus Gymnosporangium. Their cluster cups occur on apple leaves. Uredospores are lacking.

(g) Collect smutted ears of Indian corn. Mount a little of the black internal mass in alcohol, followed by weak potassium hydrate and observe the spores.

(h) Make very thin slices of young fresh or preserved specimens and examine for parasitic and spore-bearing filaments. The outer tissues of the distorted kernels are generally best.

(i) Make similar studies of the smuts of wheat, oats, or barley, which may be collected in June, or about the time of the "heading" of the grain.

(j) Make hanging-drop eultures (in water) of the teliospores of Tilletia and Ustilago, and compare their germination.

\section{The Imperfect FungI}

410. There are many fungi (about 16,00 n species), in some respects resembling the Ascus Fungi (AscosporeAE), of which we know only the conidial stages. They have been brought together temporarily in three orders under the general name of "Imperfect Fungi."

411. The Spot Fungi (Order Sphaeropsidales) are mostly parasitic on leaves and fruits of higher plants, 
producing whitish or discolored spots, and eventually developing small perithecia-like structures (pyenidia) containing conidia. Species of Phyllosticta are common on leaves of Virginia creeper, wild grape, cottonwood, willow, pansy, peach, apple, wild cherry, elm, etc., while species of Septoria are to be found on leaves of box-elder, aster, thistle, evening primrose, wild lettuce, plum, elder, etc.

412. The Black-dot Fungi (Order Melanconiales) differ from the preceding mainly in the absence of a distinct perithecium, the spores developing beneath the epidermis of the host and bursting through so as to form

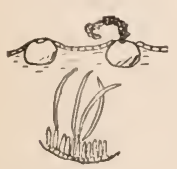

FIG. 115.-Septoria.

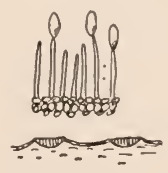

FIG. 116.Gloeosporium.

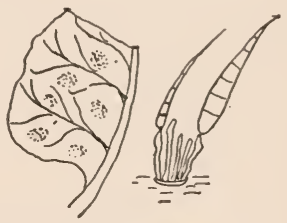

Fig. 117.-Cercospora.

small dark-colored or black dots (acervuli). Species of Gloeosporium and Melaneonium are common on leaves, fruits, and twigs.

413. In the Molds (Order Moniliales) the conidiabearing threads emerge through the stomata of the host, or grow out through the outer decaying tissues, forming moldy patches or masses. Here are many common parasites (e.g. species of Ramularia, Cereospora, Fusicladium) and saprophytes (Monilia, Botrytis, etc.), some of which are both parasitic and saprophytic.

Laboratory Studies. Although the Imperfect Fungi are quite too difficult for the beginner to do much with, it is well that he should become somewhat familiar with their general appearance; accordingly a few studies are suggested. 
(a) Look for Spot Fungi on the hosts mentioned above, and especially for the minute black fruits in the spots, making sections of the latter.

(b) Look for Black-dot Fungi on leaves, fruits and twigs of many plants, especially for Colletotrichum on bean pods.

(c) Look for Molds on leaves, as well as on some dead tissues.

414. Summary for the Higher Fungi. The theory underlying the foregoing account of the Higher Fungi is that these plants have been derived from the Red Algae by modifications, mostly degradational, due to the change from a holophytic to a hysterophytic habit, accompanied by the equally significant change from aquatic to nonaquatic life. It is here considered probable that the earliest fungi were those known as "lichens," which became parasitic upon small algae. In them the dominant modification was, of course, the disappearance of chlorophyll, and the reduction of the plant body. In the fruit resulting from the fertilization of the egg, the homologues of the carpospores of the Red Algae divided internally into spores, thus changing the carpospore into the ascus, and resulting in the considerable multiplication of spores. Thus the asci and ascospores became characteristic structures in the fruits of the fungi, and gave name to the first class-Ascosporeae.

415. Later, in the subterranean fruits of the truffles another modification took place whereby the spores instead of remaining within the ascus, push out beyond the ascus wall, so as to be more easily dispersed. In this way the basidium with its basidiospores arose from the ascus and its ascospores. These are thus to be regarded as homologous structures, in which the laterformed basidia have superior means for dispersing their spores.

416. In like manner in the Brand Fungi we find 
teliospores instead of the homologous ascospores or basidiospores, and in these plants the fruit body has become so reduced as to be scarcely recognizable as such. The excessive parasitism of these plants may account for their physical degeneration. As to the origin of the Brand Fungi it is probable that they came off from the parasitic Ascosporeae rather early in the phyletic history, and a possible relationship is here suggested with the Exoascales, and the Phacidiales.

417. The Imperfect Fungi are thought to be mainly Ascosporeae that may have lost their ascospores through excessive degeneration. It is probable, however, that many of them are the conidial stages of Ascosporeae and Basidiosporeae whose relationship is not yet recognized. In recent years many conidial forms hitherto placed here have been found to belong to well known ascigerous fungi.

\section{LITERATURE OF CARPOMYCETEAE}

F. E. Clements, The Genera of Fungi, Minneapolis, 1909. P. A. SacCardo, Sylloge Fungorum, Vols. I to XXII, 1SS2-1913. These are comprehensive works; the following include certain portions of the Higher Fungi.

J. B. Eluis and B. M. Everhart, North American Pyrenomycetes, Newfield, 1892.

Bruce Fink, Lichens of Minnesota, Washington, 1910.

Albert Schneider, A T'ext-book of Lichenology, Binghamton, 1897.

L. M. Underwood, Molds, Mildews and Mushrooms, New York, 1899.

C. B. Plowright, A Monograph of the British Uredineae and Ustilagincaea, London, 1589. 


\section{CHAPTER XIV}

\section{PHYLUM VIII. BRYOPHYTA}

\section{THE MOSSIVORTS}

418. This phylum includes plants of much greater complexity than any of the preceding. In very many cases they have distinct stems and leaves, whose tissues often show a differentiation into several varieties. In the sexual organs the cell to be fertilized (the egg) is from the first enclosed in a protective layer of cells, and after fertilization it develops into a complex spore-bearing body.

419. The life-cycle of the Mossworts includes a distinct alternation of generations. The immediate product of the fertilization of an egg is not a thalloid or leafy plant like that which bears the sexual organs, but, on the contrary, it is a many-celled leafless structure, spherical or approximately cylindrical, which eventually produces spores internally. The plant which produces the sexual organs is the gametophyte, while that which produces the spores is the sporophyte.

420. So the Mossworts have a marked duality, and we must consider both phases when we wish to get a complete idea of any particular plant. This duality has permitted the acquisition of the land habit, since the gametophytes have retained some of their aquatic characteristics, while the sporophytes have become modified for a terrestrial life. Accordingly in Bryophytes we find the beginning of the terrestrial habit in green plants. 
421. Mossworts may then be described as green plants in which the gametophyte is a prostrate or erect somewhat long-lived plant, producing antherids, and oogones (the latter enclosed in archegones). After fertilization a distinct structure, the sporophyte, is produeed, but although it rests on and in the gametophyte and obtains its supply of water and much of its food from it there is no organic connection between them. In this sporophyte certain internal cells (the "spore mother-cells") divide twice and thus produce internally four spores each. These eventually germinate and produce other gametophytes.

422. Here it should be noted that the nuclei of the gametophyte cells contain a definite number of chromosomes, and that on the fertilization of the egg this number is doubled. This double number is maintained in the sporophyte until spores are formed by division into fours, at which time a reduction takes place to the original number. So in this phylum the two generations are separable also by their chromosome numbers in addition to the other more obvious differences.

423. The antherids are complex structures. They are usually short-stalked, and consist of a layer of large boundary cells within which are very numerous, small, more or less cubical cells, each of which produces internally an elongated, more or less spiral, biciliate sperm. The walls of these spermatogenous cells dissolve, leaving the sperms free within the cavity of the antherid. By the rupture of the apical cells the sperms escape. This occurs only when the antherid is covered with water (rain, (lew, etc.).

424. The archegone is a flask-shaped, elongated organ, consisting of an enlarged lower part (venter) containing the egg, above which is the slender neek, at first closed at 
the top and surrounding the row of canal cells, but later open with a continuous passage to the egg (owing to the dissolution of the canal cells). In fertilization which takes place in water, the sperms pass down the tubular neck to the egg below.

425. Mossworts are of small size, rarely exceeding 10 or 15 eentimeters in height. They generally prefer moist situations upon the ground, or on the sides of trees or rocks. All told there are somewhat more than 16,000 species. Two classes may be distinguished, as follows:

Mostly bilateral, often thalloid, creeping gametophytes, usually with splitting sporophytes, and mostly having elaters. ...................... Class Hepaticae. Nultilateral, leafy-stemmed, mostly erect gametophytes, usually with circularly dehiscing sporophytes, and without

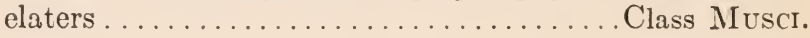

\section{Class hepaticae. Liverworts}

426. In the lower Liverworts the gametophyte is a flat, expanded thallus of parenchymatous tissue, and this gradually differentiates into a leafy stem as we pass to the higher forms, but in all cases the plant body has two distinct and well-marked surfaces, an upper and an under one, the latter bearing the root-hairs (rhizoids) by which the plant is fixed to the ground. About 4000 species are known.

427. Among the simplest of the Liverworts are the little round, flat Riccias (Riccia) which grow on wet earth or even float on the water. In the upper surface of the loose green tissue are the sunken antherids which produce biciliated spiral sperms. In a similar manner the archegones are sunken in the upper surface. After fertilization the egg develops into a globose cellular body 
(the sporophyte), whose interior cells divide into spores, but there are no "elaters." Although still surrounded by the distended archegone this sporophy te is not organically connected with any part of the gametophyte. The spores escape by the decay of the surrounding layers of cells, and on germination give rise to gametophytes like that with which we started.

428. In the Hornworts (Anthoceros) the gametophyte is a thin thallus of somewhat more compact tissue than in Riccia, and growing on moist earth. The antherids

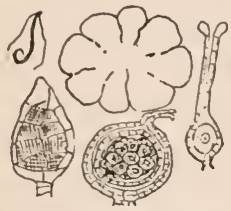

FIg. 11S.-Riccia.

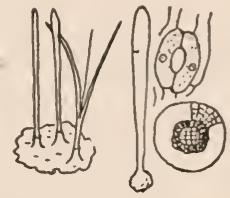

Fig. 119.-Anthoceros.

and archegones are sunken in the upper surface, and resemble those of Riccia. When fertilized the egg develops into an elongated, cylindrical sporophyte whose upper part emerges from the neck of the archegone, while the enlarged base remains seated in the venter. The sporophyte is made up of a considerable mass of green tissue, and is surrounded by an epidermis which is supplied with stomata like those of higher plants. This the first appearance of true stomata in the Vegetable Kingdom.

429. The lower part of the sporophyte continues to grow in length indefinitely. Internally there is a layer of cells by the division of which spores are formed, and intermingled with these spores are the elongated sterile cells called "elaters." As the spores ripen above the sporophyte splits from the top to permit their escape. 
On germination the spores produce gametophytes like the originals.

430. The very conspicuous Great Liverwort (Marchantia) is common on moist ground and is frequently abundant in green houses. Its gametophyte is a large, flat, branching, thalloid plant with a distinct midrib. Its epidermis is pierced with circular, many-celled

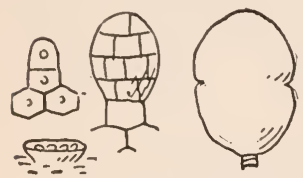
"stomata" which open into large air cavities supplied with many green cells. Here and there on the upper surface are cups containing hairs whose terminal cells develop Fig. 120.-Marchantia, into green masses (brood masses, or
brood-masses (gemmae). gemmae) which fall off and quickly develop into new gametophytes. This is thus an asexual mode of reproduction, and these brood masses take the place of the zoospores, tetraspores, and conidia of lower plants.

431. The antherids are confined to particular portions of the gametophyte (antheridial disks) which are raised on short stalks. Here they are sunken in the surface and they and the sperms resemble

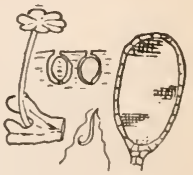

Fig. 121.-Marchantia (antherids). those of Riccia and Anthoceros.

432. The archegones are also confined to particular portions of the gametophyte (known as "receptacles"

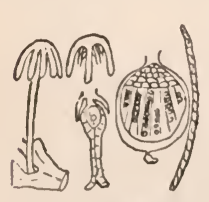

FIG. 122.-Marchantia (archegones). but really lobed disks) which are raised on more or less elongated stalks (archegonial branches). The archegones are dependent from the under side of the receptacle. When fertilized the egg develops into a globose, shortly stalked sporophyte containing spores and elongated sterile cells, the "elaters," whose walls are spirally 
thickened. By the expansive force of these elaters the sporophyte is ruptured somewhat stellately, and the spores are forced out. When the spores germinate they give rise directly to the gametophyte generation.

433. The Scale mosses (Order Jungermanniales) are the highest of the Liverworts, and also the most numerous in species. In the lower family (Metzgeriaceae) the gametophyte is usually a thallus as in the liverworts already described, but in the higher family (Jungermanniaceae) it is a creeping, leafy stem. In the first family we find all gradations from the en-

tire margined thallus to those with more and- MIetzgeria, and more pronounced lateral lobing, and finally

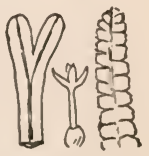
Jungermannia. to those in which the lobes have become distinct leaves on a rounded stem. The leaves of Scale mosses are but one cell thick and are not ribbed.

434. The antherids and archegones are borne dorsally or subterminally and are much like those already described. The sporophyte develops a slender stalk which carries up the enlarged spore case, and the latter when the spores are mature splits vertically into four segments and permits the escape of spores and elaters. When the spores germinate they may develop directly such adult gametophytes as are described above, while in the higher forms the gametophyte is first a filamentous or thalloid structure ("protonema") from which the adult gametophyte subsequently buds out.

435. Many Scale mosses reproduce by means of brood masses much like those of Marchantia, or even simple, single-celled structures (brood cells).

436. Scale mosses have no stomata on either gametophytes or sporophytes. 
Laboratory Studies. (a) Look for Riccias on the wet ground by the sides of ponds and slow streams from midsummer to fall. Make careful vertical sections for structure of the gametophyte, at the same time looking for the sexual organs and the imbedded sporophyte.

(b) Study Anthoceros for gametophyte, and cylindrical sporophytes. In the latter find stomata, spores and simple elaters. Anthoceros may be obtained from the South (Gulf states) for study in early spring.

(c) Collect specimens of the Great Liverwort (Marchantia) which may be found in fruit in midsummer. Note that one plant produces the antheridial branches, which have flat disks, and another produces the archegonial branches, which have lobed disks ("receptacles"). Note the eups, with contained brood masses (gemmae).

(d) Examine the upper surface of a plant with a low power of the microscope, and note the round "stomata." Next strip off some of the epidermis, mount in alcohol, and study with a high power.

(e) Make longitudinal sections of the plant through its thickened central rib, and observe the elongated cells, with foreshadow fibro-vascular bundles.

(f) Make vertical sections of the antheridial disk, mount in water, and study the antherids. By repeated trials sperms also may be scen.

(g) Make similar sections of the archegonial disk, and study archegones. By taking older specimens the sporophytes, spores, and elaters may be studied. For the latter, mount in alcohol and afterward add a little potassium hydrate.

(h) Examine the bark of trees for small brownish Scale mosses. Mount a bit of one in alcohol, afterward adding potassium hydrate, and study for structure of the gametophyte. In the spring the minute splitting spore cases may readily be found.

\section{Class MUsci. Mosses}

437. The gametophyte in this class is a leafy multilateral stem, rarely bilateral. It is fixed to the soil or other support by root-hairs (rhizoids) which grow out from the sides of the stem. The leaves are usually 
composed of a single layer of cells, and in many cases have a midrib. The sporophyte is more or less elongated, enlarged above into a spore-case (capsule) and does not contain elaters.

438. The tissues of the Mosses present a considerable advance upon those of the Liverworts. In the stem there is frequently a bundle of very narrow thin-walled cells, which in some species become considerably thickened. In a few cases there have been observed bundles of thin-walled cells extending from the leaves to the bundles in the stem. It cannot be doubted, then, that the Mosses possess rudimentary fibro-vascular bundles. As in liverworts, the tissues of mosses develop from a single apical cell. Breathing-pores (stomata) resembling those of the higher plants occur on the sporophytes; they are not found upon the leaves or stems.

439. Mosses, for the most part, grow upon moist earth or rocks, or upon the trunks and branches of trees; comparatively few are aquatic. They range in size from less than a millimeter to many centimeters in length, the most common height being from 2 to 4 centimeters. They are all chlo- Fig. 124.-A moss (protonema rophyll-bearing plants, and are

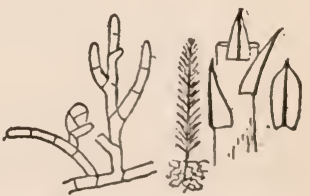
and leafy gametophyte). generally of a bright green color; occasionally, however, they are whitish or brownish.

440. The reproduction of mosses is mainly sexual, but often brood-masses are found resembling those of liverworts. The sexual organs develop either upon the ends of the main stems, within flower-like rosettes of leaves, or on the ends of short branches in the axils of the leaves.

441. The antherids are club-shaped or globose struc- 
tures whose interior cells produce sperms, which escape from the antherid through a rent in its wall. Each spermatogenous cell contains one spirally coiled sperm, which, when set free, swims by means of its two long cilia.

442. The archegones are elongated, flask-shaped bodies with a swollen base ("venter") and a long slender neck. At maturity the neck has an open channel from its apex to the base, where there is a rounded egg. In some mosses the antherids and archegones are intermixed in the same "flower," but in other cases they occur upon different parts of the same plant (monoecious), or even upon different plants (dioecious).

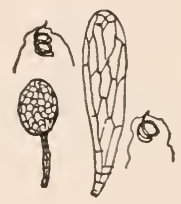

FIg. 125.-Antherids and sperms (Sphagnum and Funaria).

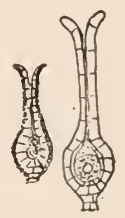

FIG. 126.-Archegones and eggs (Sphagnum and Funaria).

443. The act of fertilization requires water; but as the sperms are very minute, a dewdrop may be sufficient. The sperms swim to the open neck of the archegone, down which they pass to the egg. The egg now begins to divide rapidly, growing upward, eventually forming the sporophyte. In most mosses the sporophyte is narrow and elongated below, forming a stalk (seta) which supports the upper spore-bearing part (the capsule or spore-case). The epidermis of the latter is usually provided with stomata, especially toward its basal part.

444. The spore-case, when ripe, usually opens by a lid which falls off, leaving a round opening, generally fringed with many teeth. In most species as the sporo- 
phyte elongates it carries up the remains of the distended archegone as a little cap (calyptra).

445. The spores, which are round or angular cells containing protoplasm, chloroplasts, oil-drops, etc., germinate quickly upon moist soil. Each spore protrudes a tubular filament, which develops into a confervalike branching growth of green cells, called the "protonema." Upon this buds are eventually produced from which spring up the leafy stems, thus completing the round of life.

446. There are three orders of Mosses, including about 12,600 species, as follows: (1) Black Mosses (Order AvDREAEALES), composed of a few small and rare mosses whose spore-cases open by four longitudinal slits; Peat-mosses (Order Sphagnales), composed of large, soft and usually pale-colored plants, with clustered lateral branches; they inhabit bogs and swampy places, where they form dense moist cushions, often of great extent. On account of peculiarities in the structure of their leaves they are enabled to absorb and hold large quantities of water, and for this reason they are extensively used for "packing" in the transportation of living plants. They all belong to the genus Sphagnum, and their spore-cases open by a circular lid, leaving an unguarded

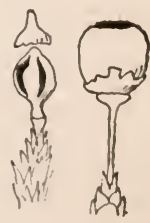

Fra. 127.Sporophytes (Andreaea and Sphagnum). opening (without teeth). In this and the preceding order the stalk supporting the spore-case is an extension of the gametophyte stem and not a part of the sporophyte.

447. (3) True Mosses (Order Bryales) include the great majority of the species of this class. They are usually bright green (in a few genera brownish), and in most instances live upon moist ground and rocks, or upon the bark of trees; in a comparatively small number 
of cases the species live in the water. They are undoubtedly the highest of the class, and show a greater differ-

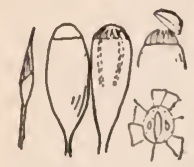

FIG. 128 Sporophytes (Bryales). entiation of tissues than either of the preceding orders. The spore-cases usually open by a circular lid (operculum), and the opening is usually guarded by one or two rows of teeth (the peristome) of which there may be $4,8,16,32$ or 64 . Here the seta is a part of the sporophyte.

448. There are more than fifty families of True Mosses, of which about one-half are Top Mosses (Acrocarpi), i.e. bearing their sporophytes at the summit of the gametophyte stem, the remainder being Side Mosses (Pleurocarpi), with laterally borne sporophytes. Among the first are Turf Mosses (Dicranaceae), Cushion Mosses (Leucobryaceae), Petticoat-mosses (Splachnum), Bristle Mosses (Funariaceae and Timmiaceae), Ephemeral Mosses (Ephemerum), Wood Mosses (Bryaceae and Mniaceae), Humpback Mosses (Buxbaumiaceae), and Hair-cap Mosses (Polytrichaceae). Among the Side Mosses are the Brook Mosses (Fon-

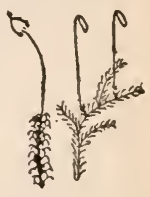

Fig. 129.Top moss, and side moss. tinalaceae), the Tree Mosses (Climaciaceae), and the Bog Mosses (Hypnaceae).

Laboratory Studies. (a) Collect several kinds of mosses in fruit; some of these should be of large species. Note the brownish root-hairs, the stem and leaves, the spore-fruit (sporophyte) composed of a slender stalk (seta) bearing a spore-case, the latter in some species covered by a membranous or hairy cap (calyptra).

(b) Select a broad-leaved species. Mount a single leaf in water, and examine with a lower power. Note that the leaf is (generally) a single layer of cells, and that the midrib (if present) is composed of elongated cells. Make cross- and longitudinal sections of stems of the larger species, and note that some of the cells are elongated and fiber-like. 
(c) Place a spore-case under the microscope and examine with a low power, noting the lid. Now remove the lid and observe the teeth. The teeth may be studied still better by splitting the spore-case from base to apex and then mounting in alcohol, and afterward adding potassium hydrate: or the lid may be removed and a transection of the spore-case made just below the peristome, so as to show the latter from above. In these specimens spores may be studied also.

(d) Split a young spore-case and examine the external surface of the lower part for breathing-pores, and note internally the adjacent chlorophyll tissues, and the sporogenous layer above.

(e) Collect a number of mosses not in fruit, showing at the apex of their stems little cup-shaped whorls of leaves. Make several vertical sections of one of these cups, and mount in water. Examine for antherids and archegones. Sperms may sometimes be seen with a high power.

$(f)$ The first stage (protonema) of a moss gametophyte may be found by scraping off some of the greenish growth from a wall or cliff or surface of a greenhouse flower pot where young mosses are just springing up. By mounting some of this in water and washing away the dirt the branching green growth may generally be seen, with here and there the buds which give rise to leafy stems.

\section{LITERATURE OF BRYOPHYTA}

D. H. Campbell, The Structure and Development of Mosses and Ferns, New York, 1905.

L. M. Underwood, Descriptive Catalogue of the North American IIepaticae, Champaign, $18 S 3$.

L. Lesquereux and T. P. James, Manual of the Mosses of North America, Boston, $18 S 4$.

A. J. Grout, Mosses with a Hand Lens and Microscope, Brooklyn, 1905-1911. 


\section{PHYLUM IX. PTERIDOPHYTA*}

\section{THE FERNS}

449. The Ferns are green plants that as to their gametophytes are of smaller size than the Mossworts, while, as to their sporophytes they are much larger and more complex. In fact the gametophyte generation is so small compared with the sporophyte that it is usually overlooked, or when seen is often not recognized as a fern at all by those who are not familiar with the whole life cycle of these plants. The fern that we commonly see with its roots, solid stems, and ample leaves is the sporophyte generation, which has become so large and conspicuous in this phylum that it completely overshadows the little gametophyte.

450. The gametophyte (commonly called the "pro-

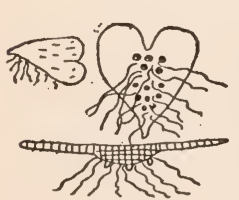
thallium") is usually a flat thallus, of one or more layers of nearly uniform chlorophyll-bearing cells, the whole being rounded or heart-shaped in outline. Its longitudinal axis is considerFrc. $130-$ Game- ably thickened, and this portion is provided underneath with many root-hairs, intermingled with which in most cases are the antherids and the archegones.

451. The antherids are nearly globular, few-celled

* This name is here used in the narrower sense excluding Calamites and Lycopods. 
structures consisting of an outer layer of cells surrounding a central mass of small cells, each of which produces a sperm. When mature, the antherids rupture and permit the eseape of the spiral multiciliated sperms which swim with a rotary motion.

452. The arehegones are flask-shaped organs sunken into the tissues of the plant. At first the neck is closed, but at maturity it opens down to the egg. Fertilization takes place in water (after rains or heavy dews), the sperms swimming to and down the neck of the archegone, where one of them unites with sporm. the egg.

453. Sporophyte. After fertilization the egg divides again and again, soon producing a solid stem from which a root springs at one end, while from the other the leaves arise. The latter are at first small and quite simple in structure, but those formed later are larger and more and more complex in structure, until finally the full form

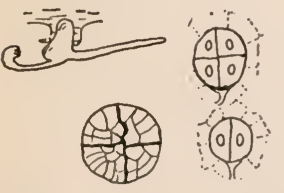

FIG. 132.-Development of fern sporophyte. is reached, and still later the full size. The stem, bearing leaves and roots, constitutes the sporophyte, which is sharply contrasted with the gametophyte in structure, size, and duration, the latter being short-lived, small, and of simple structure, while the former is long-lived, often of large size, and of great complexity of structure. On this plant the spores are eventually produced which on germination give rise to gametophytes like those with which we started, thus completing the round of life. In most Ferns the spores are of one kind, only (isospores), but in a few they are of two kinds (heterospores) in 
which some are small (microspores) and the others large (megaspores).

454. In looking over the whole structure of the Ferns it will be seen that the sporophyte has become the dominant generation. This is clue to the fact that in its development it has pushed roots of its own down into the ground from its lower end, thus insuring a constant supply of water, while at the same time it has pushed out some of the green tissue from its upper part into flat expansions (leaves), thus insuring the supply of carbohydrates. The sporophyte has thus become independent of the gametophyte, and the latter, being now useless after the maturity and disappearance of the sexual organs, has become very short-lived, while the rooted and leafy sporophyte has developed into a long-lived plant, which may continue its growth for many years.

455. With this longer life and larger size the fern sporophytes have developed many kinds of tissues in addition to parenchyma, including collenchyma, sclerenchyma, fibrous tissue, tracheary tissue, and sieve tissue, some of which appear to be as highly specialized as in the flowering plants. Furthermore, true vascular bundles as well as bundles of fibrous tissue are developed, the roots containing bundles of the radial type, and the solid stems and leaves, of the concentric type. The epidermis and stomata are scarcely to be distinguished from those of the highest plants.

456. The typically large leaves are sometimes simple, flat blades, but more commonly they have branched into "compound" blades of extraordinary complexity and beauty of outline. The young leaves before expanding are generally coiled or rolled, so that as they grow up and open they unroll from below upward (i.e. circinately). Their vascular bundles (here usually called 
"veins") present different patterns, sometimes being parallel to one another or divergent (veins "free"), or uniting here and there in a netted fashion (veins "reticulated").

457. Since the sporophytes of ferns are long-lived they delay the formation of their spores, this sometimes not taking place for a few years (or many years in tree ferns). In the more primitive ferns the spores develop from internal cells (as in Anthoceros of the Bryophyta), but in the higher forms they are produced in superficial sporangia.

458. On account of the dominance of the sporophyte its structure has been emphasized in the systematic classification of the ferns, although some consideration has latterly been given to gametophyte characters. About 3800 species of Ferns have been described, and they are widely distributed throughout warm and temperate regions.

459. There are two classes of Ferns, as follows: 1. Old-fashioned Ferns (Class Eusporangiatae) in which the spores develop from internal cells.

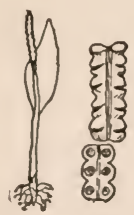

lig. 133.-Ophioglossum.

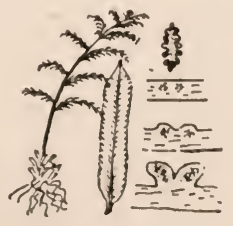

Fig. 134.-Angiopteris (Marattiales); development of sporangia.

460. Here are the Adder-tongues (Order OpHioGLOSSALES) by many botanists regarded as the lowest of the Ferns, and not very distantly related to Anthoceros of the preceding phylum. Here too are placed the 
Marattias (Order Marattiales), large, very leafy ferns of the tropics, formerly abundant, now nearly extinct, and with them may be placed the aquatic Quillworts (Order Isoctales) with slender rush-like leaves. The latter produce two kinds of spores, viz. microspores which are small, and megaspores which are much larger. The plants are thus heterosporous, in contrast with the preceding which are isosporous. The microspores produce minute antheridial gametophytes (microgametophytes), and the megaspores, larger archegonial gametophytes (megagametophytes).

2. Modern Ferns (Class Leptosporangiatae) develop their sporangia from superficial cells.

461. These are our common ferns, and this class includes the greater part of the species now living. In them the sporangia are usually developed on the lower surface of the leaves in clusters ("sori") of various shapes,

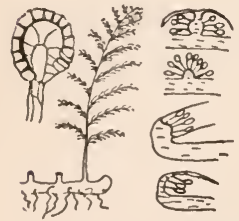

Fig. 135.-Modern ferns (sporangium and sori). and these may be naked or covered with an indusium. The mature sporangium (spore-case) in most common ferns has a ring of thicker cells extending around it. When these become dry, they contract in such a way as to break open the spore-case and thus set the spores free. Most Modern Ferns are terrestrial, and hence may be set off as Land Ferns (Order Filicales), in which are the less common Climbing Ferns (Lygodium), Tree Ferns (Family Cyatheaceae), Filmy Ferns (Family Hymenophyllaceae), and Common Ferns (Family Polypodiaceae). In the last-named family nearly all of the ferns of our woodlands are found, including such species as the common Polypody (Polypodium vulgare), the Golden Fern of California (Gymnogramme triangularis), the 
Maidenhair of the North (Adiantum pedatum), and of the South (A. capillus-veneris), the common Brake (Pteridium aquilinum) the Spleenworts (Asplenium) of many species, the Shield-ferns (Aspidium), also of many species, the curious little Walking-fern (Camptosorus rhizophyllus), the Bladder-fern (Filix fragilis) and the large Ostrich-fern (Onoclea struthiopteris).

462. Some of the Modern Ferns have become aquatic and hence are known as Water Ferns (Order Marsiliales) in which two kinds of spores ("heterospores") are produced, microspores and megaspores, which in time give rise respectively to antheridial, and archegonial gametophytes. The Marsilias are rooted plants, with floating, 4-parted leaves,

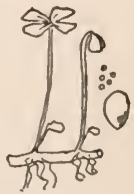

Fig. 136.Marsilia. while the Salvinias are small, floating, nearly rootless plants, with simple leaves.

Laboratory Studies. (a) Collect several different kinds of common ferns, including the underground portions as well as the leaves. Study the vascular bundles, stone tissue, and fibrous tissue in the underground stem.

(b) Examine the disposition of the small vascular bundles in the leaves, whether free or reticulated. Peel off a bit of epidermis from both surfaces, and study the breathing-pores.

(c) With a low-power study the sori (clusters of spore-cases), using top light only. The sporangia may be seen and their attachment made out in this way in those cases where there is no indusium covering the sorus.

(d) Make a vertical section through a sorus and study carefully, looking for the ring of darker cells on the spore cases.

(e) Gametophytes of ferns may often be found in planthouses on or in flower-pots near ferns. They may be obtained also by sowing the fresh spores in flower-pots and keeping them in a warm damp place (a greenhouse is best). In a month or two the gametophytes will be full grown. Collect a few of these of various sizes, carefully wash off the dirt from the under side, then mount in water, and examine the under surface for 
antherids and archegones. By careful searching young fernlets may be found still attached to the gametophytes (prothallia).

(f) If possible secure specimens of Adder-tongue, and compare the structure of the sporangia with the foregoing.

(g) Search the borders of lakes, ponds, and slow streams for Marsilias. They may probably be found in every part of the country, although they are rarely collected.

(h) Where possible compare the structure of the sporangia and sori of Marattias (from greenhouses) with those of common ferns.

(i) In some places it is possible to secure sporophytes of Isoetes for a comparative study.

(j) Try to secure fresh spores of Isoetes or Marsilia for a study of heterospores, and of the antheridial, and arehegonial gametophytes.

\section{LITERATURE OF PTERIDOPHYTA}

D. H. Camprell, The Structure and Development of Mosses and Ferns, New York, 1905.

N. L. Britton and Addison Brown, Illustrated Flora of the Northern States and Canada, Second Edition, New York, 1913.

B. L. Robinson and M. L. Fernald, Gray's New Manual of Botany, New York, 1908.

J. K. Small, Flora of the Southeastern United States, Second Edition, New York, 1913.

L. M. Underwood, Ferns and Fern Allies, New York, 1905. 


\section{CHAPTER XVI \\ PHYLUM X. CALAMOPHYTA \\ THE CALAMITES}

463. As far as we know them the Calamites are green plants in which the marked difference between the small gametophytes and the large sporophytes seen in the Ferns is continued, but here the sporophyte stems are mostly hollow and jointed, and the leaves relatively small. A great difficulty in studying the plants of this phylum is that although common in the Paleozoic period, but few (about 24 species) have survived to the present time, and our knowledge of them is confined to what we have been able to make out from fragmentary fossils, helped out in some details by a study of the surviving species.

464. This much, however, has been made out pretty certainly: Gametophytes small, and short-lived, mostly monoecious; Sporophytes large, long-lived, with roots, and elongated, cylindrical, jointed, often hollow stems, bearing relatively small whorled leaves at the joints; spores alike (isospores), or of two kinds (heterospores), borne in cones of sporophylls (i.e. special spore-bearing leaves).

465. Like the Ferns the Calamites have well-developed tissues in the sporophyte generation; the vaseular bundles are of a higher type ("collateral"), and are arranged in a eylinder in the stem. When these bundles are "open" the stems have the power of increasing in 
diameter. The epidermis is abundantly supplied with stomata.

\section{The Wedge-leaved Calamites (Class Spheno-}

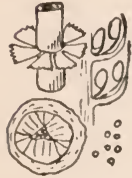

Fig. 137 - Sphenophyllum. PHYllineaE) were Paleozoic herbaceous plants of moderate dimensions, whose sporophyte stems were solid, jointed, grooved externally, and at the joints bore spreading whorls of wedge-shaped leaves. Their isospores were borne in terminal cones composed of whorls of 1 - or 2-sporangiate sporophylls. Sphenophyllum is the typical genus.

467. In the Horsetails (Class EquisetineaE). of the present, the plant-body of the sporophyte consists of a hollow, elongated and jointed herbaceous stem, bearing whorls of narrow, united leaves, which form close sheaths; the stem is grooved, and is usually rough and hard from the large amount of silica deposited in the epidermis.

468. The branches, when present, are in

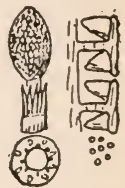

Fig. 138. - Equisetum (sporophyte). whorls. Both the main axis and the branches are in most cases richly supplied with chlorophyll-bearing tissue; but in some of the species the stems which bear the spores are destitute of chlorophyll. All of the species have underground stems, which bear roots and rudimentary sheaths, and which each year send up the vegetating and spore-bearing stems.

469. The Horsetails are perennial plants. In some species the underground portions, only, persist, the aerial stems dying at the end of each year; these are called the annual-stemmed species. In other species the aerial stems persist; they are hence known as perennialstemmed.

470. The epidermal cells are mostly narrow and 
elongated. The stomata which are present in all the chlorophyll-bearing parts of the plant, are arranged with more or less regularity in longitudinal rows; on the stem they oecur in the channels between the numerous ridges. The vascular bundles of the stem are disposed in a cylinder and run parallel with each other from node to node, where they join with one another. They contain tracheary, sieve and fibrous tissues, arranged somewhat as they are in the bundles of flowering plants.

471. The spores of Horsetails are produced in cones at the summit of the stems. The cones are composed of crowded whorls of shield-shaped leaves (sporophylls), each of which bears upon its under surface five to ten sporangia. The spores are spherical, and at maturity the outer wall splits spirally into four narrow filaments (elaters) which unroll when dry, and roll up around the spore again when moistened. Their office seems to be to aid in setting the spores free from the spore-cases. The spores germinate soon after falling upon water or moist earth, enlarging and successively dividing until a flattish irregular gametophyte (the prothallium) a few millimeters in breadth is produced. It bears antherids and archegones resembling those of the ferns upon

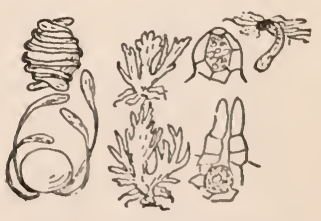

FIG. 139.-Equisetum (spores and gametophytes). its lobes or their edges; in some eases both sexual organs are on the same gametophyte, while very commonly they are upon separate gametophytes, although the spores show no differences. The sperms are spiral and multiciliated.

472. This class contains but one family (Equisctaceae), including a single genus, Equisetum, and twentyfour species of herbaceous plants usually a meter or less 
in height, but in certain tropical species attaining a length of 10 meters or more. Among the better known are the Common Horsetail (Equisetum arvense), which sends up short lived, pale or brownish cone-bearing stems in spring, and profusely branching green stems in summer (E. telmateia, the Great Horsetail of Europe and our own Northwestern region, resembles, but is larger than, the Common Horsetail); the Woodland Horsetail ( $E$. syluaticum), whose green cone-bearing stems branch profusely after fruiting, and persist all summer; and the Scouring-rush, called also Dutch Rush (E. hiemale), with green, branchless stems which produce cones, and survive the winter. The genus Equisetum originated in the Paleozoic period, and so is very old. Some of its species have become extinct, as is the case with several related genera.

473. The Old Calamites (Class CalamarineaE) were

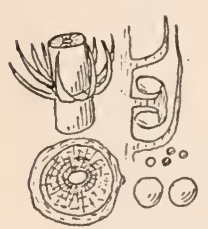

Frg. 140.-Sporophyte and spores of Old Calamite.

Paleozoic plants whose sporophytes were often trees, with hollow, jointed stems, whose collateral vascular bundles allowed an increase in diameter by the development of a cambial zone. The leaves were separate, narrow, and whorled at the joints of the stem. The heterospores were borne in terminal cones composed of whorls of sporophylls, each bearing one or more sporangia. Only fragmentary fossils of these plants are known.

Laboratory Studies. (a) Collect in early spring a number of cone-bearing stems of the Common Horsetail. Note the joints (nodes), bearing whorls of united flat leaves, and the cone, composed of whorls of shield-shaped leaves (sporophylls). Split the cone and stem and note that the latter is hollow, with closed nodes.

(b) Carefully dissect out a single sporophyll from the cone, 
and examine it, using a low power. Note the sac-shaped spore cases upon the under side of the leaf. Mount some of the spores dry, using no cover-glass, and examine with the $16 \mathrm{~mm}$. objective. Breathe upon the spores very gently to moisten them, and notice the coiling of the elaters; observe the quick uncoiling which takes place upon the evaporation of the moisture.

(c) Sow a quantity of the fresh spores upon moist earth or porous pottery, covering with a bell-jar and taking every precaution to secure constant moisture. The spores will begin to germinate in a few days, when studies of successive stages of growth may be taken up. By care the mature gametophytes (prothallia) may be grown, and the antherids and archegones studied.

(d) Make very thin cross-sections of the stem of the Common Horsetail. Note the position of the vascular bundles. Now make a rertical section of the bundles and study the tissues, using high powers.

(e) Study the breathing-pores on the green stems of the Common Horsetail. Compare these with those of the Scouring Rush. Study also the disposition of the chlorophyll-bearing tissue in cross-sections of both stems.

(f) Examine underground stems of Horsetails, and compare the structure with that of the aerial stems. Make cross-sections of the roots which are attached to these underground stems.

\section{LITERATURE OF CALAMOPHYTA}

The same as for the preceding phylum, and M. C. Stopes, Ancient Plants, London, 1910. 


\section{CHAP'TER XVII}

\section{PHYLUM XI. LEPIDOPHYTA}

\section{THE LYCOPODS}

474. Here as in the Calamites we are dealing with a phylum from which many of the forms have disappeared through extinction, leaving only their fragmentary fossils. Yet here again by a study of the plants that have survived, and a comparison of their structure with such fossil remains as have been found, we may make out pretty clearly the nature of the plants that constitute this phylum.

475. Accordingly the Lycopods may be characterized as chlorophyll-green, terrestrial plants, exhibiting two generations in each life-cycle, viz.: (1) the gametophyte, which is small, short-lived, and typically tuberous or globose, with few rhizoids or none, and often dioecious; the sexual organs are deeply sunken, and the sperms are biciliated; (2) the sporophyte, which is large and long-lived, with roots, a solid, continuous (not jointed) stem, and many small spirally arranged or opposite leaves, some of which, the sporophylls, with sporangia in their axils, are in terminal cones. The spores are mostly heterosporous. The tissues of Lycopods resemble those of Ferns and Calamites in both number and kind. Their vascular bundles are essentially like those of the Ferns (concentric), and in some cases are separate, while in others they are consolidated into a central compound bundle, surrounded by a mass of thick- 
walled fibrous tissue. The epidermis is abundantly supplied with stomata.

476. The phylum contains about 700 living species, and consists of two quite distinct classes, viz.: The Lower Lycopods (Class LycopodineaE) mainly distinguished by being isosporous, and the Higher Lycopods (Class Lepidodendrineae) which are heterosporous.

477. In the first we find the Ground Pines (Family Lycopodiaceae), otherwise known as Club-mosses, which are terrestrial, perennial, evergreen plants with many small, generally moss-like leaves covering the stems. The sporophylls are often crowded toward the summits of certain branches, in some cases forming well-marked cones (strobili). The spores are all of one kind, and are borne in roundish sporangia of which there is one on the upper surface of each leaf near the base.

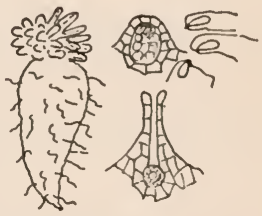

FIG. 141.-Lycopodium (gametophyte, antherids, sperms, archegones and egg.)

The Ground Pines are common in the Appalachian region, Canada, and northwestward, and all belong to the genus Lycopodium, including $L$. clavatum, $L$. complanatum and $L$. dendroideum, all ex-

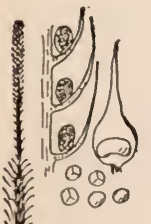

Fig. $142 .-$ Lycopodium (sporophyte, sporangia, spores). tensively used in Christmas decorations. Fossil specimens of Ground Pines from the Paleozoic period have been recorded.

478. In the second class are the Club-mosses (Family Selaginellaceae) which resemble the Ground Pines, but in our common species are generally smaller and more moss-like, and have (with few exceptions) four-ranked leaves. Their sporangia occur singly on the sporophylls which are clustered into terminal spikes (cones). The spores are of two kinds: the small ones (microspores) 
which are very numerous in their sporangia, and the larger ones (megaspores) which are mostly four in each sporangium. These microsporangia and megasporangia are intermingled in the cones. When mature the microspores fall out and are blown away, but it often happens that the megaspores remain in the old wall of the megasporangium.

479. The gametophytes of the Club-mosses have almost
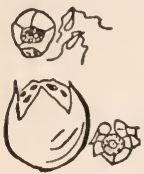

Fic. 143.- -Selaginella (gametophytes, antherid, sperms, arehegones, egg). disappeared. When a microspore germinates, it becomes divided into a considerable number of cells, one of which is the remnant of the gametophyte (prothallium), while the other cells form one large antherid, each inner cell of which produces biciliated sperms.

480. The megaspore likewise produces a very small but many-celled gametophyte, which protrudes but little from the ruptured spore-wall. Upon this several archegones develop. This development may take place while the megaspore is still enclosed in the wall of its sporangium. After fertilization the egg gives rise directly to a leafy plant, which emerges from the sporewall in a way to remind one very forcibly of the growth of a plantlet from a seed. This resemblance is made greater by the likeness of the first leaves to cotyledons.

481. But one genus, Selaginella,

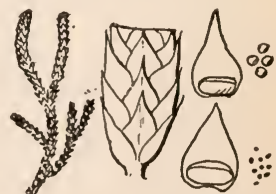

F I G. 14 4.-Selaginella (sporophyte, sporang ia, spores). is known in this family. It contains many species, most of which are tropical. Several species are common throughout the United States, and several exotic species are frequently cultivated in plant-houses. 
482. Allied to the Club-mosses are the arborescent Lepidodendrids (Order Lepidodendrales) which were abundant in the Paleozoic period, and which disappeared in the Mesozoic. We have fragmentary fossils of the sporophytes, which were large dichotomously branched trees, sometimes 30 meters high and a meter in diameter. There was a large central vascular bundle, which however formed a peripheral cambium so that the stems increased their diameter much as in the case of higher plants. The stems and branches were thickly clothed with pointed dron (sporophyte, sporleaves a decimeter or more in length, and when these fell off they left large scars of characteristic shape and arrangement.

483. The fossil remains of the spore-bearing cones, of which many specimens have been found, indicate that they contained two kinds of spores. Hence it is certain that the Lepidodendrids were allied to the Club-mosses. The more common genera are Lepidodendron, and Sigillaria.

Laboratory Studies. (a) Secure a few fresh or alcoholic specimens of various kinds of Lyeopods in fruit. Ground Pines may be collected in many places in the eastern United States. The Club-mosses may be obtained in plant-houses.

(b) Make cross-sections of the stems, and study the vaseular bundles in Lycopodium where they are imbedded in a thiek mass of fibrous tissue. Examine the leaves, noting the small vascular bundle in the midrib. Study the epidermis, which contains numerous breathing-pores.

(c) In like manner study Selaginella.

(d) Carefully remove a sporophyll from a cone of Lycopodium, and study the sporangium and spores. Further examination will show that the spores are of one kind only. 
(e) Carefully dissect out from the fruiting cone of Selaginella several sporangia, some with four large spores, and others with many small spores.

\section{LITERATURE OF LEPIDOPHYTA}

The same as for the Ferns and Calamites. 


\section{CHAPTER XVIII}

\section{PHYLUM XII. CYCADOPHYTA \\ THE CYCADS}

484. Like the two preceding phyla this one is a mere remnant of a much larger group. All told there are only about 140 living species belonging to six families, while we know of as many more families whose species have become extinet. Enough has been made out as to the structure of living and extinct forms to enable us to define the Cycad phylum as follows:

485. Their archegonial gametophytes are so dependent that they are enclosed in the megaspore, which is itself retained in the sporangium; the antheridial gametophyte is minute and free, and its tubular antherid typically develops two or more multiciliated sperms; after fertilization of the egg the megasporangium becomes a "seed." The sporophyte is first enclosed in the seed, where it is nourished by the gametophyte, and later it escapes by developing roots below, and expanding its leaves above; eventually some leaves become sporophylls and develop microspores and megaspores.

486. It is instructive here to compare the higher Lycopods with the Cycads. In both there are microspores and megaspores, and in both the microspores always are set free from the sporangium. In both again the microspore produces a very small (one- to few-celled) gametophyte. However, the antherid of the higher Lycopods is a few-celled structure, with many minute, biciliated sperms, while in the Cycads the antherid is 
reduced to a simple tube, which contains usually two large, multiciliated sperms (suggesting a correlation between size and the number of sperms). In both phyla, again, the megaspores develop from a spore mother-cell (archespore) as tetrads, but while in the

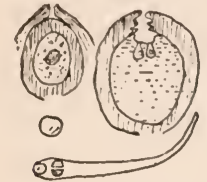

FIG. 146.-Cycad gametophytes, eggs and sperms. Lycopods all four may become mature, in the Cycads only one matures. In Lycopods the megaspores separate from the sporangial tissue as they develop, and normally are set free, while in Cycads the single megaspore remains permanently connected with and surrounded by the sporangial tissue. So the embryo sporophyte of the former normally develops outside of the megasporangium, while in the latter it does so inside of the megasporangium, and thus forms the seed.

487. The lowest Cycads, the so-called "Seed-ferns" (Class Pteridospermeae), were abundant in the Paleozoic period and are now known only from their fossil fragments. They were long thought to be ferns of an ancient type, but are now known to have been seed-bearing plants. Apparently they were derived from the Marattias among the Old Ferns. Their leaves were fern-like in shape and structure. Their stems were capable of in- sperm sporophyte creasing in diameter. It is now thought

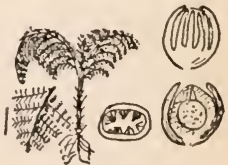

FIG. 147.-Pteridothat the Seed-ferns constituted a group of vast extent in Paleozoic times.

488. In the Common Cycads of the present (Class Cycadineae) the sporophytes are usually erect, woody, little-branched trees, rooted below, and bearing terminal crowns of evergreen, pinnate leaves. The collateral vascular bundles are arranged cylindrically in the stem, 
and inerease its thickness by the development of their cambium, and by the formation of new bundles in the eortical meristem. The sporophylls which bear microspores and megaspores form more or less distinct eones (strobili) but occur on separate plants (dioecious).

489. The common greenhouse Cyead (Cycas revoluta) produces elongated, compact cones of microsporophylls, 20 to 30 centimeters long and 5 to 6 eentimeters thick. Each sporophyll bears on

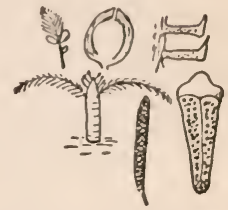

FIG. 148.-Cycas sporophyte, meg a sporophylls and $\mathrm{mi}$. crosporophylls. its lower surface numerous small seattered microsporangia eontaining microspores, eonstituting the so-called "pollen." These microspores fall out, and on germination produce a small one- or two-celled gametophyte, and a tubular antherid containing two spirally manyciliated sperms (about 0.2 millimeter in diameter). The megasporophylls constitute a loose terminal cone on the main axis of the tree. Each sporophyll bears several laterally placed megasporangia each of which has become covered with an indusium-like structure (integument). Within the body of the sporangium (now known as the ovule) a megaspore develops, but this at maturity does not fall out but remains surrounded by nutrient tissue. Here it germinates and develops a solid, many-eelled spheroidal gametophyte, and at its summit forms several deeply sunken archegones, in which the eggs are of remarkably large size (2 to 3 millimeters).

490. Fertilization of the egg takes place as follows: The microspore is carried by the wind or other means to the opening (micropyle) at the summit of the ovule integument; there it germinates, the tubular antherid penetrating the adjacent tissues; the sperms escape by the rupture of the tube, and swim through the intervening 
watery fluid to the archegone, finally reaching the egg. From the fertilized egg there is later developed a little

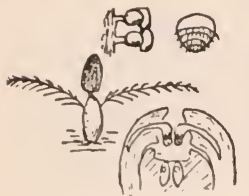

FIG. $149,-$ Zamia sporophyte and gametophytes. sporophyte which is nourished for a time by the tissue of the surrounding gametophyte. In the meantime the integument of the sporangium has greatly thickened into a mass of tissue soft externally and stony internally. When all growth ceases the megasporangium (ovule) with its contained gametophyte and sporophyte falls off, as the "seed."

491. After the fall of the seed when placed in proper conditions as to moisture and temperature, the sporophyte resumes its growth at the expense of the gametophyte (now called "endosperm"), and soon sends out a root, and later a green leaf, after which it becomes an independent long-lived plant.

492. The other living Cycads are essentially similar in structure to the foregoing. All of the species are tropical or subtropical. Many that lived in Mesozoic times have long been extinct.

493. In the Mesozoic period there flourished a group of Cycads that may be called the "Flowering Plant Ancestors" (Class Bennettitineak), and which had "flowers" containing

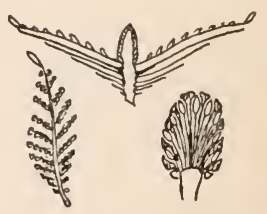

FIG. 150,-Bennettites a central cluster of stalked megasporangia, surrounded by a whorl of pinnate microsporophylls. Below these were many sterile bracts reminding one of flower-leaves (perianth). The resemblance of this primitive flower to the flowers of the simpler Flowering Plants such as Magnolia, Asimina, Ranunculus, etc., is so great as to suggest a genetic relationship. 
494. The Conifer Ancestors of the Paleozoic period (Order Cordaitales) were large trees 30 or more meters in height, and bearing a dense crown of branches and large, parallel-veined leaves, sometimes a meter or so in length. Microspore and megaspore cones are known, and even the seeds have been preserved, and many of their details of structure made out.

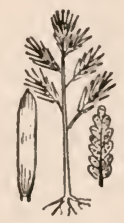

FIG. 151.-Cordaites.

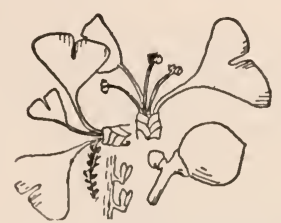

FIG. 152.-Ginkgo (staminate and ovulate).

495. The Maidenhair Trees (Order Ginkgoales) remind one in some respects of the preceding. They were common in the Mesozoic period, but all are now extinet excepting a single species (Ginkgo biloba) from eastern Asia. They have parallel-veined, fan-shaped leaves, and branching, woody stems. In the surviving species the trees are dioecious. The bisporangiate microsporophylls constitute a loose cone, while the megasporophylls remind one of those of Cycas described above. The seed integument becomes fleshy externally and stony internally when mature.

496. The Joint-firs (Order Gnetales), including several rather widely separated families, should probably be placed here, although their relationship is cloubtful, especially since they have non-ciliated sperms. Ephedra is a widely distributed genus of green, branching, leafless shrubs resembling Equisetum in appearance. Cnetum includes tropical shrubs and trees with large pinnately veined leaves; Tumboa (Welwitschia) oceurs in tropical west Africa. 
Laboratory Studies. (a) In many greenhouses may be found well-grown specimens of Cycas and Zamia. Examine these for the general appearance of Cycads.

(b) On inquiry it is possible that microspore cones of these common Cycads may be found, and secured for a closer study.

(c) Old trees of Cycas produce their "flowers" of megasporophylls every few years, and on inquiry some of the latter may be secured in various stages of development for dissection and study.

(d) Zamia plants in greenhouses frequently produce their thick, rounded megasporophyll cones. These should be dissected to find the sporangia (seeds).

(e) It should be remembered that various Cyeads, including Cycas and Zamia, grow in the Gulf states, and specimens may be obtained for study without much difficulty.

(f) Ginkgo trees are grown in many parks and door yards, and may be examined for their foliage and general appearance.

(g) In the spring look for microsporophylls and megasporophylls of Ginkgo and later for ripe, fleshy seeds.

(h) From the middle of June to early in July, depending upon the location, the sperms can sometimes be observed in the seeds as follows: Take a seed and with a stout knife split off two opposite sides (including the stony part of the integument). If properly made a slice will be removed from each side of the megagametophyte which can be removed with a portion of the megasporangium (nucellus) adhering as a cap to its apex. Upon carefully lifting this cap the microgametophytes will be found hanging to its under side as thick, glistening, tube-like bodies. Carefully dissect these off with very sharp scalpel and mount in a solution containing about 5 per cent. of cane sugar. The sperms (or at least the cells from which they arise) will readily be visible even under low power of the microseope, as they are very large, attaining a diameter of 0.1 millimeter.

\section{LITERATURE OF CYCADOPHYTA}

J. M. Coulter and C. J. Chamberlain, Morphology of Gymnosperms, Chicago, 1910.

M. C. Stopes, Ancient Plants, London, 1910. 


\section{CHAPTER XIX}

\section{PHYLUM XIII. STROBILOPHYTA}

\section{THE CONIFERS}

497. To a large extent this is a phylum of living plants, and although many species and some genera have become extinct, every family is still represented in some part of the world. The number of living species is about 400, widely distributed throughout the earth. The Conifers probably were derived from some of the old Cycads (Cordaitales) to which they show some affinities.

498. In these plants there is a still more marked alternation of generations than in the preceding phyla. The gametophytes are so minute and short-lived that they are rarely seen, while the sporophytes are mostly great trees with long-lived perennial roots and stems and mostly perennial green leaves also. The phylum may be defined as follows: Megaspores and microspores mostly borne in homogeneous cones of sporophylls on the arboreous sporophytes. Archegonial gametophytes very minute, solid, ellipsoid, and permanently enclosed in the megaspore, which in turn is retained in the megasporangium; antheridial gametophyte minute, few-celled, free, developing a tubular antherid containing two nonciliated sperms. After the fertilization of the egg and the formation of the cylindrical, leafy sporophyte, the megasporangium, covered by an indusial coat (integument), becomes a "seed." The sporophyte upon escaping from the seed in germination grows into a perennial, 
long-lived tree, rooted below, and bearing green (mostly perennial) leaves above.

499. Since the sporophytes are large and long-lived their tissues are many and well-developed. Their tracheary tissue is almost wholly of the form known as tracheids, which are here marked on their radial faces with bordered pits. Proper fibrous tissue is scanty or wanting. The vascular bundles are of the open collateral type, arranged in a cylinder so that they provide for increasing the diameter of the stems and roots. Turpentine canals are present in all parts of the plant.

500. There are nine families of conifers, a few only of which need be noticed here. In all the microspore cones are well developed, but there is a gradual simplification of the megaspore cones from those with many sporophylls to those with few or one. The Taxodiums (Family Taxodiaceae). Microsporophylls with two to eight spor-

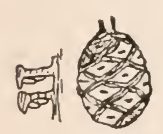

FIG. 153 Sequoia (seedcone). angia: megasporophylls woody, much enlarged distally, bearing two to several erect or inverted seeds, forming compact, ellipsoid cones; "seed scale" wanting. Here are the Bald Cypresses (Taxodium) and Redwoods (Sequoia), very old types that originated in the Mesozoic, and have persisted with reduced numbers to the present. The Redwoods, now confined to the mountains of California, were once widely distributed in the Northern Hemisphere.

501. The Old Pines (Family Araucariaceae). Microsporophylls with five to fifteen sporangia: megasporophylls woody, slightly enlarged distally, bearing one inverted seed, forming compact spheroidal cones; Fig. 154.-Arauca"seed scale" rudimentary. The Old

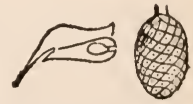

Pines are now confined to the Southern Hemisphere, and 
are represented by but two living genera, Araucaria and Agathis. These and other genera were represented in the Northern Hemisphere in Mesozoic and later periods.

502. Modern Pines (Family Abietaceae). These may be illustrated by the common Scotch Pine (Pinus silvestris), in which the microsporophylls are massed into cones 1 centimeter long, and these cones are themselves massed in clusters. Each microsporophyll bears two sporangia on its lower surface. The microspores are spheroidal but the outer layer of the Fic. $\begin{gathered}\text { 155.- } \\ \text { (micro- }\end{gathered}$ wall is often swelled out into two bladder- $\begin{aligned} & \text { spore cone and } \\ & \text { microspore). }\end{aligned}$ like distentions at opposite sides. These

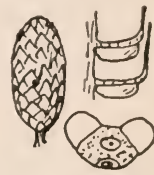
microspores ("pollen") escape from the sporangia in the spring, and may be carried by the wind for long distances (sometimes for hundreds of miles).

503. The megaspore cones grow singly near the ends of the upper twigs of the season's growth, and are about

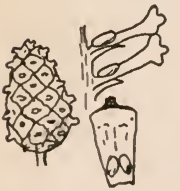

Fra. 156.-Pinus (secd-cone).

1 centimeter long. They consist of an axis on which are borne flat megasporophylls, each bearing two inverted megasporangia (ovules). In these plants fertilization is a slow process: the microspores carried by the wind fall between the megasporophylls (in the spring or early summer), where each spore pushes out a tubular antherid ("pollen tube") which penetrates the ovule tissue. This stimulates the growth of the tissues of the cone and it increases in size and bends downward on its stalk. In the meantime the ovules enlarge, the upper ("chalazal") end developing a thickened mass of green tissue which grows far beyond the end of the sporophyll, constituting the "seed sealc." These green "seed scales" are in 
reality the distal portions of the ovules, and function as photosynthetic structures for a year (or more).

504. In the first summer or autumn an axial spore mother-cell ("archespore") arises in the interior tissues of the ovule, and this ultimately divides into four cells (four young megaspores), only the lowermost of which enlarges into the fully developed megaspore. By the second spring this megaspore has divided and subdivided until a solid ellipsoidal cellular

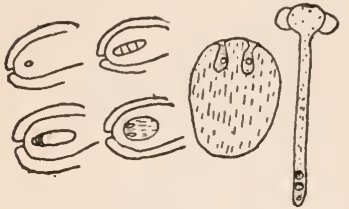

Fig. 157.-Pinus (archegonial, and antheridial gametophytes).

mass is formed-the gametophyte. Then from certain cells on the summit of the gametophyte several (usually four) sunken archegones arise, when everything is ready for the completion of the process of fertilization. In the meantime, the pollen tube resumes its growth, bringing the two non-ciliated sperms to the mouth of an archegone where one of the sperms soon fuses with the egg, and fertilization is completed, a little more than a year after pollination.

505. By repeated subdivision and continued growth of the zygote a cylindrical stem is formed, rooted below, and with a whorl of narrow leaves above. This is the sporophyte (or "embryo" of the seed). It is nourished by the gametophyte tissue in which it is imbedded. In the meantime ovule, "seed scale," and cone have increased in size, and later the "seed scales" lose their chlorophyll and become woody. Still later by the lessened supply of water all parts of the cone become dry, stopping the growth of the young sporophyte. The cone and seeds are now "ripe," and by the spreading of the dry scales the part of the seed containing the embryo is split loose and blown away. 
506. Germination of the seed takes place when water is again supplied, resulting in a resumption of the growth of the embryo, the bursting of the brittle integument (indusium) and the escape of the root, stem and leaves of the embryo. The root penetrates the soil and provides water, while the leaves (now green) provide carbohydrates, completing the establishment of the new plant.

507. There are about half a dozen genera of Modern Pines, distinguished by their

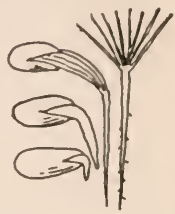

FI G. 158 . Pinus (seeds, and young sporophytes). leaves and cones, as follows:

I. Twigs with primary green leaves only.

1. Cone seales persistent.

i. Leaves prismatic, fourangled.

ii. Leaves flat.

(Spruces) Picea

(a) Megasporophylls (False long, protruding. Hemlocks) Pseudotsug.

(b) Megasporophylls short, not protruding.

(Hemlocks) Tsuga

2. Cone scales deciduous, the cone falling to pieces.

II. Twigs with both primary and (Firs)

AbIes secondary green leaves.
1. Leaves evergreen.
(Cedars) Cenrus
2. Leaves deciduous.
(Larehes) Larix

III. Twigs with only secondary green leaves.

(Pines) Prnus

508. The very young twigs of the last genus (Pinus) are covered with flat primary leaves which die immediately, and in their axils short twiglets push out bearing five, three or two very narrow leaves, the secondary leaves, which are the only ones persistent on these plants. Com- 
mon "White Pines" have five leaves in a fascicle, the "Yellow Pines" three or two. An Arizona pine has but one leaf on each twiglet.

509. In the Cypresses (Family Cupressaceae), and Thuyas (Family Thuyopsidaceae) the woody cones are small and composed of only a few scales, and the leaves are small and scale-like. In the Junipers (Family Juniperaceae) some twigs bear scale-leaves and others flat leaves, while the cone seales are few and fleshy, so that the cones are fleshy. In the Yews (Order Taxales) the reduction in the cones is carried so far that but one scale remains, and that has become fleshy. In the proper Yews (Taxus) the leaves are flat, but in some related genera they are scale-like.

Laboratory Studies. (a) In the spring of the year collect a quantity of the microspore (staminate) cones of a pine (Scotch or Austrian are very good), and preserve such as are not wanted for immediate use in alcohol. Collect at the same time the young megaspore (ovule-bearing) cones which are to be found at the ends of the new shoots.

(b) Split both kinds of cones vertically, and study their structure, comparing the one with the other.

(c) Study microspores from young and mature cones. In the young microspores look for the cells representing the gametophyte; in the mature microspores note the bladder-like enlargements of the outer coat.

(d) Study young megaspore cones of different ages, and note the growth of the "seed scale."

(e) Study megaspore cones one year old and note the development of the gametophyte, and later the archegones.

( $f$ ) Note that the megaspore cones of Scotch and Austrian pines are two years in coming to maturity. Make vertical sections of cones of various ages, and note the growth of the seed. Note the thin wing (useful in their dispersion) on the seeds. Make longitudinal sections of seeds, and note the little sporophyte with its several leaves (cotyledons).

(g) Examine the very young twigs as they develop in the 
spring and note the primary leaves with the growth of twiglets in their axils bearing young secondary leaves.

(h) Make cross-sections of mature leaves, and note the turpentine-canals, one near each angle, with others symmetrically arranged between. Make cross-sections of the young twigs, and note the canals in the rind or bark. Make similar sections of the wood of the trunk, and note similar canals at intervals.

(i) Make very thin cross-sections of the mature wood of the stem and note shape and size of the cells; note also the gradual decrease in their size in passing from the inner to the outer side of a growth ring. Now make a very thin longitudinal-radial section, and observe the bordered pits. A longitudinal section at right angles to the last (longitudinal-tangential) will show no bordered pits. In all these sections note that the wood is made up of but one kind of cells, viz. tracheids.

(j) In a cross-section of a stem note the thin radiating plates of tissue (medullary rays), in many cases extending from pith to bark. In longitudinal-tangential section of the stem these rays are seen in cross-scction to be made of thick-walled cells. In longitudinal-radial sections the rays are seen split lengthwise.

(k) Make very thin cross-sections of the stem through bark and wood, and note the layers of very soft thin-walled tissue (cambium) between wood and bark. This may be made more evident by soaking the section for some time in eosin, by which the cambium will be stained.

( $l$ ) Compare the cones of Pinus, Picea, Abies, Taxodium, Sequoia, Cupressus, Thuya, and Juniperus.

( $m$ ) Compare the leaves of Pinus, Picea, Abies, Thuya, and Juniperus.

\section{LITERATURE OF STROBILOPHY־TA}

J. M. Coulter and C. J. Chamberlain, Morphology of Gymnosperms, Chicago, 1910.

C. S. Sargext, Manual of the Forest Trees of North America, Boston, 1905. 


\section{CHAPTER XX}

\section{PHYLUM XIV. ANTHOPHYTA}

\section{FLOWERING PLANTS}

510. In this highest phylum we have the culmination of the repeated structural advances in earlier phyla. These plants are mainly modern, although some of the more primitive forms originated as far back as the Cretaceous period. It includes more than 132,000 known species, that is, more than all the other phyla together.

511. The Anthophyta probably were derived from the Bennettitales among the Cycads. It is certain, at any rate, that the flower structure of this ancient order bears a remarkable resemblance to that of the lower orders of the Flowering Plants.

512. This phylum may be characterized summarily as follows: Microspores and megaspores borne in flowers on the leafy, rooted sporophytes. Flowers normally consisting of more or less cone-like clusters of closed megasporophylls (carpels) above, and microsporophylls (stamens) below, and subtended by a perianth. Microspores (pollen-cells) free at maturity, each producing a one-celled gametophyte, and a tubular antherid, the latter containing two non-ciliated sperms. Megaspore retained within the megasporangium (ovule) where it develops an egg in a reduced archegone and immature gametophyte. After fertilization the gametophyte matures ("endosperm"), and the zygote develops into a cylindrical, leafy sporophyte. The megasporangium 
(covered by one or two indusial coats) now becomes the "seed." Upon germination of the seed the sporophyte escapes, sending its roots downward into the soil, and its stem upward into the light, bearing green (annual or perennial) leaves.

513. The tissues of the Flowering Plants show a higher development than in any of the preceding phyla. They range, in size and duration, from herbs, a few millimeters in extent and living but a few days or weeks, to enormous trees, 50 to 100 meters high and many centuries old; they live in all kinds of habitats from very wet to very dry, and from the most protected to the most exposed situations; accordingly their tissues, especially those which are supporting and conducting, show all degrees of variation from very simple to the most complex. The supporting and conducting bundles are here frequently united into fibrovascular bundles, which in the higher forms remain "open" and are arranged in a cylinder in the stem, thus providing a cambium zone for the thickening of the perennial stem.

514. Most Flowering Plants are terrestrial and chlorophyll-bearing; there are, however, many aquatic and aerial species, and a considerable number of parasites and saprophytes.

515. A Typical Flower. Flowers have so many particular forms that it would be impossible to describe them here, and yet they all conform to a general plan of structure. In other words, each particular flower shows a greater or less modification of or departure from what may be called the typical structure.

516. First of all, every flower has a central stem portion (axis), on which there grow pistils, stamens, and a perianth. This flower axis may be elongated, globular or very short, or it may be flattened into a disk or hollow 
cup ("receptacular cup"). In such a typical flower as a Buttereup (Ranunculus) this axis is globular.

517. In the Buttercup the globular axis is spirally studded with many carpels (simple pistils) each consisting of a closed cavity below (ovary), gradually tapering

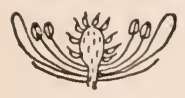

FIG. 159. Vertical plan of $\mathrm{R}$ an unculus flower. above to the soft terminal part (stigma). When young the carpel (megasporophyll) is an open, flattish, leaf-like structure, but as it grows larger its margins eurve upward until they meet and grow together. While the carpel is closing, an ovule grows out from the base, and becomes enclosed by the carpel walls.

518. Below the globular head of carpels (pistils) are several rows of stamens spirally encircling the axis. Each stamen is a stalked, somewhat flattish structure (microsporophyll), bearing four elongated, parallel sporangia which eontain mierospores (pollen). Commonly the stalk is ealled the filament, and the four sporangia together, the anther. The sporangia (pollen sacs) split longitudinally at maturity and permit the escape of the pollen.

519. Still lower on the flower axis are two series of leaf-like structures also spirally arranged, constituting the perianth. The upper series includes five rounded, yellow petals, the whole being known as the corolla. The lower series is made up of five pointed, green sepals, this being known as the calyx.

520. The purpose of a flower is the production of seed, and in the Buttereup this is accomplished as follows:

521. In the ovule (megasporangium) an axial spore mother cell (archespore) arises, and later this divides into four young cells (megaspores), but only the deeper 
lying one of these develops, the others perishing. So the ovule comes to have one megaspore, which is retained in the ovule tissues. A little later this megaspore develops an egg in connection with a greatly reduced archegone, and a very immature gametophyte, in the following manner:

The nucleus of the megaspore divides into two, which move to opposite poles of the megaspore cavity; here they divide twice resulting in four nuclei at each pole; then a nucleus from each pole (the so-called polar nuclei) moves to the center, where they ultimately unite. At the upper (micropylar) end one of the (naked) cells becomes the egg, accompanied by two companion cells

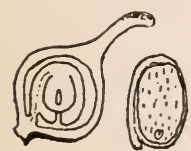

Frg. 160.-Ranunculus (pis til and seed).

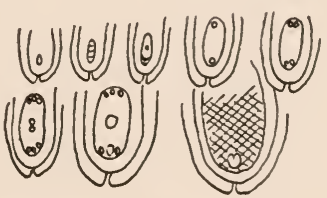

Fig. 161.-Ranunculus (development of ovule).

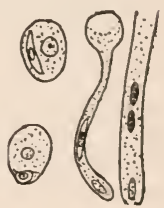

FIG. 162.-Pollen, tubular antherid and sperms.

("synergids"). At the lower end are the antipodal nuclei (or cells). About this time any pollen cell (microspore) that may have fallen upon the soft tissue of the carpel stigma germinates there producing its most reduced gametophyte, and a tubular antherid (pollen tube). The latter penetrates the soft stigma tissues toward the ovary cavity, carrying down the two sperms. When the tubular antherid reaches the ovule it enters the little pore (micropyle) at the summit of the indusial coats, and penetrates the ovule to the egg where one of the sperms then unites with the egg, this constituting fertilization. The zygote now divides repeatedly and 
finally takes the form of a very small stem, tipped with a root at one end, and bearing two rudimentary leaves at the other. In the meantime the immature gametophyte resumes its development as the result of the union of the second sperm nucleus with the two polar nuclei to form the so-called endosperm nucleus, which by its rapid division, with much delayed formation of cell walls, results in the development of a mass of tissue surrounding and nourishing the embryo sporophyte and filling the growing ovule. It is now known as the endosperm, but it is in reality only the belated gametophyte.

522. The ovule has now grown much in size. Externally its outer coat has become thicker and harder, while internally the gametophyte has enlarged and solidified. A layer of cells at the base of the ovule now becomes corky and checks the supply of water, drying and hardening the whole ovule, and stopping further growth. In this final state the ovule is called the seed.

523. In the Buttercup the carpel enlarges to accommodate the growing ovule, but finally its tissues harden and dry so that when the seed is mature it is contained within the close-fitting wall of the old carpel and, in this condition, it finally falls off from the flower axis and is known as a fruit. The term "fruit," therefore, is here used for the ripened carpel and its contained seed, and in flowering plants this is the generally accepted signification of the term.

524. When these fruits fall to the ground and absorb moisture, the embryo plant in each seed renews its growth, getting its food from the endosperm. At length it is able to push out a root into the soil, and much later it escapes wholly from seed and fruit and pushes up 
its stem and leaves to the light above ground, and becomes an independent plant (sporophyte).

525. The flower structure of the Water Plantain (Alisma) is essentially the same as that of the Buttercup. In it the flower axis is less enlarged, the carpels are fewer, in only a single whorl (i.e. not spirally arranged), and the stamens are usually six. The rounded, white petals are in a whorl of three, and the pointed, green sepals are also in a whorl of three. In the single ovule the development of the megaspore and later of the egg is similar to that in the Buttercup, as is also the growth of the pollen tube, and the process of fertilization. The endosperm develops as a belated gametophyte, and the zygote divides repeatedly, eventually becoming a small stem with a root at one end and a single rudimentary leaf at the other. Here this embryo sporophyte continues its growth until it has absorbed all of the endo-

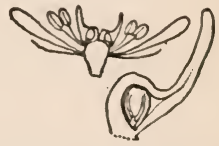

FIG. 163.-Vertical plan of Alisma flower (and pistil). sperm: as a consequence it is much larger than in the Buttercup, and the seed at maturity contains no endosperm.

526. The structure and behavior of the fruits (ripened carpels with their contained seeds) are in no wise unlike those in the Buttercup. So too the germination of the seed inside of the ripened carpels is similar to what has been described above. However, as there is no more endosperm remaining in the seed, the embryo escapes from it shortly after the root has appeared and pushes up its stem and leaves to the light above ground, as an independent plant (sporophyte).

527. A third example of a typical flower may be seen in the Strawberry (Fragaria) in which the flower resembles that of the Buttercup and the Water Plantain. 
Here the flower axis is globularly enlarged somewhat as in the Buttercup, and this is covered likewise with many spirally arranged carpels (megasporophylls). At the base of this globular body of carpels the axis is flattened out into a rim or collar, on the margin of which the stamens grow in several whorls of 5 or 10 each. On this margin there grow also the five rounded, white petals, and the five pointed, green sepals, both series in whorls. The development of the single ovules

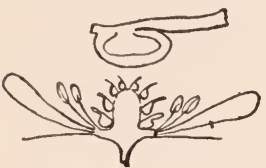

FIG. 164.-Vertical plan of Fragaria flower (and pistil). and the production of the egg are essentially the same as in the two preceding examples. After fertilization the zygote develops into an embryo plant consisting of a small stem with a root at one end and two rudimentary leaves at the other. The endosperm which appeared in abundance after fertilization is here wholly absorbed by the growing embryo, so that at maturity the seed contains a large embryo, and no endosperm.

528. While these changes are taking place in the seed the carpel enlarges, and the inner layers of the ovary cells thicken their walls into sclerenchyma, while the outer layers soften into a juicy flesh (parenchyma). The ripe carpels are thus very small fruits consisting of a thin flesh surrounding a tiny stone, which encloses a single seed. The proper fruits of the Strawberry are these small ripened carpels. When they fall to the ground the contained seed germinates by pushing out the root of the embryo, and since there is no remaining endosperm this is quickly followed by the escape of the remainder of the plant from seed and carpel, when it pushes its stem and leaves into the light, becoming an independent plant (sporophyte). 
529. Here it should be said that in the Strawberry while the fruits are developing the globular flower axis enlarges very greatly, and its tissues become soft and juicy, and this is what we eat with so much relish. So the "strawberry" as we eat it is not a fruit properly speaking. It is a thickened flower axis (stem), covered with the tiny proper fruits, popularly supposed to be seeds.

Laboratory Studies. NoTE: In eonnection

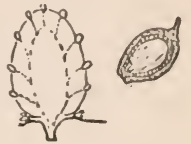

FIG. 165.-Fragaria ("strawberry," and a true fruit). with the anatomical studies of special plants suggested below the student is referred to the general studies on the cell, tissues, and tissue systems, already taken up in Chapters I, II, and III respectively.

In working out the following studies the student should have before him specimens of the three plants named so as to make comparative studies of the struetures represented by them.-

(1) Ranunculus, (2) Alisma, and (3) Fragaria. Where these eannot be obtained, acceptable substitutions may be made as follows: for (1) Myosurus, Magnolia, Caltha, Hepatica, Anemone; (2) Sagittaria; (3) Potentilla, Rubus, Geum, Duchesnea.

(a) Make a macroscopic examination of the stems (of the sporophytes) noting their shape, nodes, branching, bud and leaf arrangement, and follow with a microscopic examination of (i) a cross-section to show the location and structure of the vascular bundles, and the distribution of green and colorless tissues; and (ii) a longisection to show the tissues, epidermis, hairs and stomata.

(b) Examine the roots (of the sporophytes) and note whether there is one main root (tap root) with lateral rootlets, or a cluster of roots arising from about the same point on the stem. Note the shape, size and character of the roots and rootlets. Make cross- and longisections of the younger and older parts and a longisection of the tip of a root, to study the location and character of the vascular bundles, the kinds and distribution of tissues, the origin of lateral roots, the character of the root eap, etc. 
(c) Make a similar macroseopic examination of the leaves (of the sporophytes), noting whether they arise singly at the nodes ("alternate" leaves), or in pairs ("opposite"), or in whorls of three or more ("whorled"); determine the shape (sometimes variable), margin, surface, size and variation of the leaf blades; the length and shape of the petioles; and the shape and position of the stipules (where present). For the microscopic anatomy make cross-sections of the leaves and note shape and size of the epidermal cells, thickness of cuticle, character of hairs, type and location of vaseular bundles (veins), and amount and location of the forms of parenchyma tissue (the mesophyll) called "palisade" and "sponge" parenchyma respectively. In cross-sections of the petioles note size of intercellular spaces. Make sections of the blade parallel to the surface, and note the comparative frequency of the stomata in the upper and lower epidermis, shape of epidermal cells (and correlation with type of venation if any), component tissues of the veins and the course of the latter, etc.

(d) Study the macroscopic structure of the flowers observing them from above, note that they are radially symmetrical (actinomorphic). Note the shape of the axis (torus) and how the flower parts are attached to it, making a longitudinal section if necessary; observe that it does not surround or grow fast to any floral parts. Note the number and arrangement (in spirals or whorls) of the megasporophylls (carpels), and observe that they are free from one another (apocarpous); distinguish the ovary and stigma (and style if present); make transverse and longitudinal sections of earpels and observe number and location of the megasporangia (ovules). Count and note arrangement (in spirals or whorls) of the microsporophylls (stamens); examine one carefully and note the filament (stalk) and anther (cluster of microsporangia); section transversely an unopened anther and note the four microsporangia; examine the microspores (pollen) from a mature anther. For the petals note number, shape, color, size, and particularly their arrangement (spirals or whorls). Make a similar study of the sepals; note whether free or united; observe their arrangement with reference to the petals.

(e) The study of the female gametophyte will require the use of prepared slides. If possible they should show the development from the megaspore mother-cell (archespore) to four 
megaspores, thenee to the formation of the immature gametophyte (embryo sac) with its egg, arrangement of cells and nuclei being noted. A slide should also be studied in which a young sporophyte is developing amid the cells representing the further growth of the gametophyte (i.e. the endosperm). The male gametophyte may also be studied in a prepared slide showing mierospores (pollen cells) that have been germinated so as to show the tubular antherids (pollen tubes) and which should also show the antheridial nucleus, and the generative nucleus (or possibly the two non-ciliated sperms derived from it).

( $f$ ) Strictly considered the fruits consist of the modified carpels containing the ripe seeds, but any accessory modification of adjacent parts should also be noted. Examine the flowers when the fruits are mature and note the structure of the carpels, whether dry or partly fleshy, and dehiscent (i.e. opening to permit the eseape of the seeds) or not (indehiscent). Note (in Fragaria or Duchesnea) the considerable enlargement of the torus, and eonsequent separation of the earpels. Note how the calyx is modified, and whether it remains or falls. Remove a mature seed from a carpel and note its size and shape, and the external characters of the seed coat (consisting of the integuments); section it transversely and longitudinally and determine the presence or absence of endosperm, the relative size of the embryo, and the number of cotyledons.

530. If now we compare the three flowers described above it will be seen that they are very similar. Yet the Buttercup and Strawberry have their petals and sepals in whorls or series of five each, while they are in whorls of three each in the Water Plantain. Again in the former there are two rudimentary leaves ("cotyledons") on the embryo sporophyte, while in the latter there is but one. Now if we carry our comparison to the plants bearing the flowers we find other differences. The first leaves on the little plant in the Buttercup and the Strawberry as it appears above ground are opposite on the stem, while in the Water Plantain they are alternate, 
and continue to be so throughout the life of the plant. In the first two the vascular bundles of the leaves are irregularly netted with one another, while in the Water Plantain the bundles are quite as markedly parallel. Also in the stems of the first two there is a more or less cylindrical arrangement of the vascular bundles, showing as a ring in a cross-section, while in the Water Plantain the bundles show little if any cylindrical arrangement, the bundles being more or less scattered throughout the cross-section.

531. These differences are pretty constant for the plants related to Buttercups, Strawberries and Water Plantains respectively, so that botanists have been led to use them for the division of the Flowering Plants into two classes. Thus the first two plants and their relatives constitute the Class Dicotyledoneae, that is the plants with two cotyledons, while the Water Plantains and their relatives constitute the Class Monocotyledoneae that is the plants with one cotyledon. These classes are of very unequal size, the Dicotyledons containing nearly

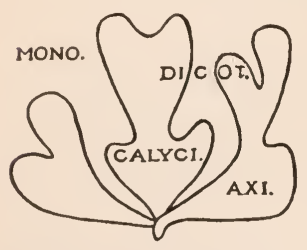

FIG. 166.-Chart of the Flowering llants. 109,000 species, while the Monocotyledons contain somewhat less than 24,000 species.

532. It is now thought that the Dicotyledons originated earlier than the Monocotyledons, and that the latter must be considered an early offshoot of the former. Yet the Monocotyledons are by no means higher in rank than the Dicotyledons as a whole; they show fewer variations from a common type; they are more nearly uniform in structure and at no point do they rise as high as do many of the Dicotyledons. For these reasons the Monocotyledons are usually discussed 
before the Dicotyledons, as a lower class, in spite of the fact that they appear to have originated from the latter. The Dicotyledons are an earlier class, but they have risen higher than the later derived Monocotyledons.

\section{CLASS MONOCOTYLEDONEAE.}

\section{The Monocotrledons}

533. Cotyledon one; leaves on the stem alternate; vascular bundles in the stem scattered (as seen in crosssection), in the leaf blades parallel ("parallel-veined"); perianth whorls mostly ternate (in 3's).

534. There are seven or eight types (orders) of Monocotyledons. The lowest of these (Alismatales) is represented by the Water Plantain, already described. The others are briefly as follows:

535. Lilies (Litiales). In a Lily the carpels (megasporophylls) have been reduced to three, and these have grown together into a single pistil ("compound pistil"), in which each carpel retains its ovule-bearing cavity (i.e. the pistil is "3-celled"). The stamens (microsporophylls) are in two whorls of three each: the petals are three; and the sepals three. Commonly the perianth is relatively large, and the two whorls of

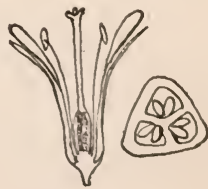

FIg. 167.-Lilium (vertical and transverse plans). similar texture. Throughout the flower the members of successive whorls are alternate.

536. The flower structure here reached appears to be typical of the great body of the Monocotyledons; and the structural peculiarities of the following orders are only modifications of those of the Lilies.

537. Calla Lilies (Arales). In the Calla Lilies the individual flowers are small, and massed on a thick 
stem, commonly diclinous (i.e. stamens and pistils in separate flowers, monoecious or dioecious) usually subtended by a colored leaf (spathe). Each flower is like a very small lily, but it is very short verti-

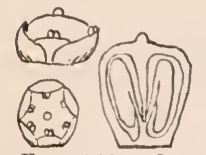

FIg. 168.-Calla Lily flowers and pistil (Pothos). cally, and relatively thick ("squatty"). The short stamens are usually six, and the very short-styled pistil is 3-celled (or 1-celled). The perianth lobes are short, thick and fleshy or wanting. Throughout the order (which is largely tropical) there is a marked tendency toward fleshiness both as to the plant body (always herbaceous) and the flowers.

538. Palms (Palmales). This order of woody trees and coriaceous leaves has small flowers resembling those of the Lilies, but with the parts usually harder and more parchment-like in texture. In the Coconut the flowers are separated (diclinous), one kind having functional stamens (staminate), and the other a functional pistil (pistillate). The staminate flower has a perianth of two ternate whorls, the outer (sepais) shorter than the inner (petals). The stamens are six in two whorls, and there is a small, tricarpellary functionless pistil. The pistillate flower is much larger, and has a perianth of two ternate whorls, the sepals and petals being similar to each other. There are no stamens. The large pistil is tricarpellary and should contain a seed in each of the carpels, but two seeds are always

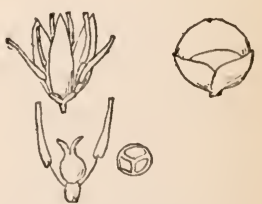

Fig. 169.-Palm flowers (Cocos). suppressed and their carpellary cavities are crushed by the growth of the third large seed. The fruit has much the structure of a plum; in which the inner part of the ovary wall becomes stony (sclerenchyma), while the outer part remains 
fleshy in the plum, but eventually becomes fibrous in the coconut. The coconut of the northern markets is the stone of the ovary wall, containing one large seed. This stone shows its tricarpellary structure by the ridges on its surface.

539. Grasses (Graminales). In these plants (including several families) the stems and leaves have become elongated and markedly fibrous and tough. The flowers are of the Lily type but much reduced, and are clustered uniformly on slender axes into "spikelets." In the Grasses proper (Family Poaceae) each flower is in the axil of an outer bract (flowering glume, flowering scale, lemma). The perianth consists of a scale-like, 2-keeled calyx (palet, palea) representing the two united posterior sepals (the third being absent) and of two (anterior), rarely three, small, fleshy petals (lodicules). Two whorls of three stamens each are present, or more often only the outer whorl. The pistil is tricarpellary with two stigmas (very rarely three stigmas) and there is but one ovule in the single ovary cavity.

540. The Bamboos are large, woody, hollow-stemmed tropical grasses, in which the corolla is trimerous, with the petals (lodicules)

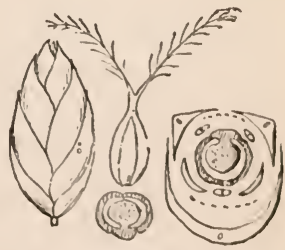

FIG. 170.-Grass flowers and spikelet.

relatively large, the stamens are mostly six, and the pistil is frequently tristigmatic. In some bamboos the fruit is externally fleshy, while in others it is like that in the Brome Grasses.

541. Brome Grass (Bromus) has a hollow herbaccous stem, and its large spikelets are several flowered; the corolla is reduced to two small petals (lodicules); the stamens are three, and the pistil has two feathery 
stigmas. The ripened pistil tightly encloses the seed, forming the "grain" or "caryopsis."

542. Maize (Indian Corn) has a solid (not hollow) stem and its spikelets are diclinous, the staminate forming a branching inflorescence at the top of the stem, the pistillate being crowded upon the lateral "ears," which terminate short lateral branches, whose numerous crowded leaf sheaths form the "husks." The staminate spikelets are in pairs (one sessile, the other stalked), and each is two-flowered. The pistillate spikelets are also in pairs, but here there is only one flower in each. The styles ("silks") are long, and bistigmatic. The corn "kernel" is the ripened ovary with its tightly fitting single seed.

543. The Sedges (Family Cyperaceae) are a family of widely distributed, somewhat more primitive, grasslike plants that differ in vegetative structure from the Grasses in that the leaves are three-ranked, instead of two ranked, and the stems solid instead of hollow. The spikelets more often have the bracts spirally arranged, only a few genera having them two-ranked as in the grasses. The axillary flower consists of a tri- or a bicarpellary pistil, six, or more often three, stamens, and a

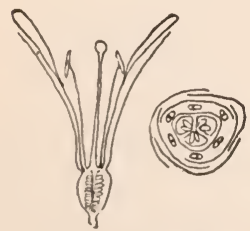

FIG. 171.-Amaryllis. perianth of two ternate whorls of narrow segments, or bristles or wanting. The ovary wall is not grown fast to the single seed.

544. Amaryllis (Iridales). In the Amaryllis the flower is Lily-like with a well developed perianth of six equal petaloid segments (sepals three, petals three), six stamens, and a tricarpellary, long-styled pistil, whose ovary is overgrown by the receptacular cup which carries up the perianth and stamens, so that the ovary 
is said to be "inferior." The nearly related Iris has its sepals reflexed and its petals erect: its stamens are three, and the three style branches are broad and spreading. The ovary is inferior as in Amaryllis.

545. Orchids (Orchidales). Here the ovary is inferior as in Amaryllis, but the perianth is made up of unequal and unlike segments, the stamens are reduced to two or one (very rarely three), and the tricarpellary pistil has but two functional stigmas in the large majority of species.
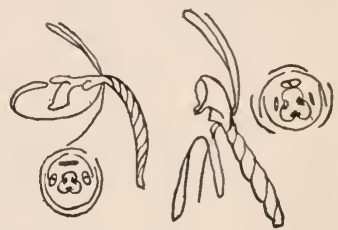

FIG. 172.-Orchids (Cypripedium and Orchis).

546. In all the foregoing Monocotyledons the embryos have one cotyledon, the stems have scattered vascular bundles, the leaves are alternate on the stems, and parallel-veined, and the perianth whorls are ternate.

Laboratory Studies. Note: In these studies, and those upon Dicotyledons, the aim should be to bring out the successive advances in flower structure from the lower to the higher forms. With this object in view many other details may well be omitted, but some attention should be given also to special modifications of the general plant body.

(a) Make cross- and longitudinal sections of onion seeds and note the seed coats (integuments) enclosing the rather horny endosperm within which lies the embryo sporophyte. In similar sections of grains of Indian corn the external coat consists of the ovary wall grown fast to the integuments; the remainder of the grain consists of endosperm except the elongated or shield-shaped "germ," which is the embryo sporophyte.

(b) Sow a number of onion seeds and grains of Indian corn and examine one of each crery day after germination begins. In the onion note that the plantlet "backs out" of the seed, as it were, the root first appearing, followed by the stem, and last of all, the single cotyledon. In the corn the cotyledon remains in the grain as a special absorbing organ, so that after the root 
emerges the leaves appear, the short stem remaining in the seed for some time before it begins to elongate.

(c) For the lilies use any true lily (Lilium) or one of the following: Erythronium, Yucea, Allium, or Trillium. IBy longitudinal and transverse sections of the flowers show the single, superior, tricarpellary pistil, the double, trimerous whorl of stamens, the three petals, and the three sepals.

(d) In like manner examine the small flowers of any cultirated "Calla Lily" (or Arisaema, Pothos, or Acorus), and note also the thick axis (spadix) on which the flowers are collected, and the large, subtending bract (spathe). Look for more or less reduction in the structure of the flowers in some of these plants.

(e) The lily-like staminate flowers of the Coconut (Cocos nucifcra) should be studied like those of the true lilies (c) for general plan, and the pistillate flowers for a considerable modification of that plan. Add a study of the mature nut. The perfect flowers of the palmettos (Sabal) are much like the staminate flowers of the coconut, but the fruits may develop one, two or three of their carpels.

(f) Examine segments of Bamboo stems for woodiness. Dissect Bamboo spikelets, noting their general structure; study the flowers with their nearly complete perianth whorls, three or six stamens, and two or three stigmas.

(g) A further reduction of the flower structure together with a typical, not much reduced, spikelet structure, may be found in the herbaceous grasses Bromus, Poa, Triticum, or Avena. Study the spikelet structure, and then the flowers, in which both perianth whorls are incomplete, one whorl of stamens is lacking, and the pistil has but two stigmas. Examine also the hollow stem (including nodes and internodes) and leaves (including sheaths and blades).

(h) Examine the solid stem (stalk) of Indian Corn (Zea) in cross and longitudinal sections, and also the leaves and sheaths. Dissect a staminate spikelet (from the "tassel") with its two tristaminate flowers. Dissect out from a young "ear" a pistil with its long style ("silk"), and reduced and distorted scales at its base.

(i) Examine a plant of Bulrush (Scirpus) and note arrangement of leaves on the solid (parenchymatous) stem, and the structure of blade and sheath. Dissect a spikelet (noting its 
spiral arrangement), and study a flower with its tri- or bistigmatic pistil, three stamens and (usually) six perianth bristles. Cyperus differs mainly in its two-ranked spikelets, and absence of perianth bristles.

(j) Study an Amaryllis flower in longitudinal and crosssections as in the lily $(c)$. The small, somewhat zygomorphic flowers of the banana (Musa) may be substituted for the amaryllis. Note the absence of one stamen. Study also the mature fruit (usually seedless) in sections.

(k) Make a similar study of the Iris flower.

(l) For Orchids the Lady's Slipper (Cypripedium) should be studied, and its two stamens grown fast to the tristigmatic style, one petal slipper-shaped ("lip"), the other two much like the pointed, rather elongated sepals (two of which are often united). Note the sticky pollen, and the very numerous, minute seeds. For this may be substituted the native Orchis, or Ibidium, or various greenhouse orehids; here the single stamen is attached to the bistigmatic style, and the petals and sepals are very variable, one petal ("lip") being always much longer and more showy.

\section{CLASS DICOTYLEDONEAE.}

\section{The Dicotyledons}

547. Cotyledons two; leaves opposite on the stem, later ones opposite or alternate; vascular bundles in the stem arranged cylindrically (in a ring as seen in cross-section); vascular bundles in the leaf-blades irregularly netted ("netted-veined"); perianth whorls mostly quinate (in 5's).

548. There are two greater types (subclasses) of Dicotyledons, which are dis-

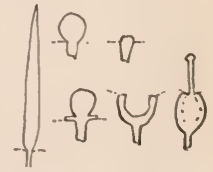

FIG. 173.-Di:grams of flower axes. tinguished by the structure of the flower axis, as follows:

1. Flower axis cylindrical, spherical, hemispherical or flattened, bearing on its surface the flower parts (perianth, stamens and carpels).... "Axis Flowers" (Axiflorae).

2. Flower axis more or less expanded into a disk or cup, 
bearing on its margin the perianth and stamens, subtending or surrounding the carpels . "Cup Flowers" (Calyciflorae).

\section{Axis Flowers ${ }^{1}$}

549. The Buttercup (Ranunculus) described above is one of the simplest of the Axis Flowers, in which the flower axis is nearly spherical.

550. The Magnolia flower (Magnolia) is much like a gigantic Buttercup, the axis being more elongated, but with essentially the same structural plan. This flower also has many separate carpels.

551. The common Mallow (Malva) has many carpels in a single whorl, whose adjacent sides feebly cohere to form a compound pistil. The many

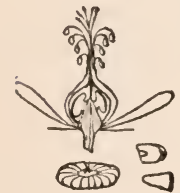

FIG. 174

Mallow. stamens also cohere below into a tube, but above they are separate and spreading. The perianth whorls are dissimilar, the outer being green and coarser, and the inner white or bluish, and of soft texture. All these flower parts are borne on the small, conical axis.

552. The Wild Geranium (Geranium) has an elongated axis on the sides of which is borne the whorl of five feebly adherent carpels. The stamens are similarly reduced in number (two whorls of 5 each) and the perianth consists of dissimilar whorls, the outer of green sepals, and the inner of pink or purplish petals.

553. In the Violet (Viola) the axis is very short and bears on its summit the tricarpellary pistil. The carpels are united by their margins, making but one

${ }^{1}$ For the more systematic arrangement of the plants in this and the following sub-class the reader is referred to the outline of the Plant Phyla in Chapter XXII, where the orders and families are given in what is believed to be their proper sequence. 
pistil cavity, and the ovules grow upon these margins, i.e. the placentae (the areas from which the ovules grow) are "parietal." The stamens are five, the usually blue petals five and the green sepals five. In all violets the front lower petal is large and spurred at its base, the side petals are smaller, while the back petals are larger. There is an unlikeness in the petals, and the flower is "irregular."

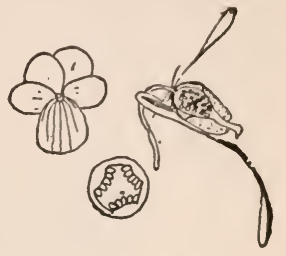

Frg. 175.-Yiola.

554. The Mustard flower (Brassica) has reduced the number of its parts still further, the pistil being bicarpellary. Its two carpels are united at their margins, and the ovules grow upon these margins (parietal placentae), as in the Violet. Here, however, a thin membrane stretches across from margin to margin dividing the cavity into two. The stamens are six in two whorls (4 and 2), the yellow petals four, and the green sepals four. All of these parts grow upon the very short flower axis.

555. In some Pinks (Lychnis) the five-carpelled pistil has broken away the partitions between the carpels so

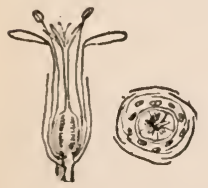

FIG. 176.-Lychnis. that there is but one pistil cavity, although the five styles indicate its structure. The ovules grow upon a central column, the united placentae. The stamens are ten (two whorls), the petals five, and the united green sepals five (gamosepalous). In some other pinks the carpels are reduced to two, but the flowers are otherwise like those of Lychnis.

556. The Primrose flower (Primula) reminds one of the pinks, but here the five petals have grown together into a tubular corolla, so that it is spoken of as gamopetalous. The pistil is composed of several (probably five) carpels, 
closely fused together, and their partitions have broken away, leaving a central ovuliferous column. The stamens are five, and they have grown fast to the corolla tube. The sepals are fire, and they have united with one another for some distance from their bases.

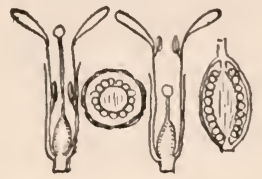

FIG. 177.-Primula.

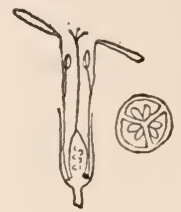

FIG. 178.-Phlox.

557. The Phlox (Phlox) again reminds one of the pinks, and primroses, to which it is related. The corolla is gamopetalous, and the five stamens are attached to the corolla tube. The five sepals are united for some distance from their bases (gamosepalous). The pistil is reduced to three carpels, but here the carpel cavities persist, and in each there are from one to four ovules.

558. In the Petunia (Petunia) the gamopetalous corolla is more widely open, while the attachment of the five stamens, and the gamosepaly of the calyx are like those of phloxes and primroses. The reduction in

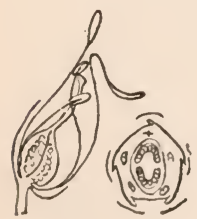

FIg. 179. Antirrhinum. the number of carpels has continued so that here there are only two, each with its many-ovuled cavity.

559. The Snapdragon (Antirrhinum) has intensified the slight irregularity of the corolla of the Petunia so that it is markedly 2-lipped. Its stamens which are attached to the corolla are reduced to four, one having disappeared. The pistil is bicarpellary, and the seeds many in each carpel cavity. The calyx is gamosepalous.

560. The Sage (Salvia) carries the preceding modifications a step further. The gamopetalous corolla is 
strongly 2- lipped, and its attached stamens are reduced to two, the other three having disappeared. The bicarpellary pistil contains two ovules in each carpel cavity. The calyx is gamosepalous.

In the Salvia and the related mints we have the highest development of the Axis Flowers. Compare them with the Buttercups and Magnolias, and note what changes have taken place.

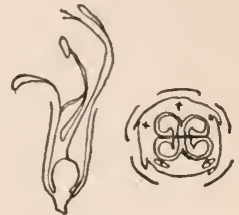

FIg. 180.-Salvia.

The axis has been shortened and reduced; the carpels have been reduced from many and separate to two, united; the stamens, from very many to two; the petals from separate (apopetalous) to united (gamopetalous); as well as from regular to irregular; the sepals, from separate to united.

Laboratory Studies. (a) Examine externally and by cross and longitudinal sections the seeds of Castor Bean (Ricinus), Pea (Pisum), and Squash (Cucurbita), noting the character of the seed coat; the presence of endosperm in Ricinus, its absence in the other two; and the two cotyledons, and between them the rudiments of the next leaves (the plumule). Where the endosperm is lacking note that the cotyledons are thickened into storage organs.

(b) Germinate some of the foregoing seeds, examining at frequent intervals, and note that in the Castor Bean the thin cotyledons remain in the seeds (in eontact with the endosperm) for a longer time than in the Squash, but eventually in both they become green, and function as leaves. In the pea the hemispherical cotyledons are too thick to function as leaves, and remain in the seed coats.

(c) Examine, in sections if necessary, a flower of the common Mallow (Malva), or of Hollyhock (Althaea), or Cotton (Gossypium), noting number and arrangement on the torus of the united carpels, united stamens, petals and sepals, bearing in mind the resemblance to and differences from the general plan of the Buttereup type of flower. 
(d) In a similar way and making similar comparisons study the flower of Wild Geranium (Geranium), or Cultivated Geranium (Pelargonium).

(e) In the Violets and Pansy (Viola) make out especially the structure of the pistil and its stigma, the fewer stamens (the two lower extended backward), and the zygomorphic perianth.

( $f$ ) In studying the flowers of Mustard (Brassica) or of Radish (Raphanus), note particularly the reduction of the general flower-parts to fours, with the carpels and outer whorl of stamens further reduced to two.

(g) In the Pinks (using Lychnis, Silene or Dianthus) observe the disappearance of the septa in the ovary, leaving a free central placenta, and note the number of styles and number and arrangement of the stamens, petals and (united) sepals.

(h) For the Primrose flower (Primula) make out the pistil structure, comparing with that of the Pinks, the central placental column, the capitate stigma, the five stamens attached to the tubular spreading corolla, and somewhat united sepals.

(i) Note the similarities and dissimilarities in the structure of the flower of Phlox as compared with Primula.

(j) Study the funnel-shaped Petunia flower noting especially the reduction of the carpels to two and the slight zygomorphy of some of the corollas. The more open flower of Solanum, or the long-tubular flower of Nicotiana may be substituted for Petunia.

(k) In the Snapdragon (Antirrhinum) in addition to the marked zygomorphy of the corolla, note that one of the stamens (the posterior) has disappeared. Digitalis with similar stamens, or Pentstemon with four fertile and one sterile stamen may be substituted for Antirrhinum.

(l) In the flowers of Sage (Salvia) or Horsemint (Monarda) note the strongly-marked bilabiate structure, and the reduced number of stamens, as well as the reduction of the pistil to two bilobed, biovulate carpels. In Dead Nettle (Lamium) the stamens are four instead of two.

\section{Cup Flowers}

561. The Strawberry (Fragaria) described above is one of the simplest of the Cup Flowers; in fact it is so 
simple that at first sight we scarcely recognize it as a Cup Flower. The expanded rim below the globular axis is however the beginning of the cup form of the flower axis.

562. The Spiraea or Bridal Wreath (Spiraea) of the gardens shows a great reduction in the number of carpels, from many (in the Strawberry) to five each with several ovules, and with this we have the disappearance of the globular flower axis, while the fleshy rim or disk

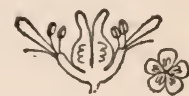

FIG. 181.-Spiraea. has now become somewhat cup-shaped. On the margin of the cup are borne the many stamens, usually 20, in whorls of 5 or 10 each, the five separate, white, rounded petals, and the five separate pointed, green sepals.

563. The Rose flower (Rosa) shows a considerable advance over that of the Spiraea in its general structure although more primitive as to its carpels and stamens. The cup is very deep and completely encloses the many free, biovulate (but one-seeded) carpels. The stamens are very many (40-50, or more) in whorls of 5 or 10 , attached to the cup margin. The five petals are large and rounded, and with the pointed, green sepals are attached to the margin of the cup. After flowering the cups ripen into edible, fleshy "rose-apples."

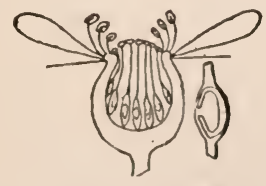

FIG. 1S2.-Rosa.

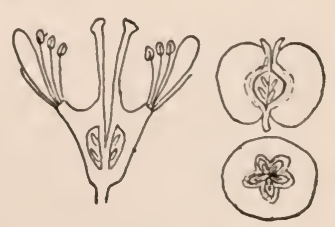

Fig. 183.-MIalus.

564. In the Apple flower (Malus) the cup is still deeper, narrower, and more fleshy, and it encloses and is grown to the five, slightly united biovulate carpels. The many stamens, 20 or more, in whorls of 5 or 10 each, 
are borne on the margin of the cup, and here are found the five round, pinkish petals, and the five, green-pointed sepals. As the seeds mature the tissue of the cup enlarges and softens into the flesh of the ripe apple, while the five carpels constitute the "core." Thus in the apple as in the strawberry the fleshy, edible tissue belongs to the flower-axis, and not to the proper fruit (the core). In fact we eat the cup (flower axis) and throw the fruit (core) away!

565. In the Plum (Prunus) the cup has become deeper and narrower than in the Spiraea, while the carpels are

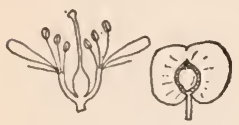

Fig. 184.-Prunus. reduced to only one with 2 ovules. The stamens are still many, 20 or more in whorls of 5 or 10 each, on the margin of the cup, while the petals and sepals are as in Spiraea. The (free) carpel in ripening softens and thickens its outer tissues into an edible flesh, while the inner tissues immediately surrounding the seed are hardened into a stone (sclerenchyma).

566. The Pea flower (Pisum) has a shallow cup, and in its center a single monocarpellary pistil, as in the Plum flower. Here, however, instead of two ovules there are several, so that the pistil becomeselongated. The stamens on the margin of the cup have been reduced to ten, and nine of these have grown together by their filaments, leaving one free. The five white petals are unlike, so that the flower is "irregular." The back (upper) petal is large and broad (the

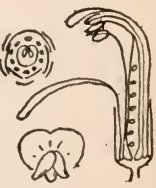

Fig. 185.

Pisum. "banner"), the two lateral petals ("wings") are narrower and hoodecl, while the two lower petals are still narrower, united along their lower margins and much curved upward (forming the "keel"). The green calyx is 
gamosepalous and nearly regular. The carpel, which is somewhat fleshy when young, on ripening becomes dry and fibrous. This form of fruit is known as a "legume."

567. It should be noted that the flowers of the plum and the pea are very much alike in plan, the greatest difference being the irregularity of the corolla, and the fewer, united stamens. The pea represents an immense group of plants (Bean Family) of 6,000 to 7,000 species, which appear to have been developed from plum-like ancestors by their corollas becoming irregular. They constitute an evolutionary side line in which irregularity of the corolla ("zygomorphy") has been especially developed with reference to insect agency in pollination.

568. The flower of the Garden Currant (Ribes) reminds one a little of that of the Apple. Its cup is deep enough to enclose the ovary of the bicarpellary pistil. The carpels are united at their margins, so that there is but one cavity with two parietal placentae. The margin of the cup bears the perianth (five sepals, five petals) and the five stamens. The ovary in ripening thickens and softens its wall, becoming a many-seeded berry, a portion of which consists of the thickened cup.

569. The cup of the Evening Primrose

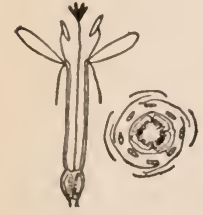

FIG. 157.

Oenothera.

(Oenothera) is very deep, not only enclosing the quadricarpellary ovary, but extending as a tube much beyond it. The carpels are wholly united so that the ovary has four many-seeded cavities. The eight stamens (in two whorls) are borne on the edge of the tubular cup, as are the four large yellow petals and the narrow, greenish sepals. The ripening ovary becomes hard and dry, 
eventually splitting open to permit the escape of the seeds.

570. The flower of the Prickly Pear (Opuntia, a cactus) is in plan much like the preceding, but there are more carpels (four to eight): these are united at their margins,

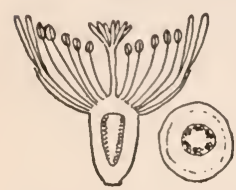

FIg. 18s.-Opuntia. so that there is but one, many-ovuled cavity, with four to eight parietal placentae. The cup is very fleshy, and bears on its margin and inner face the very many stamens, many petals and many sepals. Cactuses are eviclently related to the Evening Primroses, but are peculiar in being very fleshy, and mostly leafless. The stems of the Prickly Pear when young bear small leaves, but these soon dry up and fall off after which the stems are leafless.

571. The Walnut flowers (Juglans) are small and diclinous, those with stamens being in drooping, cylinclrical, crowded clusters, those with pistils solitary or in pairs. Staminate flowers with a reduced perianth (calyx), and many short stamens; pistillate flowers with a bicarpellary

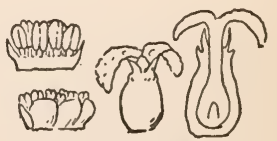

Fig. 189.-Juglans. pistil which is wholly covered with the thick cup, on the margin of which are four reduced sepals, and as many very small petals. The fruit is fleshy externally while the single seed is surrounded by a mass of stone tissue, as in the plum.

572. The flowers of the Oak (Quercus) are much like those of the Walnut, but the staminate flower clusters are less dense, and the pistillate flowers are solitary in scaly involucres (i.e. a collection of several to many crowded bracts). The staminate flowers have a reduced perianth (calyx) and six to twelve long stamens, while the single 
pistillate flower in each scaly cup-like involucre consists of a tricarpellary pistil, wholly covered by a thin cup bearing on its margin the very minute perianth (calyx). The fruit is a thin, tough-shelled nut ("acorn") usually with but one large seed. The ripe acorn rests in the enlarged scaly involucre, now known as the acorn cup.

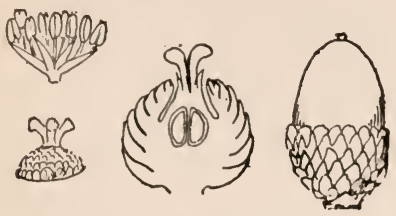

FIG. 190.-Quercus.

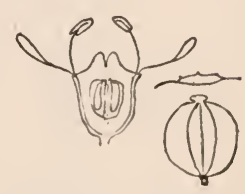

Fig. 191:-Pastinaca.

573. In the Parsnip (Pastinaca) the small flowers are clustered at the ends of slender spreading rays (in an umbel). The bicarpellary pistil is covered with the thin cup, on the margin of which are the five very minute sepals, the five yellow petals, and the five elongated stamens. Each earpel cavity contains a single pendulous ovule. In ripening the bicarpellary ovary becomes much flattened (dorsally) so that each carpel becomes winged marginally, and later the two carpels split apart.

574. The flower of the Honeysuckle (Lonicera) has its bi- or tricarpellary pistil covered with the deep cup, as in the preceding plants. The five sepals on the cup margin are very small, and the five petals are united into a tube which widens upward to its irregular margin. The five stamens are attached to the inside of the corolla tube. On ripening, the cup and enclosed ovary develop into a

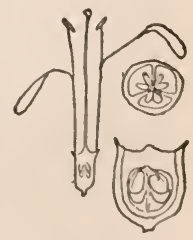

FIG. 192. Lonicera. fleshy few-seeded berry.

575. In the Sunflower (Helianthus) which is one of the lowest niembers of the highest order (Asterales) of 
Flowering Plants the small flowers are clustered into many-flowered heads, from which fact these plants and their relatives are known as "Composites." The face or top of the head is flat, and its back is covered with many spreading, green bracts, constituting the "involucre." The face of the head bears the many small crowded flowers each in the axil of a stiff bract. Those

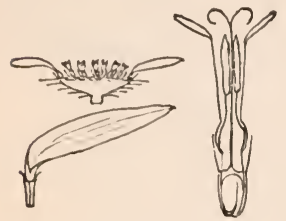

FIG. 193.-Helianthus. on the margin ("ray flowers") are quite sterile, and have large flat corollas (of five petals united below into a tube, but "ligulate" above), while the remainder. (" lisk flowers") produce seeds and have tubular corollas. Examining one of the latter we find that the bicarpellary pistil is wholly covered by the thin cup: the calyx ("pappus") is reduced to two or a few scales: the corolla consists of five petals united into a tube which is five-pointed at its summit: the five stamens are borne on the inside of the corolla tube, and the anthers are united by their margins into a tube which surrounds the style. The pistil has a long style which divides above into two recurved style branches, each stigmatic on its upper surface. There is but one erect ovule at the base of the single cavity of the ovary. On ripening the cup and ovary wall become tough and leathery, and closely surround the relatively large seed, and this structure is known as an "achene."

576. The Dandelion flower head (Taraxacum, or Leontodon) is in plan much like that of the Sunflower, but here the flowers all have flat (ligulate) corollas, and all produce seeds. Each flower consists of a bicarpellary ovary which is wholly covered by the thin cup, on whose upper margin is the whorl of many fine bristles (the calyx, or pappus), 
and the five-petaled corolla, tubular below, but open and flat above. The five stamens are borne on the inside of the tubular part of the corolla, and their anthers are united around the style, as in the Sunflower. The ovule also is quite like that in the Sunflower. On ripening the upper part of the cup becomes prolonged into a slender beak far beyond the ovary carrying the spreading calyx whorl upon its summit,

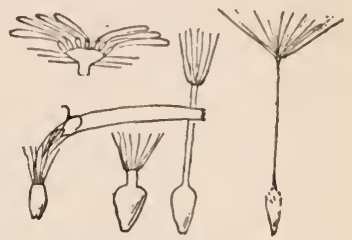

FIG. 194.-Dandelion. and forming a veritable parachute which readily carries away the achene and its seed in even the lightest of breezes.

577. Here it may be remarked that the Dandelion shows the highest development of flower structure found in the Anthophyta, and so it may be considered as the highest plant in the Vegetable Kingdom.

Laboratory Studies. (a) With longitudinal sections of the flowers of Spiraea make out especially the thickened cup (torus), the smaller number of several-seeded carpels (five), and the many stamens.

(b) Examine externally and in longitudinal section flowers and "apples" of any rose (Rosa). Note the great number of one-seeded earpels (resembling those of Strawberry), and stamens, and the deeply hollowed out, fleshy, receptacular cup, comparing with Spiraea.

(c) Making comparisons with the Rose examine in a similar way the flowers and fruit of the Apple (Malus), or Pear (Pirus), Quince (Cydonia) or Hawthorn (Crataegus), noting especially the great thickening of the torus and its adherence to the five united carpels.

(d) Make vertical sections of Plum flowers (Prunus) so as to show the single free pistil (of one earpel) at the bottom of the cup, and the many stamens on its margin. Make eross-sections of growing plums (fruits) showing stony endocarp, and fleshy 
exocarp. Cherry, Peach or Almond flowers and fruits may be substituted for the Plum.

(e) Dissect a flower of the Garden Pea (Pisum) so as to show the zygomorphy of the corolla, the ten curved stamens, the single, elongated and several-ovuled pistil. Study developed pods (legumes) and young seeds. Compare the zygomorphic, shallow-cupped Pea flower with the related actinomorphic Plum flower. The Sweet Pea (Lathyrus), Bean (Phaseolus), and Locust (Robinia) flowers are similar to those of the Pea.

(f) Study the flowers and fruits of the Currant or Gooseberry (Ribes), observing their general resemblance to the Apple, but noting the bicarpellary pistil with parietal placentae and the reduced number of stamens.

(g) Compare the flower of Oenothera with that of Spiraea noting the extreme elongation of the receptacular cup, which adheres to the united, many-seeded carpels; and the reduction of the stamens to two whorls.

(h) Study macroscopically the mature sporophyte of a Prickly Pear (Opuntia), noting the small, narrow, fleshy, shortlived leaves on the young shoots. In longitudinal and crosssections of the flowers make out the fleshy cup surrounding the compound ovary, and the many spirally arranged stamens, petals and scpals. Other genera of cactuses show a similar flower structure, and may be substituted for Opuntia, but the plants are mostly wholly leafless.

(i) Examine macroscopically a staminate flower cluster (catkin) of the Walnut (Juglans) or Hickory (Hicoria) noting the crowded, small, many-stamened, apetalous flowers. Make cross and longitudinal sections of the pistillate flower showing the inferior ovary, surmounted by two large stigmas. Make comparative studies of the fruits and nuts.

(j) Examine the staminate flower clusters of the Oak (Quercus) or Chestnut (Castanea), comparing the scveral staminate flowers with those of the preceding $(i)$. As the leaves are unfolding, or soon after, find near the tips of the twigs the clusters of two or three pistillate flowers. Dissect these out from their involucres, and note the calyx borne on the edge of the thin receptacular cup which adheres to the tricarpellary ovary. Examine ripe acorns which are found single seated in the cup-like involucre, or chestnuts which occur several together entirely enclosed in the prickly involucre. 
(k) In examining the flowers of the Parsnip (Pastinaca), note first the umbellate inflorescence, and then dissect out a little flower, noting especially the very small vestiges of sepals. Study the matured fruit noting that it splits vertically into two halves. The Carrot (Daucus) or Cow Parsnip (Heracleum) may be substituted for the Parsnip.

(l) Make dissections of the flowers of the Honeysuckle (Lonicera), Snowberry (Symphoricarpos) or Elder (Sambueus) and note the few-celled, few-seeded, inferior ovary, very small sepals, and the somewhat zygomorphie (regular in Sambucus) corolla of united petals, upon which are borne the few stamens.

(m) Make a macroscopic examination of a Sunflower head (Helianthus), noting the involucre of green bracts on the back, the marginal row of ligulate flowers ("rays"), and the central mass ("disk") of tubular flowers. Dissect out and examine carefully an individual flower of each kind, noting particularly the calyx ("pappus"), and inferior, bicarpellary, one-seeded pistil. Dissect a mature achene ("seed"). Rudbeckia or Coreopsis may be substituted for Helianthus.

(n) Study the flower-head of the Dandelion (Taraxacum or Leontodon), comparing it with that of the Sunflower. Note the following points of difference: the development of the corollas of all flowers into ligules, fertility of all flowers, development of calyx (pappus) as a whorl of numerous fine bristles, and absence of bracts subtending each flower. Examine a fruiting head. Note the presence of latex in the plant. Wild or cultivated Lettuce (Lactuca) may be substituted for the Dandelion.

\section{Summary of ANthophyta}

578. Looking back over the Flowering Plants it is seen that their simpler forms are like those of Buttercups and their near relatives, and that from this primitive type there have arisen three diverging phyletic groups. One of these (the Monocotyledons) begins with the Water Plantains, and culminates in the Orchids: another (the Axis Flowers) begins with the Buttercups and passing through various intermediate forms culminates in 
the Mints: while still another (the Cup Flowers) begins with the Strawberries and culminates in the Sunflowers and Dandelions. It will be noted furthermore that the Axis Flowers and Cup Flowers agree in regard to their cotyledons, arrangement of leaves, vascular bundles of stems and leaves, and perianth whorls, causing us to consider them as two subdivisions of a common class,Dicotyledons, - coordinate with the Monocotyledons.

579. Taking a longer look backward it may be seen that in the Anthophyta we have the culmination of the evolutionary tendencies manifested in the main line of plant progress over which we have travelled:-from Myxophyceae to Chlorophyceae, thence to the lower Bryophyta, and from these to the Old-fashioned Ferns (Pteridophyta) and from these again to the Seed Ferns and Flowering Plant Ancestors (in Cycadophyta), from which the step is relatively short to the simpler Flowering Plants. It follows that but five of the preceding phyla have contributed to the development of the Flowering Plants, and that the eight remaining phyla are side branches whose developmental accretions added nothing that continued to the Flowering Plants. These five contributing phyla contain somewhat less than one-fourth of the non-flowering plants, and yet it may be doubted whether even more than one-fifth of these again contributed in any way to the structure of the Flowering Plants. So we may say that of the approximately 100,000 plants in the thirteen phyla preceding Anthophyta, probably no more than 5,000 represent structures in any sense ancestral.

580. It will be instructive to enumerate the greater steps in this progressive development from the Myxophyceae to Anthophyta, as follows: 
Mrxopiyceae, contributed first of all the cell unit, to which they added a definite nucleus, and definite plastids.

Chlorophyceae, carried the plant body from the single cell to the rooted, branched filament,

- added ciliated gametes,

- carried generation from isogamy to heterogamy,

- carried the result of fertilization from the simple zygote to the simple fruit.

Bryophyta, developed the plant body as a cell mass,

- developed the sporophyte from the simple fruit, and so brought in an obvious alternation of generations, and with it terrestrial life,

with which eame the beginning of supporting tissues (woody strands),

and simultaneously the beginning of conducting tissues (vascular strands).

Pteridophyta, reduced the gametophyte to a smaller and short-lived structure,

- developed an independent sporophyte by the production of roots and leaves;

- differentiated isospores into heterospores; (microspores and megaspores);

- perfected the supporting tissues (woody strands);

- perfected the conducting tissues (vascular bundles).

Cycadophyta, developed special sporophylls for megaspores (megasporophylls),

- retained the megaspore in the megasporangium,

-which became covered by an indusium (integument),

-reduced the archegonial gametophyte to a dependent structure retained by the megasporangium,

- which led to the development of the seed,

- developed special sporophylls for microspores (microsporophylls),

- developed tubular antherids,

-reduced the sperms to two,

- aggregated the sporophylls into a cone (strobilus);

-developed the beginnings of the perianth,

- produced an ereet, long-lived stem,

- developed fibro-vascular bundles, and modes of thickening the stem. 
Aлтнорнута, developed microsporophylls into stamens,

-reduced the sperms to non-ciliated cells,

-developed megasporophylls into pistils,

- developed a proper perianth,

- perfected fibrovascular bundles, arranging them in a cylinder,

- perfected the thickening of the stem, by fibrovascular and interfascicular cambium.

\section{LITERATURE OF ANTHOPHYTA}

J. M. Coulter and C. J. Chamberlain, Morphology of Angiosperms, New York, 1903.

N. L. Britton and Addison Brown, Illustrated Flora of the Northern States and Canada, Second Edition, New York, 1913.

N. L. Britton, Manual of the Flora of the Northern States and Canada, Second Edition, New York, 1905.

B. L. Robinson and M. L. Fernald, Gray's New Manual of Botany, New York, 1908.

J. K. Small, Flora of the Southeastern United States, Second Edition, New York, 1913.

J. M. Coulter and Aven Nelson, New Manual of Botany of the Central Rocky Mountains, New York, 1909.

F. E. and E. S. Clements, Rocky Mountain Flowers, New York, 1914.

T. C. Frye and G. B. RigG, Northwest Flora, Seattle, 1912.

L. R. Abrams, Flora of Los Angeles and Vicinity, Stanford University, 1911. 


\section{CHAPTER XXI \\ SOME SPECIAL ADAPTATIONS}

581. The plant body (sporophyte) of the Anthophyta, while standardized as to general plan, is very plastic as to the details of its structure. This plasticity has enabled it to respond so fully to various needs as to bring about marked changes in its size, form, proportions of parts, surface characters, etc. Only the more important of these need be noticed here.

582. For particular purposes some parts of the plant body may have a special development, as the thorny (not

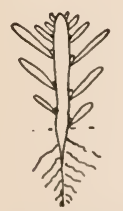

FIG. 195.-Standard FIG. 196.-Runners, above plant (Anthophyta).

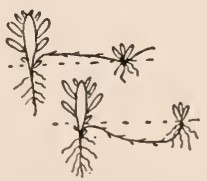

and under ground.

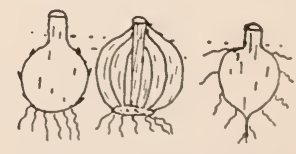

Fig. 197.-Corm, bulb, and root.

parenchymatous) leaves of the Barberry, the thorny leafless branches of the Honey Locust (both protective), the runners of the Strawberry above ground, and the under-ground rootstocks of the Canada Thistle (both for vegetative reproduction).

583. Many plants store up food substances in some part of the plant body, resulting in considerable changes in form. Thus the lower part of the stem may be spherically enlarged, as in the so-called corms of Arisaema and Gladiolus. In the bulbs of many plants, as the 
Onion, and Hyacinth, the food substances are stored in the thickened leaf bases. Turnips, radishes, dahlias, etc., store their food substances in their roots which are accordingly much thickened. Other plants develop the ends of their rootstocks into storage structures, as the tubers of the potato and Jerusalem Artichoke; while again some thick leaves, as those of the Century Plant (Agave), and many other Monocotyledons, are storage organs.

584. Habitat. Most flowering plants grow with their roots in moist (not wet) soil, with their leaves in air of moderate humidity. Stated otherwise we may say that under these conditions the great majority of flowering plants developed the forms which they have. So when we say that such plants are "mesophytes" we are merely stating the fact that the majority of plants live under these quite similar conditions. And these have the usual leaves and stems. A much smaller number have been able to live in drier soil and drier air, their leaf surfaces being smaller or wanting, their epidermis thicker, their tissues harder, and these we have denominated "xerophytes," literally, dry plants. On the other hand some plants have been able to live partly or wholly in the water. Their stems and leaves are weak and soft and their submerged leaves reduced (dissected). Such plants we have called "hydrophytes" (i.e. water plants). Other adaptations still less marked have been noticed, as the "halophytes" of salt waters or soils, the "ruderal plants" of waste places, "shade plants," "sun plants," etc.

585. Here may be noted the modifications of the plant body following the acquisition of a parasitic habit. These are well illustrated in the common Dodder (Cuscuta, a climbing vine related to the Morning Glories) 
which has lost its leaves, its green color, and its firm stem structure. The Broom-rapes (Orobanchaceae) likewise have bract-like, chlorophyll-less leaves. And so the saprophytic Indian Pipes (Monotropaceae) show a similar reduction. Somewhat allied to these modifications are those in the case of the so-called Insectivorous plants where the leaves are modified into pitchers, or other structures for the capture or digestion of insects.

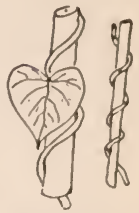

Fig. 198 . Morning glory and dodder.

586. In their evolution from the primitive type of flower to the more derived structures the Flowering Plants have produced a multitude of forms of flowers many of which show themselves extremely well-fitted for certain very definite conditions. It is in connection with the methods of pollination that the greatest variation is shown. It seems certain that the primitive flowers were dependent, as are the vast majority of flower types now, upon the aid of insects in pollination. However, very numerous groups of Flowering Plants have given up this so-called "entomophilous" habit, and are pollinated by the wind ("anemophilous"). Such

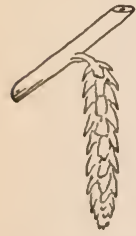

FIG. 199. Catkin of Carpinus. flowers are usually marked by certain characters in common, viz. the abundance and lightness of the pollen, the occurrence of the staminate flowers in hanging elusters, "catkins" (easily swung by the wind, as in the Walnut, Oak, etc.); or with the branches or inflorescence slender and swinging easily in the wind (as in various grasses); the styles and stigmas are usually very large, thus exposing more surface on which the chance pollen grains may be eaught; usually too the pistils have but one, or very few ovules, for each ovule requires a pollen grain for its fertilization 
and the chances are fewer for a multiple pollination by wind-blown pollen. Wind-pollinated flowers are usually small and dull in color.

587. On the contrary the insect (and bird) pollinated flowers are usually bright colored (and it has been found that many insects are attracted long dis-

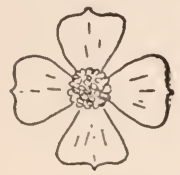

FIG. 200.-Dogwood (Cornus). tances by bright colors). They are usually large enough to be easily visible, or if small are bunched in large, conspicuous masses (as in Elder). If not showy themselves they are often bordered by showy leaves (as in Snow-on-the-Mountain Euphorbia marginata), or some of the flowers are converted into showy structures at the sacrifice of their sexual function (e.g. marginal flowers of some Dogwoods). In addition to these it is usual for entomophilous flowers to emit perfumes of various kinds, some of which are perceived by insects at great distances. Some of these are very unpleasant to man, but are attractive to certain insects, e.g. Stapelia, whose carrion-like odor is attractive to carrion insects.

588. Within the flowers are developed the secretory glands which secrete a sugary liquid. Attracted by color and odor the insects fly to the flowers and seek out this nectar which they imbibe. In so doing they come in contact with the stamens, and become powdered with pollen, and later touch the pistil to which the pollen is transferred. In flowers with many
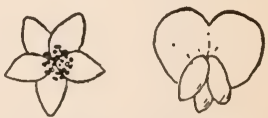

Fig. 201.-Regular (actinomorphic) and irregular (zygomorphic) flowers. stamens and pistils the nectaries are usually several in all the radii of the flower, and the insect in visiting will manage to become thoroughly covered with pollen and to put it on the summit of the stigma. In many 
flowers, however, the stamens are few, and the pistils few or anly one. Here often the flowers become onesided (zygomorphic), of such a structure that access to the nectary can be obtained only at such a point that pollination is rendered all the more certain. In this connection adaptation of flowers to certain insects is very apparent. Thus certain orchids are of such a structure that only certain butterflies or bees can reach the nectary, and in so doing pollinate the flowers. Other insects either cannot reach it at all, or in so doing fail to remove the pollen or transfer it to the stigma.

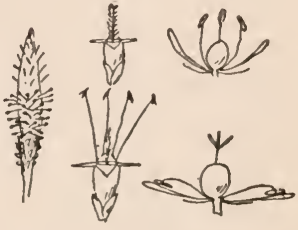

Fig. 202.-Proterogynous (Plantago) and proterandrous (Claytonia) flowers.

589. In connection with entomophily it was early observed that many flowers were of such structure that selffertilization (i.e. pollination with pollen of the same flower) is impossible. Thus in the majority of such flowers the pollen is all shed before the stigma is receptive (proterandrous), or much less frequently the stigma passes the receptive stage before the pollen is set free

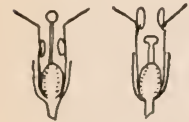

Fig. 203.-Dimorphic flower (Primula).

(proterogynous). In some plants the flowers are "dimorphic," i.e. on certain individuals the stamens are at one level and the stigmas at a different level in the same flower, while in other individuals of the same species they occupy the reverse positions. An insect visiting the flowers of the first plant, becomes pollinated at a definite part of its body which does not come into contact with the stigma at all in that same type of flower. When, however, it visits the other type of flower, the stigma is at the level of the stamens of the first type, and it comes in 
contact with the pollen-bearing portion of the insect's body. It has been shown that even artificial pollination of flowers of these species with pollen from the same type of flower is unfavorable to seed production, this occurring best when the pollen comes from the other type.

590. A few plants (e.g. the common Dandelion, and some of the Hawkweeds) whose structures would indicate entomophily, and whose near relatives are so pollinated, seem to have dropped the habit of requiring pollination, and the eggs develop without fertilization. Thus we find a loss of sexuality in these plants (apogamy, parthenogenesis).

591. In their methods of seed distribution also, the Flowering Plants show great variation. Some seeds are let fall directly from the parent plant, and are of such structure that they are not suited to any special means of distribution. The result is a crowding of the young seedlings, and competition between them and with the parent plant. Such plants do not extend their range rapidly. On the other hand a great proportion of the Flowering Plants have structures, either of the parent plant or of

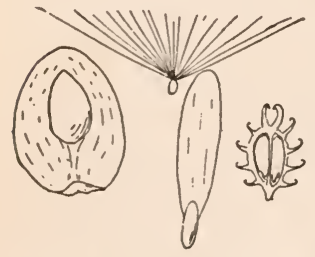

FIG. 204.-Coconut, thistle, ash, cocklebur. the seed, that fit the seeds for special modes of distribution. Depending upon the habitat, and means of seed distribution the spread of such plants may be more or less rapid.

592. The chief agents in seed distribution are (1) water, (2) wind, (3) animals (including man), and (4) mechanical expulsion. Adapted to distribution by water are seeds (or fruits) with an abundance of corky or woody tissue which buoys up the seed, and, in the case of ocean-borne forms (e.g. coconut), protects the seed from mechanical 
injury by the pounding of the surf. The abundant springing up of many kinds of weeds (great ragweed, etc.), on flooded lands after the water has subsided is due to water-borne seeds. Many of the seeds so transported are the small rounded seeds that are washed along in the mud (not floating). Structures that enable the wind to transport seeds are almost innumerable. Chief among them are the long hairs on seeds and fruits (thistle, milkweed, cottonwood); flattened extensions into wings, which may be more or less spirally warped (elm, maple, ash, catalpa); the inflorescence (tickle grass, sycamore), or the whole plant (Russian thistle, and other "tumbleweeds"), both rolled over the ground in the wind, dropping the seeds as they go.

593. Distribution by animals is accomplished in many ways. Some seeds and fruits are provided with hooks or prickles which become eaught in the hairs of the passing

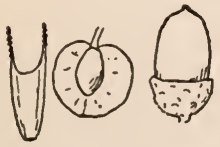

Fra. 205.-Spanish needles, cherry, acorn.

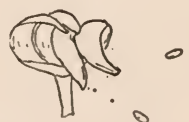

FIG. 206.-Touch-me-not.

animal and so provide for the carrying of the seed (e.g. cocklebur, sand-bur, stickseed, Spanish needles, bedstraw, burdock, etc.). Other seeds are edible and so are sought by various animals which eat many but drop some in transporting them, or bury them for future consumption, thus planting them (e.g. acorns, achenes of sunflowers, nuts, ete.). Probably the development of fleshy fruits, however, is the one that most perfectly provides for seed distribution. Animals of all kinds gather and eat the fruits, and in doing so drop the sclerenchymaenclosed seeds (plums, cherries, etc.), or eat the fruits 
with the seeds, the latter passing through the body unharmed (strawberries, grapes, and most berries). Many small, rounded seeds dropping to the earth are widely distributed by animals to whose feet the earth containing them clings, thus being carried long distances. Such are the majority of the common weeds of the roadsides, barnyards, and waste places (pigweeds, lamb's quarters, purslane, knot-grass, etc.). Of special interest, but relatively infrequent, are the plants that have fruits that dehisce explosively so that their seeds are flung comparatively long distances, thus placing them where they do not compete with their parents (Oxalis, touch-me-not, various vetches, wild geranium, etc.).

\section{REFERENCE BOOKS}

W. F. Ganong, The Living Plant, New York, 1913.

F. E. Clements, Plant Physiology and Ecology, New York, 1907.

H. C. Cowles, Ecology (in Textbook of Botany by Coulter, Barnes and Cowles) Chicago, 1911.

Hermann Muller, The Fertilization of Flowers, Engl. Ed., London, 1883.

PaUl Knuth, Handbook of Flower Pollination, Engl. Ed. Oxford, 1906-9.

Eng. Warming, Oecology of Plants, Engl. Ed., Oxford, 1909. 


\section{CHAPTER XXII \\ THE PLANT PHYLA}

\section{WITH THEIR CLASSES, ORDERS, FAMILIES AND IL LUSTRATIVE GENERA}

The Plant World is here regarded as readily separable into fourteen Phyla (often called "Branches" or "Divisions"). These are subdivided into Classes, and these again into Orders, and the latter into Families. The latest enumeration of the species of plants shows that we now know approximately a quarter of a million recognizable forms. These numerical data may be shown concisely in tabular form as follows:

\begin{tabular}{|c|c|c|c|c|}
\hline & Classes & Orders & Families & Species \\
\hline 1. Myxophyceac ... & 2 & 4 & 16 & About 2,020 \\
\hline 2. Chlorophyceae.. & 2 & 7 & 16 & About $\quad 1,090$ \\
\hline 3. Zygophyceae ... & 2 & 4 & 21 & About 7,000 \\
\hline 4. Siphonophyceae & 3 & 9 & 26 & About 1,260 \\
\hline 5. Phacophyceae.. & 3 & $\tilde{j}$ & 24 & About 1,030 \\
\hline 6. Rhodophyceae. & 2 & 7 & 24 & About 3,050 \\
\hline 7. Carpomyceteae. & 3 & 29 & 145 & About 64,000 \\
\hline 8. Bryophyta...... & 2 & 7 & 65 & About 16,600 \\
\hline 9. Pteridophyta... & 2 & 5 & 13 & About 3,800 \\
\hline 10. Calamophyta... & 3 & 3 & 4 & About $\quad 24$ \\
\hline 11. Lepidophyta.... & 2 & 3 & 7 & About \\
\hline 12. Cycadophyta... & 4 & 6 & 13 & About \\
\hline 13. Strobilophyta... & 1 & 2 & 9 & About $\quad 400$ \\
\hline 14. Anthopliyta.... & 2 & 32 & 300 & About 132,500 \\
\hline Total. & 33 & 123 & $6 \$ 3$ & About 233,614 \\
\hline
\end{tabular}




\section{KEY TO THE PHYLA OF PLANTS}

In this key only the general or typical characters are indicated, and it must be remembered that many variations ("exceptions") occur in every phylum.

A. Cells typically with poorly developed nuclei and chromatophores; reproducing by fission and spores; mostly blue-green, brown-green or fuliginous (or colorless), never chlorophyll green.

I. Unicellular to filamentous plants.

Phylum 1. Myxophyceate.

B. Cells typically with well-developed nuclei and chromatophores (chloroplasts); reproducing by fission and spores, and mostly by gametes also; chlorophyll-green, sometimes hidden by other coloring matter (or colorless).

I. Plants usually of but one obvious generation, typically aquatic.

a. The fertilized egg developing into a zygote only.

1. Unicellular, to filamentous, many-celled plants (rarely a plate of cells); isogamic to heterogamic, one or both gametes eiliated.

Phylum 2. Chlorophyceae.

2. Filamentous many-celled plants, mostly breaking up early into single cells; isogamic, gametes not ciliated. Phylum 3. Zygophyceae.

3. Tubular filamentous (or saccate) coenocytic plants, usually attached basally by rhizoids; isogamic to heterogamic.

Phylum 4. Siphonophyceae.

4. Cellular filamentous (rarely unicellular) to massive plants, attached basally by rhizoids (or roots); isogamic to heterogamic; the green color hidden by a brownish pigment.

Phylum 5. Phaeophyceae.

b. The fertilized egg developing into a spore-fruit.

1. Cellular filamentous to massive holophytic plants, attached basally by rhizoids (or roots); heterogamic; the green color mostly hidden by a red or purple pigment.

Phylum 6. Rhodophyceae. 
2. Cellular filamentous hysterophytic plants, often much degenerated, without chlorophyll; heterogamic.

Phylum 7. Carpomyceteae.

II. Plants of two obvious, alternating generations, typically terrestrial.

a. Gametophyte generation larger, and longer-lived than the dependent sporophyte generation.

1. Gametophytes from prostrate and thalloid to erect leafy shoots; sporophytes globose to cylindrical or stalked, neither expanded nor rooted.

Phylum 8. BRYophyta.

b. Gametophyte generation smaller and shorterlived than the independent sporophyte generation.

1. Both generations mostly holophytic, independent of one another.

(a) Gametophytes typically flat and thalloid, normally attached by rhizoids, mostly monoecious; sporophytes consisting of large-leaved, solid stems, which are rooted below.

Phylum 9. Preridophyta.

(b) Gametophytes typically flat and thalloid, normally attached by rhizoids, mostly monoecious; sporophytes consisting of mostly solid, cylindrical, jointed and fluted stems, bearing small, whorled leaves at the nodes, and rooted below. Phylum 10. Calamophyta.

(c) Gametophytes typically tubular or globose, with few rhizoids or none, often dioecious; sporophytes consisting of solid, cylindrical, continuous (not jointed) and not fluted stems, bearing small spirally arranged (or opposite) leaves, and rooted below.

Phylum 11. Lepidophyta.

2. Gametophytes hysterophytic, dependent upon and nourished by the sporophyte. 
(a) Sporophylls open, ovules and seeds naked (gymnospermous).

(1) Gametophytes dioecious; sperms ciliated and motile; sporophytes producing microspores and megaspores in spiral or whorled sporophylls, or these aggregated into cones.

Phylum 12. Cycadophyta.

(2) Gametophytes dioecious; sperms not ciliated, not motile; sporophytes with sporophylls in cones.

Phylum 13. Strobilophyta.

(b) Sporophylls closed, ovules and seeds covered (angiospermous).

(1) Gametophytes dioecious; sperms not ciliated, not motile; sporophytes with sporophylls in flowers.

Phylum 14. ANThOPHYTA.

In the following systematic enumeration many of the families are merely named in their sequence, without any characterization or examples. Moreover the characterizations of all groups are necessarily very brief and general. The examples cited are of the more common genera, or those of particular interest to the student.

Phylum I. MYXOPHYCEAE. The Slime Algae

Usually blue-green, poorly developed cells, or filaments

Class 1. ARCHIPLASTIDEAE (Cyanophyceae). "Blue Greens." Without nuclear membrane. (Sp. about 2,000.)

Order Coccogonales. Green or greenish; unicellular.

Family 1. Chroococcaceae. Cells rounded.-Chroococcus, Glococapsa, Merismopedia.

Family 2. Chamaesiphonaceae. Cells elongated.Chamaesiphon.

Order Hormogonales. Mostly green or greenish; filamentous.

Family 3. Oscillatoriaceae. No heterocysts.-Oscillatoria, Lyngbya. 
Family 4. Nostocaceae. Heter ocysts intercalary prominent. $-\mathrm{N}$ ostoc, Cylindrosper mum.

Family 5. Scytonemataceae. Heterocysts intercalary, not prominent.-Scytonema.

Family 6. Rivulariaceae. Heterocysts basal.-Rivularia.

Family 7. Camptotrichaceac. No heterocysts.Camptothrix.

Family S. Stigonemataceac. Heterocysts intercalary, not prominent; cells in more than one row.-Stigonema.

Order Bacteriales. The Bacteria. Not green; typically filamentous, but becoming few- or one-celled by the solution of the filament. Related to the foregoing bluegreen plants.

Sub-order Tniobacteria. With sulphur granules in the cells.

Family 9. Beggiatoaceae. Cells in motile filaments, colorless.-Beggiatoa.

Fanily 10. Rhodobacteriaceae. Cells single, or in colonies; red, rose or violet colored.Chromatium.

Sub-order Eubacteria. Without sulphur granules in the cells.

Family 11. Phycobacteriaceae. Cells in straight, motionless filaments.-Crenothrix, Sphaerotilus.

Family 12. Spirillaceae. Cells in spirally coiled, motile filaments.-Spirillum, Microspira, Spirochaete.

Family 13. Bacteriaceae. Cells mostly single, elongated, straight.-Bacterium (no flagella), Bacillus (surface flagella), Pseudomonas (polar flagella).

Family 14. Myxobacteriaceae. Cells elongated, without flagella, growing in definite, slimy colonies.-Chondromyces.

Family 15. Coccaceae. Cells mostly single, spherical. -Micrococcus, Streptococcus, Sarcina. 
Class 2. HOLOPLASTIDEAE. With nuclear membrane. (Sp. about 20.)

Order Glaucocystales. Dividing in one plane.

Family 16. Glaucocystaceae.-Glaucocystis.

Phylum II. CHLOROPHYCEAE. The Simple Algae Normally chlorophyll-green, with well-developed single cells, or filaments. (Here restricted to two classes of green algae).

Class 3. PROTOCOCCOIDEAE. Green Slimes. Unicellular. (Sp. about 450.)

Order Palmellales. Cells not in colonies.

Family 1. Protococcaceae. No zoospores.-Protococcus, Trochiscia, Crucigenia.

Family 2. Chlorococcaceae. With zoospores.-Chlorococcum, Tetraspora. Botryococcus.

Family 3. Synchytriaceae. Colorless parasites.Olpidium, Synchytrium.

Order Coenobiales. Cells in colonies.

Family 4. Hydrodictyaceae. Vegetative cells not ciliated.-Scenedesmus, Hydrodictyon.

Family 5. Volvocaceae. Vegetative cells ciliated.Gonium, Pandorina, Volvox. (Animals!)

Class 4. CONFERVOIDEAE. Confervas. Filamentous, or a plane. (Sp. about 640.)

Order Microsporales. Unbranched.

Family 6. Microsporaceae--Microspora.

Order Schizogoniales. Unbranched.

Family 7. Prasiolaceae.-Prasiola.

Order Ulvales. Plant a plane or tube.

Family 8. Ulvaceae.-Ulva, Enteromorpha.

Order Chaetophorales. Usually branched. Zoospores and ciliated gametes.

Family 9. Ulotrichaceae. Unbranched.-Ulothrix.

Family 10. Chaetophoraceac. Branches attenuated into hairs.-Draparnaldia, Chaetophora.

Family 11. Microthamniaceae. Scarcely attenuated, no hairs.-Microthamnion. 
Family 12. Trentepohliaceae. Scarcely attenuated, no hairs.-Trentepohlia.

Family 13. Herposteiraceae. Scarcely attenuated, with hairs.-Herposteiron.

Family 14. Cylindrocapsaceae. Unbranched, heterogamic.-Cylindrocapsa.

Family 15. Oedogoniaceac. Unbranched or branched, heterogamic.-Oedogonium.

Order Coleochaetales. Branched, fusing into discs.

Family 16. Coleochaetaceae. Minute disk-like plants.-Coleochaete.

Phylum III. ZYGOPHYCEAE. The Conjugate Algae Chlorophyll-green sluggish filaments, often fragmenting into single cells

Class 5. CONJUGATAE. Typically filamentous, green plants, with cellulose walls. (Sp. about 1,300 .)

Order Zygnematales. Pond Scums. Filamentous.

Family 1. Mesocarpaceae. Chloroplast single, long, axial.-Mougeotia, Gonatonema.

Family 2. Zygnemataceae. Chloroplaststwo, short, axial.-Zygnema, Zygogonium.

Family 3. Spirogyraceae. Chloroplasts 1 to 9, parietal, spiral.-Spirogyra.

Order Desmidiales. Desmids. Filaments usually early fragmenting into single cells.

Family 4. Desmidiaceae. Unbranched filaments.Genicularia, Hyalotheea, Desmidium.

Family 5. Closteriaceae. Cells solitary, elongated. -Closterium, Penium.

Fanily 6. Cosmariaceae. Cells solitary, broad, flattened.-Cosmarium, Micrasterias.

Class 6. BACILLARIOIDEAE. The Diatoms. Brownishgreen plants, with silicified walls. (Sp. about 5,700.)

Order Eupodisciles. Round Diatoms. Filaments commonly cylindrical, usually fragmented into single cells. 
Family 7. Coscinodiscaceae. Cells short, ends not ribbed.-Coscinodiscus.

Family 8. Actinodiscaceae. Cells short, ends ribbed.-Actinodiscus, Arachnoidiscus.

Family 9. Eupodiscaceae. Cells short, ends with "eves."-Eupodiscus, Actinocyclus.

Family 10. Soleniaceac; 11, Chactocerotaceae; 12, Biddulphiaceac; 13, Euodiaceae; 14, Anauliaceae; 15, Rutilariaceae.

Order Naviculales. Flat Diatoms. Filaments flattened, usually fragmented into single cells.

Family 16. Tabellariaccae. Mostly filaments, cells short, rectangular in side view.Grammatophora, Rhabdonema.

Family 17. Meridionaceae; 18, Fragilariaceae.

Family 19. Naviculaceae. Cells single, end with central slit.-Navicula, Amphipleura.

Family 20. Bacillariaceae; 21, Surirellaceae.

Phylum IV. SIPHONOPHYCEAE. The Tube Algae Normally chlorophyll-green filaments composed of one or more coenocytes

Class 7. VAUCHERIOIDEAE. Lower Tube Algae. Filaments septate or tubular. (Sp. about 400.)

Order Cladophorales. The Cladophoras. Septate, the segments coenocytic.

Family 1. Cladophoraceae. Unbranched or branched, isogamic.-Cladophora, Pithophora.

Family 2. Sphaeropleaceae. Unbranched, heter ogamic. Sphaeroplea.

Order Siphonales. Green Felts. Tubular, irregularly branched, chlorophyllose.

Family 3. Phyllosiphonaceae. Endophytic.-Phyllosiphon.

Family 4. Codiaceae. Filaments compacted into a large plant-body.-Codium, Penicillus.

Family 5. Vaucheriaceae. Filaments single, free.Vaucheria. 
Class S. PHYCOMYCETEAE. Tube Fungi. Lower Fungi. Filaments tubular, mostly irregularly branched, chlorophyll-less. (About 400 species.)

Order Saprolegniales. Typically aquatic; mostly saprophytic; forming zoospores in zoosporangia.

Family 6. Monoblepharidaceae. Aquatic saprophytes; antherids producing uniciliated sperms.-Monoblepharis.

Family 7. Saprolegniaceae. Water Molds. Aquatic, parasitic or saprophytic; antherids not producing sperms.-Saprolegnia, Achlya.

Family S. Pythiaceae; 9, Cladochytriaceae; 10, Ancylistaceac.

Order Peronosporales. Non-aquatic; mostly parasitic in the tissues of higher plants; usually forming zoospores in conidia.

Family 11. Albuginaceae. White Rusts. Conidia in chains.-Albugo.

Family 12. Peronosporaceae, Downy Mildews. Conidia terminal singly on branched conidiophores.-Phytophthora, Plasmopara, Peronospora.

Order Mucorales. Typically non-aquatic; saprophytic, or parasitic on other fungi; not forming zoospores; spores single, clustered, or in sporangia.

Family 13. Mucoraceae, Black Molds. Sporangium with a columella.-Rhizopus, Mucor, Pilobolus.

Family 14. Mortierellaceae. Sporangium without a columella.-Mortierella.

Family 15. Chactocladiaceae. Spores single, or clustered on branched conidiophores.Chaetocladium.

Family 16. Piptocephalidaceae. Spores in chains, clustered on the ends of branches.Piptocephalis, Syncephalis. 
Order Extomophthorales. Non-aquatic; mostly parasitic in insects; without zoospores.

Family 17. Entomophthoraccae. Fly Fungi.-Entomophthora.

Class 9. BRYOPSIDOIDEAE. Higher Tube Algac. Globular to stipitate or dendroid, septate or continuous. (Sp. about 460.)

Order Valoviales. Globular coenocytes to compound septate plants. Isogamic.

Family 18. Botrydiaceae. Little Bladder Algae. Minute, globular, terrestrial green plants.-Botrydium, Protosiphon.

Family 19. Chytridiaceae. Minute, globular, endophytic, colorless plants. - Chytridium.

Family 20. Valoniaceae. Large Bladder Algae. Large, usually septate, marine plants. Valonia, Struvea, Halicystis.

Order Dasycladales. Regularly branched, non-septate, marine plants. Mostly isogamic.

Family 21. Derbesiaceae.

Family 22. Bryopsidaceae. Sea Ferns. Dendroid,

Family 23. Caulerpaceae.

erect, pinnately branched.-Bryopsis.

Family 24. Dasycladaceac. Erect with whorled branches.-Dasycladus, Acetabularia.

Order Charales. The Stoneworts. Erect, rooted, septate, dendroid, with whorled branches, heterogamic, antherids compound. (Sp. about 160.)

Family 25. Nitellaceae. Oogone crown of ten cells.Nitella, Tolypella.

Family 26. Characeae. Oogone crown of five cells.Chara, Lamprothamnus.

Phylum V. PHAEOPHYCEAE. The Brown Algae Brown-green filamentous to large, massive plants, marine Class 10. PHAEOSPOREAE. Kelps. Reproductive organs external, isogamic to heterogamic. (Sp. about 550.) 
Order Ectocarpales. Zoospores and isogametes similar and motile.

Family 1. Ectocarpaceae. Mostly filamentous, simple or branched, with zoospores and gametes.-Ectocarpus, Streblonema.

Family 2. Myriotrichiaceae; 3, Choristocarpaceae; 4 . Elachistaceae; 5, Chordariaceae; 6, Stilophoraceae; 7, Spermatochnaceae; 8, Sporochnaceae; 9, Encoeliaceae; 10, Desmarestiaceae; 11, Arthrocladiaceae; 12 , Sphacelariaceae; 13, Ralfsiaceae; 14 , Striariaceae; 15 , Dictyosiphonaceae.

Family 16. Laminariaceae. Large, parenchymatous, usually stalked, with zoospores only. -Laminaria, Alaria, Postelsia, Nereocystis, Macrocystis. Egregia.

Order Cutleriales. Zoospores and heterogametes dissimilar and motile.

Family 17. Cutleriaceae; 18, Splachnidiaceae.

Order Tilopteridales. Zoospores and heterogametes dissimilar, eggs non-motile.

Family 19. Tilopteridaceae.

Class 11. DICTYOTINEAE. Reproductive organs external, heterogamic. (Sp. about 130.)

Order Dictyotales. Plants erect, flat, leaf-like.

Family 20. Dictyotaceac.-Dictyota, Padina, Zonaria. Class 12. CYCLOSPOREAE. Rockweeds. Reproductive organs in sunken conceptacles, heterogamic. (Sp. about 350.)

Order Fucales. Usually flattish, branched.

Family 21. Durvillaeaceac. Conceptacles on vegetative parts of plant.-Durvillaea.

Family 22. Himanthaliaceae. Conceptacles on long branches arising from a vegetative cup.-Himanthalia.

Family 23. Fucaceae. Conceptacles on ends of vegetative branches.-Fucus, Ascophyllum.

Family 24. Sargassaceae. Conceptacles on small lateral branches.-Sargassum, Halidrys. 
Phylum VI. RHODOPHYCEAE. The Red Algae

Red to purple filamentous to massive plants; marine

Class 13. BANGIOIDEAF. Antherids and oogones developed from ordinary cells of plant body; propagation by monospores. Red or purple plants. (Sp. about 50, doubtfully belonging here.)

Order Bangiales. One chloroplast in each cell.

Family 1. Bangiaceae. Including the genus Porphyra.

Order Rhodochaetales. Several to many chloroplasts in each cell.

Family 2. Rhodochaetaceae; 3, Campsopogonaceae. Class 14. FLORIDEAE. Red Seaweeds. Antherids and oogones specially developed; propagation by tetraspores. Red or purple plants. (Sp. about 3,000.)

Order Nemalionales. Lower Red Seaweeds. Mostly filamentous plants. Sporophores produced directly from fertilized eggs.

Family 4. Lemaneaceae.

Family 5. Helminthocladiaceae. Filamentous or parenchymatous, variously branched. -Batrachospermum, Nemalion.

Family 6. Thoreaceae; 7, Chactangiaceae; 8, Gelidiaceae.

Order Cryptonemiales. Hard Red Seaweeds. Filiform, branched, often complanate; sporophores produced by remote auxiliary cells.

Family 9. Gloiosiphoniaceac; 10, Grateloupiaceae; 11, Dumontiaceae; 12, Nemastomaceae; 13, Rhiziphyllidaceae; 14, Squamariaceac.

Family 15. Corallinaceae. Filamentous, branched (and jointed) to crustaceous.-Corallina.

Order Ceramiales. "Sea Mosses." Filiform to foliaceous plants. Sporophores produced by nearby auxiliary cells. 
Family 16. Delessarieceac. Foliaceous.-Delesseria, Grinnellia, Nitophyllum.

Family 17. Bonnemaisoniaceae.

Family 18. Rhodomelaceae. Cylindrical, flattened, to foliaceous.-Polysiphonia, Rhodomela, Dasya.

Family 19. Ceramiaceae. Filiform, branched, complanate.-Ceramium, Lejolisia, Ptilota.

Order Gigartinales. Soft Red Seaweeds. Parenchymatous plants; sporophores produced by the nearby auxiliary cells branching in the tissues.

Family 20. Acrotylaceae.

Family 21. Gigartinaceae. Erect or spreading, branching, cylindrical to flat plants. Chondrus, Gigartina, Callophyllis.

Family 22. Rhodophyllidaceac. Erect, or spreading branching, flat plants.-Rhodophyllis Rhabdonema.

Order Rhodymeniales. Higher Red Seaweeds. Filiform, to foliaceous and massive plants; sporophores produced by nearby auxiliary cells growing outward in plant body.

Family 23. Sphaerococcaceac.

Family 24. Rhodymeniaceae. Filiform to foliaceous. Rhodymenia, Plocamium.

Phylum VII. CARPOMYCETEAE. The Higher Fungi Terrestrial, chlorophyll-less, filamentous, parasites and saprophytes, producing spore-fruits

Class 15. ASCOSPOREAE. Ascus Fungi. Spore-fruits containing one or more asci with ascospores. (Sp. about 29,000.)

Order Laboulbeniales. Beetle Fungi. Erect, minute, few celled, bearing simple ascigerous fruits.

Family 1. Iaboulbeniaceac. Parasitic on beetles.Laboulbenia, Ceratomyces, Dichomyces. 
Order Discolichenes. Disk Lichens. Lichen-forming fungi with asci in apothecia.

Family 2. Lecanactidaceae; 3, Pilocarpaceae; 4, Chrysothricaceae; 5, Thelotremataceae; 6, Diploschistaceae; 7, Ectolechiaceae; 8 , Gyalectaceae; 9, Coenogoniaceae; 10, Lecidiaceae; 11, Phyllopsoraceae.

Family 12. Cladoniaceae. Crustaceous to scaly or foliose, with Protococeus hosts (rarely Myxophyceae hosts).-Beomyces, Cladonia, Stereocaulon.

Family 13. Gyrophoraceae. Foliose, coriaceous, with Protococcus hosts.-Umbilicaria.

Family 14. Acarosporaceae. Crustaceous, scaly or foliose, with Protococcus hosts-Thelocarpon, Acarospora.

Family 15. Ephebaceae; 16, Pyrenopsidaceae; 17, Lichinaceae.

Family 18. Collemataceae. Gelatinous to crustaceous, scaly foliose to fruticose, with Nostoc hosts.-Physma, Collema, Leptogium.

Family 19. Heppiaceac; 20, Pannariaceae.

Family 21. Stictaceae. Foliose, with Palmella or Nostoc hosts. - Sticta, Lobaria.

Family 22. Peltigeraceae. Foliose with Palmella or Nostoc hosts.-Peltigera.

Family 23. Pertusariaceae. Crustaccous, with Protococcus hosts.-Pertusaria.

Family 24. Lecanoraceac. Crustaceous, with Protococcus hosts.-Lecanora.

Family 25. Parmeliaceac. Foliose, with Protococcus hosts.-Parmelia.

Family 26. Usneaceae. Fruticose, with Protococcus hosts.-Usnea, Ramalina.

Family 27. Caloplaceae. Crustaceous, with Protococcus hosts.-Caloplaca.

Family 28.-Theloschistaceae. Foliose to fruticose, with Protococcus hosts.-Theloschistes. 
Family 29. Buelliaceae. Crustaccous, with Protococcus hosts. - Buellia.

Family 30. Physciaceae. Foliose to fruticose, with Protococcus hosts.-Physcia.

Order Caliciales. Powdery Lichens. Common fungi, and lichen-forming fungi; apothecia spheroidal, pulverulent.

Family 31. Protocaliciaceac. True fungi, saprophytic.-Mycocalicium.

Family 32. Caliciaceae. Crustaceous lichens, with Protococcus or Stichococcus hosts. -Calicium.

Family 33. Cypheliaceae. Crustaceous lichens with

Protococcus or Trentepohlia hosts. -Cyphelium, Tylophoron.

Family 34. Sphaerophoraceae. Foliose or fruticose lichens with Protococcus hosts.Sphaerophorus.

Order Phacidiales. Little Cup-fungi. Common fungi, spore-fruits open (apothecia).

Family 35. Stictidaceae. Fleshy, yellow.-Stictis, Propolis.

Family 36. Tryblidiaceae. Leathery or carbonaceous, black.-Tryblidium, Scleroderris.

Family 37. Phacidiaceae. Leathery or carbonaceous, black.-Phacidium, Rhytisma.

Order Exoascales. Pocket Fungi. Common fungi; apothecia much reduced and simplified.

Family 38. Exoascaceae. Parasitic in higher plants. -Exoascus, Taphrina.

Family 39. Ascocorticiaceae. Saprophytic, asci forming a cushion.-Ascocorticium.

Family 40. Endomycetaceac. Asci single, not in masses or in cushions.-Endomyces, Eremascus.

Order Pezizales. Cup-fungi. Common fungi; apothecia at length cup-shaped, fleshy or leathery. 
Family 41. Pyronemataceae. Fleshy, open from the first.-Pyronema.

Family 42. Pezizaceae. Fleshy, first spherical, later open.-Lachnea, Peziza.

Family 43. Ascobolaceac. Fleshy, first spherical, later open.-Ascobolus.

Family 44. Helotiaceae. Fleshy, mostly open from the first.-Sclerotinia, Dasyscypha, Helotium.

Family 45. Mollisiaceae; 46, Celidiaceae; 47, Patellariaceae; 48 , Cenangiaceae; 49 , Cordieritidaceae; 50, Cyttariaceae.

Order Helvellales. Helvellas. Common fungi; apothecia open from the first; fleshy or gelatinous.

Family 51. Rhizinaceae. Sessile.-Rhizina.

Family 52. Geoglossaceae. Stalked, capitate.-Mitrula, Geoglossum.

Family 53. Helvellaceae. Stalked, capitate-Morchella, Verpa, Helvella.

Order Graphidales. Slit Lichens. Lichen-forming fungi, allied to the preceding families.

Family 54. Arthoniaceae. Crustaceous, with Palmella, Trentepohlia, or Phyllactidium hosts.-Arthonia, Arthothelium.

Family 55. Graphidaceae. Crustaceous, with Palmella or Trentepohlia hosts.-Opegrapha, Graphis, Graphina.

Family 56. Chiodectonaceae; 57 , Dirinaceae.

Family 58. Roccellaceae. Fruticose, erect, with Trentepohlia hosts.-Roccella.

Order Pyrenolichenes. Closed Lichens. Lichen-forming fungi, allied to the preceding families.

Family 59. Moriolaceae. Crustaceous, with Cystococcus hosts.-Moriola.

Family 60. Epigloeaceae. Gelatinous, with Palmella hosts._Epigloea.

Family 61. Verrucariaceae. Crustaceous with Protococeus or Palmella hosts.-Verrucaria, Thelidium. 
Family 62. Dermatocarpaceae; 63, Pyrenothamniaceae; 64, Pyrenulaceae; 65, Phyllopyreniaceae; 66, Trypetheliaceae; 67, Paratheliaceae; 68, Astrotheliaceae; 69, Strigulaceae; 70, Pyrenidiaceae; 71, Mycoporaceae.

Order Pyrenomycetales. Closed Fungi. Filamentous, with mostly compound closed sporefruits.

Family 72. Hypocreaceae. Mostly reddish or yellowish.-Nectria, Cordyceps, Claviceps.

Family 73. Dothidiaceae. Black.-Plowrightia, Dothidea, Phyllachora.

Family 74. Sordariaceae; 75, Chaetomiaceae.

Family 76. Sphaeriaceae. Simple, superficial or sunken.-Trichosphaeria, Lasiosphaeria.

Family 77. Ceratostomataceae; 78, Cucurbitariaceae; 79, Amphisphaeriaceae; 80, Lophiostomataceae; 81, Mycosphacrellaceae; 82 , Pleosporaceae; 83 , Massariaceae; 84, Gnomoniaceae.

Family 85. Valsaceae. Permanently enclosed in a black stroma.-Valsa, Anthostoma, Diaporthe.

Family 86. Melanconidiaceae; 87, Diatrypaceae; 88, Melogrammataceae.

Family 89. Xylariaceae. Peripheral in massive stroma.-Hypoxylon, Xylaria.

Order Hysteriales. Slit Fungi. Common fungi; saprophytic, apothecia opening by a slit.

Family 90. Hypodermataceae; 91, Dichaenaceae; 92 , Ostropaceae.

Family 93. Hysteriaceae. Carbonaceous or leathery, elongated.-Hysterographium, Hysterium.

Family 94. Acrospermaceae.

Order Perisporiales. Mildews. Filamentous, with simple, mostly spherical spore-fruits. 
Family 95. Erysiphaceae. Superficial parasites upon higher plants.-Erysiphe, Microsphaera, Uncinula, Podosphaera.

Family 96. Perisporiaceae; 97, Microthyriaceae. Order Aspergillales. Little Tubers. Common fungi; spore-fruits minute or small, mostly not subterranean.

Family 9S. Gymnoascaceae. Loose hyphac, centrally ascigerous.-Gymnoascus.

Family 99. Aspergillaceae. Spheroidal, parenchymatous, sessile.-Aspergillus, Penicillium.

Family 100. Onygenaceae; 101, Trichocomataceae; 102, Elaphomycetaceae.

Family 103. Terfeziaceae. Spore-fruits subterranean resembling small Tubers.--Terfezia.

Order Heniascales. Common fungi; no apothecia; asci single, scattered.

Family 104. Ascoideaceae; 105, Protomycetaceae.

Family 106. Saccharomycetaceae. Yeast fungi, asci early isolated.--Saccharomyces.

Order Tuberales. Tubers. Common fungi; spore-fruits large, tuberous, subterranean, fleshy, internally ascigerous.

Family 107. Tuberaceae. Eventually opening.Tuber.

Family 108. Balsamiaceae. Not opening.-Balsamia. Class 16. BASIDIOSPOREAE. Basidium Fungi. Spore-fruits containing one or more basidia with basidiospores. (Sp. about 14,000.)

Order Hymenogastrales. False Tubers. Spore-fruits large, tuberous, subterranean, fleshy, with internal hymenium. Saprophytes.

Family 109. Hymenogastraceae. Resembling Tuberaceae.-Hysterangium, Hymenogaster, Octaviana, Rhizopogon.

Order Sclerodermatales. Hard puff-balls. Sporefruits small to large, roundish, eventually pulverulent. Saprophytes. 
Family 110. Sclerodermataceae. Spore-fruits round, often stalked.-Scleroderma.

Family 111. Podaxaceae. Spore-fruit pyriform or clavate, stalked.-Secotium, Podaxon.

Order Lycoperdales. Puff-balls. Spore-fruits large, fleshy, at first subterranean, later emerging-Saprophytes.

Family 112. Lycoperdaceae. Sessile or short-stalked. -Lyeoperdon, Bovista, Geaster.

Family 113. Tylostomataceae. Long-stalked.--Tylostoma, Battarea.

Order Nidulariales. Bird-nest Fungi. Spore-fruits small, spherical or top-shaped, leathery, containing one or more peridioles. Saprophytes.

Family 114. Nidulariaceae. With several peridioles. -Nidularia, Crucibulum, Cyathus.

Family 115. Sphaerobolaceae. With but one peridiole. -Sphaerobolus.

Order Phallales. Stink-Horns. Spore-fruits large, fleshy, at first tuberous and subterranean, later stalked and emerging. Saprophytes.

Family 116. Phallaceae. Stalk cylindrical, capped with spore-mass.-Mutinus, Ithyphallus, Dictyophora.

Family 117. Clathraceae. Stalk ovoid and reticulated, or branched.-Simblum, Clathrus, Ascroe.

Order Agaricales. Toadstool Fungi. Spore-fruits large, umbrella-shaped, bracket-shaped or variously branched; hymenium eventually external.-Saprophytes and parasites.

Family 118. Agaricaceae. Agaries or Toadstools; typically umbrella-shaped, usually fleshy; hymenium on gills.-Coprinus, Russula, Psalliota, Agaricus, Amanita.

Family 119. Polyporaceae. Polypores: from umbrella-shaped to bracket-shaped, fleshy to 
leathery or woody; hymenium lining pits or pores.-Boletus, Polyporus, Fomes, Polystictus.

Family 120. Hydnaceae. Prickly Fungi. From umbrella-shaped to bracket-shaped, fleshy to leathery or woody; hymenium on warts or prickles.-Hydnum, Irpex.

Family 121. Clavariaceae. Coral Fungi. Cylindrical to clavate and fruticose, mostly leathery; hymenium superficial.-Pistillaria, Clavaria.

Family 122. Thelephoraceae. Leathery Fungi. Flat, shell-shaped, capitate or branched, mostly leathery; hymenium superficial.-Thelephora, C o r t i c i u m, Stereum.

Order Exobasidiales. Reduced and degraded plants related to the preceding families; basidia undivided.

Family 123. Dacryomycetaceae; 124 , Tulasnellaceae; 125, Hypochnaceae; 126, Exobasidiaceae.

Order Tremellales. Jelly Fungi. Reduced and degraded plants related to the preceding families; basidia divided vertically.

Family 127. Sirobasidiaceae.

Family 128. Tremellaceae. Basidia collateral, spore fruits open.-Tremella, Exidia.

Family 129. Hyaloriaceae.

Order Auriculariales. Ear Fungi. Reduced and degraded plants related to the preceding families; basidia divided transversely.

Family 130. Auriculariaceae. Hymenium exposed, on a gelatinous, foliose or vague spore fruit.-Auricularia.

Family 131. Pilacraceae.

Class 17. TELIOSPOREAE. Brand Fungi. Parasitic, much reduced plants, producing erumpent sori (but no definite spore fruits) 
consisting of teliospores. (Sp. about 4,200.)

Order Unedinales. Rusts. Typically with sporidia, pycniospores, aeciospores, urediniospores and teliospores.

Family 132. Aecidiaceae. Teliospores free or fascicled.- "Puccinia," Dicaeoma, Nigredo, Uropyxis, Aecidium, Phragmidium, Uromyces.

Family 133. Uredinaceae. Teliospores compacted into a crust or column.- "Melampsora," Uredo, Cronartium.

Family 134. Coleosporiaceae. Teliospores compacted laterally into waxy layers.-Coleosporium.

Order Ustilaginales. Smuts. Typically with sporidia and teliospores.

Family 135. Ustilaginaceae. Germinating teliospore producing a septated promycelium.Ustilago, Sphacelotheca.

Family 136. Tilletiaceae. Germinating teliospore producing a tubular promycelium.Tilletia, Entyloma.

FUNGI IMPERFECTI. The "Imperfect Fungi." Including 16,000 to 17,000 species with regard to which our knowledge is quite imperfect. Most of them are regarded as conidial states of Ascosporeac. The classification here given is merely provisional.

Order Sphaeropsidales. Spot Fungi. Conidia developed in pyenidia.

Family 137. Sphaerioidaceae. Pyenidia more or less spherical, black.-Phyllosticta, Sphaeropsis, Septoria.

Family 13S. Nectrioidaceae. Pyenidia more or less spherical, bright colored.-Sphaeronemella, Aschersonia.

Family 139. Leptostromataceae. Pycnidia shicldshaped, black.-Leptostroma, Leptothyrium. 
Family 140. Excipulaceae. Pycnidia more or less disk-shaped, round or elongated, black.-Excipula, Discella.

Order Melanconiales. Black-dot Fungi. Conidia developed on a stroma.

Family 141. Melanconiaceae. Including Gloeosporium, Colletotrichum, Melanconium, Pestalozzia, Cylindrosporium, etc.

Order Moniliales. Molds. Conidia developed upon separate conidiophores which do not form a stroma.

Family 142. Mucedinaceae. Conidiophores separate, hyaline.-Oospora, Monilia, Oidium, Sterigmatocystis, Botrytis, Ramularia.

Family 143. Dematiaceae. Conidiophores separate, dark or black.-Torula, Dematium, Fusicladium, Cladosporium, Macrosporium, Cercospora.

Family 144. Stilbaceae. Conidiophores united into an erect, compound, spore-bearing body. -Stysanus, Isaria, Graphium.

Family 145. Tuberculariaceae. Conidiophores united into a compound, cushion-like, sporebearing body.-Tuberculina, Fusarium, Epicoccum.

Phylum VIII. BRYOPHYTA. The Mossworts

Chlorophyll-green, small, massive, sexual plants (gametophytes), producing a small, spore-bearing generation (sporophyte)

Class 18. HEPATICAE. Liverworts. Gametophytes mostly bilateral, often thalloid, creeping; sporophytes usually splitting and containing elaters. (Sp. about 4,000.)

Order Ricciales. The Riccias. Sporophyte globose, sessile, without columella or elaters.

Family 1. Ricciaceae. Small thallose plants, floating or terrestrial.-Riccia. 
Order ANthocerotales. Hornworts. Sporophyte elongated, with a columella and elaters, two-valved.

Family 2. Anthocerotaceae. Gametophyte a flat thallus.-Anthoceros.

Order Marchantiales. Great Liverworts. Sporophyte rounded, without columella, indehiscent.

Family 3. Corsiniaceae.

Family 4. Marchantiaceae. Gametophyte large, thallose, branching, with elaters.Marchantia, Conocephalus.

Order Jungermanniales. Scale Mosses. Sporophyte stalked, four-valved; with elaters.

Family 5. Metzgeriaceae. Gametophyte usually thallose, arehegones lateral.-Metzgeria, Pellia, Fossombronia.

Family 6. Jungermanniaceae. Gametophyte a bilateral leafy stem, archegones terminal.-Lophosia, Bazzania, Scapania, Frullania.

Class 19. MUSCI. Mosses. Gametophytes multilateral, usually erect; sporophytes mostly dehiscent by a circular lid, and without elaters. (Sp. about 12,600.)

Order Axdreateales. Black Mosses. Sporophyte shortstalked, opening by four to six longitudinal slits.

Family 7. Andreaeaceae. Small mosses.-Andreaea. Order Sphagnales. Peat Mosses. Sporophyte shortstalked, opening by a circular lid.

Family S. Sphagnaceae. Large bog mosses.-Sphagnum.

Order Bryales. True Mosses. Sporophytes mostly longstalked, generally opening by a circular lid, usually with a peristome.

Sub-order Acrocarpi. "Top Mosses." Sporophytes terminal on the main axis of the gametophyte.

Family 9. Archidiaceac; 10, Dicranaceae ("Turf Mosses"); 11, I,eucobryaceae ("Cush- 
ion Mosses"); 12, Fissidentaceae; 13, Calymperaceae.

Family 14. Pottiaceae. Small to medium plants, with erect capsules usually having a peristome of 16 teeth.-Weisia, Barbula, Phascum, Pottia, Encalypta.

Family 15. Grimmiaceae.

Family 16. Orthotrichaceae. Erect, tufted plants, with erect capsules usually with one or two rows of $S$ or 16 teeth.-Orthotrichum, Macomitrium.

Family 17. Splachnaceae. "Petticoat Mosses." Capsule stalked, generally with an enlarged base.-Splachnum.

Family 18. Oedipodiaceae; 19, Disceliaceae.

Family 20. Funariaceae. "Bristle Mosses." Capsule from erect and regular to drooping and curved or oblique; teeth 0 , or one or two rows of 16 each.-Ephemerum, Physcomitrium, Funaria.

Family 21. Schistostegiaceae; 22, Drepanophyllaceae; 23, Mitteniaceae.

Family 24. Bryaceae. "Wood Mosses." Small to large plants with costate leaves, and pear-shaped, long-stalked capsule; teeth usually in two whorls of 16 each.-Bryum.

Family 25. Leptostomataceae.

Family 26. Mniaceae. "Wood Mosses." Rather large, leafy plants, with ovoid to cylindrical, pendent capsule; peristome usually double, each whorl of 16 teeth.-Mnium.

Family 27. Rhizogoniaceae; 28 , Meeseaceae; 29, Aulocomniaceae; 30, Catascopiaceae; 31, Bartramiaceae.

Family 32. Timmiaceae. "Bristle Mosses." Rather large leafy plants, with long-stalked capsules; peristome in two rows of 16 and 64 teeth.-Timmia. 
Family 33. Weberaceae; 34 , Buxbaumiaceae ("Humpback Mosses"); 35, Georgiaceae.

Family 36. Polytrichaceae. "Hair-caps." Large, leafy plants, with long-stalked capsules; teeth short in one row of 32 or 64.-Polytrichum, Pogonatum.

Sub-order Pleurocarpi. "Side Mosses." Sporophytes terminal on short lateral axes of the gametophyte.

Family 38. Erpodiaceae; 39, Hedwigiaceae; 40, Fontinalaccae ("Brook Mosses").

Family 41. Climaciaceae. "Tree Mosses." Large erect dendroid plants, with erect or recurved capsules; teeth in two rows of 16 each.-Climacium.

Family 42. Cryphaeaceae; 43, Leucodontaceae; 44, Prionodontaceae; 45, Ptychomniaceae; 46, Spiridentaceae; 47, Lepyrodontaceae; 48, Pleurophascaceae.

Family 49. Neckeraceae. More or less rigid, leafy plants, with short-stalked, erect capsules, having single or double peristome.-Leptodon, Neckera.

Family 50. Lembophyllaceae; 51, Entodontaceae; 52, Fabroniaceae; 53, Pilotrichaceae; 54 Nematocaceae; 55, Hookeriaceae; 56, Hypopterygiaceae; 57, Helicophyl-, laceae; 58 , Rhacopilaceae.

Family 59. Leskeaceae. Cushion-forming, leafy plants, with symmetrical, erect capsules, having double peristome.Leskea, Anomodon, Thuidium.

Family 60. Leucomiaceae; 61, Sematophyllaceae; 62, Rhegmatodontaceae; 63, Brachytheciaceae; 64 , Hypnodendraceae.

Family 65. Hypnaceae. "Bog Mosses." Of variable size and habit, with long-stalked capsules, which have a double peristome, of 16 teeth in each row.Hypnum, Amblystegium. 
Phylum IX. PTERIDOPHYTA. The Ferns

Chlorophyll-green, small, sexual plants (gametophytes), producing a large-leaved, rooted generation (sporophyte).

(Here restricted to the ferns alone and including about 3,800 sp.)

Class 20. EUSPORANGIATAE. Old-fashioned Ferns. Sporangia developed from internal cells.

Order Ophioglossales. Adder-tongues. Gametophyte tuberous, subterranean; sporophyte with large leaves, some parts sporogenous.

Family 1. Ophioglossaceae. Including Ophioglossum, Botrychium, etc.

Order Marattiales. Marattias. Gametophyte flat, green, superficial; sporophyte with large compound leaves; sporangia hypophyllous.

Family 2. Marattiaceae. Large tropical ferns, from the Paleozoic to the present.-Angiopteris, Marattia.

Order Isoetales. Quillworts. Gametophytes dioecious rounded; sporophyte with erect, crowded, narrow leaves; sporangia epiphyllous, basal.

Family 3. Isoetaceae. Aquatic, rush-like plants.Isoetes.

Class 21. LEPTOSPORANGIATAE. Modern Ferns. Sporangia developed from superficial cells.

Order Filicales. Land Ferns. Spores of one kind; gametophytes foliose, monoecious.

Family 4. Osmundaceae. Sporangia globose, splitting vertically.-Osinunda.

Family 5. Schizaeaceac; 6, Gleicheniaceae; 7, Matoniaceac; S, Parkeriaceae.

Family 9. Cyatheaceae. Tree Ferns. Sporangia compressed, splitting transversely.Alsophila, Cyathea, Dicksonia.

Family 10. Hymenophyllaceae. Filmy Ferns. Sporangia compressed, splitting vertically. -Hymenophyllum, Trichomanes. 
Family 11. Polypodiaceae. Common Ferns. Sporangia compressed, splitting transversely.-Polypodium, Asplenium, Nephrodium, Adiantum, Pteridium.

Order Marsiliales. Water Ferns. Spores of two kinds; gametophytes dioecious, rounded.

Family 12. Marsiliaceae. Perennial plants rooted in the mud, mostly bearing 4-parted leaves.-Marsilia, Pilularia.

Family 13. Salviniaceae. Annual, small, floating, nearly rootless plants.-Azolla, Salvinia.

\section{Phylum X. CALAMOPHYTA. The Calamites}

Minute sexual plants (gametophytes), producing cylindrical, jointed and rooted sporophytes which bear whorled leaves. (Living species about 24 , but very many extinct.)

Class 22. SPHENOPHYLLINEAE. Wedge-leaved Calamites. Paleozoic herbaceous plants of moderate dimensions and solid, jointed stems; long extinct. Isosporous.

Order Sphexophyllales, including Family 1, Sphenophyllaceae.

Class 23. EQUISETINEAE. Horsetails. Paleozoic to recent herbaceous plants with hollow, jointed stems. Isosporous.

Order Equisetales. Spore-bearing cones terminal. Family 2. Equisetaceae. With one living genus.Equisetum.

Class 24. CALAMARINEAE. Old Calamites. Paleozoic plants, often trees, with hollow, increasing stems, long extinct. Heterosporous.

Order Calamariales, including Family 3, Protocalamariaceae; 4, Calamariaceae. 
Phylum XI. LEPIDOPHYTA. The Lycopods

Ninute gametophytes, producing branching, small-leaved, rooted sporophytes. (Living species about 700 , but very many extinct.)

Class 25. LYCOPODINEAE. Lower Lycopods. Isosporous; leaves without ligules.

Order Lycopodiales. Gametophytes much larger than the spore.

Family 1. Lycopodiaceae. Ground Pines. Dendroid,

Family 2. Psilotaceae. evergreen plants.-Lycopodium.

Class 26. LEPIDODENDRINEAE. Higher Lycopods. Heterosporous; leaves with ligules.

Order Selaginellales. Small plants; stems not thickening.

Family 3. Selaginellaceae. Club Mosses. Moss-like plants bearing terminal cones.Selaginella.

Order Lepidodendrales. Paleozoic and Mesozoic trees, long extinct.

Family 4. Lepidodendraceae; 5, Bothrodendraceae; 6 , Sigillariaceae; 7 , Pleuromoiaceae.

Phylum XII. CYCADOPHYTA. The Cycads

Minute gametophytes developed in naked seeds produced by the large, leafy-stemmed and rooted sporophytes;

sperms motile. (Living species about 140, but very many extinct.)

Class 27. PTERIDOSPERMEAE. Seed Ferns. Paleozoic, fern-like plants, long extinct.

Order Pteridospermales. With characters of the class. Family 1. Lyginopterideae; 2, Medullosae; 3, Cladoxyleae; 4, Protopityeae; 5 , Araucarioxyleae.

Class 28. CYCADINEAE. Common Cycads. Mesozoic to present plants with pinnate leaves.

Order Cycadales. With the characters of the class.

Family 6. Cycadaceae. Mostly tropical trees with staminate cones only.-Cycas. 
Family 7. Zamiaceae. Tropical trees with staminate and seed cones.-Zamia, Macrozamia, Dioon.

Class 29. BENNETTITINEAE. Flowering-plant Ancestors. Mesozoic plants with pinnate leaves, long extinct.

Order Bennettitales. With the characters of the class. Family 8. Bennettitaceae.

Class 30. CORDAITINEAE. Conifer Ancestors. Paleozoic to present, trees and shrubs with typically parallel-veined leaves, mostly long extinct.

Order Condaitales. Branching trees with elongated

Family 9. Cordaitaceae. parallel-veined leaves. (Extinct.)

Order Ginkgoales. Maidenhair Trees. Branching trees with fan-shaped, parallel-veined leaves. (All extinct but one species.)

Family 10. Ginkgoaceae. But one genus remaining. -Ginkgo.

Order Gxetales. Joint Firs. Anomalous woody plants of doubtful relationship, probably to be placed here, but the sperms not motile.

Family 11. Ephedraceae. Small Equisetum-like shrubs with reduced, opposite leaves. -Ephedra.

Family 12. Gnetaceae. Shrubs and trees with large, opposite, pinnately reined leaves.Gnetum.

Family 13. Tumboaceae. Short, thick-stemmed woody plants with two large, opposite, parallel-veined leaves.-Tumboa (Welwitschia).

\section{Phylum XIII. STROBILOPHYTA. The Conifers}

Minute gametophytes developed in naked seeds produced by the large, leafy-stemmed and rooted sporophytes; sperms not motile. (Sp. about 400.)

Class 31. PINOIDEAE. Mostly trees with increasing stems 
and small mostly persistent leaves; sporophylls mostly in cones.

Order Coniferales. Microsporophylls and megasporophylls in cones.

Family 1. Taxodiaceae. Taxodiums. Microsporophyll with 2 to 8 sporangia; megasporophyll woody, with 2 to several erect or inverted seeds; "sced-scale" wanting.-Taxodium, Sequoia.

Family 2. Araucariaceae. Old Pines. Microsporophyll with 5 to 15 sporangia; megasporophyll woody, with 1 inverted sced; "seed-scale" rudimentary.Araucaria.

Family 3. Abietaceae. Modern Pines. Microsporophyll with 2 sporangia; megasporophyll woody, with 2 inverted seeds; "seed-scale" prominent.-Pinus, Larix, Picea, Abies.

Family 4. Cupressaceae. Cypresses. Microsporophyll with 4 to 8 sporangia; megasporophyll woody, with 1 to many seeds; no "seed-scale."-Cupressus, Chamaecyparis.

Family 5. Thuyopsidaceae. Thuyas. Microsporophyll with 3 to 5 sporangia; megasporophyll woody, with 1 to many seeds.-Thuya, Libocedrus.

Family 6. Juniperaceae. Junipers. Microsporophyll with 4 to 8 sporangia; megasporophyll fleshy, with 1 to 2 seeds.Juniperus.

Order TAxales. Microsporophylls in cones, megasporophylls in very small cones or solitary.

Family 7. Podocarpaceae. Microsporophyll with 2 sporangia; megasporophylls in very small cones or solitary; seed 1 , inverted.-Podocarpus.

Family 8. Phyllocladaceae. Microsporophyll with 2 sporangia; megasporophylls soli_ tary; seed 1, erect.-Phyllocladus. 
Family 9. Taxaceae. Yews. Microsporophyll with

3 to 5 sporangia; megasporophyll solitary; seeds 1 or 2 , erect.-Taxus, Torreya.

Phylum XIV. ANTHOPHYTA. The Flowering Plants

Minute gametophytes developed in seeds enclosed in carpels in flowers, produced by the large, leafy-stemmed and rooted sporophytes; sperms not motile

(Sp. about 132,500.)

Class 32. MONOCOTYLEDONEAE. M on oc otyled ons. Leaves of sporophyte alternate, from the first, usually parallel veined; fibrovascular bundles of stem scattered. (Sp. about 23,700.)

Sub-Class MONOCOTYLEDONEAE-HYPOGYNAE. Perianth and stamens arising below the carpels (carpels superior).

Order Alismatales. Carpels separate, superior to all other parts of the flower.

Family 1. Alismataceae. Water Plantains. Largeleaved herbs with rather large flowers having calyx and corolla of 3 leaves each.-Alisma, Sagittaria.

Family 2. Butomaceae;3, Triuridaceae; 4 , Scheuchzeriaceae.

Family 5. Typhaceae. Cat-tails. Tall herbs with linear, sheathing leaves and cylindrical-crowded flowers.-Typha.

Family 6. Sparganiaceae; 7, Pandanaceae; $S$, Aponogetonaceae.

Family 9. Potamogetonaceae. River-weeds. Mostly aquatic herbs with reduced small flowers.-Potamogeton, Zostera, Zannichellia.

Order Liliales. Carpels (usually 3) united forming a compound pistil, superior; perianth in two whorls (of 3 each), corolla-like.

Family 10. Liliaceae. Lilies. Pistil, mostly 3celled; stamens 6.-Lilium, Erythron- 
ium, Tulipa, Yucca, Asparagus, Allium.

Family 11. Stemonaceac; 12, Pontederiaceac; 13, Cyanastraceac; 14, Philydraceae.

Family 15. Commelinaceac. Spiderworts. Succulent herbs with 3 or 2-celled pistil, and 6 stamens.-Commelina, Tradescantia.

Family 16. Xyridaceac; 17, Mayaceae.

Family 18. Juncaceac. Rushes. Herbs with stiff, narrow leaves, and 1 to 3 -celled pistil. -Juncus.

Family 19. Eriocaulonaceae; 20, Thurniaceae; 21, Rapateaceae; 22, Naiadaceae.

Order Arales. Compound pistil mostly tricarpellary, superior; ovules solitary.

Family 23. Cyclanthaceae.

Family 24. Araceae. Arums. Mostly herbs with broad, petioled reticulate-veined leaves; flowers small, clustered.Acorus, Symplocarpus, Calla, Caladium, Arum, Arisaema.

Family 25. Lemnaceae. Duckweeds. Reduced plants related to the Araceae, with flat plant-body floating free on water. -Lemna, Spirodela.

Order Palmales. Compound pistil mostly tricarpellary, superior; ovule usually 1; perianth reduced to rigid scales.

Family 26. Palmaceae. Palms. Trees or shrubs with pinnate or palmate leaves.Phoenix, Chamaerops, Calamus, Oreodoxa, Cocos.

Order Graminales. Compound pistil reduced to 2 or 3 carpels; ovule solitary; perianth reduced to small scales, or wanting.

Family 27. Restionaceae; 28, Centrolepidiaceae; 29, Flagellariaceae.

Family 30. Cyperaceac. Sedges. Grass-like herbs with 3-ranked leaves.-Cyperus, Scirpus, Carex. 
Family 31. Poaceae. Grasses, with 2-ranked leaves. (Sp. about 3,545.)

There are six tribes and several sub-tribes, of which the Bamboos are the lowest, while the Agrostideac, Paniceac and Maydeac are at the summits of as many diverging phyletic lines. These groups may be distinguished as follows:

A. Woody plants; a joint between the leaf-blade and the sheath. 1. Bamboos. (Bambuseae) Bambusa.

B. Herbaceous plants; no joint between the leaf-blade and sheath.

I. Spikelets with the larger flowers at the base.

1. Spikelets typically containing several to many flowers.

a. Mostly arranged in panieles; awns terminal. 2. Fescue Grasses (Festuceae) -Bromus.

b. Arranged in panicles; awns dorsal. 2a. Cat Grasses (Aveneae)-Avena.

c. Sessile in two rows on the opposite sides of the main stem. 2b. Wheat Grasses (Triticeae)-Triticum.

d. Sessile in two rows on one side of a flattened axis. 2e. Gramma Grasses. (Chlorideae)-Bouteloua.

2. Spikelets containing but one flower. 3. Redtop Grasses (Agrostideae)-Agrostis.

II. Spikelets with the larger flowers at the top.

1. A joint above the empty glumes.

a. Spikelets with five glumes; palets onenerved. 4. Canary Grasses (Phalarideae)-Phalaris.

2. A joint below the empty glumes.

a. Spikelets flattened laterally, one-flowered. 4a. Rice Grasses (Oryzeae)-Oryza.

b. Spikelets not flattened laterally, one to two-flowered.

(1) Stems hollow, medium sized to small. 5. Panic Grasses (Paniceae)Panicum. 
(2) Stems mostly solid, often large and tall.

(a) Spikelets perfect or staminate, not separated. 6. Blue-stem Grasses (Andropogoneae)Andropogon.

(b) Spikelets all unisexual, separate, monoecious. 6a. Maize Grasses (Maydeae)-Zea.

Sub-Class MONOCOTYLEDONEAE-EPIGYNAE. Perianth and stamens arising above the carpels; carpels inferior.

Order Hydrales, with one family, 32, Hydrocharitaceae. Order IRIDAles. Compound tricarpellary pistil inferior; whorls of perianth mostly alike and regular.

Family 33. Amaryllidaceae. Amaryllises. Leaves narrow to broad, the veins longitudinal.-Amaryllis, Narcissus, Agave, Hypoxis.

Family 34. Haemodoraceae.

Family 35. Iridaceae. Irises. Leaves sword-shaped; stamens 3.--Iris, Crocus, Sisyrinchium, Gladiolus.

Family 36. Velloziaceae; 37, Taccaceae; 38, Dioscoreaceae.

Family 39. Bromeliaceae. Leaves mostly rosulate elongated and pointed.-Tillandsia, Ananas.

Family 40. Musaceae. Bananas. Large herbs, often tree-like.-Musa, Strelitzia.

Family 41. Zingiberaceae.

Family 42. Cannaceae. Perennial herbs with pinnately-veined leaves and irregular flowers.-Canna.

Family 43. Marantaceae.

Order Orchidales. Compound tricarpellary pistil inferior; perianth irregular.

Family 44. Burmanniaceae.

Family 45. Orchidaceae. Orchids. Flowers irregular, 
stamens 1 or 2.-Cypripedium, Orchis, Platanthera, Vanilla, Spiranthes.

Class 33. DiCOTYLEDONEAE. Dicotyledons. Leaves of young sporophyte opposite, sometimes remaining so, usually reticulate veined; fibrovascular bundles of stem in one or more rings. (Sp. about 108,800 .)

Sub-Class DICOTYLEDONEAE-AXIFLORAE. "Axis Flowers." Axis of the flower normally cylindrical, spherical, hemispherical or flattened, bearing on its surface the hypogynous perianth, stamens and carpels (or the stamens may be attached to the corolla).

Super-Order Axiflorae-Apopetalae-Polycarpellatae.

Carpels typically many, separate or united; petals separate.

Order Ravales. All parts of the flower free (not united); carpels separate; typically many.

Family 46. Magnoliaceae. Magnolias. Trees and shrubs with many petals in 1 to many whorls.-Magnolia, Liriodendron.

Family 47. Calycanthaceae; 48, Monimiaceae; 49, Cercidiphyllaceae; 50, Trochodendraceae; 51, Leitneriaceae.

Family 52. Anonaceae. Papaws. Trees and shrubs with 6 petals in two whorls.Asimina.

Family 53. Lactoridaceae; 54, Gomortegaceae; 55, Myristicaceae; 56, Saururaceae; 57, Piperaceae; 58, Lacistemaceae; 59, Chloranthaceae.

Family 60. Ranunculaceae. Buttercups. Mostly herbs, normally with 5 petals in 1 whorl.-Myosurus, Ranunculus, Anemone, Clematis.

Family 61. Lardizabalaceae; 62, Berberidaceac; 63 , Menispermaceae; 64, Lauraceac.

Family 65. Nelumbaceae. Lotuses. Aquatic herbs with separate carpels. - Nelumbo. 
Family 66. Cabombaceae; 67, Ceratophyllaceae; 68, Dilleniaceae; 69, Winteranaceae.

Order Malvales. Pistil usually of 3 to many carpels, with as many cells; stamens normally indefinite, monadelphous, branched.

Family 70. Sterculiaceae.

Family 71. Malvaceae. Mallows. Herbs, shrubs and trees; flowers regular with monadelphous stamens.-Malva, Hibiscus, Althaea, Abutilon, Gossypium.

Family 72. Bombacaceae; 73, Scytopetalaceae; 74, Chlaenaccae; 75, Gonystylaceae.

Family 76. Tiliaceae. Lindens. Mostly trees and shrubs; flowers regular with free stamens.-Tilia.

Family 77. Elacocarpaceae; 78, Balanopsidaceae.

Family 79. Ulmaceae. Elms. Trees and shrubs; flowers reduced, small, apetalous; pistil 1 or 2-celled.-Ulmus, Celtis, Planera.

Family 80. Moraceae. Figs. Trees, shrubs and herbs, mostly with a milky juice; flowers reduced, small, apetalous; pistil 1-celled.-Morus, Toxylon, Ficus, Humulus, Cannabis.

Family 81. Urticaceae. Nettles. Herbs, shrubs and trees, juice not milky; flowers reduced, small apetalous; pistil 1celled.-Urtica, Boehmeria.

Order Sarraceniales. "Insectivorous" plants.

Family 82. Sarraceniaceae; 83, Nepenthaceae.

Order Geraniales. Pistil of several carpels; receptacle usually with an annular or glandular disk.

Family 8t. Geraniaceae. Geraniums. Herbs, shrubs and trees; pistil 3 to 5 -celled on an elongated receptacle.-Geranium, Pelargonium, Erodium.

Family 85. Oxalidaceac. Sorrels. Mostly herbs with a sour juice; flowers pentamerous.-Oxalis. 
Family 86. Tropacolaceac. Succulent, trailing herbs with alternate, peltate leaves, and irregular flowers.-Tropaeolum.

Family 87. Balsaminaceae. Touch-me-nots. Suceulent, mostly erect herbs with alternate leaves, and irregular flowers.Impatiens.

Family SS. Limnanthaceae; 89, Linaceae; 90, Humiriaceae; 91 , Erythroxylaceae; $92,7 y$ gophyllaceae; 93, Cneoraceae.

Family 94. Rutaceae. Herbs, shrubs and trees usually with opposite, glandular-dotted leaves, and regular flowers.-Xanthoxylum, Ruta, Ptelea, Limonia, Citrus.

Family 95. Simarubaceae; 96, Burseraceae; 97 , Meliaceae; 9S, Malpighiaceae; 99, Trigoniaceae; 100, Vochysiaceae; 101, Polygalaceae; 102, Tremandraceae; 103 , Dichapetalaceae.

Family 104. Euphorbiaceae. Herbs, shrubs and trees, mostly with a milky juice; flowers diclinous; pistil usually 3-celled.Euphorbia, Croton, Ricinus, Manihot.

Family 105. Callitrichaceae.

Order Guttiferales. Pistil mostly of 2 or more carpels; stamens usually indefinite; endosperm usually wanting.

Family 106. Theaceae. Shrubs and trees with regular flowers.-Thea, Gordonia, Stuartia.

Family 107. Cistaceae; 108, Guttiferaceae; 109, Eucryphiaceae; 110, Ochnaceae; 111, Dipterocarpaceae; 112, Caryocaraceae 113, Quiinaceae; 114, Marcgraviacene; 115, Flacourtiaceae; 116, Bixaceae; 117, Cochlospermaceae.

Family 118. Violaceae. Violets. Herbs and shrubs and trees, with irregular flowers and tricarpellary pistil.-Viola.

Family 119. Malesherbiaceae; 120, Turneraceae. Family 121. Passifloraceae. Passion Flowers. Climb- 
ing herbs and shrubs with regular flowers.-Passiflora.

Family 122. Achariaceae; 123, Caric ac ea e; 124 , Stachyuraceae; 125 , Koeberliniaceae.

Order Rhoedales. Pistil of two or more united carpels, mostly one-celled with parietal placentae.

Family 126. Papaveraceae. Poppies. Perianth 2 to 4-merous, stamens indefinite, pistils 2 to many carpellary.-Eschscholtzia, Sanguinaria, Argemone, Papaver, Bicuculla.

Family 127. Tovariaceae.

Family 128. Nymphaeaceae. Water lilies. Aquatic herbs with floating leaves.-Nymphaea, Castalia, Victoria.

Family 129. Moringaceae; 130, Resedaceae; 131, Capparidaceae.

Family 132. Brassicaceae. Mustards. Perianth 4merous, stamens 6 or 4 , pistil 2-carpellary.-Sinapis, Brassica, Raphanus, Bursa, Alyssum.

Order Caryophyllales. Pistil usually of 3 or more united carpels, mostly 1-celled; stamens as many or twice as many as the petals.

Family 133. Caryophyllaceae. Pinks. Mostly herbs, with opposite leaves; ovules many on a central placenta.-Silene, Lychnis, Dianthus, Alsine, Paronychia.

Family 134. Elatinaceae.

Family 135. Portulacaceae. Mostly succulent herbs with 2 sepals and 4 to 5 petals.Portulaca, Claytonia.

Family 136. Aizoaceae; 137, Frankeniaceae; 138, Fouquieraceae; 139, Tamaricaceae.

Family 140. Salicaceae. Willows. Shrubs and trees with alternate leaves and no perianth. -Salix, Populus.

Family 141. Podostemonaceae; 142, Hydrostachydaceae; 143, Phytolaccaceae; 144, Basellaceae. 
Family 145. Amaranthaceae. Mostly herbs and shrubs with opposite or alternate leaves; perianth harsh.-Amaranthus, Celosia, Froelichia.

Family 146. Chenopodiaccae. Mostly herbs and shrubs with alternate or opposite leaves; perianth soft.-Beta, Chenopodium, Atriplex, Salsola.

Family 147. Polygonaceae. Herbs, shrubs and trees, with alternate, rarely opposite leaves; perianth petal-like. - Eriogonum, Rheum, Polygonum, Fagopyrum, Coccoloba.

Family 148. Nyctaginaceae; 149, Cynocrambaceae; 150 , Batidaceae.

Super-Order Axiflorae-Gamopetalae-PolycarpelLATAE. Carpels typically many, united; petals united.

Order Primulales. Pistil mostly 1-celled, with a central placenta; stamens mostly opposite the corolla lobes.

Family 151. Primulaceae. Primroses. Herbs with showy flowers.-Primula, Cyclamen, Dodecatheon.

Family 152. Plantaginaceae. Plantains. Herbs with reduced flowers; stamens alternate with the petals.-Plantago.

Family 153. Plumbaginaceae; 15t, Theophrastaceae; 155, Myrsinaceae.

Order Ericales. Pistil more than 1-celled, with many minute seeds; stamens alternate with the corolla lobes.

Family 156. Clethraceae.

Family 157. Ericaceae. Heaths. Shrubs and small trees with mostly evergreen leaves; anthers opening by a terminal pore.Rhododendron, Kalmia, Arctostaphylos, Vaccinium, Erica.

Family 158. Epacridaceae; 159, Diapensiaceae; 160, Pirolaceac; 161, Lennoaceae.

Order Ebexales, with four families of mostly 
tropical trees.-162, Sapotaceae; 163, Ebenaceae; 164, Symplocaceae; 165, Styracaceae.

Super-Order Axiflorae-Gamopetalae-Dicarpellatae. Carpels typically two, united; petals united.

Order Polemoniales. Corolla regular; stamens as many as the corolla lobes; leaves mostly alternate.

Family 166. Polemoniaceae. Phloxes. Mostly herbs with alternate or opposite leaves; pistil tricarpellary.-Phlox Gilia, Polemonium.

Family 167. Convolvulaceae. Morning Glories. Mostly herbs and shrubs with alternate leaves; pistil mostly bicarpellary. -Convolvulus, Ipomoea, Evolvulus, Cuscuta.

Family 168. Hydrophyllaceae. Soft herbs; pistil bicarpellary.-Hydrophyllum, Phacelia.

Family 169. Borraginace:ae. Forget-me-nots. Herbs, shrubs and trees; pistil bicarpellary, 4-celled.-Heliotropium, B or r a g o, Myosotis, Mertensia, Lithospermum.

Family 170. Nolanaceae.

Family 171. Solanaceae. Nightshades. Mostly herbs and shrubs; pistil bicarpellary, mostly 2-celled.-Solanum, Atropa, Physalis, Capsicum, Datura, Nicotiana, Petunia.

Order Gentianales. Corolla regular; stamens as many as the corolla lobes; leaves opposite.

Family 172. Oleaceac. Olives. Mostly shrubs and trees; stamens 2 or 4 ; ovary 2-celled. -Olea, Syringa, Jasminum, Fraxinus.

Family 173. Salvadoraceae; 174, Loganiaceae.

Family 175. Gentianaceac. Mostly herbs with limpid juice; ovary usually 1-celled.-Gentiana, Eustoma, Menyanthes.

Family 176. Apocynaceae. Trees, shrubs and herbs 
with milky juice; ovary 2-celled, or of two separated carpels.-Apocynum, Vinca, Nerium.

Family 177. Aselepiadaceae. Milkweeds. Herbs and shrubs with milky juice; ovary of two separated carpels.-Asclepias, Ceropegia, Stapelia, Hoya.

Order Scrophulariales. Corolla mostly irregular; stamens fewer than the corolla lobes; ovules many.

Family 178. Scrophulariaceae. Snapdragons. Mostly herbs; ovary 2-celled; seeds endospermous.-Verbascum, Antirrhinum, Scrophularia, Mimulus, Veronica, Gerardia, Castilleia, Pedicularis.

Family 179. Bignoniaceae. Catalpas. Mostly trees and shrubs; ovary 1 or 2-celled; seeds without endosperm.-Bignonia, Catalpa, Tecoma.

Family 180. Pedaliaceae; 181, Martyniaceae; 182, Orobanchaceae; 183, Gesneraceae; 184, Columelliaceae; 185, Lentibulariaceae; 186, Globulariaceae; 187, Acanthaceae.

Order Lamiales. Corolla mostly irregular; stamens fewer than the corolla lobes; ovules usually solitary.

Family 188. Myoporaceae; 189, Phrymaceae.

Family 190. Verbenaceae. Herbs, shrubs and trees, with usually undivided stigma.Verbena, Lantana, Lippia, Tectona, Vitex.

Family 191. Lamiaceae. Mints. Mostly herbs and shrubs, aromatic, with usually bifid stigma.-Lavandula, Nepeta, Salvia, Thymus, Mentha, Coleus.

Sub-Class DICOTYLEDONEAE-CALYCIFLORAE. " $\mathrm{Cup}$ Flowers." Axis of the flower normally expanded into a disk or cup, bearing on its margin the perianth and 
stamens (or the latter may be attached to the corolla).

Super-Order Calyciflorae-Apopetalae. Petals separate.

Carpels many to few, separate to united, superior to inferior.

Order Rosales. Flowers usually perfect, regular or irregular; carpels from wholly separate to more or less united, sometimes overgrown by the axis-cup; styles distinct. - Family 192. Rosaceae. Roses. Herbs, shrubs and trees, with mostly alternate leaves and indefinite stamens; carpels from many to one, free.-Potentilla, Fragaria, Spiraea, Rosa.

Family 193. Malaceae. Apples. Shrubs and trees, with alternate leaves, and usually many stamens; carpels few, more or less united to the axis cup.-Malus, Pirus, Crataegus.

Family 194. Prunaceae. Plums. Shrubs and trees with alternate leaves, and many stamens; carpel one, in the bottom of the deep cup, becoming a drupe on ripening.--Prunus, Amygdalus.

Family 195. Crossosomataceae; 196, Connaraceae.

Family 197. Mimosaceae. The Mimosas. Trees, shrubs and herbs, with alternate, mostly compound leaves; flowers regular; stamens 10 or more, usually separate; carpel one, ripening into a legume.-Acacia, Mimosa.

Family 198. Cassiaceae. The Sennas. Trees, shrubs and herbs, with alternate, mostly compound leaves; flowers irregular; stamens 10 or less, usually separate; carpel one, ripening into a legume.Cassia, Caesalpinia, Gleditsia, Gymnocladus.

Family 199. Fabaceae. The Beans. Herbs, and some shrubs and trees, with alternate, mostly compound leaves; flowers ir- 
regular; stamens 10 or less, usually united; carpel one, ripening into a legume.-Lupinus, Medicago, Trifolium, Robinia, Vicia, Pisum, Phaseolus.

Family 200. Saxifragaceae. Saxifrages. Herbs with alternate or opposite leaves; flowers regular; stamens 8 to 10 ; carpels 2, superior.-Saxifraga, Heuchera, Mitella.

Family 201. Hydrangeaceae. Hydrangeas. Shrubs and trees with mostly opposite leaves; flowers regular; stamens 8 to 40 ; carpels 2 to 5 , united, more or less overgrown by the axis-cup.-Philadelphus, Hydrangea.

Family 202. Grossulariaceae. Gooseberries. Shrubs with alternate leaves; flowers regular; stamens 5; carpels 2 to several, wholly overgrown by the fleshy axiscup.-Ribes.

Family 203. Crassulaceae; 204, Droseraceae; 205, Cephalotaceae; 206, Pittosporaceae; 207, Brunelliaceac; 208, Cunoniaceae; 209, Myrothamnaceae; 210, Bruniaceae; 211, Hamamelidaceae; 212, Casuarinaceae; 213, Eucommiaceae.

Family 214. Platanaceae. Trees with alternate leaves and reduced, monoecious flowers in globular heads; no perianth.Platanus.

Order Myrtales. Flowers usually perfect, regular; pistils several, united, usually inferior.

Family 215. Lythraceae. Herbs, shrubs and trees, usually with opposite leaves; pistil free.-Lythrum, Cuphea.

Family 216. Sonneratiaccae; 217, Punicaceae; 218, Lecy thidaceae; 219, Melastomataceac.

Family 220. Myrtaceac. Myrtles. Trees and shrubs with opposite or alternate leares; 
stamens indefinite; pistil 2 to manycelled, inferior.-Myrtus, Pimenta, Eugenia, Jambosa, Eucalyptus, Malaleuca.

Family 221. Combretaceae; 222, Rhizophoraceae. Family 223. Oenotheraceae. Evening Primroses. Mostly herbs, with opposite or alternate leaves; stamens 1 to 8 ; pistil usually 4-celled, inferior.-Epilobium, Anogra, Oenothera, Gaura, Fuchsia, Circaea.

Family 224. Halorrhagidaceae; 225, Hippuridaceae; 226, Cynomoriaceae; 227, Aristolochiaceae; 228, Rafflesiaceae; 229 , Hydnoraceae.

Order Cactales. Flowers regular and perfect; pistil syncarpous, 1-celled, with parietal placentae, inferior; mostly leafless plants.

Family 230. Cactaceae. Cactuses. Fleshy-stemmed, mostly leafless plants.-Peireskia, Opuntia, Cereus, Carnegiea, Echinocactus, Cactus, Melocactus, Rhipsalis.

Order LoAsales. Flowers regular and perfect or diclinous; pistil syncarpous, 1-celled, with parietal placentae, inferior; leaves ample.

Family 231. Loasaceae. Star Flowers. Erect herbs with perfect, regular flowers, and many stamens.-Mentzelia, Loasa.

Family 232. Cucurbitaceae. Melons. Mostly climbing herbs with but 3 stamens.Cucurbita, Cucumis, Lagenaria, Citrullus, Momordica.

Family 233. Begoniaccae. Begonias. Mostly erect herbs, with diclinous flowers and many stamens.-Begonia.

Family 234. Datisaaceae; 235, Ancistrocladaceae. Order Celastrales. Flowers regular, receptacular disk annular or turgid, sometimes adnate to the 1 to several-celled pistil, the latter sometimes inferior; ovules few. 
Family 236. Rhamnaceae. Buckthorns. Erect trees and shrubs.-Rhamnus, Ceanothus, Colletia.

Family 237. Vitaceae. Grapes Woody climbers.Vitis, Parthenocissus, Ampelopsis.

Family 238. Celastraceae; 239, Buxaceae; 240, Aquilfoliaceae; 291, Cyrillaceac; 242, Pentaphyllaceae; 243 , Corynocarpaceae; 244 , Hippocrateaceae; 245, Stackhousiaceae; 246 , Staphyleaceae; 247 , Geissolomataceae; 248, Penaeaceae; 249, Oliniaceae; 250, Thymelaeaceae; 251, Hernandiaceae; 252, Elaeagnaceae; 253, Myzodendraceac; 254, Santalaceae; 255, Opiliaceae; 256, Grubbiaceae; 257 , Olacaceae.

Family 258. Loranthaceae. Mistletoes. Parasitic herbs or shrubs with opposite or alternate leaves; flowers perfect or diclinous, apetalous; pistil 1-celled, inferior.-Loranthus, Viscum, Phoradendron, Razoumofskya.

Family 259. Balanophoraceae.

Order Sapindales. Flowers mostly regular, disk tumid (or wanting); pistil 1 to several-celled, sometimes inferior; ovules 1 to 2.

Family 260. Sapindaceae. Mostly tropical trees and shrubs, with alternate leaves, and regular flowers.- Sapindus, Koelreuteria.

Family 261. Hippocastanaceae. Buckeyes. Trees and shrubs with opposite, palmate leaves, and large, irregular flowers; pistil superior.-Aesculus.

Family 262. Aceraceae. Maples. Trees and shrubs with opposite, palmate or pinnate leaves, and small, regular flowers; pistil superior.-Acer.

Family 263. Sabiaceae; 264, Icacinaceac; 265, Melianthaceae; 266, Empetraceac; 267, Coriariaceae. 
Family 268. Anacardiaceae. Sumachs. Trees and shrubs with alternate pinnate leaves; and small flowers with superior or inferior, 1 to 5-celled pistil.-Rhus, Mangifera, Cotinus.

Family 269. Juglandaceae. Walnuts. Trees and shrubs, with alternate, pinnate leaves; and small much reduced flowers with inferior, 1-celled pistil.-Juglans, Hicoria.

Family 270. Betulaceae. Birches. Trees and shrubs with alternate, pinnate leaves, and diclinous flowers in aments; pistil 1 to 2-celled, superior or inferior.Betula, Alnus, Corylus, Ostrya, Carpinus.

Family 271. Fagaceae. Beeches. Trees and shrubs with alternate, pinnate leaves and diclinous flowers in aments; pistils 2 to 6-celled, inferior.-Fagus, Castanea, Quercus.

Family 272. Myricaceae; 273, Julianaceae; 274, Proteaceae.

Order Umbellales. Flowers regular, usually perfect, disk adherent to the mostly bicarpellary pistil which is inferior and 2 . celled; ovules 1 in each cell.

Family 275. Araliaceae. Ginsengs. Mostly trees and shrubs; pistil 2 to 15 -carpellary; fruit a berry.-Aralia, Hedera, Panax.

Family 276. Apiaceae. Parsleys. Mostly herbs; pistil bicarpellary; fruit dry, splitting vertically; inflorescence umbellate.Sanicula, Coriandrum, Apium, Cicuta, Pastinaca, Foeniculum, Ferula, Heracleum, Daucus.

Family 277. Cornaceac. Cornels. Mostly shrubs and trees with usually opposite leaves; pistil 2 to 4-carpellary; fruit a drupe. -Cornus, Nyssa. 
Super-Order Calyciflorae-Ganopetalae. Petals united. Carpels few, united, inferior.

Order Rubiales. Flowers regular or irregular; ovary 2 to 8-celled; ovules 2 to many.

Family 278. Rubiaceae. Coffees. Trees, shrubs and herbs with opposite or whorled leaves and mostly regular flowers.-Galium, Houstonia, Cinchona, Coffea, Mitchella.

Family 279. Caprifoliaceae. Honeysuckles. Mostly woody plants, with opposite leaves and mostly irregular flowers.-Sambucus, Viburnum, Linnaea, Lonicera.

Family 280. Adoxaceae; 281, Valerianaceac;282, Dipsacaceae.

Order Campanulales. Flowers regular to irregular, stamens mostly free from the corolla; ovary 1 to several-celled; ovules 1 to 8 .

Family 283. Campanulaceae. Bellworts. Mostly herbs; stamens, usually 5, free from the style.-Campanula, Lobelia.

Family 284. Goodeniaceae; 2S5, Stylidiaceae; 2S6, Calyceraceae.

Order Asterales. Composites. Flowers regular to irregular, collected into involuerate heads; calyx small and often forming a "pappus" or wanting; stamens 5, epipetalous, mostly with their anthers connate; carpels 2, united, inferior, with one style which is 2-branched above; ovule one, erect, anatropous. An immense order (commonly regarded as a family) of more than 14,300 species, which are usually distributed among fourteen tribes, all of which are here raised to families. In the following arrangement the Helian thaceac are regarded as the lowest, from which the two principal phyletic lines have arisen, 
culminating on the one hand in the Eupatoriaceae, and on the other in the Lactucaceae.

Key to the Families of Asterales

A. Pappus not capillary; plants typically large and coarse.

I. Receptacle chaffy.

1. Usually with ray flowers-287. Helianthaceae.

2. Without ray flowers-28s. Ambrosiaceae.

II. Receptacle naked (rarely chaffy).

1. Anthers tailless.

a. Involucral bracts mostly in 2 series-289. Heleniaceae.

b. Involueral bracts in many series-290. Arctotidaceae.

2. Anthers tailed or mucronate -291 . Calendulaceae.

B. Pappus bracteose, none, or capillary; receptacle usually naked; plants typically low to medium sized.

I. Usually without ray flowers; anthers tailed-292. Inulaceae.

C. Pappus from short bracteose to capillary or none; receptacle naked; plants typically medium sized.

I. Usually with ray flowers-293. Asteraceae.

II. Without ray flowers; style branches filiform, hispidulous.-294. Vernoniaceae.

III. Without ray flowers; style branches clavate, papillose-295. Eupatoriaceae.

D. Pappus a short crown or none; involucral bracts dry, scarious, imbricated; plants typically medium sized.

I. Usually with white ray flowers-296. Anthemidaceae. 
E. Pappus capillary; involucral bracts mostly valvate, not scarious; plants larger.

I. With or without rays-297. Senecionidaccae.

F. Pappus mostly capillary, plants usually rather large and stout.

I. Involucral bracts much imbricated.

1. Flowers all tubular, receptacle usually bristly-298. Carduaceae.

II. Involucral bracts little imbricated.

1. Flowers all labiate, receptacle usually naked-299. Mutisiaceae.

2. Flowers all ligulate, receptacle usually naked-300. Lactucaceae.

Family 287. Helianthaceae. Sunflowers. Herbs; calyx not capillary; receptacle chaffy; usually rayed; mostly large, coarse plants.-Helianthus, Zinnia, Rudbeckia, Silphium.

Family 288. Ambrosiaceae. Ragweeds. Herbs; calyx not capillary; receptacle chaffy; rayless; mostly large, coarse plants. -Ambrosia, Xanthium.

Family 289. Heleniaceae. False Sunflowers. Herbs; calyx not capillary; receptacle naked; rayed or rayless; anthers tailless; medium sized plants.-Helenium, Gaillardia.

Family 290. Arctotidaccae. Gazanias. Herbs; calyx not capillary; receptacle naked; anthers tailless. South African plants. - Gazania, Arctotis.

Family 291. Calendulaceae. Marigolds. Herbs; calyx not capillary; receptacle naked; anthers tailed. Old World plants, mostly tropieal.-Calendula.

Family 292. Inulaceae. Everlastings. Herbs, with some shrubs and small trees; calyx from bracteose to capillary; receptacle usually naked; anthers tailed; usually rayless; mostly low plants.- 
Antennaria, Gnaphalium, Helichry sum, Inula.

Family 293. Asteraceae. Asters. Herbs and undershrubs; calyx from bracteose to capillary; receptacle naked; usually rayed; medium sized plants.-Aster, Solidago, Erigeron, Bellis, Baccharis.

Family 294. Vernoniaceae. Ironweeds. Herbs; calyx from bracteose to capillary; receptacle naked; rayless; stylebranches filiform, hispidulous; medium sized plants.-Vernonia, Elephantopus.

Family 295. Eupatoriaceae. Blazing Stars. Herbs; calyx from bracteose to capillary; receptacle naked; rayless; stylebranches thickened upward, papillose; medium sized plants.-Lacinaria, Eupatorium, Kuhnia.

Family 296. Anthemidaceae. Camomiles. Herbs, shrubs, and small trees; calyx a short crown or wanting; receptacle chaffy or naked; usually with white rays; mostly medium sized plants.-Anthemis, Chrysanthemum, Artemisia.

Family 297. Senecionidaceae. Groundsels. Herbs, shrubs, and trees; calyx capillary; receptacle naked; rayed or rayless; mostly medium sized plants.-Senecio, Arnica.

Family 298. Carduaceae. Thistles. Herbs; calyx mostly capillary; receptacle usually bristly (not chaffy); rayless; mostly stout plants.-Carduus, Arctium, Cnicus.

Family 299. Mutisiaceae. Mutisias. Herbs, shrubs, and small trees; calyx mostly capillary; receptacle usually naked; flowers all two-lipped, so no proper rays; mostly medium sized tropical plants. -Mutisia, Chaptalia. 
Family 300. Lactucaceae. Lettuces. Herbs with a milky juice; calyx mostly capillary; receptacle usually naked; flowers all ligulate, so no proper rays; medium sized to small plants.-Lactuca, Hieracium, Cichorium, Taraxacum, (Leontodon).

\section{REFERENCE BOOKS}

A. Engler and K. Prantl, Die Natürlichen Pflanzenfamilien, Leipzig, 1889 to 1909.

C. E. Bessey, A Synopsis of Plant Phyla, Lincoln, 1907.

A. Engler and E. Gilg, Syllabus der Pflanzenfamilien, Berlin, 1912.

C. E. Bessey, Revisions of Some Plant Phyla, Lincoln, 1914. 


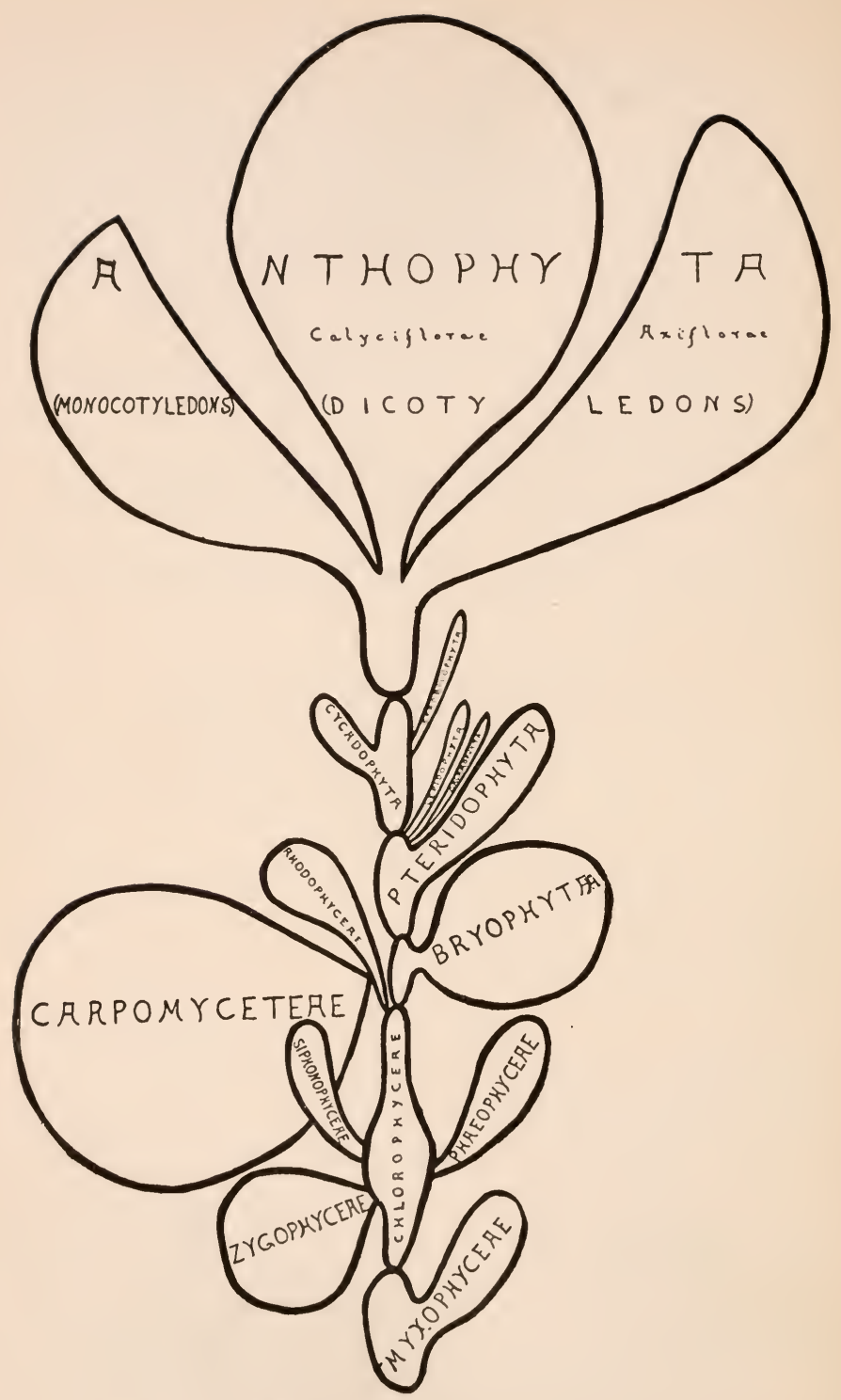

Chart to Show Relationship of the Plant Phyla. 


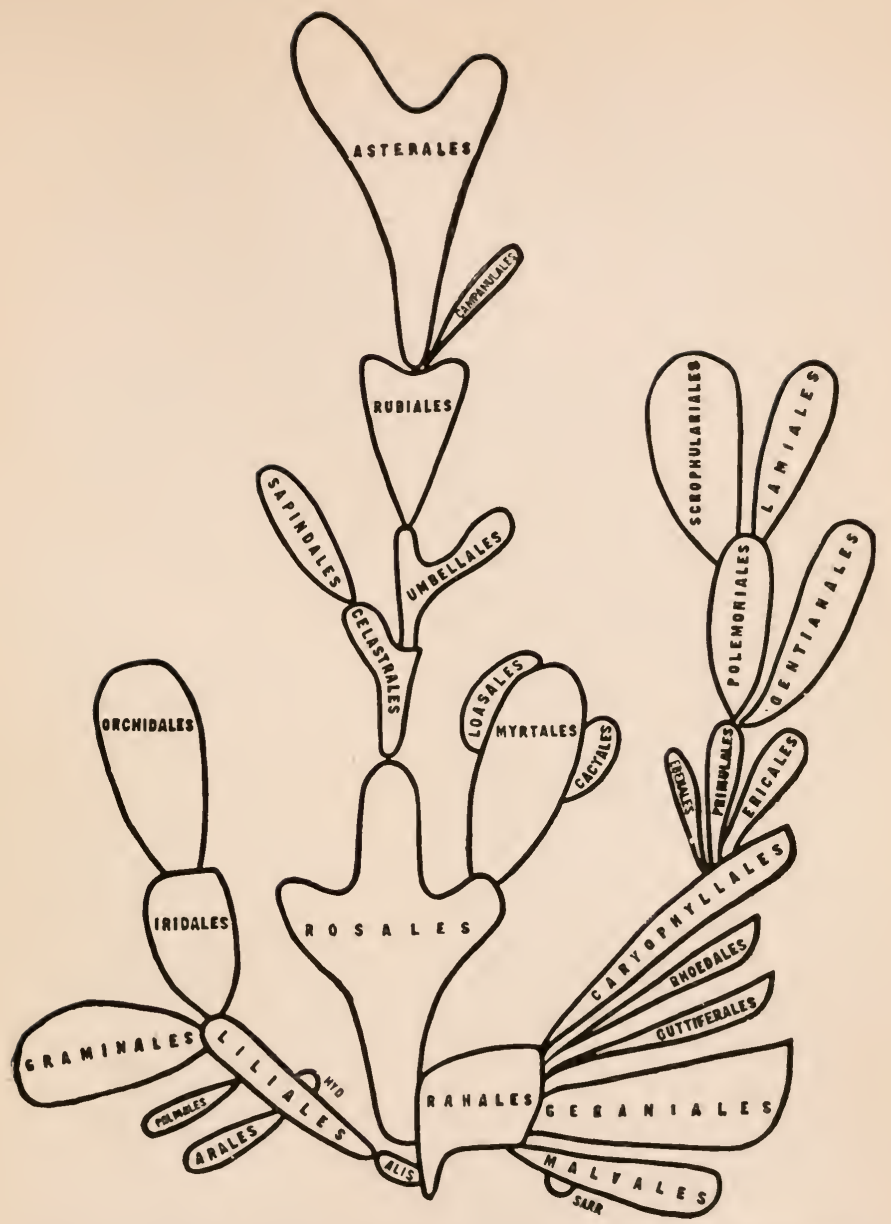

Cinart to Show Relationship of the Orders of Anthophyta. APPROXIMATE NUMBERS OF SPECIES IN THE ORDERS OF ANTHOPHYTA.

Alismatales, 409; Liliales, 3370; Arales, 1052; Palmales, 1085; Graminales, 5795; Hydrales, 53; Iridales, 4419; Orchidales, 757s; Ranales, 5551; Malvales, 3829; Sarraceniales, 66; Geraniales, 926s; Guttiferales, 3138; Rhoedales, 2856; Caryophyllales, 4330; Primulales, 1581; Ericales, 1730; Ebenales, 1136; Polemoniales, 4112; Gentianales, 4664; Scrophulariales, 7081; Lamiales, 4119; Rosales, 14261; Myrtales, 7323; Caetales, 1165; Loasales, 1392; Celastrales, 2741; Sapindales, 2903; Umbellales, 2S09; Rubiales, 5063; Campanulales, 1539; Asterales, 14324. 



\section{INDEX}

Abies, 281, 356

Abietaceae, 279, 356

Abrotanin, 149

Abutilon, 362

Acacia, 368

Acanthaceac, 367

Acarospora, 340

Acarosporaceae, 340

Acer, 371

Aceraceae, 371

Acervuli, 239

Acetabularia, 192, 336

Acetic acid, 140

Achariaceae, 364

Achene, 312

Achlya, 335

Acids, 18, 139

Aconitin, 149

Acorn, 311, 325

Acorns, 300, 358

Acrocarpi, 252, 349

Acrospermaceae, 343

Acrotylaceae, 339

Actinocyclus, 334

Actinodiscaceac, 334

Actinodiseus, 181, 334

Actinomorphic, 292, 322

Adder-tongues, 257, 352

Adiantum, 259, 353

Adoxaceae, 373

Accidiaceae, 347

Aecidiospores, 233

Aecidium, 234, 347

Acciospores, 233

Aerobic respiration, 91

Aesculin, 149

Aesculus, 371

A garicaceae, 229

Agaricales, 229, 345

Agaries, 345

Agaricus, 229, 345
Agathis, 279

Agave, 320,360

Agrostideae, 359

Agrostis, 359

Aizoaceae, 364

Alaria, 337

Albuginaceae, 187, 335

Albugo, 188

Albumens, 151

Albuminoids, 152

Albumoses, 152

Alcohols, 141

Aleuron, 14

Alisma, 289, 357

Alismataceae, 357

Alismatales, 295, 357

Alkaloids, 18, 149

Allium, 300, 358

Almond, 314

Alnus, 372

Alsine, 364

Alsophila, 352

Alternate leaves, 292

Alternation of Generations, 242

Althaea, 305, 362

Alyssum, 364

Amanita, 345

Amaranthaceae, 365

Amaranthus, 365

Amaryllidaceac, 360

Amaryllis, 29s, 360

Amaryllises, 360

Amblystegium, 351

Ambrosia, 375

Ambrosiaceac, 375

Ampelopsis, 371

Amphipleura, 334

Amphisphaeriaceac, 343

Amygdalin, 148

Anygdalus, 368

Amylase, 153 
Amylum, 147

Anabaena, 165

Anacardiaceae, 372

Anaerobic respiration, 91

Ananas, 360

Anauliaceae, 334

Ancistrocladaceae, 370

Ancylistaceae, 335

Andreaea, 251, 349

Andreaeaceae, 349

Andreaeales, 251, 349

Andropogon, 360

Andropogoneae, 360

Anemone, 291, 361

Anemophilous, 321

Angiopteris, 352

Angiospermous, 330

Animal Kingdom, 171

Animals, 172, 332

Anogra, 370

Anomodon, 351

Anonaceae, 361

Antennaria, 376

Anthemidaceae, 376

Anthemis, 376

Anther, 292

Antheridial cells, 174 disks, 246 gametophytes, 258

Antherids, 186

Anthoceros, 245, 349

Anthocerotaceae, 349

Anthocerotales, 349

Anthocyanin, 156

Anthophyta, 284, 357

Anthostoma, 343

Antipodal nuclei, 287

Antirrhinum, 304, 367

Aphanocapsa, 164

A piaceae, 372

A pical cell, 43

Apium, 372

Apocarpous, 292

A pocynaceae, 366

Apocynum, 367

Apogamy, 324

Aponogetonaceae, 357

Apopetalous, 305

Apothecia, 215

Appendages, 221

Apple, 307
Apple, Blight bacteria, 169

Apples, 368

Aquifoliaceae, 371

Arabinose, 145

Araceae, 358

Arachnoidiscus, 334

Arales, 295, 358

Aralia, 372

Araliaceae, 372

Araucaria, 279, 356

Araucariaceae, 278, 356

Araucarioxyleac, 354

Arbutin, 149

Archegone, 110, 243

Archegonial gametophytes, 258

Archespore, 272, 292

Archidiaceae, 349

Archiplastideae, 164, 330

Arctium, 376

Arctostaphylos, 365

Arctotidaccae, 375

Arctotis, 375

Argemone, 364

Arisaema, 300, 319, 358

Aristolochiaceae, 370

Arnica, 376

Aromatic oils, 143

Artemisia, 376

Arthonia, 218, 342

Arthoniaceae, 342

Arthrocladiaceae, 337

Arthothelium, 342

Arum, 358

Aschersonia, 347

Asclepiadaceae, 367

Asclepias, 367

Ascobolaceae, 342

Ascobolus, 342

Ascocorticiaceae, 341

Ascocorticium, 341

Ascoidaceae, 344

Ascophyllum, 337

Ascosporeae, 211, 339

Ascospores, 213

Ascus, 213

Fungi, 213, 339

Aseroc, 345

Asexual reproduction, 109,171

Ash, 324

Asimina, 274, 361

Asparagin, 154 
Asparagus, 358

Aspergillaceae, 344

Aspergillales, 344,222

Aspergillus, 221, 344

Aspidium, 259

Asplenium, 259, 353

Assimilative processes, 84

Aster, 376

Asteraceae, 376

Asterales, 311, 373

Asters, 376

Astrotheliaceae, 343

Atriplex, 365

Atropa, 366

Atropine, 150

Aulocomniaceae, 350

Auricularia, 346

Auriculariaceae, 346

Auriculariales, 230, 346

Austrian Pine, 282

Autonomous movements, 121

Auxanometer, 108

Auxiliary cells, 208

Avena, 300, 359

Aveneac, 359

Axes of flowers, 301

Axiflorae, 301

-A popetalae-Polyearpellatae, 361

-Gamopetalae-Diearpellatae, 366

-Gamopetalae-Polyearpellatae, 365

Axis Flowers, 301, 302, 361

(of flower), 285

Azolla, 353

\section{B}

Baccharis, 376

Bacillaria, 181

Bacillariaceae, 334

Bacillarioideae, 177, 179, 333

Bacillus, $3: 31$

Bacteria, 166, 331

Bacteriaceae, 331

Bacteriales, 166, 331

Bacterium, 331

Balanophorneeae, 371

Balanopsidaceae, 362

Bald Cypresses, 278
Balsamia, 344

Balsamiaceae, 344,363

Bamboo, 297, 359

Bambusa, 359

Bambuseac, 359

Banana, 301

Bananas, 360

Bangiaceac, 338

Bangiales, 338

Bangioideae, 207, 338

Banner, 308

Barberry, 319

Barbula, 350

Barley Smut, 237

Bartramiaceae, 350

Basellaceae, 364

Basidia, 226

Basidiosporeae, 211, 226, 344

Basidiospores, 226

Basidium Fungi, 226, 344

Bast fibers, 33

Batidaceae, 365

Batrachospermum, 209, 338

Battarea, 345

Bazzania, 349

Bean, 314

Family, 309

Beans, 368

Bedstraw, 325

Beeches, 372

Beetle Fungi, 339

Beggiatoa, 331

Beggiatoaceae, 331

Begonia, 370

Begoniaceae, 370

Begonias, 370

Bellis, 376

Bellworts, 373

Bennet titaceae, 355

Bennettitales, 355

Bennettites, 274

Bennettitineae, 274, 355

Benzoic acid, 141

Beomyces, 340

Berberidaceae, 361

Berberin, 150)

Bergamot oil, 14.4

Berries, 326

Berry, 309

Beta, 365

Betula, 372 
Betulaceae, 372

Bicollateral bundles, 59

Bicuculla, 364

Biddulphiaceae, 334

Bignonia, $36 \tau$

Bignoniaceae, 367

Birches, 372

Bird-nest Fungi, 228, 345

Bixaceae, 363

Black Blast, 237 -dot Fungi, 239, 348

Knot, 219

Molds, 189, 335

Mosses, 251, 349

Rust, 233

Bladder Algae, 192, 336

-fern, 259

Kelp, 201

Blanc mange, 209

Blazing Stars, 376

Blue Greens, 164, 330

Molds, 222

-stem Grasses, 360

Boehmeria, 362

Bog Mosses, 252, 351

Boletus, 346

Bombacaceae, 362

Bonnemaisoniaceae, 339

Borraginaceae, 366

Borrago, 366

Bothrodendraceae, 354

Botrychium, 352

Botrydiaceae, 336

Botrydium, 192, 336

Botryococcus, 332

Botrytis, 239, 348

Boundary tissue, 46

Bouteloua, 359

Bovista, 345

Brachy theciaceae, 351

Brake, 259

Brand-Fungi, 232, 346

Brassica, 303, 364

Brassicaceae, 364

Breathing pores, 51

Breeding of Plants, 115

Bremia, 188

Bridal Wreath, 307

Bristle Mosses, 252, 350

Brome Grass, 297

Bromeliaceae, 360
Bromus, 297, 359

Brood cells, 247

Masses, 246, 252, 351

Bronm-rapes, 321

Brown Algae, 199, 336

Seaweeds, 201

Brucine, 150

Brunelliaceae, 369

Bruniaceae, 369

Bryaceae, 252, 350

Bryales, 251, 349

Bryophyta, 242, 348

Bryopsidaceae, 336

Bryopsidoideae, 185, 336

Bryopsis, 192, 336

Bryum, 350

Buckeyes, 371

Buckthorns, 371

Bud, 45

Budding, 21, 223

Buellia, 341

Buelliaceae, 341

Bulbs, 319

Bulrush, 300

Bunt, 237

Burdock, 325

Burmanniaceae, 360

Bursa, 364

Burseraceae, 363

Butomaceae, 357

Buttercup, 286, 361

Butyl, 142

Butyric acjd, 140

Buxaceae, 371

Buxbaumiaceae, 252, 351

\section{C}

Cabombaceae, 362

Cactaceae, 370

Cactales, 370

Cactus, 310,370

Cactuses, 370

Caesalpinia, 368

Caffeine, 149

Caladium, 358

Calamariaceac, 353

Calamariales, 353

Calamarineae, 264, 353

Calamites, 254, 261, 264, 353

Calamophyta, 261, 353 
Calamus, 358

Calendula, 375

Calendulaceae, 375

Caliciaceae, 341

Caliciales, 341

Calicium, 341

Calla, 35s Lilics, 295

Callitrichaceac, 363

Callophyllis, 209, 339

Callymenia, 209

Caloplaca, 340

Caloplaceae, 340

Caltha, 291

Calvatia, 228

Calyeanthaceae, 361

Calyceraceae, 373

Calyciflorae, 302 -A popetalae, 368 -Gamopetalac, 373

Calymperaceae, 350

Calyptra, 251

Calyx, 286

Cambium, 58, 60, 269, 283

Camomiles, 376

Campanula, 373

Campanulaceae, 373

Campanulales, 373

Camphor, 144

Camphors, 143

Campsopogonaceae, 338

Camptosorus, 259

Camptotrichaceae, 331

Camptothrix, 331

Canada Thistle, 319

Canal Cells, 244

Canary Grasses, 359

Cane Sugar, 17,146

Canna, 360

Cannabis, 362

Cannaceac, 360

Caoutchouc, 144

C'apparidaceac, 364

Caprifoliaceae, 373

C'apsicum, 366

C'apsule, 250

Carbohydrates, 13, 84, 85, 144

Carbonic Acid, 85, 139

('arduaceac, 376

Carduus, 376

Carex, 358
Caricaceac, 364

C'arnegica, 370

C'arotin, 155

Carpels, 286

Carpinus, 321, 37:2

Carpomycetrae, 211, 339

Carpospores, 206

Carrot, 315

Caryocaraccae, 363

Caryophyllaceae, 364

Caryophyllales, 364

Caryopsis, 298

Cassia, 368

Cassiaccae, 368

Castalia, 364

Castanea, 314, 372

Castilleia, 367

Castor Bean, 305 oil, 143

Casuarinaceae, 369

Catalase, 153

Catalpa, 367

Catascopiaceae, 350

Catkins, 321

Cat-tails, 357

Caulerpa, 197

Caulerpaceae, 336

Ceanothus, 371

Cedar-apples, 238

Cedars, 281

Cedrus, 281

Celastraccae, 371

Celastrales, 370

Celidiaceae, 342

Cell, 4 division, 19 inclusions, 13

sap, 17

wall, 5

Cellulose, 5

Celluloses, 147

Celosia, 365

Celtis, 362

Cenangiaceac, 342

Centrifugal apparatus, 131

Centrolepidiaceac, $35 \mathrm{~s}$

Centrosome, 2

C'cntury Plant, 320

Cephalotaceac, 36 !

Ceramiaceae, 339

Ceramiales, 335 
Ceramium, 339

Ceratomyces, 339

Ceratophyllaceae, 362

Ceratostomataceae, 343

Cercidiphyllaceae, 361

Cercospora, 239, 348

Cereus, 370

Ceropegia, 367

Chaetangiaceae, 338

Chactocerotaceae, 334

Chaetocladiaceae, 335

Chaetocladium, 335

Chaetomiaceae, 343

Chaetophora, 173, 332

Chaetophoraceae, 332

Chaetophorales, 332

Chalazal, 279

Chamaecyparis, 356

Chamaerops, 358

Chamaesiphon, 330

Chamaesiphonaceae, 330

Chaptalia, 376

Chara, 193, 336

Characeae, 194, 336

Charales, 193, 336

Chemistry of the plant, 139

Chemotaxy, 119

Chemotropism, 127

Chenopodiaceae, 365

Chenopodium, 365

Cherry, 314, 325

Chestnut, 314

Chiodectonaceae, 342

Chitin, 5, 154

Chlaenaceae, 362

Chlamydomonas, 173

Chlamydospores, 184

Chloranthaceae, 361

Chlorideae, 359

Chlorococcaceae, 332

Chlorococcum, 171, 332

Chlorophyceae, 170, 332

Chlorophyll, 11, 155

Chlorophyllan, 155

Chloroplasts, 2, 11, 84

Cholera bacteria, 169

Chondromyces, 331

Chondrus, 208, 339

Chordariaceae, 337

Choristocarpaceae, 337

Christmas decorations, 267
Chromatin, 2

Chromatium, 331

Chromoplasts, 2, 12

Chromosome number, 110

Chromosomes 22, 110

Chroococcaceae, 164, 330

Chroococcus, 164, 330

Chrysanthemums, 376

Chrysothricaceae, 340

Chytridiaceae, 336

Chytridium, 336

Cichorium, 377

Cicuta, 372

Cilia, 118

Cinchona, 373

Cineol, 144

Circaea, 370

Circinately, 256

Circumnutation, 123

Cistaceae, 363

Citral, 144

Citric acid, 141

Citrullus, 370

Citrus, 363

Cladochytriaceae, 335

Cladonia, 216, 340

Cladoniaceae, 340

Cladophora, 185, 334

Cladophoraceae, 334

Cladophorales, 334

Cladosporium, 348

Cladoxyleae, 354

Classes, 159

Classification of plants, 157

Clathraceae, 345

Clatlırus, 345

Clavaria, 346

Clavariaceae, 230, 346

Claviceps, 220, 343

Claytonia, 323, 364

Clematis, 361

Clethraceae, 365

Climaciaceae, 252, 351

Climacium, 351

Climbing Ferns, $25 \mathrm{~s}$

Closed bundles, 58

Fungi, 218, 343

Lichens, 218, 342

Closteriaceae, 179, 333

Closterium, 179, 333

Clover-nodule bacteria, 169 
Club-Mosses, 267, 354

Cluster-cups, 233

Cneoraceae, 363

Cnicus, 376

Cocaine, 150

Coceaceae, 331

Cocei, 166

Coccogonales, 164, 330

C'occoloba, 365

Cochlospermaceae, 363

Cocklebur, 324

Coconut, 296, 324

Cocos, 296, 358

Codiaceae, 334

Codium, 195, 334

Coenobiales, 172, 332

Coenocytes, 8, 172

Coenogoniaceae, 340

Coffea, 373

Coffees, 373

Coleochactaceae, 174, 333

Coleochaetales, 333

Coleochaete, 174, 333

Coleosporiaceae, 347

Coleosporium, 347

Coleus, 367

Collateral bundles, 58

Collema, 216, 340

Collemataceae, 340

Collenchyma, 32

Colletia, 371

Colletotrichum, 240, 348

Colon bacteria, 169

Colors of flowers, 322

Columelliaceae, 367

Combretaceae, 370

Commelina, 358

Commelinaceac, 358

Common Cycads, 272, 354

Ferns, 258, 353

Horsetail, 264

Companion cells, 39

Composites, 312,373

Compound pistil, 295

Concentric bundles, 57

Conceptacles, 202

Conducting System, 54

Confervas, 173, 332

Confervoidene, 171, 173, 332

('onidia, 188

Conidiophore, 18.
Coniferales, 356

Conifer Ancestors, 275, 355

Coniferin, 148

Conifers, $277,35 j$

Coniine, 150

Conjugatae, 177, 333

Conjugate Algae, 177, 333

Conjugation, 182

Connaraceae, 368

Conocephalus, 349

Constituents of plants, 82

Convolvulaceae, 366

Convolvulus, 366

Coprinus, 345

Coral Fungi, 230, 346

Corallina, 207, 338

Corallinaceae, 338

Corallines, 207

Cordaitaceae, 355

Cordaitales, 275, 355

Cordaites, 275

Cordaitineac, 355

Cordieritidaceae, 342

Cordyceps, 343

Core (apple), 308

Coreopsis, 315

Coriandrum, 372

Coriariaceae, 371

Cork, 67

Corms, 319

Cornaceae, 372

Cornels, 372

Corn (Indian), 298

Smut, 236

Cornus, 322,372

Corolla, 286

Corsiniaceac, 349

Corticium, 346

Corylus, 372

Corynocarpaceae, 371

Coscinodiscaceac, 334

Coscinodiscus, 181, 334

Cosmariaceae, 179, 333

Cosmarium, 179, 333

Cotinus, 372

Cotton, 305

Cotyledons, 268, 282, 293

Cow Parsnip, 315

Crassulaceae, 369

Crataegus, 313, 365

Crenothrix, 331 
Crocus, 360

Cronartium, 347

Crossosomataceae, 368

Croton, 363 oil, 143

Crotonic acid, 143

Crown-gall bacteria, 169

Crucibulum, 345

Crucigenia, 332

Cryphaeaceae, 351

Cryptonemiales, 338

Crystals, 15

Cucumber-wilt bacteria, 169

Cucumis, 370

Cucurbita, 305, 370

Cucurbitaceae, 370

Cucurbitariaceae, 343

Culture solutions, 97

Cunoniaceae, 369

Cup Flowers, 302, 306, 367 -fungi, 216, 341

Cuphea, 369

Cupressaceae, 282, 356

Cupressus, 356

Currant, 309

Cuscuta, 320, 366

Cushion Mosses, 252, 349

Cutin, 155

Cutleriaceae, 337

Cutleriales, 337

Cyanastraceae, 358

(Cyanophyceae, 330

Cyathea, 352

Cyatheaceae, 258, 352

Cyathus, 345

Cycadaceae, 354

Cycadales, 354

Cycadineae, 272, 354

Cycadophyta, 27 1, 354

Cycads, 271, 354

Cycas, 273, 354

Cyclamen, 365

Cyclanthaecae, 358

Cyclosporeae, 337

Cydonia, 313

Cylindrocapsa, 333

Cylindrocapsaceae, 333

Cylindrospermum, 165, 3.31

C'ylindrosporium, 346

Cymathere, 201

Cynocrambaceae, 365
Cynomoriaceae, 370

Cyperaceae, 298, 358

Cyperus, 301, 358

Cypheliaceae, 341

Cyphelium, 341

Cypresses, 282, 356

Cypripedium, 299, 361

Cyrillaceae, 371

Cystocarp, 110, 206

Cytasc, 152

Cytology, 1

Cytoplasm, 1

Cyttariaceae, 342

D

Dacryomycetaceae, 346

Dahlias, 320

Dandelion, 312, 313, 324

Dasya, 209, 339

Dasycladaceae, 336

Dasycladales, 336

Dasycladus, 336

Dasyscypha, 342

Datiscaceae, 370

Datura, 366

Daucus, 315, 372

Dead nettle, 306

Death from disease, 136

Death of plants, 95

Delesseria, 339

Delesseriaceae, 339

Dematiaceae, 348

Dematium, 348

Derbesiaceae, 336

Dermatocarpaceae, 343

Dermatogen, 44

Desmarestiaceae, 337

Desmidiaceae, 178, 333

Desmidiales, 333

Desmidium, 333

Desmids, 178, 333

Devil's aprons, 200

Dextrose, 145

Dextro-tartaric acid, 141

Dianthus, 306, 364

Diapensiaceae, 365

Diaporthe, 343

Diastase, 153

Diatomin, 156, 179

Diatoms, 179,333 
Diatrypaceae, 343

Dicacoma, 347

Dichaenaceae, 343

Dichapetalaceae, 363

Dichomyces. 339

Dicksonia, 352

Diclinous, 296

Dicotyledoneae, 294, 301, 361

-Axiflorae, 361

-Calyciflorae, 367

Dicotyledons, 301, 361

Dicranaceae, 252, 349

Dictyophora, 345

Dictyosiphonaceae, 337

Dictyota, 337

Dictyotaceae, 337

Dictyotineae, 337

Digitalis, 306

Dilleniaceac, 362

Dimorphism, 323

Dioecious, 273

Dioon, 355

Dioscoreaceae, 360

Diphtheria bacteria, 169

Diploid, 24, 110

Diploschistaceae, 340

Dipsacaceae, 373

Dipterocarpaceae, 363

Dirinaceae, 342

Disaceharids, 146

Disceliaceae, 350

Discella, 348

Discolichenes, 214, 340

Diseases of Plants, 133

Dise Algae, 174

flowers, 312

Lichens, 214, 340

Division of cells, 19

Dodder, 320, 321

Dodecatheon, 365

Dogwood, 322

Dothidia, 343

Dothidiaceae, 343

Downy Mildews, 187, 335

Draparnaldia, 173, 332

Drepanophyllaceae, 350

Droseraceac, 369

Duchesnea, 291

Duckweeds, 358

Dulcite, 142

Dumontiaciae, 338
Durvillaea, 337

Durvillaeaceae, 337

Duteh Rush, 264

I)warf males, 174

F.

Ears, 298

Far Fungi, 230, 346

Earth Stars, 231

Ebenaceae, 366

Ebenales, 365

Echinocactus, 370

Ectocarpaceae, 337

Eetocarpales, 337

Eetocarpus, 200, 337

Ectolechiaceae, 340

Egg, 110, 174

Egregia, 201, 337

Elachistaceae, 337

Elaeagnaceae, 371

Elaeocarpaceae, 362

Elaphomycetaceae, 34

Elaters, 245, 263

Elatinaceae, 364

Elder, 315

Elephantopus, 376

Elms, 362

Embryo, 280

Emergencies, 51

Empetraceae, 371

Emulsin, 153

Encalypta, 350

Encoeliaceae, 337

Endocarpon, 218

Endomyces, 341

Endomycetaceae, 341

Endosperm, 274, 284, 288 nucleus, 288

Endospores, 166

Energy, 90 supply of, 91

Enteromorpha, 174, 332

Entodontaceae, 351

Entomophilous, 321

Entomophily, 323

Entomophthora, 191, 336

Entomophthoraceae, 191, 336

Entomophthorales, 336

Entyloma, 347

Enzymes, 152

Epacridaceac, 365 
Ephebaceae, 340

Ephebe, 216

Ephedra, 275, 355

Ephedraceae, 355

Ephemeral Mosses, 252

Ephemerum, 252, 350

Epicoccum, 348

Epidermal System, 47

Epidermis, 48

Epigloea, 342

Epiglueaceae, 342

Epilobium, 370

Epiplasm, 24

Equisetaceae, 263, 353

Equisetales, 353

Equisetineae, 262, 353

Equisetum, 262, 353

Eremascus, 341

Ergot, 220

Erica, 365

Ericaceae, 365

Ericales, 365

Erigeron, 376

Eriocaulonaceae, 358

Eriogonum, 365

Erodium, 362

Erpodiaceae, 351

Erysiphaceae, 220, 344

Erysiphe, 220, 225, 344

Erythronium, 300, 357

Erythroxylaceae, 363

Eschscholtzia, 364

Ethyl alcohol, 141

Euastrum, 179

Eubacteria, 331

Eucalyptol, 144

Eucalyptus, 370 oil, 144

Eucomiaceae, 369

Eucryphiaceae, 363

Eugenia, 370

Euodiaceae, 334

Eupatoriaceae, 376

Eupatorium, 376

Euphorbia, 322, 363

Euphorbiaceae, 363

Eupodiscaceae, 334

Eupodiscales, 181, 333

Eupodiscus, 334

Eusporangiatae, 257, 352

Eustoma, 366
Evaporation of water, 74,75

Evening Primrose, 309, 370

Everlastings, 375

Evolution, 160 of Anthophyta, 316

Evolvulus, 366

Excipula, 348

Excipulaceae, 348

Exidia, 346

Exoascaceae, 341

Exoascales, 218, 341

Exoascus, 218, 341

Exobasidiaceae, 346

Exobasidiales, 231, 346

F

Fabaceae, 368

Fabroniaceae, 351

Fagaceae, 372

Fagopyrum, 365

Fagus, 372

False Hemlocks, 281

Sunflowers, 375

tissues, 28

Tubers, 227, 344

Families, 159

Fats, 14, 142

Fatty oils, 142

Fermentation, 223

Ferns, 254

Fertilization of the egg, 273

Ferula, 372

Fescue Grasses, 359

Festuceae, 359

Fibrous tissue, 33

Fibrovascular system, 47

Ficus, 362

Figs, 362

Filament, 292

Filicales, 258, 352

Filix, 259

Filmy Ferns, 258, 352

Firs, 281

First stomata, 245

Fissidentaceae, 350

Fission, 20

Flacourtiaceae, 362

Flagella, 118

Flagellariaceae, 358

Flagellata, 172 
Flat Diatoms, 181, 334

Kelps, 200

Florideae, 207, 338

Flower, 274, 285

axes, 301

Flowering Plant Ancestors, 274, 355

Plants, 274, 284, 357

"Flower" of Mosses, 250

Fly Fungi, 336

Foeniculum, 372

Fomes, 230, 346

Fontinalaceac, 252, 351

Forget-me-nots, 366

Formaldehyde, 85,153

Formation of New Cells, 19

Formic Acid, 140

Fossombronia, 349

Fouquieraceae, 364

Fragaria, 289, 306, 368

Fragilariaceae, 334

Frankeniaceae, 364

Fraxinus, 366

Free veins, 257

Freezing of plants, 96

Froelichia, 365

Fructose, 18, 145

Fruit, 288 -spores, 175

Sugar, 145

Frullania, 349

Fucaceae, 337

Fucales, 201, 337

Fuchsia, 370

Fueus, 201, 337

Funaria, 250, 350

Funariaceae, 252, 350

Fungi, 179, 211

Imperfecti, 213, 347

Fungus cellulose, $5,15 t$ sugar, 146

Fusarium, 348

Fusel oil, 142

Fusicladium, 239, 345

G

Gaillardia, 375

Galactose, 145

Galium, 373

Gall-fungi, 172
Gallic acid, 141

Gallotannic acid, 141

Gametangia, 200

Gametes, 109

Gametophyte, 110, 242

Gamopetalous, 303

Gamosepaly, 304

Garden Currant, 309

Gaura, 370

Gazania, 375

Gazanias, 375

Geaster, 231, 345

Geissolomataceae, 371

Gelidiaceac, 338

Gemmae, 246

Genera, 158

Generation, 171

Genicularia, 333

Gentiana, 366

Gentianaceae, 366

Gentianales, 366

Geoglossaceae, 342

Geoglossum, 342

Geologic time, 161, 162

Georgiaceae, 351

Geotropism, 125

Geraniaceae, 362

Geraniales, 362

Geranium, 302, 362

Geraniums, 362

Gerardia, 367

Germination of sced, 281, 288

Gesneraceac, 367

Geum, 291

Giant Kelp, 201

Puff-ball, 228

Gigartina, 339

Gigartinaceae, 339

Gigartinales, 339

Gilia, 366

Gills, 230

Ginkgo, 275, 355

Ginkgoaceae, 355

Ginkgoales, 275, 355

Ginsengs, 372

Girdle, 1 so

Gladiolus, 319, 360

Glaueocystaceae, 167, 332

Glaucocystales, 167, 332

Glaucoeystis, 167, 332

Gleba, 22S 
Gleditsia, 368

Gleicheniaceae, 352

Globulariaceae, 367

*Gloeocapsa, 164, 330

Gloeosporium, 239, 348

Gloiosiphoniaceae, 338

Glucose, 18, 85, 145

Glucosides, 148

Glume, 297

Glycerine, 142

Glycogen, 147

Glycollie acid, 140

Gnaphalium, 376

Gnetaceae, 355

Gnetales, 275, 355

Gnetum, 275, 355

Gnomoniaceae, 343

Golden Fern, 258

Gomortegaceae, 361

Gonatonema, 333

Gonidia, 214

Gonium, 332

Gonystylaceae, 362

Goodeniaceae, 373

Gooseberries, 314, 369

Gordonia, 363

Gossypium, 305, 362

Grain (of grass), 298

Graminales, 297, 358

Gramma Grasses, 359

Grammatophora, 334

Grapes, 326, 371

Grape Sugar, 18, 145

Graphidaceae, 342

Graphidales, 218, 342

Graphina, 342

Graphis, 218, 342

Graphium, 348

Grasses, 297, 359

Grasshopper Fungus, 191

Grateloupiaceae, 338

Gray Mosses, 214

Great Horsetail, 264

Liverwort, 246,349

Green Felts, 185, 334

Slimes, 171, 332

Grimmiaceae, 350

Grinnellia, 209, 339

Grippe bacteria, 169

Grossulariaceae, 369

Ground Pines, 267, 354
Groundsels, 376

Growing point, 45

Growth, 104 movements, 122 rings, 62

Grubbiaceae, 371

Gulfweeds, 201

Gum canals, 66

Gutta Percha, 144

Guttation, 77

Guttiferaceae, 363

Guttiferales, 363

Gyalectaceae, 340

Gymnoaseaceac, 344

Gymnoaseus, 344

Gymnocladus, 368

Gymnogramme, 258

Gymnospermous, 330

Gymnosporangium, 235

Gyrophoraceae, 340

\section{$\mathrm{H}$}

Habitat, 320

Hadromal, 154

Haematococcus, 173

Haemodoraceae, 360

Hair-cap Mosses, 252

Hair Caps, 351

Hairs, 49

Halicystis, 336

Halidrys, 337

Halimeda, 195

Halophytes, 320

Halorrhagidaceae, 370

Hamamelidaceae, 369

Haploid, 24, 110

Haplosiphon, 165

Hard Puff-balls, 344

Red Seaweeds, 338

Haustoria, 188

Hawkweed, 324

Hawthorn, 313

Heartwood, 62

Heaths, 365

Hedera, 372

Hedwigiaceae, 351

Heleniaceae, 375

Helenium, 375

Helianthus, 311, 312, 375

Helianthaceae, 375 
Helichrysum, 376

Helicophyllaceae, 351

Heliotropium, 366

Helminthocladiaceae, 338

Helotiaceac, 342

Helotium, 342

Helvella, 342

Helvellaceae, 342

Helvellales, 217, 342

Helvellas, 342

Hemiascales, 223, 344

Hemlocks, $2 \$ 1$

Hepatica, 291

Hepaticac, 244, 348

Heppiaceac, 340

Heptane, 153

Heracleum, 315, 372

Herbarium Mold, 221

Hernandiaceae, 371

Herposteiraceae, 333

Herposteiron, 333

Hesperidin, 149

Heterocysts, 165

Heteroecism, 234

Heterogametes, 174

Heterogamous, 110

Heterospores, 255

Heterothallic, 191

Heuchera, 369

Hibiscus, 362

Hickory, 314

Hicoria, 314,372

Hicracium, 377

Higher Fungi, 211, 339

Lycopods, 267, 354

Red Seaweeds, 339

Tube Algae, 336

Highest plant, 313

Himanthalia, 337

Himanthaliaceac, 337, 371

Hippocrateaceae, 371

Hippuridaceae, 370

Histology, 27, 43

Hollyhock, 305

Holophy tes, Ss

Holoplastideae, 164, 167, 332

Homothallic, 197

Honey Locust, 319

Honeysuckle, 311, 373

Hookeriaceae, 351

Hormogonales, 165, 330
Hormogones, 163

Hornworts, 245, 349

Horsemint, 306

Horsetails, 262, 353

Houstonia, 373

Hoya, 367

Humiriaceae, 363

Humpback Mosses, 252, 351

Humulus, 362

Husks, 298

Hyacinth, 320

Hyaloriaceae, 346

Hyalotheca, 333

Hydnaceae, 230, 346

Hydnoraceae, 370

Hydnum, 346

Hydrales, 360

Hydrangea, 369

Hydrangeaceae, 369

Hydrocharitaceae, 360

Hydrochinin, 150

Hydrochloric acid, 139

Hydrocyanic acid, 148

Hydrodictyaceae, 332

Hydrodicty on, 172, 332

Hydrophyllaceae, 366

Hydrophyllum, 366

Hydrophytes, 320

Hydrostachydaceae, 364

Hygroscopic movements, 116

Hymenium, 213, 226

Hymenogastraceae, 344

Hymenogastrales, 227, 344

Hymenophyllaceae, 25S, 352

Hymenophyllum, 352

Hyoscyamine, 150

Hyperplasy, 13t

Hypertrophy, 134

Hyphae, 189

Hypnaceae, 252, 351

Hypnodendraceae, 351

Hypnum, 351

Hypochnaceac, 346

Hypocreaceae, 343

Hypodermataceae, 343

Hypoplasy, 13.4

Hypopterygiaceae, 351

Hypoxis, 360

Hypoxylon, 343

Hysterangium, 344

Hysteriaceae, 343 
Hysteriales, 218, 343

Hysterium, 343

Hysterographium, 218, 343

Hysterophytes, 88

\section{I}

Icacinaceac, 371

Immunity to diseases, 137

Impatiens, 363

Imperfect Fungi, 347

Imperfecti (Fungi), 213

Increased parental care, 110

Indian Corn, 298

Smut, 236

Pipes, 321

Indusium, 273

Inferior ovary, 298

Influenza bacteria, 169

Inheritable variations, 113

Inorganic Acids, 139

Salts, 139

Inula, 376

Inulaceae, 375

Inulin, 18, 147

Insect Fungi, 191

Insectivorous Plants, 362

Integument, 273

Intercellular spaces, 65

Interzones, 180

Invertase, 152

Involucre, 311,312

Ipomoea, 366

Iridaceae, 360

Iridales, 298, 360

Iris, 299,360

Irish Moss, 208

Ironweeds, 376

Irpex, 346

Irregular flowers, 303, 322

Isaria, 348

Isobutyl, 142 carbinol, 142

Isobutyric acid, 140

Isoetaceae, 352

Isoctales, 258,352

Isoetes, 260,352

Isogametes, 171

Isogamous, 110

Isospores, 255

Ithyphallus, 345
Jambosa, 370

Jasminum, 366

Jelly Fungi, 230, 346

Jelly Lichens, 216

Jerusalem Artichoke, 320

Joint-firs, 275, 355

Juglandaceae, 372

Juglans, 310,372

Julianaceae, 372

Juncaceae, 358

Juncus, 358

Jungermannia, 247

Jungermanniaceac, 247, 349

Jungermanniales, 247, 349

Juniperaceae, 282, 356

Junipers, 282

Juniperus, 356

K

Kalmia, 365

Karyokinesis, 20

Keel, 308

Kelps, 200, 336

Kernel (of grass), 298

Key to families of Astcrales, 374 to the Phyla, 328

Kinoplasm, 22

Klinostat, 131

Knot-grass, 326

Koeberliniaceae, 364

Koelreuteria, 371

Kuhnia, 376

L

Laboratory suggestions, 8

Laboulbenia, 339

Laboulbeniaceae, 339

Laboulbeniales, 339

Lachnea, 342

Lacinaria, 376

Lacistemaceae, 361

Lactic acid, 141

Lactoridaceae, 361

Lactose, 146

Lactuca, 315, 377

Lactucaceae, 377

Lady's Slipper, 301 
Lagenaria, 370

Lamb's quarters, 326

Lamiaceae, 367

Lamiales, 367

Laminaria, 200, 337

Laminariaceae, 200, 337

Lamium, 306

Lamprothamnus, 336

Land Ferns, 252, 258 Habit, 242

Lantana, 367

Larehes, 281

Lardizabalaceae, 361

Large Bladder Algae, 331

Larix, 281, 356

Lasiosphaeria, 343

Latex, 39

Lathyrus, 314

Laticiferous tissue, 39

Lauraceae, 361

Lavandula, 367

Lavender oil, 144

Laver, 207

Leafy Kelp, 201

Leathery fungi, 230

Leaves, 247, 249, 255

Lecanactidaceae, 340

Lecanora, 340

Lecanoraceae, 340

Lecidiaceae, 340

Leeythidaceae, 369

Legume, 309

Leitneriaceae, 361

Lejolisia, 339

Lemaneaceae, 338

Lembophyllaceae, 351

Lemma, 297

Lemna, 358

Lemnaceae, 358

Lennoaceae, 365

Lentibulariaceae, 367

Lenticels, 68

Leontodon, 312, 377

Lepidodendraceae, 354

Lepidodendrales, 269, 354

Lepidodendrids, 269

Lepidodendrineae, 267, 354

Lepidodendron, 269

Lepidophyta, 266, 35.4

Leptodon, 351

Leptogium, 216, 340
Leptosporangiatae, 258, 352

Leptostomataceae, 350

Leptostroma, 347

Leptostromataceae, 347

Leptothyrium, 347

Lepyrodontaceae, 351

Leskea, 351

Leskeacene, 351

Lessonia, 201

Lettuces, 377

Leucobryaceac, 252, 349

Leucodontaceae, 351

Leueomiaceae, 351

Leucoplasts, 2, 12

Levulose, 145

Libocedrus, 356

Lichens, 214

Lichinaceae, 340

Light, 106

L'gnin, 5, 154

Ligulate flowers, 312

Lilac Mildew, 225

Liliaceae, 357

Liliales, 295,357

Lilies, 295, 357

Lilium, 295, 357

Limnanthaceae, 363

Limonene, 144

Limonia, 363

Linaceae, 363

Linalool, 144

Lindens, 362

Linin, 2

Linnaea, 373

Linoleic acid, 143

Linseed oil, 143

Lipase, 153

Iip (of orehids), 301

Lippia, 367

Liriodendron, 361

Lithospermum, 366

Little Bladder Algae, 336

Cup-fungi, 341

Tubers, 221, 344

Liver starch, 147

Liverworts, 244, $34 \mathrm{~s}$

Loasa, 370

Loasaceae, 370

Loasales, 370

Lobaria, 340

Lobelia, 373 
Locomotion of cells, 118

Lodicule, 297

Loganiaceac, 366

Lonicera, 311, 373

Lophiostomataceae, 343

Lophosia, 349

Loranthaceae, 371

Loranthus, 371

Lotuses, 361

Lower Fungi, 186, 335

Lycopods, 267, 354

Red Seaweeds, 338

Tube Algae, 334

Lupinin, 150

Lupinus, 369

Lychnis, 303, 364

Lycoperdaceae, 228, 345

Lycoperdales, 227, 345

Lycoperdon, 345

Lycopodiaceae, 267, 354

Iycopodiales, 354

Lycopodineae, 267, 354

Lycopodium, 354

Lycopods, 254, 266, 354

Lyginopterideac, 354

Lygodium, 258

Lyngbya, 165, 330

Ly thraceae, 369

Lythrum, 369

\section{M}

Macomitrium, 350

Macrocystis, 201, 337

Macrosporium, 348

Macrozamia, 355

Magnolia, 274, 291, 302, 361

Magnoliaceae, 361

Maidenhair Fern,259

Trees, 275,355

Maize, 298

Grasses, 360

Malaceae, 368

Malaleuca, 370

Malesherbiaceae, 363

Malic acid, 141

Mallow, 302

Mallows, 362

Malpighiaceae, 363

Malus, 307, 368

Malva, 302, 362

Malvaceae, 362
Malvales, 362

Maltose, 146

Malt Sugar, 146

Mangifera, 372

Manihot, 363

Manna Ash, 146

Manneotetrose, 146

Mannite, 142

Mannose, 145

Maples, 371

Marantaceae, 360

Marattia, 352

Marattiaceae, 352

Marattiales, 258, 352

Marattias, 258, 352

Maregraviaceae, 363

Marchantia, 246, 349

Marchantiaceae, 349

Marchantiales, 349

Marigolds, 375

Marsilia, 259, 353

Marsiliaceae, 353

Marsiliales, 259, 353

Martyniaceae, 367

Massariaceae, 343

Matoniaceae, 352

Mayaceae, 358

Maydeae, 360

Measurements, 9

Medicago, 369

Medullary rays, 61, 283

Medullosae, 354

Meeseaceae, 350

Megagametophytes, 258

Megasporangia, 268

Megaspores, 256, 268

Melampsora, 235, 347

Melanconiaceae, 348

Melanconiales, 239,348

Melanconidiaceae, 343

Melaneonium, 239, 348

Melastomataceae, 369

Meliaceae, 363

Melianthaceac, 371

Melocactus, 370

Melogrammataceae, 343

Melons, 370

Melosira, 181

Mendel, 112

Menispermaceae, 361

Mentha, 367 
Menthol, 144

Mentzelia, 370

Menyanthes, 366

Meridionaceac, 334

Merismopedia, 164, 330

Meristem, 29

Mertensia, 366

Mesocarpaceac, 333

Mesophyll, 292

Mesophy'tes, 320

Methane, 153

Methyl alcohol, 141

Methylamine, 153

Metzgeria, 247, 349

Metzgeriaceae, 247,349

Micrasterias, 179, 333

Micrococeus, 331

Microcoleus, 165

Microgametophytes, 258

Micropylar end, 287

Micropyle, 273

Microsphaera, 225, 344

Microspora, 332

Microsporaceae, 332

Microsporales, $3: 32$

Microsporangia, 268

Microspores, 256, 268

Microthamniaceae, 332

Microthamnion, 332

Microthyriaceae, 344

Mildews, 220, 343

Milk Sugar, 146 tissue, 39

Milkweeds, 367

Millon's reagent, 9

Mimosa, 368

Mimosaceae, 368

Mimulus, $36 \overrightarrow{\boldsymbol{T}}$

Mints, 367

Mitchella, 373

Mitella, 369

Mitosis, 20

Mitrula, 342

Mitteniacear, 350

Miniaceae, 252, 350

Mnium, 350

Modern Ferns, 25\$, 352 Pines, 279, 356

Molds, 239, 348

Mollisiaceae, 342

Momordica, 370
Nonarda, 306

Monilia, 239, 348

Moniliales, 239, 348

Monimiaceac, 361

Monoblepharidales, 335

Monoblepharis, 335

Monocotyledoneae, 294, 295, 357 -Epigynae, 360

-Hypogynae, 357

Monocotyledons, 295, 357

Monosaccharids, 145

Monospores, 206

Monostroma, 173

Monotropaceae, 321

Moraceae, 362

Morchella, 217, 342

Morels, 217

Moringaceae, 364

Moriola, 342

Moriolaceae, 342

Morning Glories, 320, 321, 366

Morphine, 150

Mortierella, 335

Mortierellaceae, 335

Morus, 362

Mosses, 248, 349

Mossworts, 242,348

Mougeotia, 333

Movements, 116

Mucedinaceae, 348

Mucor, 189, 335

Mucoraceae, 189, 335

Mucorales, 335

Musa, 301,360

Musaceae, 360

Musci, 244, 349

Mushroom, 218, 229

Spawn, 229

Mustard, 303, 364

Mutations, 114

Mutinus, 345

Mutisia, 376

Mutisiaceae, 370

Mycelium, 189

Mycocalicium, 341

Mycoporaceae, 343

Mycosphacrellaceae, 343

Myoporace:ne, $36 \overrightarrow{7}$

Myosotis, 366

Myosurus, 291, 361

Myricaceae, 37:2 
Myriothamnaceae, 369

Myriotrichiaceae, 337

Myristicaceae, 361

Myrsinaceae, 365

Myrtaceae, 369

Myrtales, 369

Myrtles, 369

Myrtus, 370

Myxobacteriaceae, 331

Myxophyceae, 163, 330

Myzodendraceae, 371

\section{N}

Naiadaceae, 358

Names of plants, 159

Narcissus, 360

Nastic movements, 128

Natural Selection, 113

Navicula, 334

Naviculaceae, 334

Naviculales, 334

Neckera, 351

Neckeraceae, 351

Nectar of flowers, 322

Nectria, 343

Nectrioidaceae, 347

Nelumbaceae, 361

Nelumbo, 361

Nemalion, 207, 338

Nemalionales, 338

Nemastomaceae, 338

Nematocaceae, 351

Nepenthaceae, 362

Nepeta, 367

Nephrodium, 353

Nereocystis, 201, 337

Nerium, 367

Netted-veined, 301

Nettles, 362

New Cells, formation of, 19

Nicotiana, 306, 366

Nicotine, 150

Nidularia, 345

Nidulariaceae, 345

Nidulariales, 228, 345

Nightshades, 366

Nigredo, 347

Nitella, 194, 336

Nitellaceae, 194, 336

Nitophyllum, 209, 339
Nitric acid, 139

Nolanaceae, 366

Nostoc, 165, 331

Nostocaceae, 165, 331

Nucleus, 1

Number of plants, 157

Numerical data, 327

Nutation, 123

Nutrition, 71

Nutritive tissues, 65

Nux vomica, 150

Nyctaginaceae, 365

Nymphaea, 364

Nymphaeaceae, 364

Nyssa, 372

\section{O}

Oak, 310

Oat Grasses, 359

Smut, 237

Ochnaceae, 363

Octaviana, 344

Odors of flowers, 322

Oedogoniaceae, 174, 333

Oedogonium, 174, 333

Oedopodiaceae, 350

Oenothera, 309,370

Oenotheraceae, 370

Oidium, 348

Oils, 14

Olacaceae, 371

Old Calamites, 264, 353

-fashioned Ferns, 257, 352

Pines, 278, 356

Olea, 366

Oleaceae, 366

Oleic acid, 143

Olein, 143

Oliniaceae, 371

Olives, 366

Olpidium, 332

Onion, 320

Onoclea, 259

Onygenaceae, 34

Oogones, 174

Oospora, 348

Opegrapha, 342

Open bundles, 59

Operculum, 252

Ophioglossaceae, 352 
Ophioglossales, 257, 352

Ophioglossum, 352

Opiliaccae, 371

Opposite leaves, 292

Opuntia, 310,370

Orchidaceae, 360

Orchidales, 299, 360

Orchids, 299, 360

Orchis, 299, 361

Orders, 159

Oreodoxa, 358

Organic Acids, 140

Origin of Phyla, 161 of Zygophyceae, 181

Orobanchaceae, 321,367

Orthotrichaceae, 350

Orthotrichum, 350

Oryza, 359

Oryzeae, 359

Oscillatoria, 165, 330

Oscillatoriaceae, 165,330

Osmosis, 72

Osmunda, 352

Osmundaceae, 352

Ostrich-fern, 259

Ostropaceae, 343

Ostrya, 372

Ovary, 286, 292

Ovulate, 275

Ovule, 273

Oxalic acid, 141

Oxalidaceae, 362

Oxalis, 326,362

Oxidases, 153

Padina, 337

Palea, 297

Palet, 297

Palisade tissue, 292

Palmaceae, $35 \mathrm{~s}$

Palmales, 296, 358

Palmatin, 143

Palmellales, 171, 332

Palmettos, 300

Palmitic acid, 140, 143

Palms, 296, 358

Panax, 372

Pandanaceae, 357

Pandorina, 172, 332
Paniccae, 359

Panic Grasses, 359

Panicum, 359

Pannariaceac, 340

Pansy, 306

Papaver, 364

Papaveraceae, 364

Papaws, 361

Pappus, 312

Parallel veined, 295

Paraphyses, 203, 215

Parasitic habit, 320

Paratheliaceae, 343

Paratonic movements, 123

Parenchyma, 29

Parental care, 110

Parietal placentac, 303

Parkeriaceae, 352

Parmelia, 216, 340

Parmeliaceae, 340

Paronychia, 364

Parsleys, 372

Parsnip, 311

Parthenocissus, 371

Parthenogenesis, 324

Passage of Water, 73

Passiflora, 364

Passifloraceac, 363

Passion Flowers, 363

Pastinaca, 311, 372

Patellariaceae, 342

Path of the Water, 75

Pathology, 133

Pea, 305, 308

Peach, 314

Pear, 313

blight bacteria, 169

Peat-mosses, 251, 349

Pectase, 153

Pectose, 5

Pedaliaceae, 367

Pediastrum, 172

Pedicularis, 367

Peireskia, 370

Pelargonium, 306, 362

Pellia, 349

Peltigera, 340

Peltigeracene, 340

Penaeaceae, 371

Penicillium, 222, 344

Penicillus, 195, 334 
Penium, 333

Pentaphyllaccae, 371

Pentstemon, 306

Peppermint oil, 144

Pepsins, 153

Perianth, 274, 284

Periblem, 44

Pericarp, 175, $20 \mathrm{~s}$

Peridium, 228

Perisporiaceae, 344

Perisporiales, 220, 343

Peristome, 252

Perithecia, 215

Peronospora, 188, 335

Peronosporaceae, 187, 335

Peronosporales, 335

Peroxidases, 153

Perseite, 142

Pertusaria, 340

Pertusariaceae, 340

Pestalozzia, 348

Petals, 286

Petticoat Mosses, 252

Petunia, 304, 366

Peziza, 216, 342

Pezizaceae, 342

Pezizales, 216, 341

Phacelia, 366

Phacidiaceae, 341

Phacidiales, 341

Phacidium, 341

Phaeophyceae, 199, 366

Phaeosporeae, 336

Phalarideae, 359

Phalaris, 359

Phallaceae, 345

Phallales, 228, 345

Phascum, 350

Phaseolus, 314, 369

Phellonic acid, 155

Philadelphus, 369

Philydraceae, 358

Phloem, 55

Phloeonic acid, 155

Phlox, 304, 366

Phoenix, 358

Phoradendron, 371

Phosphoric acid, 139

Photonasty, 124

Photosynthesis, 84

Phototaxy, 119
Phototropism, 124

Phragmidium, 235, 347

Phrymaceae, 367

Phycobacteriaceae, 331

Phycocyanin, 156, 163, 205

Phycoerythrin, 156, 205

Phycomyceteac, 185, 335

Phycophaein, 156, 199

Phyla, 159, 327

Phylogeny, 114, 157

Phylogeny of Fungi, 240

Phyllachora, 343

Phyllactinia, 225

Phyllocladaceac, 356

Phyllocladus, 356

Phyllopsoraccae, 340

Phyllopyreniaceae, 343

Phyllosiphon, 334

Phyllosiphonaceae, 334

Phyllosticta, 239, 347

Physalis, 366

Physcia, 216, 341

Physciaccae, 341

Physcomitrium, 350

"Physiological Diseases," 134

Physiology, 71

Physma, 340

Phytolaccaceae, 364

Phytophthora, 188, 335

Picea, 281, 356

Pigments, 155

Pigweeds, 326

Pilacraceae, 346

Pilobolus, 335

Pilocarpaceae, 340

Pilotrichaceae, 351

Pilularia, 353

Pimenta, 370

Pinene, 144

Pines, 281, 356

Pinks, 303, 364

Pinoideae, 355

Pinus, 279, 281, 356

Piperaceac, 361

Piperin, 149

Piptocephalidaceae, 335

Piptocephalis, 335

Pirolaccae, 365

Pirus, 313,368

Pistillaria, 346

Pistils, 284 
Pisum, 305, 308, 369

Pithophora, 334

Pitted vessels, 36

Pit tosporaceae, 369

Planera, 362

Plant Breeding, 115

Cell, 4

Plantaginaceae, 365

Plantago, 323, 365

Plantains, 365

Plasmolysis, 72

Plasmopara, 187, 335

Plasticity of Plant body, 319

Plastids, 2, 10

Platanaceae, 369

Platanthera, 361

Platanus, 369

Pleosporaceae, 343

Plerome, 44

Pleurocarpi, 252, 351

Pleuromoiaceae, 354

Pleurophascaceae, 351

Plocamium, 209, 339

Plowrightia, 219, 343

Plum, 308

Plumbaginaceae, 365

Plum-pocket Fungus, 218

Plums, 368

Plumule, 305

Poa, 300

Poaceae, 297, 359

Pocket Fungi, 341

Podaxaceae, 345

Podaxon, 345

Podocarpaceae, 356

Podoearpus, 356

Podosphacra, 225, 344

Podostemonaceae, 364

Pogonatum, 351

Poisons, 96

Polar nuelei, 287

Polemoniaceae, 366

Polemoniales, 366

Polemonium, 366

Pollen, 273

-cells, 284

-sacs, 286

tube, 279,287

Pollination, 280, 321

Polygalaceae, 363

Polygonaceae, 365
Polygonum, 365

Polypodiacear, 258, 353

Polypodium, 258, 353

Polypody, 258

Polyporaceae, 230, 345

Polypores, 232, 345

Polyporus, 346

Polysaccharids, 147

Polysiphonia, 208, 339

Polystictus, 346

Polytrichaceae, 252, 351

Polytriehum, 351

Pond Scums, 178, 333

Pontederiaceae, 358

Poppies, 364

Populus, 364

Pore Fungi, 230

Porphyra, 207, 338

Portulaca, 364

Portulacaceae, 364

Postelsia, 201, 337

Potamogeton, 357

Potamogetonaceae, 357

Potato, 320

Potentilla, 291, 368

Pothos, 296, 300

Pottia, 350

Pottiaceae, 350

Powdery Mildews, 220

Prasiola, 332

Prasiolaceae, 332

Prickly Fungi, 230, 346

Pear, 310

Primary leaves, 281

Prinrose, 303, 365

Primula, 303, 304, 323, 365

Primulaceae, 365

Primulales, 365

Prinodontaceac, 351

Promyeclium, 234

Propagation, 1\%1

Propolis, 341

Propyl, 142

Proteaceae, 372

P'roteins, 87, 150

Proterandrous, 323

Proterogynous, 323

Prothallium, 254

Protocalamariaceae, 353

Protocaliciaceae, 341

Protococeaceac, 332 
Protococcoideac, 171, 332

Protococcus, 171, 332

Protomycetaceac, 344

Protonema, 247

Protopityeae, 354

Protoplasm, 1, 151

Protoplasmic movements, 110

Protosiphon, 192, 336

Prunaceae, 368

Prunus, 308,368

Psalliota, 345

Pseudomonas, 331

Pseudotsuga, 281

Psilotaceae, 354

Ptelea, 363

Pteridium, 259, 353

Pteridophyta, 254, 352

Pteridosperm, 272

Pteridospermales, 354

Pteridospermeae, 272, 354

Ptilota, 339

Ptychomniaceae, 351

Puccinia, 232, 347

Puff-balls, 227, 345

Punicaceae, 369

Purslane, 326

Pycnia, 233

Pycnidia, 239

Pycniospores, 233

Pyrenidiaceae, 343

Pyrenoids, 11

Pyrenolichenes, 218, 342

Pyrenomycetales, 218, 343

Pyrenopsidaceae, 340

Pyrenothamniaceae, 343

Pyrenulaceac, 343

Pyronema, 217, 342

Pyronemataceae, 342

Pythiaceae, 335

Quercus, 310, 311, 372

Quiinaceae, 363

Quillworts, 258, 352

Quince, 313

Quinine, 150

$\mathrm{R}$

Radial bundles, 56

Radish, 306

Radishes, 320
Raffinose, 146

Rafflesiaceae, 370

Ragweeds, 375

Ralfsiaceae, 337

Ramalina, 216, 340

Ramularia, 239, 348

Ranales, 361

Ranunculaceae, 361

Ranunculus, 274, 286, 361

Rapateaceae, 358

Raphanus, 306, 364

Raphe, 181

Raphids, 15

Ray flowers, 312

Razoumofskya, 371

Receptacles, 246

Receptacular cup, 286

Red Algae, 205, 338

-rust, 233

Seaweeds, 338

Snow plant, 172

-top Grasses, 359

Reductase, 153

Reduction Division, 111

Redwoods, 278

Regular flowers, 322

Rejuvenescence, 181

Relationship, 157

Reproduction, 109

Resedaceae, 364

Respiration, 90

Resting spore, 174

Restionaceae, 358

Reticulated veins, 257 vessels, 36

Rhabdonema, 334, 339

Rhacopilaceae, 351

Rhamnaceae, 371

Rhamnus, 371

Rhegmatodontaceae, 351

Rheum, 365

Rhipsalis, 370

Rhizina, 342

Rhizinaceae, 342

Rhiziphyllidaceae, 338

Rhizoids, 244

Rhizogoniaceae, 350

Rhizophoraceae, 370

Rhizopogon, 344

Rhizopus, 335

Rhodobacteria, 331 
Rhodochaetaceae, 338

Rhodochaetales, 338

Rhododendron, 365

Rhodomela, 339

Rhodomelaceae, 339

Rhodophyceae, 205, 338

Rhodophyllidaceae, 339

Rhodophyllis, 339

Rhodymenia, 339

Rhodymeniaceae, 339

Rhodymeniales, 339

Rhoedales, 364

Rhus, 372

Rhytisma, 341

Ribes, 309, 369

Riceia, 244, 348

Ricciaceae, 348

Ricciales, 348

Riccias, 348

Rice Grasses, 359

Ricinoleic acid, 143

Ricinus, 305, 363

Ringed vessels, 36

River-weeds, 357

Rivularia, 3:31

Rivulariaceae, 165, 331

Rivularias, 165

Robinia, 369

Roccella, 342

Rocellaceac, 342

Rockweeds, 201, 337

Root (thickened), 320

Roots, 256

Rootstocks, 319

Rosa, 307, 368

Rosaceae, 368

Rosales, 368

Rose, 307, 368 -apples, 307

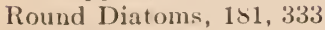

Rubiacear, 373

Rubiales, 373

Rubus, 291

Rudbeckia, 315,375

Ruderal plants, 320

Runners, 319

Rushes, 358

Russian 'Thistle, 325

Russula, 345

Rusts, 232, 347

Ruta, 36:3
Rutaceae, 363

Rutilariaceae, 334

Si

Sabal, 300

Sabiaceac, 371

Saccharomyces, 223,344

Saccharomycetaceae, 344

Saceharose, 17, 146

Sac-Fungi, 213

Sachs's solution, 98

Sac-spores, 213

Sage, 304

Sagittaria, 291, 357

Salicaceae, 364

Salicin, 149

Salicylic acid, 141

Salix, 364

Salsola, 365

Salvadoraceae, 366

Salvia, 304, 305,367

Salvinia, 259, 353

Salviniaceac, 353

Sambueus, 315,373

Sand-bur, 325

Sanguinaria, 364

Sanicula, 372

Santalaceae, 371

Sapindaceae, 371

Sapindales, 371

Sapindus, 371

Saponin, 148

Sapotaceae, 366

Saprolegnia, 186, 335

Saprolegniaceae, 186,335

Saprolegniales, 335

Sap wood, 62

Sarcina, 331

Sarcoseypha, 224

Sargassaceae, 337

Sargasso Sea, 203

Sargassum, 202, 337

Sarraceniaceae, 362

Sarraceniales, 362

Saururaceac, 361

Saxifraga, 369

Saxifragaceae, 36

Saxifrages, 369

Sealariform vessels, 36

Scale Mosses, 247, 349 
Scapania, 349

Scenedesmus, 172, 332

Scheuchzeriaceae, 357

Schistostegiaceae, 350

Schizacaceae, 352

Schizogoniales, 332

Schulze's reagent, 35

Seirpus, 300, 358

Selerenchyma, 32

Scleroderma, 345

Sclerodermataceae, 345

Selerodermatales, 344

Scleroderris, 341

Sclerotinia, 342

Scotch Pine, 279

Scouring-Rush, 264

Serophularia, 367

Serophulariaceae, 367

Serophulariales, 367

Scytonema,. 165, 331

Scytonemas, 165

Scytonemataceae, 165, 331

Scytopetalaceae, 362

Sea Ferns, 192, 336

Girdle, 201

Lettuces, 173

Mosses, 338

Palm, 201

Tree, 201

Umbrellas, 192

Secondary leaves, 281 thickening, 60

Secotium, 345

Secretory cells, 66

Sedges, 298, 358

Seed, 271

distribution, 324

-ferns, 272, 354

scale, 278,279

Selaginella, 268, 354

Selaginellaceae, 267

Selaginellales, 354

Self fertilization, 323

Sematophyllaceae, 351

Senecio, 376

Senecionidaceae, 376

Sennas, 368

Sepals, 286

Septoria, 239, 347

Sequoia, 278, 356

Seta, 250
Sexual cells, 112 reproduction, $109,170,171$

Shade plants, 320

Shicld-Ferns, 259

Shoot, 329

Side Mosses, 252, 351

Sieve tissue, 38

Sigillaria, 269

Sigillariaceae, 354

Silene, 306, 364

Silicic acid, 140

Silks (of maize), 298

Silphium, 375

Simarubaceae, 363

Simblum, 345

Simple Algae, 170, 332 pistils, 286

Sinapis, 364

Siphonales, 334

Siphonophyceae, 184, 334

Sirobasidiaceae, 346

Sisyrinchium, 360

Size of Cells, 7

Skeletal tissue, 46

Slime Algae, 163, 330

Slit-Fungi, 218, 343

-Lichens, 218, 342

Smuts, 347

Snapdragon, 304, 367

Snowberry, 315

Snow-on-the-Mountain, 322

Soft Red Seaweeds, 339

Solanaceae, 366

Solanin, 148

Solanum, 366

Soleniaceae, 334

Solidago, 376

Solutes, 81

Solutions, 81

Somatic cells, 112 division, 112

Sonneratiaceae, 369

Sorbinose, 146

Sorbite, 142

Sordariaceae, 343

Soredia, 215

Sori, 232

Spadix, 300

Spanish needles, 325

Sparganiaceae, 357

Spathe, 296 
Spawn, 229

Special Adaptations, 319

Species, 114, 158

Spermatochnaceae, 337

Spermogones, 215, 233

Sperms, 110, 174

Sphacelariaceae, 337

Sphacelotheca, 347

Sphaerobolaceae, 345

Sphaerobolus, 345

Sphaerococcaceae, 339

Sphaeriaceae, 343

Sphaerioidaceae, 347

Sphaeronemella, 347

Sphaerophoraceae, 341

Sphaerophorus, 341

Sphaeroplea, 334

Sphaeropleaceae, 334

Sphaeropsidales, 238, 347

Sphacropsis, 347

Sphaerotheea, 225

Sphagnaceae, 349

Sphagnales, 251, 349

Sphagnum, 250, 349

Sphenophyllaceae, 353

Sphenophyllales, 353

Sphenophyllineae, 262, 353

Sphenophyllum, 262

Spiderworts, 358

Spikelet, 297

Spiraea, 307, 368

Spiral vessels, 36

Spiranthes, 361

Spiridentaceae, 351

Spirochaete, 331

Spirodela, 358

Spirogyra, 178, 333

Spirogyraceae, 333

Spirulina, 165

Splachnaceae, 350

Splachnidiaceae, 337

Splachnum, 252, 350

Spleenworts, 259

Sponge tissue, 292

Spontaneous Generation, 166

Sporangium, 190

Spore-case, 250

-fruit, 109, 175, 213

mother-cells, 243

-prints, 2:31

Sporids, 233
Sporoearp, 175, 213

Sporochnaceae, 337

Sporodinia, 197

Sporogenous tissues, 211

Sporophyll, 261

Sporophyte, 110, 242

Spot Fungi, 238, 347

Spruces, 281

Squamariaceae, 338

Squash, 305

Stachyuraceae, 364

Stackhousiaceae, 371

Stalked Puff-balls, 231

Stamens, 284

Staminate, 275

Stapelia, 322, 367

Staphyleaceae, 371

Stareh, 13, 85, 147

Star Flowers, 370

Statocysts, 127

Statoliths, 126

Stearic acid, 143

Stearin, 143

Stem, 255

Stemonaceae, 358

Sterculiaceae, 362

Stereocaulon, 340

Stereum, 230, 346

Sterigmata, 222

Sterigmatocystis, 348

Sterile tissues, 211

Stickseed, 325

Sticta, 340

Stictaceae, 340

Stictidaceae, 341

Stictis, 341

Stigma, 286, 292

Stigmonose, 134

Stigonema, 165, 331

Stigonemataceae, 165, 331

Stilbaceae, 348

Stilophoraceae, 337

Stink-horns, 228, 345

Stinking Smut, 237

Stipules, 292

Stomata, 51

Stone cells, 32

Stoneworts, 193, 336

Storage tissues, 66

Store of food, 319

Sitrawberry, 289, 306, 319, 320 
Streblonema, 337

Strelitzia, 360

Streptococeus, 331

Striariaceae, 337

Strigulaceae, 343

Strobilophyta, 277, 355

Strobilus, 273

Struvea, 336

Strychnine, 150

Stuartia, 363

Style, 292

Stylidiaceae, 373

Styracaceae, 366

Stysanus, 348

Sub-classes, 160 -families, 160 -orders, 160

Suberin, 155

Succinic acid, 141

Sugar, 145

Sugars, 17

Sulphur-bacteria, 169

Sulphuric Acid, 139

Sumachs, 372

Summary of Anthophyta, 315

Sunflower, 311

Sunflowers, 375

Sun plants, 320

Super-orders, 160, 361, 365, 366, 368,373

Supply of energy, 91

Supporting System, 64

Surirellaceae, 334

Survival of the fittest, 113

Susceptibility to diseases, 137

Sweet Pea, 314

Symbiosis, 216

Symphoricarpos, 315

Symplocaceae, 366

Symplocarpus, 358

Synapsis, 111

Syncephalis, 335

Synchytriaceae, 172, 332

Synchytrium, 332

Synergids, 287

Syringa, 366

Tabellariaceae, 334

Taccaceae, 360

Tamaricaceae, 364
Tanacetone, 144

Tannin, 141

Tansy oil, 144

Taphrina, 341

Taraxacum, 312, 377

Tassel, 300

Taxaceac, 357

Taxales, 282, 356

Taxin, 150

Taxodiaceac, 278, 356

Taxodium, 278, 356

Taxodiums, 278, 356

Taxus, 282, 357

Tecoma, 367

Tectona, 367

Teliosporeae, 213, 232, 346

Teliospores, 232

Temperature, 95

Terfezia, 344

Terfeziaceae, 344

Tetrasaccharids, 146

Tetraspora, 332

Tetraspores, 206

Thea, 363

Theaceae, 363

Theine, 149

Thelephora, 346

Thelephoraceae, 230, 346

Thelidium, 342

Thelocarpon, 340

Theloschistaceae, 340

Theloschistes, 216, 340

Thelotremataceae, 340

Theobromine, 149

Theophrastaceae, 365

Thigmotropism, 127

Thiobacteria, 331

Thistle, 324, 376

Thorcaceae, $33 \mathrm{~s}$

Thorns, 319

Thread Lichen, 216

Thuidium, 351

Thurniaceae, 358

Thuya, 356

Thuyas, 282, 356

Thuyopsidaceae, 282,356

Thymelaeaceac, 371

Thymus, 367

Tilia, 362

Tiliaccae, 362

Tillandsia, 360 
Tilletia, 237, 347

Tilletiaceae, 237, 347

Tilopteridaceae, 337

Tilopteridales, 337

Timmia, 350

Timmiaceae, 252, 350

Tissues, 28

Tissue systems, 43,46

Toadstools, 229,345

Tolypella, 336

Tolypothrix, 165

Top Mosses, 252, 349

Torreya, 357

Torula, 348

Torus, 292

Touch-me-not, $325,326,363$

Tovariaceae, 364

Toxylon, 362

Tracheae, 36

Tracheary tissue, 35

Tracheids, 36

Tradescantia, 358

Transpiration, 76

Tree Ferns, 258, 352

Mosses, 252, 351

Trehalose, 146

Tremandraceae, 363

Tremella, 346

Tremellaceae, 346

Tremellales, 231, 346

Trentepohlia, 333

Trentepohliaceae, 333

Trichocomataceae, 3.44

Trichogyne, 174

Trichomanes, 352

Trichosphaeria, 343

Trifolium, 369

Trigoniaceae, 363

Trillium, 300

Tri-methylamine, 153

Trisaccharids, 146

Triticeae, 359

Triticum, 300, 359

Triuridaceae, 357

Trochiseia, 332

Trochodendraceac, 361

Tropaeolaceae, 363

Tropaeolum, 363

Tropisms, 124

True Mosses, 251, 349

Truffles, 223
Tryblidiaceac, 341

Tryblidium, 341

Trypetheliaceae, 343

Trypsines, 153

Tube Algae, 184, 334

Fungi, 186, 335

Tuberaceae, 344

Tuberales, 223, 344

Tuber, 344

Tuberculariaceae, 348

Tuberculina, 348

Tuberculosis bacteria, 169

Tubers, 320,344

Tulasnellaceae, 346

Tulipa, 358

Tumble weeds, 325

Tumboa, 275, 355

Tumboaceae, 355

Turf Mosses, 252, 349

Turgor, 73 movements, 120

Turneraceae, 363

Turnips, 320

Turpentine, 144 canals, 283

Tylophoron, 341

Tylostoma, 231, 345

Tylostomataceae, 345

Typha, 357

Typhaceae, 357

Typhoid bacteria, 169

Typical flower, 285

\section{$\mathrm{U}$}

Ulmaceae, 362

Ulmus, 362

Ulothrix, 173, 332

Ulotrichaceae, 332

Ulva, 173, 332

Ulvaceae, 332

Ulvales, 332

Umbellales, 372

Umbilicaria, 342

Uncinula, 225, 344

Union of cells, 24

Uredinaceae, 347

Uredinales, 232, 347

Urediniospores, 233

Uredo, 234, 347 
Uredospores, 233

Uromyces, 235, 347

Uropyxis, 347

Urtica, 362

Urticaceae, 362

U'snea, 216, 224, 340

Usneaccae, 340

Ustilaginaceae, 347

Ustilaginales, 235, 347

Ustilago, 237, 347

\section{V}

Vaccinium, 365

Vacuoles, 17

Valerianaceae, 373

Valonia, 192, 336

Valoniaceae, 336

Valoniales, 336

Valsa, 343

Valsaceae, 343

Valve, 180

Vanilla, 361

Vanillin, 154

Variations, 112

Vascular Bundles, 55

Vaucheria, 185, 334

Vaucheriaceae, 334

Vaucherioideac, 185, 334

Vegetable Kingdom, 159

Veins, 257 of leaves, 60

Velloziaceae, 360

Venter, 243

Veratrine, 150

Verbascum, 367

Verbena, 367

Verbenaceae, 367

Vernonia, 376

Vernoniaceae, 376

Veronica, 367

Verpa, 342

Verrucaria, 342

Verrucariaceae, 342

Vetches, 326

Viburnum, 373

Vicia, 369

Victoria, 364

Vinca, 367

Viola, 302, 303, 363

Violaceae, 363
Violet, 302, 363

Viscum, 371

Vitaceae, 371

Vitex, 367

Vitis, 371

Vochysiaceac, 363

Volvocaceae, 332

Volvoces, 172

Volvox, 172, 332

IV

Walking-fern, 259

Walnut, 310,372

Water, 71, 139

Cultures, 97

Ferns, 259, 353

Flannel, 185

-lilies, 364

Molds, 186, 335

Net, 172

Plantain, 289, 357

pores, 77

Weberaceae, 351

Wedge-leaved Calamites, 262, 353

Weisia, 350

Welwitschia, 275, 355

Wheat Grasses, 359

rust, 232

Smut, 237

White Pines, 282

Rusts, 187, 335

Whorled leaves, 292

Wild Geranium, 302, 326

Willows, 364

Wings, 308

Winteranaceae, 362

Wood-fibers, 33

Wood Mosses, 252, 350

\section{X}

Xanthium, 375

Xanthophyll, 11, 155

Xanthoxylum, 363

Xerophytes, 320

Xylaria, 343

Xylariaceae, 343

Xylem, 55

Xyridaceae, 358 
Zinnia, 375

Zonaria, 337

Yeast-Fungi, 344

Plants, 222

Zoospores, 171

Zostera, 357

Yellow Pines, 282

Yews, 282, 357

Yucea, 300, 358

Zy gnema, 182, 333

Zygnemataceae, 333

Zygnematales, 333

Zygogonium, 333

Zygomorphic, 322

Zygomorphy, 309

Zygophyceae, 177, 333

Zamia, 274, 355

Zamiaceae, 355

Zannichellia, 357

Zea, 300, 360

Zingiberaceae, 360

Zygophyllaceae, 363

Zygospore, 190

Zygote, 109, 171

Zymase, 153

\section{PROPERTY LIBRARY
N. C. State College}







